\title{
Propuesta de fortalecimiento para la empresa Velerito
}

Grupo de Investigación

GAIA

Autor

Juan Pablo Sánchez Santana

Línea de Investigación

Cultura de la Innovación

Área de Trabajo

Fortalecimiento

Universidad Santo Tomás, Sede Bogotá

Maestría en Administración de Negocios- MBA

2018

Documento Final Tesis de Maestría 
Proyecto de fortalecimiento empresarial aplicado a la empresa Velerito

Juan Pablo Sánchez Santana

Tutor:

Héctor Horacio Murcia Cabra

Ingeniero Agrónomo / Especialista en Gestión y Sistemas Empresariales

\section{Universidad Santo Tomás de Aquino}

Maestría en Administración de Negocios, División De Ciencias Económicas, Administrativas Y Contables.

Facultad De Administración De Empresas

Bogotá 
Nota de aceptación.

Firma del jurado.

Firma del jurado.

Firma del jurado.

Bogotá D.C. Junio 28 de 2018 
"Las personas no quieren comprar un taladro de un cuarto de pulgada, lo que quieren es hacer un agujero de un cuarto de pulgada" Theodore Levitt 
DEDICATORIA

Dedico a Jesús quien ha hecho todo posible para la realización de este sueño, a mis padres por su paciencia y tolerancia en los momentos de la vida, ser mi ejemplo y el regalo más hermoso de Dios para mí. A mi compañera de vida por su apoyo y su amor por Dios. A mis hermanos, por su apoyo y su empuje para la realización de este sueño. A mi tutor por su entrega y apoyo. 
Agradezco al señor Jesucristo por ser mi guía en este camino, por darme la fuerza para lograr este sueño aun en los momentos de mayor dificultad. Es él el mayor tesoro, a él agradezco todo lo que soy, y tengo.

Agradezco a los fundadores de Velerito, quien a su vez son mis padres, por su ayuda, ejemplo y tenacidad por hacer empresa e impulsar el progreso de nuestro

país. Agradezco a mi pareja por su compromiso y apoyo en la realización de mi sueño. 


\section{Contenido}

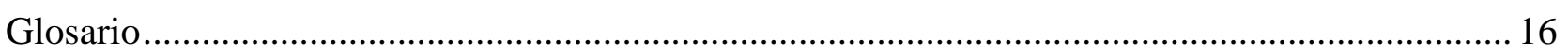

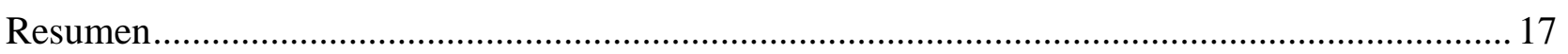

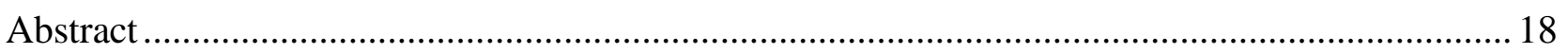

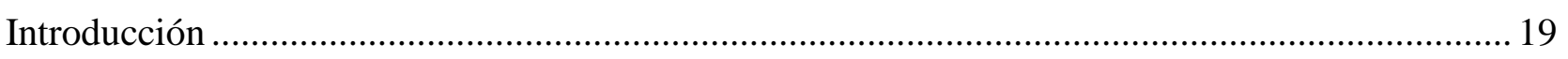

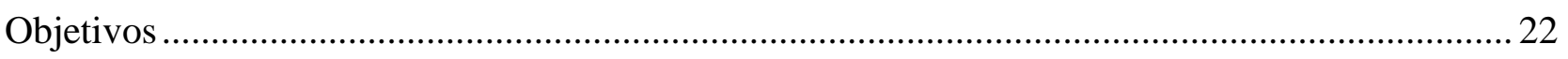

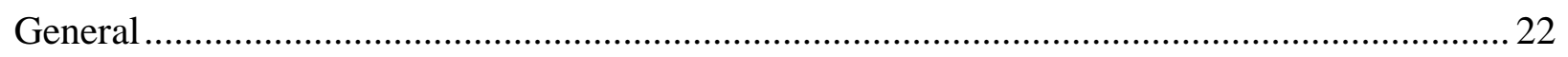

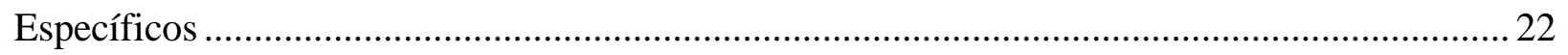

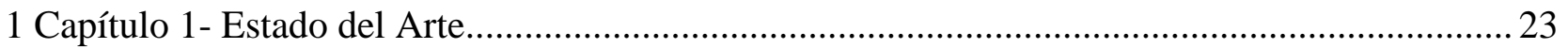

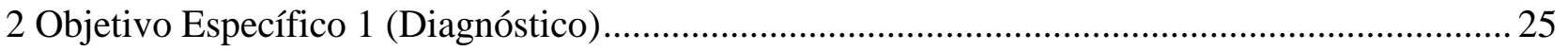

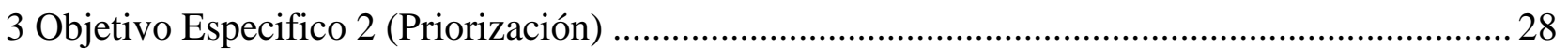

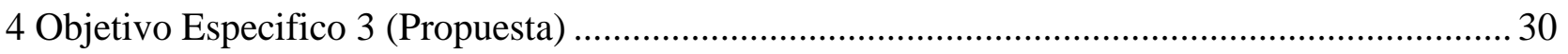

4.1 Conceptos relevantes para el desarrollo del fortalecimiento empresarial........................... 31

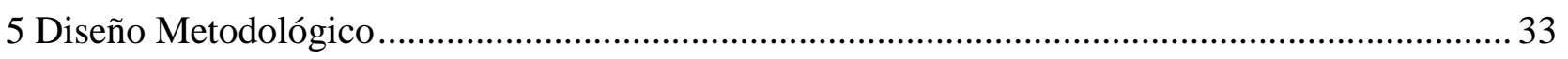

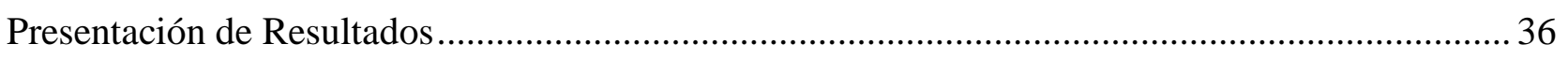

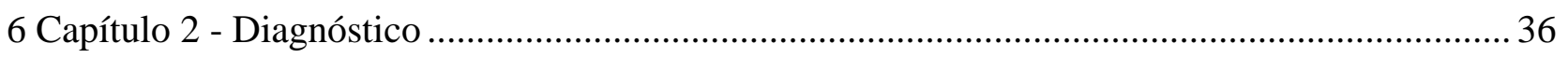

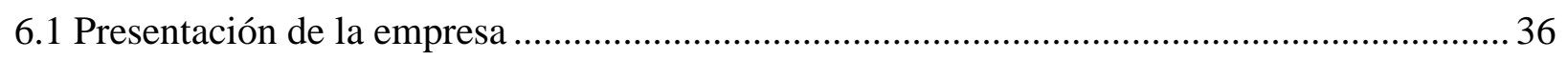

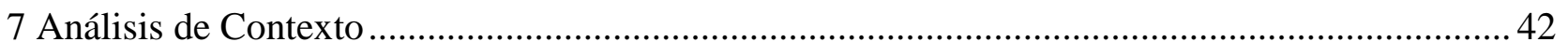

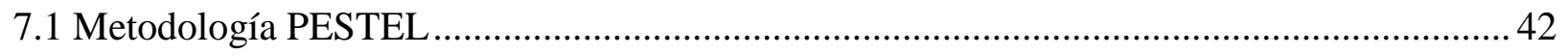

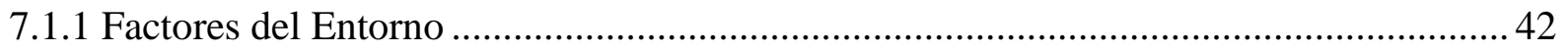

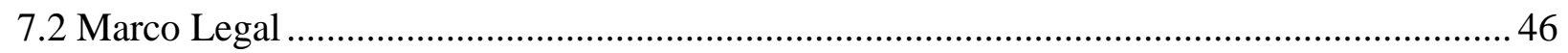

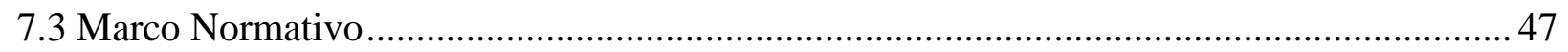

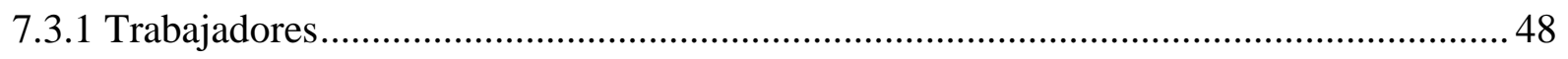

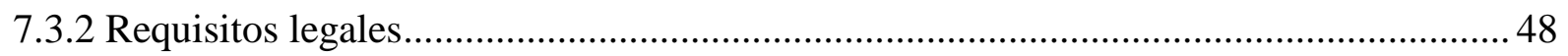

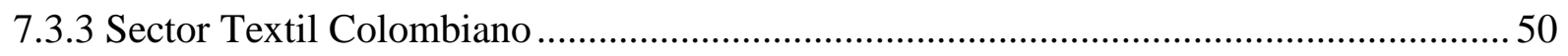

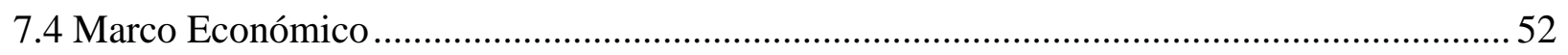




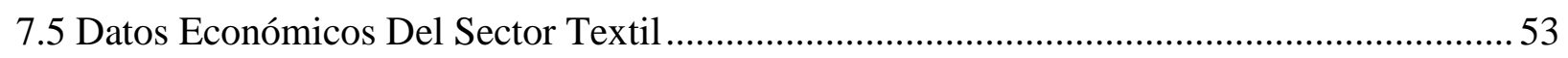

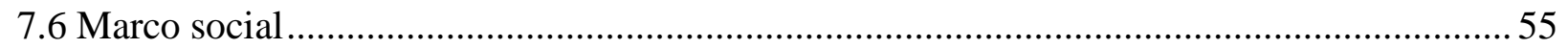

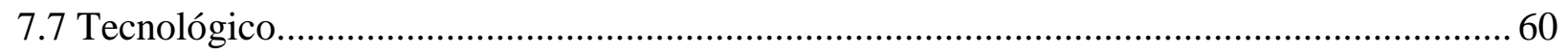

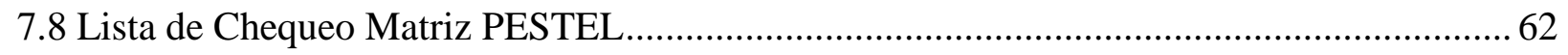

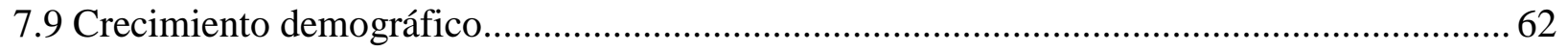

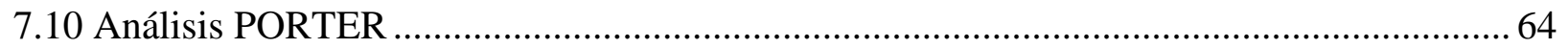

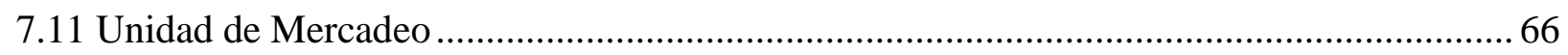

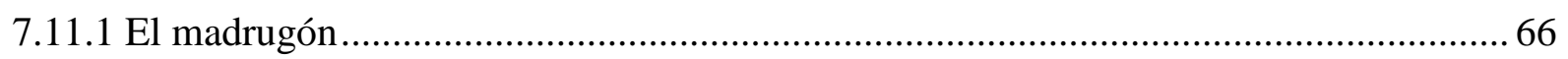

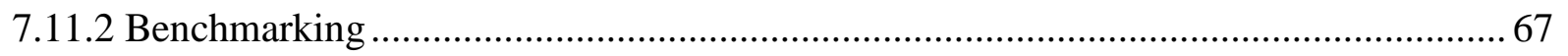

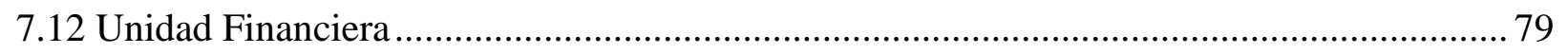

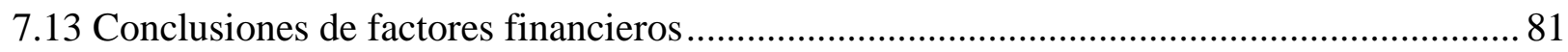

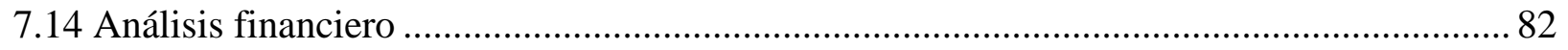

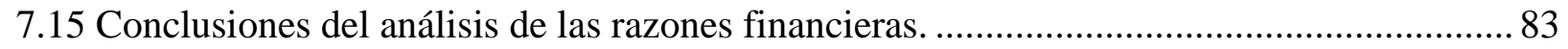

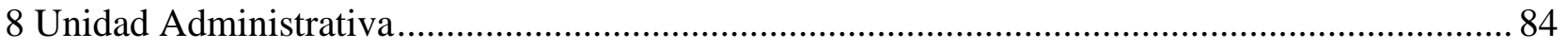

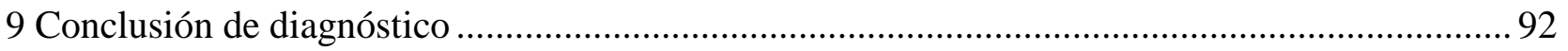

10 Capítulo 3- Priorización e Identificación de la Problemática a Solucionar. ...............................95

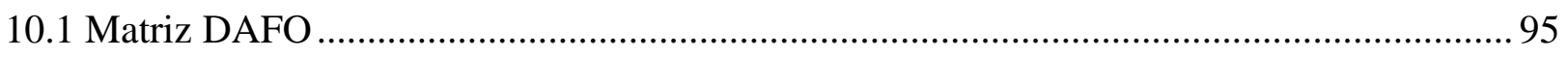

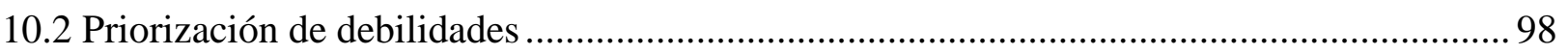

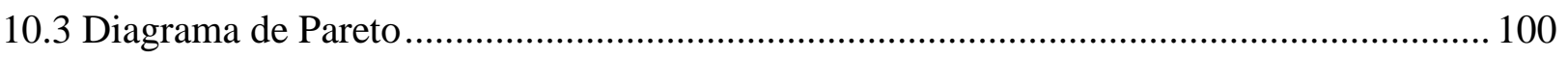

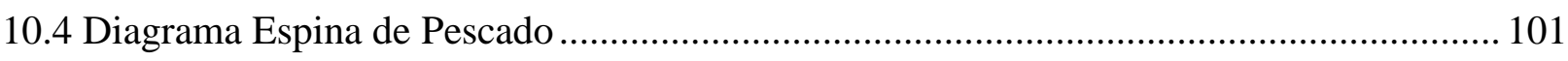

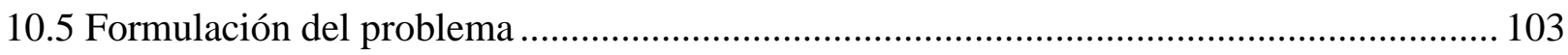

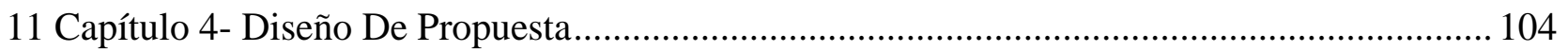

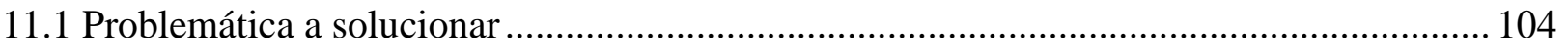

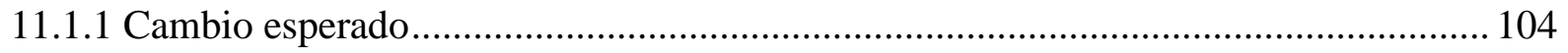

11.2 Recursos para el desarrollo de la estructura administrativa.......................................... 109

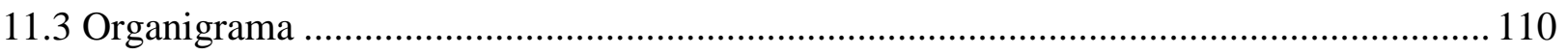

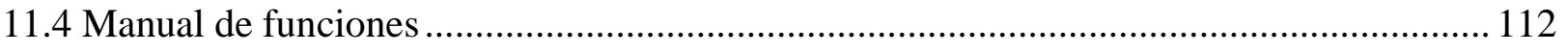




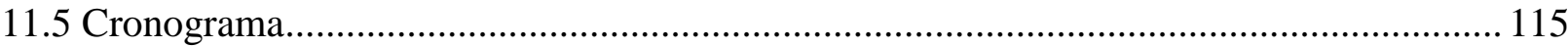

11.6 Recursos Para la Estructura Administrativa ………………………………………........ 117

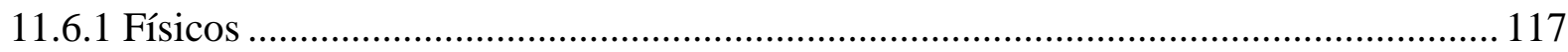

11.7 Recursos humanos para la creación de la estructura empresarial ........................................119

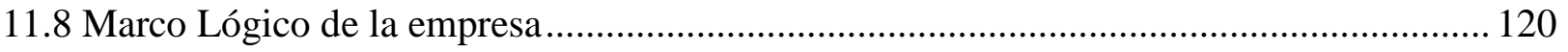

11.9 Análisis de la parte financiera de la propuesta de fortalecimiento empresarial.................. 122

11.10 Línea de impacto de la estructura administrativa …………………………………....... 123

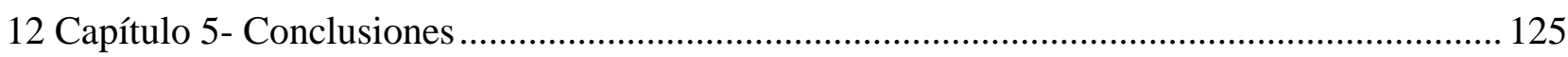

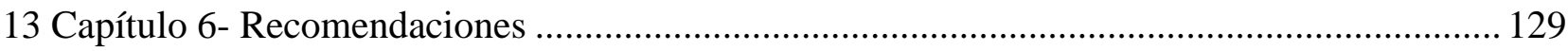

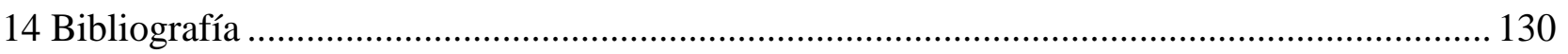

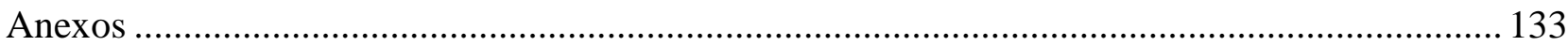




\section{Lista de Graficas}

Gráfica 1 Empresas creadas en el primer periodo de 2016 y 2017 ............................................ 44

Gráfica 2 Distribución de empresas según su tamaño ............................................................... 49

Gráfica 3 Porcentaje de Valor Agregado de manufactura en el PIB Colombiano...........................55

Gráfica 4 Cuadro comparativo de crecimiento demográfico entre niños y niñas entre los cero a los

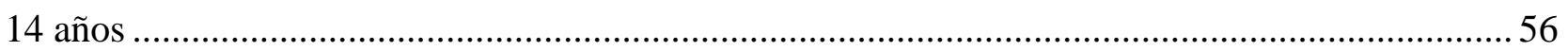

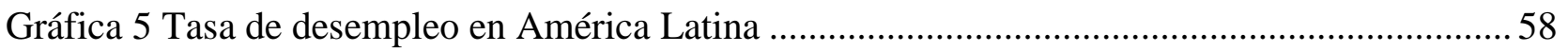

Gráfica 6 Porcentaje de empresas que están adoptando una estrategia de transformación digital .. 61

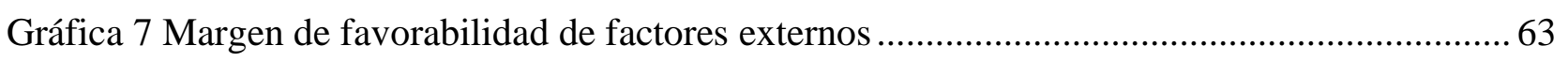

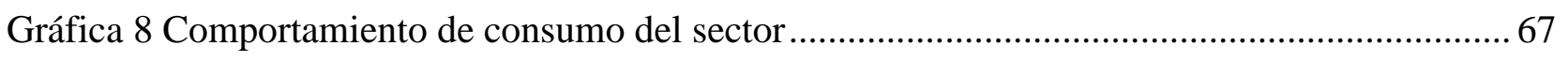

Gráfica 9 Análisis de Mercadotecnia en procesos de desarrollo empresarial .................................74

Gráfica 10 Análisis de Factores de Mercadotecnia.................................................................... 76

Gráfica 11 Variación porcentual de ventas Velerito (2015-2016-2017) ......................................79

Gráfica 12 Comportamiento relativo de la utilidad antes de impuestos ....................................... 80

Gráfica 13 Resultados de análisis de factores financieros ....................................................... 81

Gráfica 14 Análisis de resultados- lista de chequeo administrativa ........................................... 87

Gráfica 15 Comparativo general de fortalezas y debilidades de Velerito. ....................................92

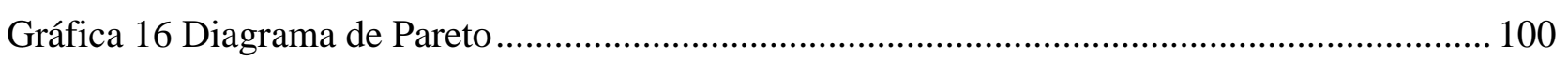

Gráfica 17 Diagrama " Espina de Pescado" ........................................................................... 101

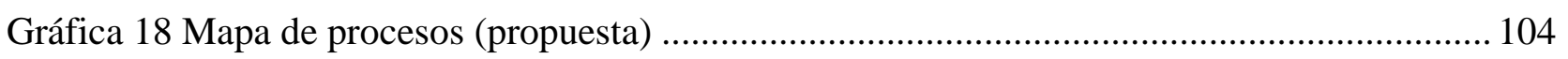

Gráfica 19 Temas claves para diseño de la propuesta .............................................................. 120 


\section{Lista de Ilustraciones}

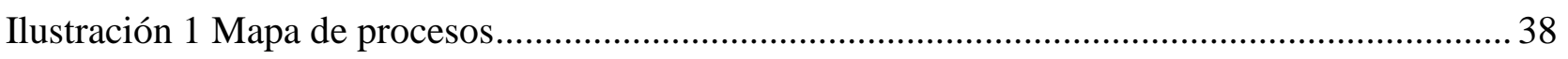

Ilustración 2 Unidades Básicas de la empresa ........................................................................... 40 


\section{Lista de Chequeo}

Lista de Chequeo 1 Aspectos Externos con base en metodología PESTEL.................................. 62

Lista de Chequeo 2 Análisis de las 5 Fuerzas de Porter ............................................................. 64

Lista de Chequeo 3 Análisis de mercadotecnia en procesos de desarrollo empresarial ................. 71

Lista de Chequeo 4 Función operacional de Mercadotecnia ........................................................ 76

Lista de Chequeo 5 Aspectos Internos de la Empresa a considerar............................................... 77

Lista de Chequeo 6 Detalles De Análisis Económicos Y Financieros .......................................... 80

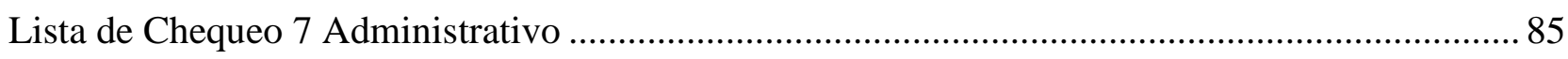




\section{Lista de Tablas}

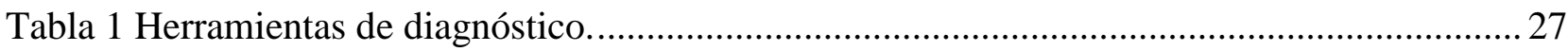

Tabla 2 Estado del arte (concepto de Estructuras administrativas) .............................................. 31

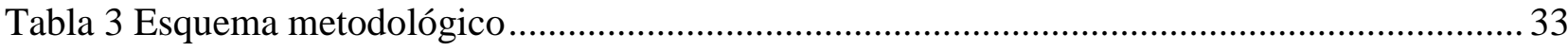

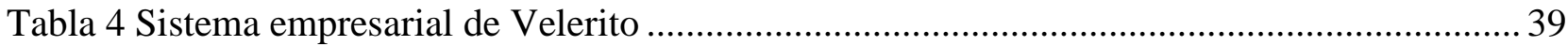

Tabla 5 Mega procesos en el sistema de la empresa Velerito....................................................... 41

Tabla 6 América Latina, Balance Fiscal- Porcentaje del PIB .................................................... 43

Tabla 7 Tasa de Impuesto sobre la renta- América Latina .......................................................... 46

Tabla 8 Crecimiento económico de Colombia............................................................................ 52

Tabla 9 Tasa de crecimiento anual del PIB, por ramas de la actividad económica 2017-IV /2016-

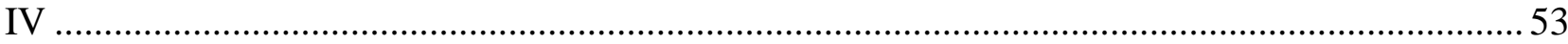

Tabla 10 Subsectores que contribuyeron positivamente al PIB Industrial y manufacturero ...........54

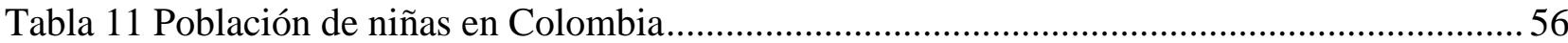

Tabla 12 Tasa de Inflación en América Latina ..............................................................................59

Tabla 13 Crecimiento de la industria manufacturera mundial ..................................................... 59

Tabla 14 World digital competitiveness ranking- Colombia....................................................... 61

Tabla 15 Comparativo de empresas de confecciones relevantes en Colombia. ............................6 68

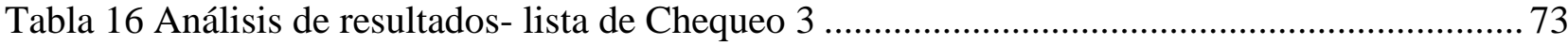

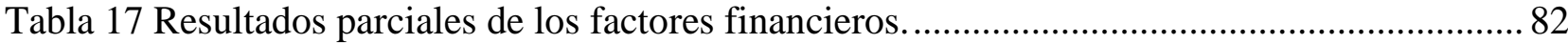

Tabla 18 Razones financieras de 2016 de Velerito..................................................................... 82

Tabla 19 Resultados y conclusiones, unidad administrativa ...................................................... 87

Tabla 20 Análisis de aspectos administrativos dentro del diagnóstico estratégico de Velerito....... 88

Tabla 21 Análisis de ASPECTOS SOCIALES dentro de un Diagnóstico Estratégico ...................89

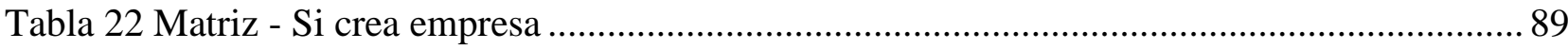

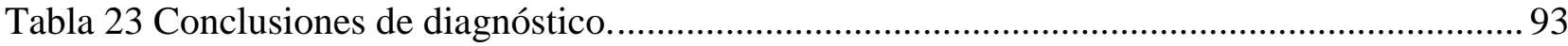

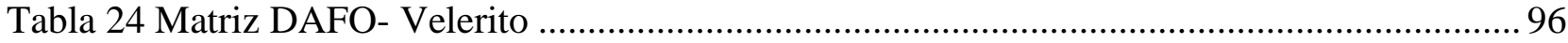

Tabla 25 Resultados de la aplicación del proceso democrático para el ordenamiento de debilidades

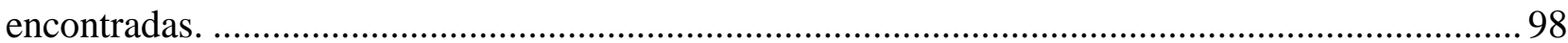

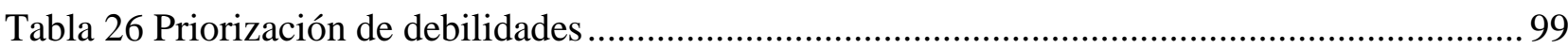

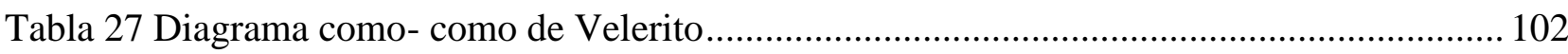

Tabla 28 Tabla comparativa (debilidades administrativas frente a cambios y productos) ............ 105

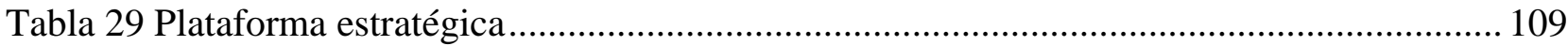

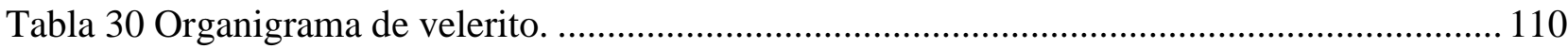


Tabla 31 Definición de estructura de mando. ............................................................................. 111

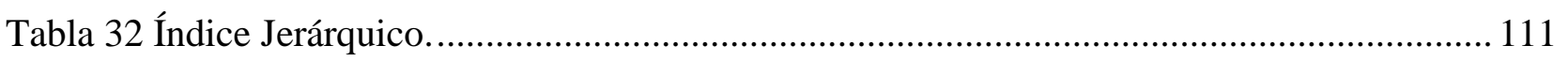

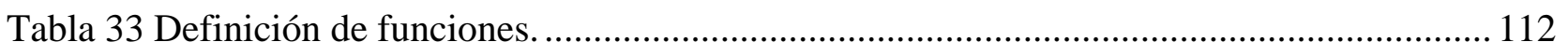

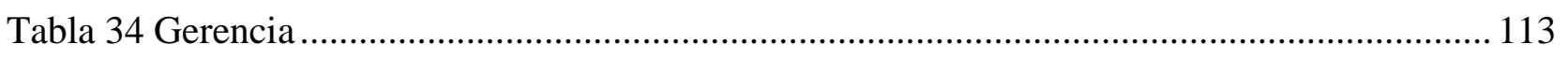

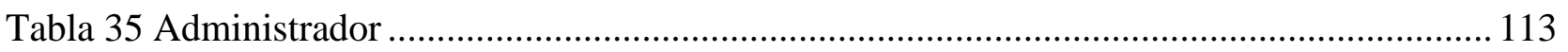

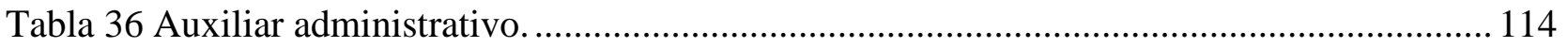

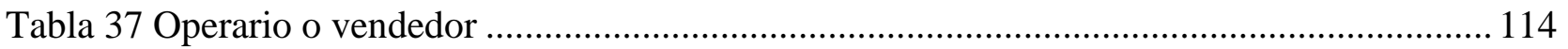

Tabla 38 Esquema básico de planilla de registro de información. .............................................. 114

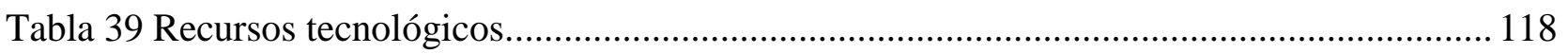

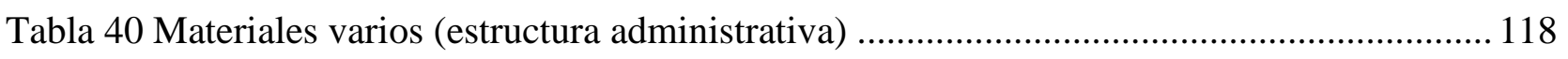

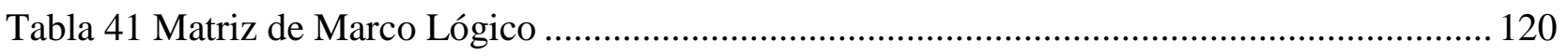




\section{Lista de Anexos}

Anexo 1 Presentación de empleados de la empresa Velerito ..................................................... 133

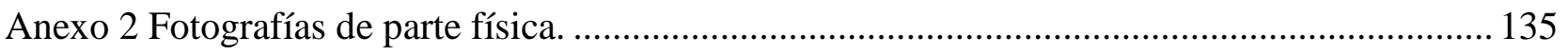

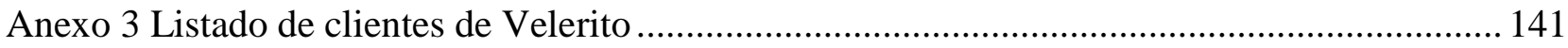

Anexo 4 Balance y Estado de Resultados para los años 2015, 2016, 2017 .............................. 143

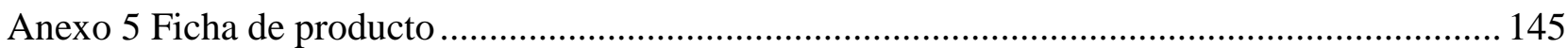




\section{Glosario}

PTP: Programa de transformación productiva.

OIT: Organización Internacional del Trabajo.

OMT: Organización Mundial de Comercio.

IED: Inversión Extranjera Directa

POLFA: Policía Fiscal y Aduanera.

CIIU: Clasificación Internacional Industrial Uniforme (NACIONES UNIDAS , s.f.)

OIT: Organización Internacional del trabajo.

OMC: Organización Mundial de Comercio.

CCB: Cámara de Comercio de Bogotá.

Metodología CARIBE: Calidad Total, Reingeniería y Bases Estratégicas para el Fortalecimiento Empresarial. 


\section{Resumen}

En el siguiente documento se presentará el desarrollo del ejercicio de fortalecimiento empresarial en la empresa Velerito, el cual según relato de sus fundadores presenta diferentes anomalías dentro de su sistema productivo. Velerito es una empresa que cuenta con más de 12 años de experiencia en el sector textil Bogotano y fue el objeto de estudio para este ejercicio académico.

El fortalecimiento empresarial se realizó bajo los lineamientos de la metodología CARIBE y auditoria administrativa, que fueron desarrolladas por el docente Héctor Horacio Murcia quien a su vez es el tutor de este trabajo de tesis. Además, se debe recalcar que se agregaron elementos y herramientas técnicas de otros autores para lograr configurar una metodología de fortalecimiento acorde con las necesidades de la empresa Velerito.

La pertinencia de la metodología de fortalecimiento elaborada por el tutor para la empresa objeto de estudio se da por los procesos de revisión, interpretación, análisis e información que se configuran al interior de la metodología y que denotan tres puntos fundamentales que son: el diagnóstico total de la organización desde un enfoque holístico y sistémico, la priorización de debilidades de acuerdo a los resultados extraídos en el proceso de diagnóstico, para finalmente desembocar en la consolidación del cambio requerido, que para efectos de este trabajo fue descrito como la propuesta.

Dentro de los tres pasos descritos anteriormente, se establecieron análisis internos y externos de factores tales como: contexto político, económico, social, jurídico, financiero, administrativo, de mercadotecnia, de comercialización, entre otros, por medio de herramientas académicas tales como listas de chequeo, diagramas, cuadros y matrices.

Es importante señalar que la propuesta de mejoramiento tiene como fin generar un cambio administrativo en la organización; sin embargo, esto está sujeto a la aprobación e implementación por parte de los dueños de la empresa Velerito.

Para finalizar, este documento tendrá repercusiones positivas tanto para el autor como para la empresa Velerito, puesto que será el medio por el cual se logre aplicar el conocimiento adquirido en el proceso de formación de la Maestría por parte del estudiante, y a su vez será una herramienta importante para la compañía para debatir, y sentar precedente de nuevas formas de agregar valor al interior de la organización. 


\begin{abstract}
This document will be presented the development of the entrepreneurial strengthening exercise in Velerito company, because according to the story of its founders, Velerito has been administrative and production problems.

Velerito Company has 12 years of experience on the textile market in Bogota; This Company was looked at this academic project.

This academic project is about entrepreneurial strengthening that is performed under the guidelines of the CARIBE methodology and administrative audit, which one was developed by the teacher Héctor Horacio Murcia, who is the tutor of this thesis as well. Additionally authors were taken into account adding their theoretical elements and technical tools, in order to develop a methodology to entrepreneurial strengthen according to the requirements of Velerito Company.

The relevance of the CARIBE methodology from Héctor Horacio Murcia to Velerito Company it's given by the processes of review, interpretation, analyses and information that are formed inside of that methodology, that headline 3 fundamental aspects: first one is the general diagnostic of the company from a holistic and systemic approach, second one is the prioritization of capacities according to the results as an answer of the diagnostic process, and finally finished in the required change, that for this thesis is called as proposal.

In the 3 fundamental aspects described above was set up internal and external analysis of factors such as: political, economic, social, legal, financial, administrative, merchandising, marketing, among others, by means of academic tools as, checkup lists, diagrams, graphics, tables and matrices.
\end{abstract}

Is too important to mark out that the project of entrepreneurial strengthens in this thesis, is developed to generate a positive impact on the company, however, it application and develop depends on the positive answer of the Valerio's owners.

Finally this project will be have positive impact to the thesis author and to the Velerito Company as a profitable business, because this will be the way through which is possible to apply the knowledge gained during the process of formation as a student of the MBA, and an important business tool to the company to debate and set a precedent for new ways to add value inside of Velerito company. 


\section{Introducción}

Para el año 2017 se crearon 177.545 unidades productivas de las cuales 38.183 fueron sociedades y 139.362 se constituyeron bajo la figura de persona natural. Según el diario El Espectador, la creación de empresas presento un crecimiento de 8,3\% entre el 2016 y 2017 (El Espectador, 2018) Cabe acotar que para ese mismo periodo la economía nacional presentó un crecimiento de producción cercano al 2\%, lo cual describe contracción en términos de producción referente al año inmediatamente anterior. El país denota paralelos entre las dinámicas de creación de nuevas unidades productivas, en contraste a la sostenibilidad de la malla empresarial del país para mantener sus dinámicas económicas.

Dentro de las dinámicas de la malla empresarial colombiana, la deserción es un tema que llama la atención; según la Cámara de Comercio de Bogotá para el 2013 luego de la creación de las nuevas unidades productivas de dicho año, solo el 55 por ciento de las firmas constituidas sobrevivió, para el segundo año el 41 por ciento logro mantenerse a flote; al tercer año, el 31 por ciento continuo, y finalmente en el cuarto año quedó tan solo el 23 por ciento (El tiempo, 2016), demostrando la existencia de problemas de fondo que limitan la sostenibilidad y el avance del tejido empresarial del país (Sexton W. P., 1977).

Es importante precisar que, para algunas instituciones como la Cámara de Comercio de Bogotá, Fundación Bavaria, el Grupo Sura, entre otros, existen tres factores que explicarían la tendencia de insostenibilidad que las nuevas empresas presentan.

$\checkmark$ Ausencia de inversión en innovación

$\checkmark$ Negocios sin capacidad de adaptación.

$\checkmark$ Ausencia de organización al interior de las empresas, lo cual aumenta en el nivel de incertidumbre en el entorno.

Es posible afirmar que dentro de la construcción de las estructuras empresariales existe la carencia de herramientas organizacionales que fomenten la sostenibilidad y el crecimiento de nuevas ideas que están surgiendo en el plano económico del país.

Dentro del contexto anteriormente descrito se encuentra Velerito, una organización que tiene por proceso productivo la fabricación de ropa infantil para niñas y que según sus fundadores necesita de más instrumentos para hacerle frente a diversas exigencias que el entorno y su organización presenta, las cuales desligan temas como problemas en la demanda de sus productos, entrada de competidores a su mercado tanto legales como ilegales, problemas internos que afectan 
la capacidad de la organización de diseñar nuevas líneas de productos según los tiempos y las velocidades que se exige en el mercado. Todo esto está afectando la rentabilidad y la capacidad de Velerito para crear valor (indicaciones de los fundadores de la compañía).

De esta forma surge la necesidad de entender desde una visión holística y sistémica la situación actual de la empresa, con el fin de saber cuáles serían los pasos a seguir en aras del fortalecimiento empresarial que los fundadores de Velerito exponen necesitar pero que no pueden llevar a cabo debido a la falta de recursos técnicos al interior de su organización.

Lo anterior exterioriza la necesidad de utilizar herramientas académicas que permitan dar otra dimensión a la manera en que los fundadores de la organización han abordado la gestión integral de Velerito, por tal razón se definió que la metodología de fortalecimiento era la más adecuada para poder en primera instancia determinar la realidad de la empresa, para seguidamente estructurar el problema principal o clave y posteriormente estipular un cambio que propicie la mejora de la compañía según sea la naturaleza del problema que se decanteo, la cual fue de carácter administrativo.

Para ello era importante contar con técnicas que permitieran sistematizar, clasificar y dar una lógica a la información que se recogería de la compañía; de paso, que permitiera filtrar dicha información de tal forma que se pudieran encontrar puntos de mejoramiento puntuales que tuvieran implicaciones verticales y horizontales al interior de la organización, para finalmente definir y estructurar los productos que la empresa podrá aplicar para efectuar un cambio. De esta manera se dio por pertinente la aplicación de la metodología de fortalecimiento la cual ha sido trabajada por el docente Héctor Horacio Murcia y que cuenta con las bases de metodologías como la CARIBE, y la de auditoria administrativa, las cuales fueron compartidas por el docente en el módulo formativo que él impartió al interior de la maestría tiempo atrás. Por consiguiente, se procedió al diseño del ejercicio de fortalecimiento, delimitando la hoja de ruta metodología a seguir para la creación de la propuesta de fortalecimiento.

Para esto, se elaboró una hoja de ruta compuesta de cuatro capítulos, los cuales denotan la elaboración de un estado del arte mediante el cual se configuraron las herramientas técnicas y teóricas necesarias para el diseño del fortalecimiento. Dicho estado del arte se desarrolló bajo la premisa de los objetivos descritos en el documento, y busco condensar la estructura de la metodología a aplicar para este ejercicio académico. Paso siguiente se desarrolló el diagnostico requerido, el cual consistió en hacer una aproximación a la realidad de la empresa en las áreas que la configuran; para esto, se establecieron técnicas administrativas sugeridas en la metodología del docente y tutor de este trabajo académico (Héctor Horacio Murcia); dichas herramientas 
condensan un mapa de procesos, unas listas de chequeo para cada unidad de la organización, un análisis del entorno mediante técnicas como la matriz PESTEL, entre otros.

De acuerdo con la línea metodológica, se prosiguió al desarrollo de la priorización de debilidades y para focalizar la problemática a resolver; para ello se utilizaron los resultados del diagnóstico para consecuentemente mediante las técnicas descritas en la metodología filtrar las debilidades estableciendo los lineamientos del cambio para efectuar el fortalecimiento. Para la priorización se usó la matriz DOFA, mediante la cual se ordenó, agrupo y selecciono las debilidades encontradas en todo el diagnostico, para luego elaborar un análisis de ponderación y priorización con los fundadores de la compañía, de tal forma que se pedirán elaborar análisis lógicos tales como: la matriz cómo - cómo, y el diagrama espina de pescado.

Por último, se estipulo un cambio de acuerdo a la necesidad encontrada en el apartado de priorización. En dicho cambio se definieron algunas herramientas mediante las cuales se demarcaron las acciones a implementar al interior de la organización para efectuar el fortalecimiento. De esta manera se finaliza con el desarrollo de las conclusiones y recomendaciones las cuales buscaron dejar lecciones aprendidas para todas las partes intervinientes en este ejercicio, además de proponer elementos y recursos necesarios para el desarrollo de nuevos ejercicios académicos de esta índole para Velerito. 


\section{Objetivos}

\section{General}

Desarrollar una propuesta de fortalecimiento para la empresa Velerito.

\section{Específicos}

Definir un estado del arte propicio para el fortalecimiento empresarial.

Desarrollar el diagnóstico empresarial de la empresa Velerito.

Identificar y priorizar la problemática a solucionar.

Diseñar propuesta para el fortalecimiento empresarial de Velerito. 


\section{Capítulo 1- Estado del Arte}

Como se ha determinado, la línea de desarrollo de este ejercicio será el fortalecimiento empresarial, razón por la cual es menester delinear todo el componente teórico y conceptual que este proceso exige para poder establecer la hoja de ruta mediante la cual se cumplirán los objetivos establecidos y se logre enmarcar un ejercicio académico lógico y coherente.

Para ello es importante decir que la OIT (Organización Internacional del Trabajo) define el proceso de fortalecimiento como un "servicio profesional, que proporciona propuestas y sugerencias concretas a empresas en plena actividad para resolver los problemas prácticos que afectan a la organización como sistema" (OIT, 2011), lo cual indica que al ser un servicio, este debe tener un sistema de acción en el cual se acerque a la empresa comprendida como " unidad productiva microeconómica en la cual debe hacerse un uso racional de los recursos disponibles, para lograr resultados que comprendan puntos técnicos, físicos y económicos que permitan el mejoramiento de la calidad de vida del empresario y su familia, su integración efectiva y real a los procesos de desarrollo y la comprensión de su responsabilidad social junto con la promoción de una capacidad empresarial creciente" (Murcia H. H., Auditoria Administrativa con base en la innovación organizacional, 2014).

Este acercamiento debe contener un ejercicio concienzudo en el cual se logre entender cada área funcional que conforma el sistema de la organización, entendiéndola como las diversas relaciones que pueden existir entre las partes de un todo (Murcia H. H., Auditoria Administrativa con base en la innovación organizacional, 2014), es decir, desarrollando esquemas organizados que permitan establecer una visión holística y sistémica de la organización, con el fin de establecer las bases y puntos de inicio para el eventual diagnóstico.

Para establecer la visión holística de la organización desde sus relaciones internas se debe partir por identificar los procesos que configuran su cadena de valor. Los cuales son:

Operaciones técnicas (Manufactura).

$\checkmark$ Comerciales (compra, venta e intercambio).

$\checkmark$ Financieras (obtención y control de los recursos financieros).

$\checkmark$ De seguridad (protección de bienes y personas).

$\checkmark$ Contables (control financiero y movimiento contable de la empresa).

$\checkmark$ Administrativas (planeación, organización, dirección, control, coordinación y evaluación) (Murcia H. H., Auditoria Administrativa con base en la innovación organizacional, 2014) 
Para fines de organización narrativa, se establecerán los fundamentos teóricos para cada objetivo específico de manera que a partir de allí se puedan delinear los parámetros para la construcción de la metodología aplicar durante todo el ejercicio. 


\section{Objetivo Específico 1 (Diagnóstico)}

Para el académico Martin Romero, el diagnóstico empresarial es el resultado de un proceso de investigación relacionado con la organización y el funcionamiento de las empresas, que permite determinar y evaluar las relaciones de causas y efectos de los problemas detectados y dar solución integral a los mismos (Flor Romero, 2006)

Por otro lado, Peter Drucker determina que el diagnóstico empresarial es un canal mediante el cual se recopila información, para posteriormente encontrar los puntos susceptibles de mejorar. (Chiavenato, Teoría General de la Administración, 2005)

De acuerdo a los componentes u áreas que conforman a las empresas, también existen diagnósticos definidos para cada una de ella. Estos tipos de diagnósticos se realizan a través de metodologías específicas que permiten conocer todos esos detalles concretos de la compañía, lo que la sitúa como una herramienta necesaria y recomendada. (Diaz, 2013)

Los dos grupos que clasifican los tipos de diagnóstico se establecen de la siguiente manera:

$\checkmark$ Diagnósticos integrales: Son los que parten de variables que envuelven la organización por completo y qué son producto del funcionamiento de todas las partes que conforman la cadena de valor de una organización. Un ejemplo podría ser el desarrollar un diagnóstico de competitividad.

$\checkmark$ Diagnósticos específicos: Son los que apuntan a análisis específicos de un área en particular de la organización. (Diaz, 2013)

Dentro de los pasos que podrían describir una metodología de diagnóstico se encuentran cuatro etapas para el desarrollo del ejercicio, el cual tiene por objetivo encontrar las causas fundamentales de los problemas observables en la compañía. Los pasos se enmarcan de la siguiente manera:

1. Evaluación. Es la capacidad de determinar el estado real de los procesos según sea el tipo de diagnóstico establecido; para ello es necesario contar con pruebas que extraigan información que pueda ser procesada.

2. Visión. Es la manera en cómo se recoge información primaria y secundaria de la empresa que luego permitan contrastarla con la evaluación de procesos ejecutada, para tener información clara y de fácil manejo para el paso de cálculos. 
3. Cálculos. Se prioriza y se examina el real alcance que se pretende en el ejercicio global de fortalecimiento a desarrollar.

4. Conclusiones. Se delimitan los motivos de causalidad, los cuales serán la materia prima para el desarrollo de toda la propuesta a diseñar e implementar por parte de la empresa.

Según Luis Muñiz, es importante tener claridad sobre las perspectivas principales de un diagnóstico empresarial, de las cuales se desprenden otras que forman parte de un nivel más específico. Dichas perspectivas nacen a partir de las unidades que configuran una organización y que están descritas de la siguiente manera:

$\checkmark$ Financiera. Abarca todo el departamento contable y de gestión de la empresa, evalúa todos sus números y estudia cuál es su situación actual. Conoce sus inversiones y fuentes de financiación entre otros.

$\checkmark$ Consumidores. Se evalúan todos los datos relacionados con el comportamiento de los clientes y su trato.

$\checkmark$ Proceso interno. Se centra principalmente en el estudio de los procesos de producción de la compañía. Determinando su calidad y eficacia.

$\checkmark$ Personal y sus capacidades. Hace una comparativa con las capacidades que posee el personal activo de la empresa y las que teóricamente se debería de tener para alcanzar altos niveles de eficiencia. (Gonzales, 2017)

Para algunos autores como Humberto Serna o Héctor Horacio Murcia, el diagnóstico empresarial debe contener herramientas que conlleven a la consecución de un diagnóstico que construya una clara descripción interna y externa de la empresa para consecuentemente formular las estrategias que permitan cumplir todo lo descrito en el direccionamiento estratégico de la organización.

Como se verá en la tabla 1 (herramientas de diagnóstico) los autores proponen herramientas que tienen una interconexión metodológica entre en sí, es decir, que representan una directriz para la depuración sistemática de la información que contienen las áreas de una empresa; ejemplos de esto son la Matriz DOFA que condensa la información extraída de la matriz PESTEL o listas de chequeo que así mismo organizan y clasifican la información que se recauda de fuentes primarias y segundarias. Cabe acotar que, dentro del ejercicio de diagnóstico, el desarrollo del enfoque 
holístico y sistémico es fundamental para delimitar el contexto en el cual se iniciará todo el proceso de mejoramiento, como lo indica el docente Héctor Horacio Murcia. (Murcia, 2016).

Tabla 1 Herramientas de diagnóstico.

\begin{tabular}{|c|c|}
\hline Herramientas & Implicación \\
\hline DOFA & $\begin{array}{l}\text { Matriz diseñada por Michael Porter que permite encasillar de manera precisa el } \\
\text { contexto interno y externo de la compañía para identificar estrategias que permitan la } \\
\text { elaboración de un plan de mejoramiento. (Gómez, Gerencia estrategica, 1994) }\end{array}$ \\
\hline PESTEL & $\begin{array}{l}\text { Matriz diseñada por la Boston Consulting Group que permite establecer la } \\
\text { favorabilidad de factores externos para el desarrollo del ejercicio económico de la } \\
\text { empresa objeto de estudio. (Murcia H. H., Auditoria Administrativa con base en la } \\
\text { innovación organizacional, 2014) }\end{array}$ \\
\hline $\begin{array}{l}\text { Listas de } \\
\text { Chequeo }\end{array}$ & $\begin{array}{l}\text { Herramientas que contienen elementos susceptibles a ser evaluados de un área objeto } \\
\text { de estudio de la organización y que compilan acciones, recursos o actividades claves } \\
\text { dentro del plan estratégico. }\end{array}$ \\
\hline $\begin{array}{l}\text { Mapa de } \\
\text { procesos }\end{array}$ & $\begin{array}{l}\text { Estructura que propone dar una visión holística del funcionamiento de la organización; } \\
\text { mediante la descripción de los procesos de apoyo, operativos y gerenciales. (Murcia H. } \\
\text { H., Unidades básicas de la empresa, 2000- 2018). } \\
\text { Esta herramienta tiene por finalidad visualizar cómo se crea valor al interior de la } \\
\text { empresa mediante la eficacia en el manejo de recursos y cumplimiento de objetivos } \\
\text { estratégicos de la empresa. }\end{array}$ \\
\hline
\end{tabular}

Fuerzas de Las fuerzas que expone Porter son los pilares que estructuran una industria o un Porter mercado. Este proceso de análisis es un modelo que permite identificar el nivel de competencia de la empresa en su entorno; además dar claridad sobre la importancia del análisis de los grupos de interés que afectan el desarrollo del direccionamiento estratégico de la empresa. (Porter, 2008)

Fuente: Elaborado por el autor 


\section{Objetivo Especifico 2 (Priorización)}

Dentro de la línea del fortalecimiento empresarial, la priorización de debilidades es fundamental para la consecución del objetivo general de este ejercicio.

La Real Academia de la Lengua Española define el término "problema” como conjunto de hechos o circunstancias que dificultan la consecución de algún fin". Es decir, atañe a una serie de elementos que dificultan la consecución de unos objetivos. Dentro de esta definición algunos autores disponen de este elemento para la creación de puentes de mejoramiento empresarial. Puesto que son los puntos de partida para la elaboración de escenarios que representan el cambio al que se quiere llegar, y por ende, todas las implicaciones de recursos y gestionen que preceden dicho cambio.

Para determinar dichos puntos de partida, el diagnóstico debe ir acompañado de un proceso de análisis de los resultados encontrados, los cuales deben en principio abordar los factores más susceptibles a ser corregidos. Para ello, autores como Héctor Horacio Murcia precisan la necesidad de la aplicación de tablas de priorización, las cuales son instrumentos que permiten la clasificación de debilidades a partir de técnicas estadísticas.

Ahora bien, para realizar una matriz de priorización de problemas, antes se debe identificar las distintas alternativas y los criterios de decisión, con el objetivo de poner todo en común y decantarnos para encontrar la solución que mejor ponderación obtenga.

Si bien la priorización es fundamental dentro del contexto de la planeación administrativa, también es un factor que permite a las organizaciones diseñar nuevos escenarios, los cuales el direccionamiento estratégico de la empresa no ha contemplado. Esto es fundamental para el desarrollo e implementación de procesos de innovación y creatividad.

Otros beneficios de usar una matriz de priorización podrían denotar:
Soluciones eficaces.
$\checkmark$ Valoración de expectativas.
$\checkmark$ Identificación de criterios de selección.
$\checkmark$ Exploración de diferentes alternativas.
$\checkmark$ Soluciones contrastadas bajo los mismos criterios.
$\checkmark$ Identificación de riesgos. 
Henry Fayol, indica en la descripción de sus 14 principios de la administración que la configuración del ser humano dentro de las directrices que preceden a la organización, son las unidades de mando y la unidad de dirección, que hacen parte de las cinco etapas clave del proceso administrativo (planeación, dirección, control y evaluación) las cuales parten de la necesidad de la hacer frente al uso adecuado de los recursos internos que disponen las compañías. (Chiavenato, 2002).

Se podría seguir con otros aportes de grandes de la teoría de la administración como Taylor o Weeber quienes en sus teorías diseñaron e idearon esquemas que buscaban resolver problemas en cuanto al manejo eficaz y eficiente de los recursos físicos y humanos. Lo anterior se menciona para evidenciar que la configuración de problemas se da desde principios inmemorables y que es la materia prima para el desarrollo de los estándares de innovación y transformación productiva de la malla empresarial mundial.

A continuación, se describen algunos pasos para el desarrollo de la matriz de priorización de problemas

1. Identificar los principales problemas de manera genérica.

2. Formular en una frase del problema central. Este punto hace referencia a la claridad con que describimos la situación susceptible de cambio.

3. ¿Cuáles son las causas del problema central? Definir los factores que consolidan el problema central descrito.

4. ¿Cuáles son los efectos provocados por el problema central? En este punto se propone establecer una línea de escenarios que describen consecuencias e implicaciones de las anomalías encontradas.

5. Identificar las opciones resultantes. Hacemos una lista con las distintas alternativas encontradas.

6. Elaboración de criterios de selección. Se establece la conexión con fundamentos que relacionen todas las opciones listadas.

7. Ponderar los criterios. Se elabora una tabla donde se reúnan los elementos encontrados en el diagnóstico, con el fin de determinar el problema clave a partir de la metodología que se disponga por parte del consultor para desarrollar el ejercicio. (Diaz, 2013). 


\section{Objetivo Especifico 3 (Propuesta)}

La Real Academia de la Lengua Española define el término propuesta "como un verbo transitivo que implica manifestar con razones algo para conocimiento de alguien, o para inducirle a adoptarlo" (Real Academia de la Lengua Española).

Según el docente Héctor Horacio Murcia, la propuesta para un ejercicio de fortalecimiento empresarial configura el cambio que la empresa debe alcanzar para superar las debilidades internas y estructurar puentes de desarrollo. Además, el docente indica que la propuesta es el resultado de bien sea un diagnóstico, o una auditoria administrativa que lleva consigo información organizada sobre una empresa como sistema o de una unidad o departamento en especial que necesita de acciones que impliquen movilización de recursos, ya sean de capital, técnicos o físicos. (Murcia H. H., 2014)

Dentro de la elaboración de una propuesta es fundamental definir elementos como: el alcance del cambio, los recursos que se necesitan dentro del marco de las acciones y sus responsables al interior de la propuesta. Además, se debe organizar de forma sistemática los tiempos para ejecutar cada paso establecido para la consecución del cambio. Entre los elementos que conforman una propuesta se enmarca la estructura y la figura económica, en la cual se establecerá la viabilidad de la propuesta en caso de que está así lo requiera.

La estructura está configurada por objetivos, que definen el cambio que la propuesta establece, también se encuentra la descripción de cada actividad y programa de forma clara y coherente, para luego entrar en detalle del cómo se llevarán a cabo los pasos de desarrollo de la propuesta, definiendo herramientas técnicas y modelos académicos que permitan estructurar la propuesta, a esto se le denomina como metodología.

Luego de establecido el esquema de gestión de la propuesta es necesario determinar alcances a partir de los productos esperados en la propuesta. Por su lado, la figura economía determina la cantidad de recursos financieros requeridos para ejecutar la propuesta, dentro de los componentes se encuentran la definición de tiempos y costos, así como el costo de los materiales físicos y técnicos requeridos; para luego establecer por medio del método que mejor se acople a las características de la empresa y de la propuesta, sí la propuesta destruye o construye valor, por ende, sí debe o no adaptarse a la compañía. 


\subsection{Conceptos relevantes para el desarrollo del fortalecimiento empresarial.}

De acuerdo con la línea y la unidad investigativa a la que pertenece todo el desarrollo de este trabajo, se dio por pertinente establecer parámetros académicos para el tema de estructura administrativa y apoyar el componente teórico del objetivo específico 3 (propuesta).

Tabla 2 Estado del arte (concepto de Estructuras administrativas)

\begin{tabular}{|c|c|c|}
\hline Autor & Concepto de estructura & Tema \\
\hline Henry Mintzberg & $\begin{array}{l}\text { Es el conjunto de todas las formas en que se divide el trabajo en } \\
\text { tareas distintas y la posterior coordinación de las mismas. } \\
\text { (Sexton W. P., 1977). }\end{array}$ & $\begin{array}{l}\text { Concepto de } \\
\text { estructura } \\
\text { administrativa }\end{array}$ \\
\hline Strategor & $\begin{array}{l}\text { Es el conjunto de las funciones y de las relaciones que } \\
\text { determinan formalmente las funciones que cada unidad deber } \\
\text { cumplir y el modo de comunicación entre cada unidad. }\end{array}$ & $\begin{array}{l}\text { Concepto de } \\
\text { estructura } \\
\text { administrativa }\end{array}$ \\
\hline Henry Fayol & 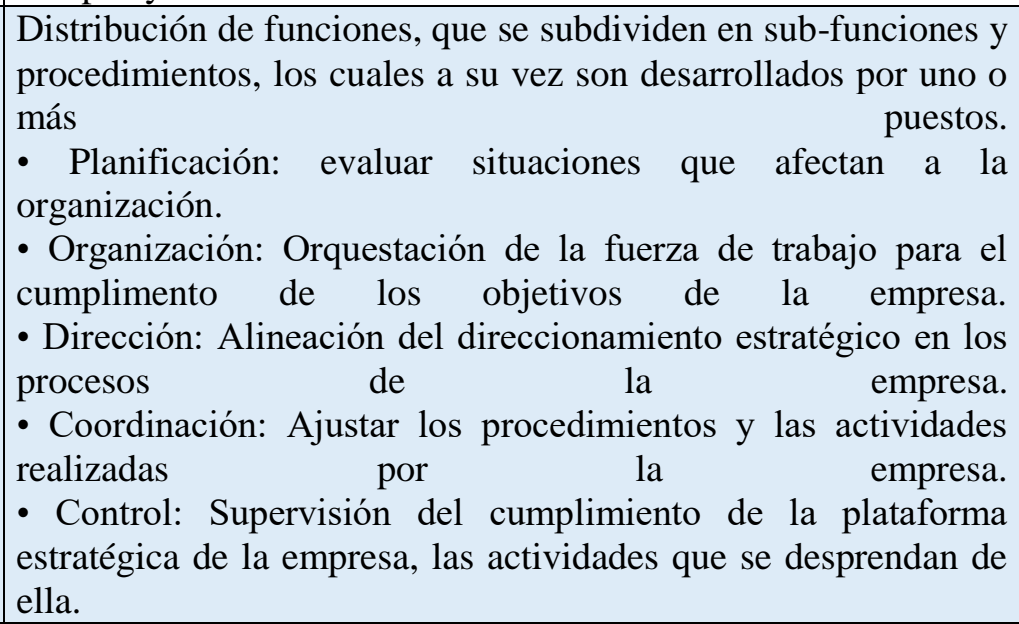 & $\begin{array}{l}\text { Concepto de } \\
\text { estructura } \\
\text { administrativa. } \\
\text { Funciones clave. }\end{array}$ \\
\hline Max Webber & $\begin{array}{l}\text { Configuración de reglas claras y racionales, decisiones } \\
\text { impersonales y excelencia técnica en sus empleados y gestores. }\end{array}$ & $\begin{array}{l}\text { Concepto de } \\
\text { estructura } \\
\text { administrativa } \\
\end{array}$ \\
\hline Jay Barney & $\begin{array}{l}\text { Estructura que gestiona más racionalmente sus recursos y } \\
\text { capacidades. }\end{array}$ & $\begin{array}{l}\text { Concepto de } \\
\text { estructura } \\
\text { administrativa } \\
\end{array}$ \\
\hline Diversos autores & 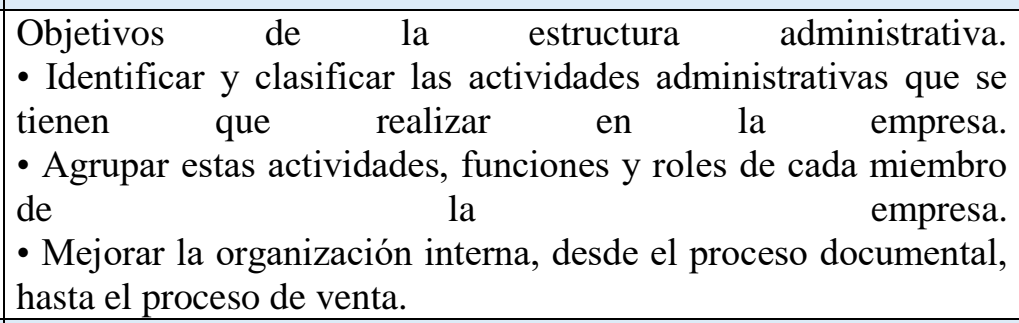 & $\begin{array}{l}\text { Objetivos de la } \\
\text { estructura } \\
\text { administrativa }\end{array}$ \\
\hline Chiavenatto & 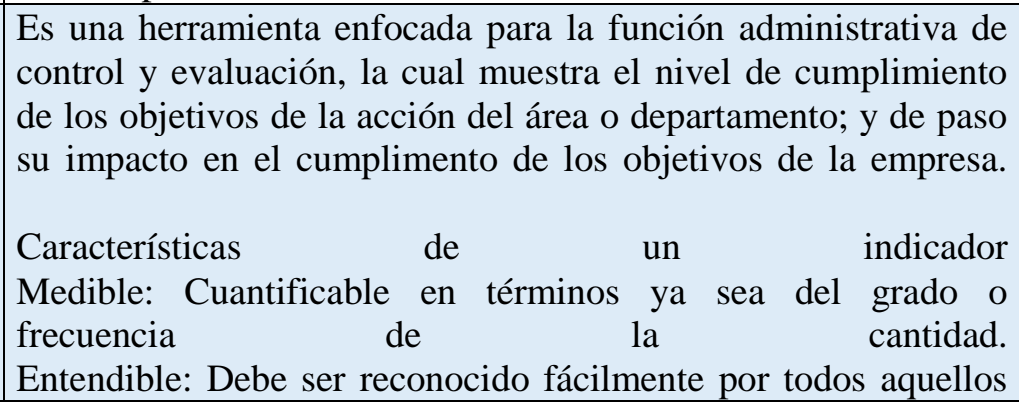 & $\begin{array}{l}\text { Indicador de } \\
\text { Gestión }\end{array}$ \\
\hline
\end{tabular}


que lo usan.

Controlable: Debe ser controlable dentro de la estructura de la organización.

Fuente: (Sexton W. P., 1977) 


\section{Diseño Metodológico}

El desarrollo metodológico de este ejercicio académico tiene por misión responder los objetivos establecidos al inicio de este documento, de tal forma, se inició por la comprensión holística de la organización objeto de estudio mediante un mapa de procesos, para luego contrastarlo con el esquema sistémico de la compañía.

Este ejercicio será de tipo inductivo, partiendo del análisis del entorno para luego llevarlo a nivel operativo, gerencial, y de apoyo; con el fin de determinar una serie de anomalías puntuales que se ponderarán y se priorizarán para seguidamente elaborar una propuesta de mejoramiento que plantee un cambio al interior de la organización. Lo anterior describe al diagnóstico, identificación del problema y a la propuesta de fortalecimiento.

Para el desarrollo de la hoja de ruta descrita es menester utilizar herramientas que permitirán condensar, organizar y procesar la información necesaria para lograr cumplir con los objetivos de este ejercicio académico; por tal razón los procedimientos que se proponen para el desarrollo de la metodología y cumplimiento de los objetivos específicos serán descritos en la tabla3 (esquema metodológico).

Dentro del diseño metodológico es importante mencionar las fuentes de información mediante las cuales se estructuro este ejercicio. Las fuentes primarias que se dispusieron fueron entrevistas a los fundadores de la compañía, las cuales se plasmaron en el desarrollo de la presentación de la empresa y el proceso de ponderación y selección del problema, además de observaciones de campo sobre los procesos descritos en este documento, los cuales dieron como resultado las listas de chequeo. Las fuentes secundarias usadas fueron libros afines a temas administrativos y organizacionales, sitios web especializados y artículos de fuentes especializadas tanto para el tema metodológico como para el tema textil.

\section{Tabla 3 Esquema metodológico}

\begin{tabular}{|c|c|}
\hline $\begin{array}{c}\text { Objetivos } \\
\text { específicos }\end{array}$ & Herramientas \\
\hline $\begin{array}{l}\text { Definir un estado } \\
\text { del arte propicio } \\
\text { para el } \\
\text { fortalecimiento } \\
\text { empresarial. }\end{array}$ & $\begin{array}{l}\text { - Análisis de literatura por objetivos, teniendo en cuenta el desarrollo de la } \\
\text { metodología seleccionada para este ejercicio académico. } \\
\text { Extracción de elementos clave para la metodología de fortalecimiento empresarial a } \\
\text { partir de la literatura especializada que proveyó el tutor de este trabajo. }\end{array}$ \\
\hline
\end{tabular}




\begin{tabular}{|c|c|}
\hline $\begin{array}{l}\text { Desarrollar el } \\
\text { diagnóstico } \\
\text { empresarial de la } \\
\text { empresa Velerito }\end{array}$ & $\begin{array}{l}\text { - Esquema de PESTEL, el cual tendrá por función describir los factores externos que } \\
\text { puedan afectar el entorno de la compañía, para luego sopesar los hallazgos en una } \\
\text { matriz que condense y clasifique los aspectos más importantes a desarrollar. } \\
\text { Matriz de Fuerzas de Porter, es una herramienta que tendrá por objeto delimitar los } \\
\text { stakeholders más importantes y denotar la relación que tienen con la compañía de } \\
\text { acuerdo a la capacidad de negociación dentro de variables específicas de la } \\
\text { metodología. Esto, con el fin de determinar la posición de negociación de la } \\
\text { compañía en su entorno (Porter, 2009). } \\
\text { - Sistema de comercialización, es una herramienta que permite establecer el nivel de } \\
\text { las dinámicas comerciales que la empresa implanta en el mercado. En ella se evalúa } \\
\text { demanda, oferta, canales, publicidad, atención al cliente, competencia etc. Estos son } \\
\text { vitales para el desarrollo de estrategia, y para determinar la cuota de mercado que la } \\
\text { empresa tiene. } \\
\text { Las listas de chequeo, son herramientas fundamentales para el recaudo y } \\
\text { procesamiento de la información de la empresa. Estas cuentan con una serie de ítems } \\
\text { qué clasifican los temas administrativos (planeación, dirección control, evaluación), } \\
\text { físicos, financieros, de mercadotecnia, legales, gerenciales, operativos y recursos } \\
\text { humanos (Coopers y Lybrand, 1997). }\end{array}$ \\
\hline $\begin{array}{l}\text { Priorizar e } \\
\text { identificar la } \\
\text { problemática a } \\
\text { solucionar }\end{array}$ & $\begin{array}{l}\text { - La matriz DOFA, será el pilar para la combinación de los resultados encontrados en } \\
\text { las diferentes herramientas de recolección y clasificación de información. Allí se } \\
\text { efectuará un mix de las variables internas y externas para dar cavidad al listado de } \\
\text { debilidades que posteriormente serán ponderadas, y priorizadas para determinar } \\
\text { mediante el diagrama de Pareto, el problema sobre el cual se formulará y diseñará la } \\
\text { propuesta de fortalecimiento empresarial. } \\
\text { Diagrama de Pareto: Gráfica que permite fortalecer la priorización de problemas, } \\
\text { con el fin de direccionar los recursos de manera eficaz para la efectuación del } \\
\text { cambio. (Murcia H. H., sicreaempresa.blogspot, 2016) } \\
\text { El esquema de la espina de pescado (por qué- por qué) es un diagrama de causa y } \\
\text { efecto que tiene por finalidad para este ejercicio de fortalecimiento la configuración } \\
\text { del problema transversal de la compañía a partir de las debilidades encontradas } \\
\text { previamente en la matriz DOFA. (Murcia H. y., 1976) } \\
\text { Formulación del problema a solucionar. }\end{array}$ \\
\hline $\begin{array}{l}\text { Diseñar propuesta } \\
\text { para el } \\
\text { fortalecimiento de } \\
\text { Velerito. }\end{array}$ & $\begin{array}{l}\text { - Cambio esperado. } \\
\text { - Extracción de elementos susceptibles de cambio al interior de la organización. Se } \\
\text { usará la lista de chequeo que corresponda con el problema priorizado. (cuadro de } \\
\text { cambio) } \\
\text { - Diseño del producto a aplicar (propuesta). } \\
\text { - Marco Lógico de la empresa. } \\
\text { - Cuadro de impacto. } \\
\text { - Cronograma. } \\
\text { - Conclusiones finales. }\end{array}$ \\
\hline $\begin{array}{l}\text { Objetivos } \\
\text { específicos }\end{array}$ & Herramientas \\
\hline $\begin{array}{l}\text { Definir un estado } \\
\text { del arte propicio } \\
\text { para el } \\
\text { fortalecimiento } \\
\text { empresarial. }\end{array}$ & $\begin{array}{l}\text { - Análisis de literatura por objetivos, teniendo en cuenta el desarrollo de la } \\
\text { metodología seleccionada para este ejercicio académico. } \\
\text { Extracción de elementos clave para la metodología de fortalecimiento empresarial a } \\
\text { partir de la literatura especializada que proveyó el tutor de este trabajo. }\end{array}$ \\
\hline
\end{tabular}




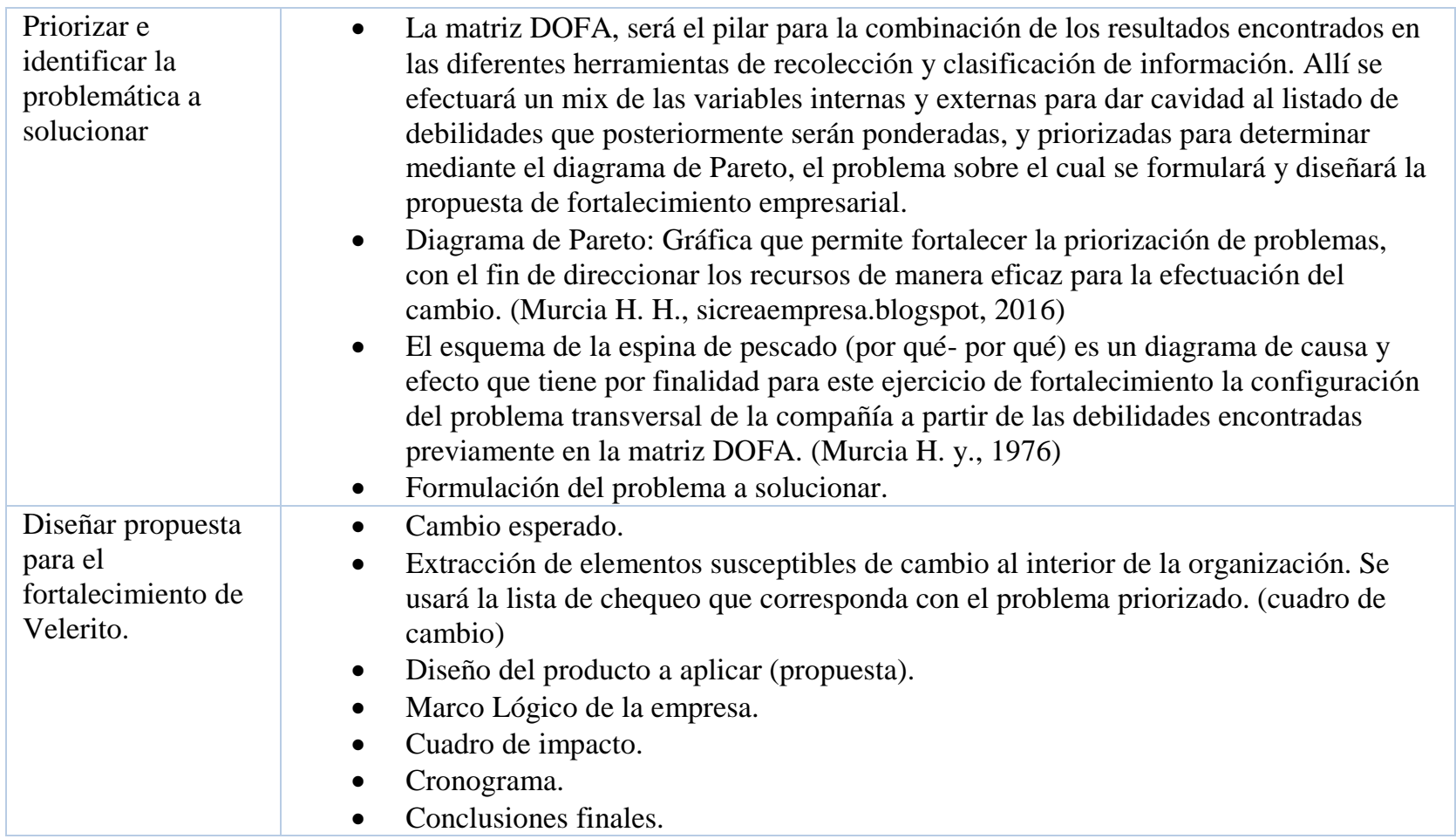

Fuente: (Murcia H. H., Auditoria Administrativa con base en la innovación organizacional, 2014) 


\section{Presentación de Resultados}

\section{Capítulo 2 - Diagnóstico}

\subsection{Presentación de la empresa}

Velerito empezó su operación en el año 2001 en la ciudad de Bogotá y fue fundada por Juan Pablo Sánchez Duarte y Martha Lucía Santana Garzón, quienes cuentan con más de 25 años de experiencia en el sector textil colombiano. Velerito es una empresa que tiene por objeto económico la elaboración de prendas de vestir infantil-femenina que oscila entre los entre los 2 a los 12 años, teniendo por producto estrella el estilo t-shirt para niña. Legalmente está constituida bajo la razón social Martha Santana Garzón con número de NIT 51966390-9. (Garzón, 2017).

Actualmente, Velerito cuenta con 12 empleados, distribuidos de la siguiente manera:

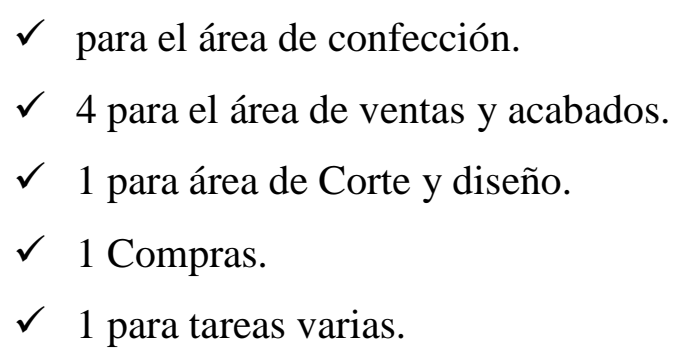

En el anexo 1 se presenta la información de los empleados vinculados con la empresa. Además, cuenta con un espacio utilizado para el proceso de fabricación, ubicado en la carrera 41 bis\#29c-50 sur de $500 \mathrm{~m} 2$, distribuido en tres pisos (en el anexo 2 estará todo el material fotográfico de las instalaciones y de las maquinas), en donde dispone de:

$\checkmark$ (11) Once máquinas de confección que están distribuidas en 6 fileteadoras, 3 collarines y dos planas

$\checkmark$ (2) dos termofijadoras manuales y una industrial con dos planchas de pliego.

$\checkmark$ (4) cuatro módulos de mesa de tendido de dos metros por dos cuarenta metros

$\checkmark$ Una cortadora industrial para tela marca Eastman.

$\checkmark$ (2) pulpos para desarrollar procesos de estampación con sus respectivas instalaciones de luz y gas para los procesos de secado.

$\checkmark$ Una sesgadora industrial. 
$\checkmark$ Espacio de almacenamiento para materia prima ( tela, hilos, repuestos de algunas máquinas, marquillas), para mordería y para agujas y demás

$\checkmark$ Tres baños distribuidos para hombres y mujeres

$\checkmark$ Una cocina integral y su respectivo espacio para tomar alimentos

$\checkmark$ Parqueadero.

$\checkmark$ Un despacho improvisado

Un espacio de almacenaje para el producto terminado. (Garzón, 2017).

Los procesos que se gestionan en el modelo de negocio de Velerito están encasillados de la siguiente forma:

1. Diseño y moldería.

2. Compras de materiales.

3. Tendido, marcación y corte.

4. Confección.

5. Acabados.

6. Estampación o aplicación del arte textil en la prenda confeccionada.

7. Embalaje.

8. Distribución al punto de venta.

9. Venta. (Garzón, 2017)

Las acciones transversales a los procesos mencionados anteriormente son la movilización de productos y la clasificación de cantidades.

Dentro de la desagregación de procesos están los que Michael Porter describe como actividades soporte que están direccionados en la cadena de valor de Velerito. Estas actividades son:

\footnotetext{
$\checkmark$ Gestión de recursos humanos.

$\checkmark$ Proceso financiera.

$\checkmark$ Proceso Contable y tributaria
}

Frente a elementos administrativos, se indica que no existe un documento que evoque un plan de acción, sino que este se da de forma empírica por los dueños de la organización. Sin embargo, es menester precisar que los dos propietarios dirigen y controlan todos los procesos que se manejan en la empresa. 
Desde una mirada externa, Velerito cuenta con varios proveedores que van desde materias primas, parte contable y tributaria hasta transporte de mercancía.

Por otra parte, Velerito cuenta con varios puntos de venta ubicados en el centro de la ciudad más específicamente en lo que se conoce como madrugón o feria de textiles y confección, en el cual tienen derecho al uso de varios espacios para la comercialización de sus productos.

El madrugón se realiza todos los miércoles y sábados, y comprende un rango de tiempo que va de 1 am hasta las $11 \mathrm{am}$, en el cual confluyen vendedores en su mayoría de textiles y mayoristas de diferentes sitios de Colombia; razón por lo cual se puede inferir que es un espacio diseñado para el comercio mayorista. (Garzón, 2017)

Los clientes frecuentes que tiene Velerito son cerca de 50 distribuidos a lo largo del plano nacional y fueron en su mayoría vinculados a la empresa por medio del espacio del madrugón. (Anexo 3, listado de los clientes que cuenta Velerito).

La acción de venta que actualmente Velerito presenta es de forma directa a los mayoristas y de forma indirecta a los consumidores finales, en donde la forma de pago es de contado y en efectivo.

Para dar orden a todo lo la información previamente descrita de Velerito se desarrolló un mapa de procesos (ilustración 1- Mapa de Procesos) en donde se graficaron los procesos que están presentes en la organización, mostrando la relación entre ellos y sus relaciones con el exterior. Para luego establecer una visión de sistema de la compañía objeto de estudio.

\section{Ilustración 1 Mapa de procesos}

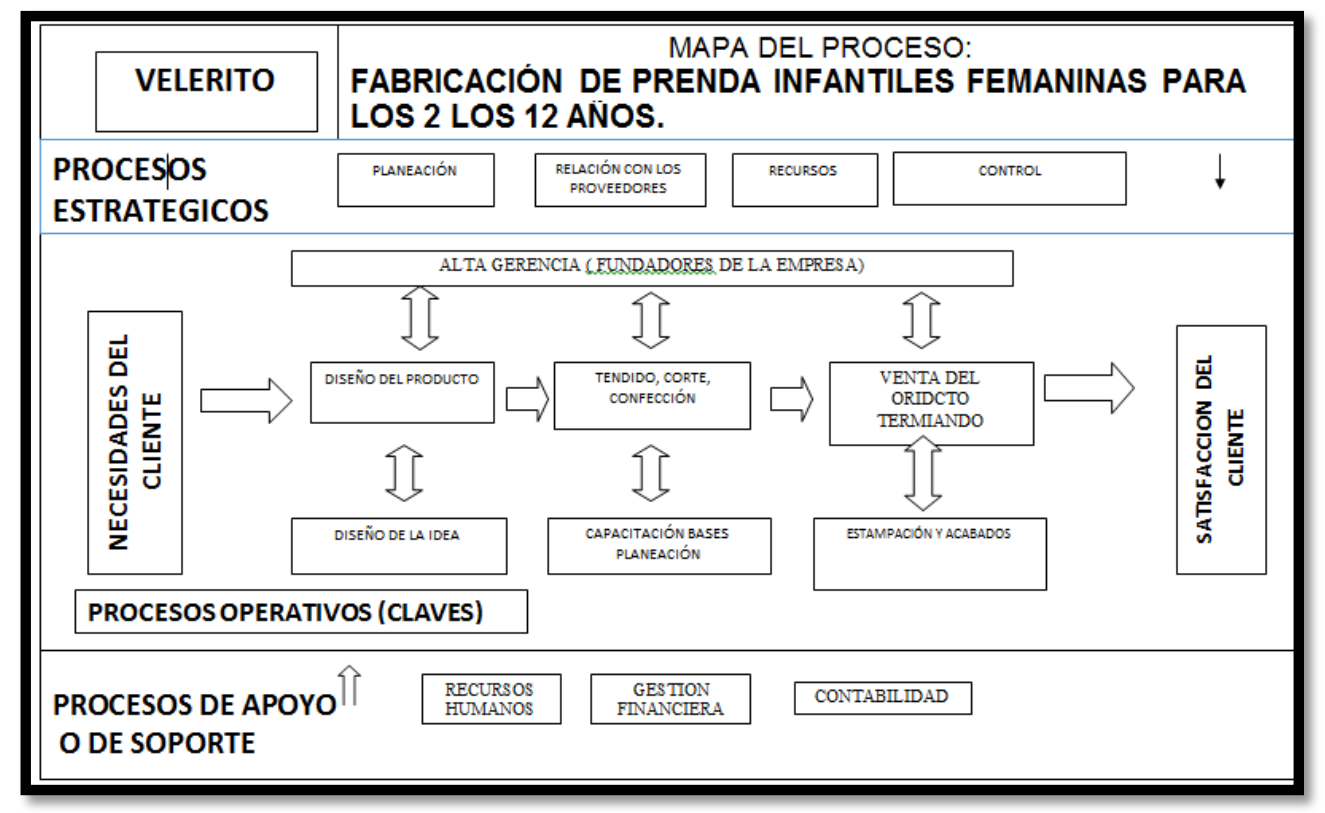

Fuente: (Murcia, 2016) 
A continuación, se desarrolló un esquema de sistema empresarial basados en la información suministrada anteriormente.

Tabla 4 Sistema empresarial de Velerito

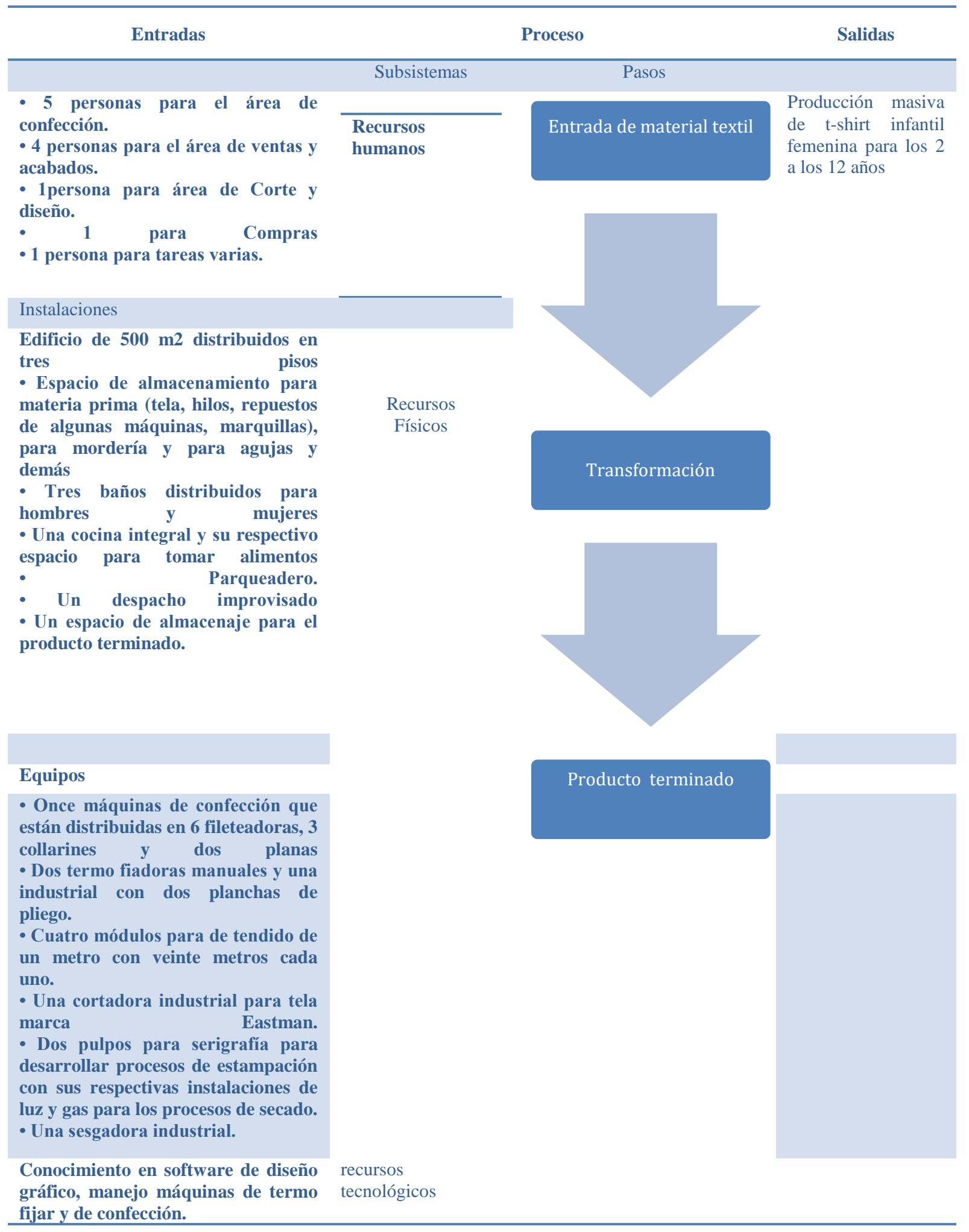


Los fundadores ejercen todos los procesos administrativos que van desde planeación y organización, hasta dirección y control; sin embargo no existe un documento guía u hoja de ruta digital o física en donde se estipulen estos elementos

El manejo del dinero se desarrolla por parte de los fundadores, quien a su vez ejecuta todas las funciones que implique flujo de dinero.

La empresa está registrada en Cámara de Comercio, y está vigilada por la dirección de impuestos y aduanas nacionales DIAN.

\section{Recursos}

administrativos

Recursos

económicos

Aspectos externos

Fuente: Elaboración Propia

Para el desarrollo del diagnóstico de la empresa Velerito se establecen las unidades básicas de una empresa como se ve en la ilustración 2(Unidades básicas de la empresa) para tener un marco de referencia para el desarrollo de la descripción real de la empresa. Además, se describirán los mega procesos (gerenciales, operativos y de apoyo) en la tabla 4 (mega procesos del sistema de la empresa Velerito) que configuran la empresa, para demarcar el contexto interno y su dinámica productiva (P.Norton, 2004).

\section{Ilustración 2 Unidades Básicas de la empresa}

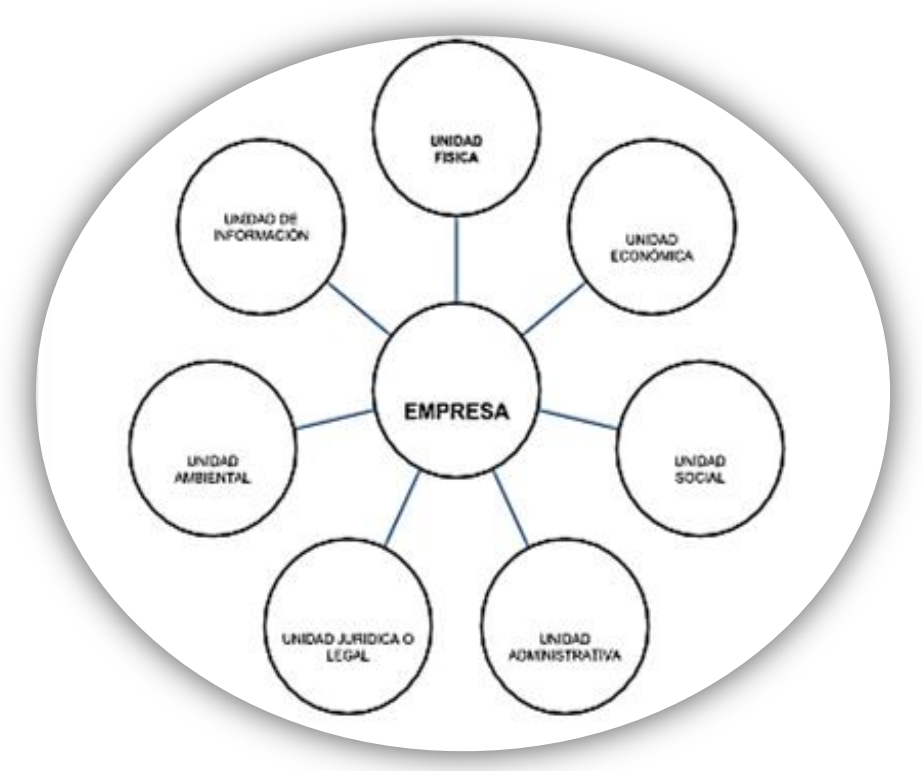

Fuente: (Murcia H. H., 2000- 2018) 
Tabla 5 Mega procesos en el sistema de la empresa Velerito

\begin{tabular}{|c|c|c|}
\hline \multicolumn{3}{|c|}{ Mega procesos en el sistema de empresa de Velerito } \\
\hline $\begin{array}{l}\text { Procesos } \\
\text { gerenciales } \\
\text { PHVA }\end{array}$ & \multicolumn{2}{|c|}{ Planeación, ejecución, negociación, relaciones con proveedores. } \\
\hline \multirow{13}{*}{$\begin{array}{l}\text { Procesos } \\
\text { Operativos }\end{array}$} & \multicolumn{2}{|l|}{ Diseño } \\
\hline & Subprocesos & Actividades \\
\hline & Diseño del modelo & $\begin{array}{l}\text { Se elabora el esquema de la prenda a fabricar a } \\
\text { partir de patronajes establecidos en revistas } \\
\text { especializadas como QUINI }\end{array}$ \\
\hline & Molderia & $\begin{array}{l}\text { Se desarrolla todo el proceso de patronaje en } \\
\text { cuanto al número de piezas que conforma la } \\
\text { prenda, y las tallas que se deseen sacar }\end{array}$ \\
\hline & Corte & $\begin{array}{l}\text { Desenvolvimiento de la tela, extendido de la } \\
\text { tela bajo una medida que está determinada por } \\
\text { el número de prendas a extraer, marcación de } \\
\text { los moldes sobre la tela previamente tendida, y } \\
\text { luego corte de las piezas demarcadas }\end{array}$ \\
\hline & Confección & $\begin{array}{l}\text { Clasificación de las piezas cortadas confección } \\
\text { de las piezas, acabados básicos. }\end{array}$ \\
\hline & Acabados & $\begin{array}{l}\text { Desdoblar la prenda por su derecho, y hacer } \\
\text { inspección en costuras. }\end{array}$ \\
\hline & $\begin{array}{l}\text { Estampación o aplicación del } \\
\text { arte textil en la prenda } \\
\text { confeccionada }\end{array}$ & $\begin{array}{l}\text { Ordenamiento de las prendas para su } \\
\text { manipulación, preparación del arte textil a } \\
\text { aplicar, aplicación, y ordenamiento para } \\
\text { embalaje. }\end{array}$ \\
\hline & Embalaje & Distribución de cantidades, empaque, \\
\hline & Distribución al punto de venta & cargue y descargue, transporte \\
\hline & & Mercadeo \\
\hline & Compras & $\begin{array}{l}\text { Selección del sustrato a usar para la prenda a } \\
\text { fabricar, cotización, elección y adquisición. }\end{array}$ \\
\hline & Venta & $\begin{array}{l}\text { Remesas, atención al cliente mayorista, manejo } \\
\text { del dinero, publicidad, exhibición, desempaque } \\
\text { y empaque del producto, seguimiento del cliente }\end{array}$ \\
\hline \multirow{3}{*}{$\begin{array}{l}\text { Procesos de } \\
\text { apoyo }\end{array}$} & Contabilidad & Declaración de impuestos, \\
\hline & gestión financiera & Pagaduría de todo lo que la empresa requiera \\
\hline & recursos humanos & $\begin{array}{l}\text { Elección del personal a ingresar, seguimiento de } \\
\text { su desarrollo laboral y personal en el ambiente } \\
\text { de la empresa, para este caso Velerito, manejo } \\
\text { de pago de prestaciones sociales }\end{array}$ \\
\hline
\end{tabular}

Fuente: (Murcia H. H., 2014) 


\section{Análisis de Contexto}

\subsection{Metodología PESTEL}

Esta metodología, es una herramienta desarrollada para la descripción y análisis del entorno de las empresas, ideas de negocio o proyectos desde las perspectivas políticas, económicas, sociales, tecnológicas, el cual para este ejercicio de fortalecimiento empresarial es el sector textil.

A continuación, se desarrollará el ejercicio propuesto desde las ópticas, mundial, Colombia en el mundo y Colombia endógena en combinación con las perspectivas previamente mencionadas; luego se pasará a un ejercicio de calificación de los ámbitos descritos, los cuales llevarán a concluir la favorabilidad del entorno del entorno para la empresa (Thompson, 1998).

\subsubsection{Factores del Entorno}

\subsubsection{Factor político}

Colombia es una república que está divida en tres las ramas del poder la legislativa, judicial, ejecutiva. Su principio se deriva del sistema demócrata. En su constitución se designa que es un Estado Social de Derecho; es decir que la nación colombiana establece una relación natural a principios y valores que competen sentido con el derecho a la vida, prevalencia del interés generales sobre el particular, solidaridad, protección de las riquezas culturales y naturales, dignidad humana y participación ciudadana. (Universidad Nacional de Colombia , 2007)

En términos actuales, la firma del acuerdo de paz entre el gobierno nacional y el grupo subversivo más grande de Colombia, FARC, es un tema que afecta todas las áreas de la vida nacional, y por ende, afecta todo lo relacionado al plano empresarial. Para los expertos esto trae más ventajas en términos de Colombia hacia el mundo, debido al impacto favorable de la imagen país que podría incidir en la entrada de inversión extranjera al país y en la demanda de turismo internacional. Sin embargo, en términos locales este proceso conlleva costos y gastos que podrían afectar el heraldo público, razón por la cual afecta la estabilidad fiscal del país. De esto derivan reformas tributarias que dejan un IVA del 19\%, lo cual desestimulan el desarrollo del sector empresarial y por ende el sector textil.

En la Tabla 6 - América Latina, Balance Fiscal- Porcentaje del PIB) diseñado por la CEPAL, se evidencia el desequilibrio fiscal de Colombia, el cual lleva por consiguiente ajustes 
fiscales que se han producido en periodos frecuentes de dos años para poder regular el manejo de las cuentas nacionales.

Tabla 6 América Latina, Balance Fiscal- Porcentaje del PIB

\begin{tabular}{|lllll|}
\hline & 2013 & 2014 & 2015 & 2016 \\
\cline { 2 - 5 } Brasil & $-2,6$ & $-5,1$ & $-9,2$ & $-7,9$ \\
Costa Rica & $-5,4$ & $-5,7$ & $-5,8$ & $-5,5$ \\
Argentina & $-2,5$ & $-4,2$ & $-3,8$ & $-5,0$ \\
Colombia & $-2,3$ & $-2,4$ & $-3,0$ & $-3,9$ \\
Chile & $-0,6$ & $-1,6$ & $-2,2$ & $-3,0$ \\
Uruguay & $-1,5$ & $-2,3$ & $-2,8$ & $-3,0$ \\
América Latina & $-2,6$ & $-2,8$ & $-3,0$ & $-3,0$ \\
México & $-2,3$ & $-3,2$ & $-3,5$ & $-2,9$ \\
Panamá & $-3,8$ & $-4,0$ & $-3,9$ & $-2,9$ \\
Perú & 0,7 & $-0,3$ & $-2,2$ & $-2,9$ \\
Paraguay & $-1,7$ & $-1,1$ & $-1,8$ & $-1,5$ \\
\hline
\end{tabular}

Fuente: CEPAL- Balance preliminar de las Economías de América Latina y el Caribe 2016.

Además, se deben precisar temas como los continuos paros camioneros, agrarios y de educación que hacen parte de los escenarios que indican una inestabilidad política y que afectan macroeconómicamente el mercado de confecciones, vía contracción del consumo. Un ejemplo de dicha contracción la cita RADDAR Consulting que evidencio en el consumo de los hogares un crecimiento de tan solo 0,54 por ciento cuando se esperaba un crecimiento cercano al 15 por ciento para el 2016 (Redacción EL TIEMPO, 2017).

Sin embargo, aunque el consumo de los hogares no ha crecido como se esperaba esto no ha sido impedimento para el crecimiento del $15 \%$ de la cantidad de unidades productivas que nacieron en el país para el primer trimestre de 2017 frente al 2016. En donde el sector comercio se llevó el $40 \%$ de dichas nuevas unidades productivas y la industria manufacturera no se quedó atrás colocando un $10 \%$ de nuevas empresas como se ve en la gráfica 1(Empresas creadas en el primer periodo de 2016 y 2017). 
Gráfica 1 Empresas creadas en el primer periodo de 2016 y 2017

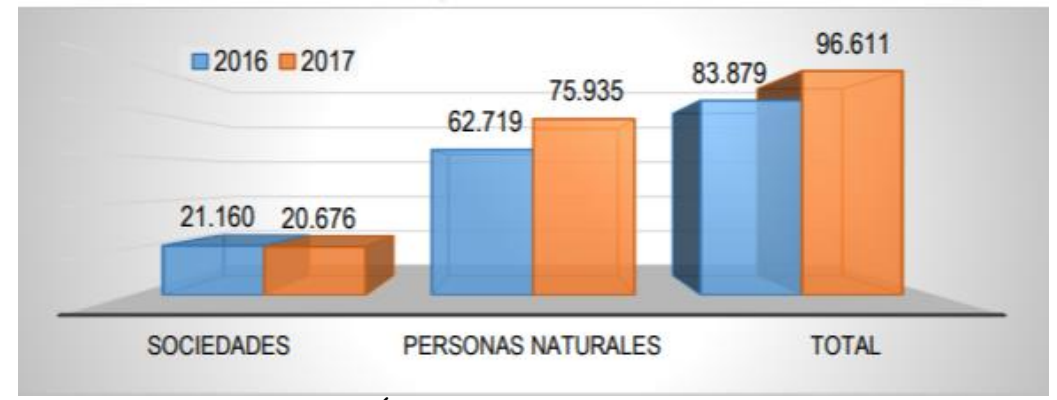

Fuente: RUES - Registro Único Empresarial y Social, CONFECAMARAS.

Pero, ¿Cómo explicar este fenómeno? Dentro de las políticas nacionales que incentivan la creación de empresa están la extensión al pago del impuesto a la renta y al pago del CREE por tres años; además, la exención del pago de la matrícula mercantil por dos años.

Otro factor que favorece el nacimiento de nuevas empresas en el país y que a su vez tiene implicaciones en la cadena textil confección hace referencia al PTP (programa de Transformación Productiva), el cual tiene por propósito apoyar a las empresas en el tema de capital humano mediante capacitación y fortalecimiento en el tema de análisis de la demanda. (PTP, 2016)

El tema de capacitación hace referencia a la implementación de dos metodologías, una es el Lean Manufacturing y la otra el demand driven. La primera busca determinar estándares de producción que buscan ajustar los procesos que conforman las cadenas productivas de forma que se reduzcan desperdicios; y se determinen tiempos de producción más precisos con el objeto de lograr unidades productivas eficaces, es decir, que entreguen valor al cliente con el máximo aprovechamiento de los recursos que posea la empresa, toda esta filosofía enfocada en la gestión del capital humano y la segunda establece un sistema que se direccione al análisis de la demanda para luego construir toda la estructura de valor que rodeará el negocio. (Colombia compite, 2016)

En términos internacionales, Colombia cuenta con 13 tratados internacionales en los cuales la cadena textil - confección tiene gran incidencia para el comercio colombiano, dentro de estos tratados, cabe rescatar el existente con los Estados Unidos, con una participación cercana al $30 \%$ de destino de exportación en las manufacturas, de las cuales la ropa interior, femenina y masculina, vestidos de baño y ropa de control, encabezan la lista. Estos tratados aportan significativamente a la exportación de la manufactura colombiana, convirtiéndose en canales que fortalecen la oportunidad para nuevas empresas de la cadena objeto de estudio. Adicionalmente dentro de estos tratados se destaca el TLC, que permite a más de 900 productos de esta cadena, entrar con un arancel cero (Procolombia, 2015).

Otras ventajas que se destacan a favor de la industria Colombiana son: 
Según el PROCOLOMBIA, Colombia cuenta con una ventaja competitiva en cuanto una reducción de costos logisticos que estarían a 3 veces inferior al coste normal que incurre el comercio Chino. (Procolombia, 2015)

$\checkmark$ Colombia cuenta con más 700 frecuencias internacionales por semana y más de 4900 frecuencias nacionales; esto sumado a la pocisión geografica de Colombia le dan una ventaja logistica y de conectividad regional.

$\checkmark$ El gobierno apoya al sector textil para desarrollar su oferta exportable, y para eso destino más de 30 millones de dolares para mipymes del sector. (Revista Dinero, 2016)

$\checkmark$ El sector textil-confección hace parte prioritaria del programa de trasformación productiva que desarrolla el gobierno nacional en alianza con el sector privado, con el fin de consolidar la cadena en un nivel mundial. (Procolombia, 2015)

Dentro del tema internacional es importante descartar los Aliados estratégicos clave en los cuales destacan México quien es un país con un mercado de más de 125 millones de personas y con múltiples acuerdos internacionales, y donde Colombia tiene una preferencia de cero arancel, sumando a esto, los parecidos culturales en cuanto a idioma, industrias culturales y demás, es un mercado atractivo y de alto potencial para Colombia. (Procolombia, 2015).

Sin lugar a dudas, con los Estados Unidos son con quienes se sigue elevando una participación en el intercambio de mercancías por medio de Ley de Preferencias Arancelarias Andinas, la cual permite el ingreso de textiles y confecciones con cero arancel. Por otro lado, cabe señalar que Ecuador quien en años anteriores había sido un socio estratégico para Colombia y que debido a distorsiones políticas regionales había cerrado puertas para el intercambio con Colombia, hoy es de nuevo alternativa para la exportación en especial de manufacturas Colombianas. (Procolombia, 2015)

El impuesto a la renta como se verá en la tabla 7 (tasa de impuesto sobre la renta en América Latina) evidencia el serio problema fiscal que tiene el gobierno colombiano al tener el más alto impuesto de renta de la región, lo cual es una desventaja para el sostenimiento de toda malla empresarial del país. Dicha tasa está compuesta de la siguiente forma: Impuesto de Renta + CREE+ sobre tasa de CREE $=$ a $40 \%$ tasa nominal. (SURA, 2016). 
Tabla 7 Tasa de Impuesto sobre la renta- América Latina

\begin{tabular}{|l|c|}
\hline PAís & $\mathbf{2 0 1 6}$ \\
\hline Colombia & $\mathbf{4 0 , 0}$ \\
\hline Argentina & 35,0 \\
\hline Venezuela & 34,0 \\
\hline Brasil & 34,0 \\
\hline México & 30,0 \\
\hline Nicaragua & 30,0 \\
\hline Honduras & 30,0 \\
\hline Costa Rica & 30,0 \\
\hline Perú & 28,0 \\
\hline República Dominicana & 27,0 \\
\hline Guatemala & $\mathbf{2 5 , 0}$ \\
\hline Bolivia & 25,0 \\
\hline Panamá & 25,0 \\
\hline Uruguay & 25,0 \\
\hline Ecuador & $\mathbf{2 5 , 0}$ \\
\hline Chile & 24,0 \\
\hline Paraguay & 10,0 \\
\hline PROMEDIO AMÉRICA LATINA & $\mathbf{2 8 , 1}$ \\
\hline
\end{tabular}

En conclusión, respecto al escenario internacional el sector textil tendrá ventajas respecto a el crecimiento de intercambio que se presenta dando con países como por ejemplo con los Estados Unidos, que se espera dinamice su consumo y por ende, impulse el comercio binacional; sin embargo en el escenario interno, los impuestos y trabas administrativas perjudican la competitividad y desarrollo de la malla empresarial nacional.

\subsection{Marco Legal}

Desde la óptica nacional es importante ver la incidencia de las Pymes en el tejido empresarial según algunas entidades del gobierno. Sin lugar a dudas, las más de 25 mil PYMES inscritas en las cámaras de comercio, las cuales según datos oficiales generan actualmente el $80 \%$ del empleo nacional.

Para iniciar a ondear sobre el tema propuesto, primeramente, se dispondrá a traer a disposición el concepto de empresa, el cual para el académico Idalberto Chiavenato es una organización social que utiliza gran variedad de recursos para alcanzar unos objetivos determinados (Chiavenato, 2002), con lo cual se sopesa la incidencia que dicha organización tendrá en el devenir de cualquier orden de carácter humano. Razón a la cual y dada su importancia, la empresa está vigilada y regulada en el caso colombiano, por el gobierno de turno según los estatutos dispuestos por el contrato social que enmarca las directrices del entorno empresarial colombiano. 
En razón a lo anterior, es imperativo hacer mención al capítulo XII- artículo 333, a la ley 590 de 2000, y las modificaciones de la ley 905 de 2004, en la cual el Estado en su calidad de veedor de la libre competencia económica y el apoyo al desarrollo empresarial establece la clasificación que agrupa a las micro, pequeñas y medianas empresas. Para esto, citaremos algunos apartados de la ley 590 de 2004, para establecer las clasificaciones que estipula la ley por número de empleados y activos.

Toda unidad de explotación económica, realizada por persona natural o jurídica, en actividades empresariales, agropecuarias, industriales, comerciales o de servicio, rural o urbana, que responda conjuntamente a los siguientes parámetros:

1. Número de Trabajadores Permanentes. En esta clasificación existen estos rangos:
a. Planta con 51 y 200 trabajadores- MEDIANA
b. Planta con 11 y 50 trabajadores- PEQUEÑA
c. Planta con menos de 10 trabajadores- MICRO

2. En otra clasificación encontramos la relación entre el valor de las Ventas Brutas Anuales y/o Activos Totales; para la cual existen los siguientes rangos:
a. Activos totales por valor entre cinco mil uno (5.001) y quince mil (15.000) salarios mínimos mensuales legales vigentes- MEDIANA
b. Activos totales por valor entre quinientos uno (501) y menos de cinco mil (5.001) salarios mínimos mensuales legales vigentes- PEQUEÑA
c. Activos totales por valor inferior a quinientos uno (501) salarios mínimos mensuales legales vigentes-MICROEMPRESA (BANCOLDEX)

Teniendo en consideración los procesos establecidos por la ley es necesario, consecuentemente mencionar aspectos correspondientes a la normatividad

\subsection{Marco Normativo}

La Ley 1429 de 2010 hace referencia a la formalización del empleo según los parámetros establecidos por la ley. Según el Congreso de la Republica de Colombia esta ley busca motivar a las empresas a partir de incentivos de carácter tributario a alinear sus actividades económicas según las directrices de gubernamentales. (Colombia se Formaliza, 2010). Esta ley va muy de la 
mano con el Decreto 545 de 2011, el cual hace referencia a la progresividad de los aportes para fiscales señalando a quienes se les aplican este tipo de beneficios.

Otras leyes para tener en cuenta son:

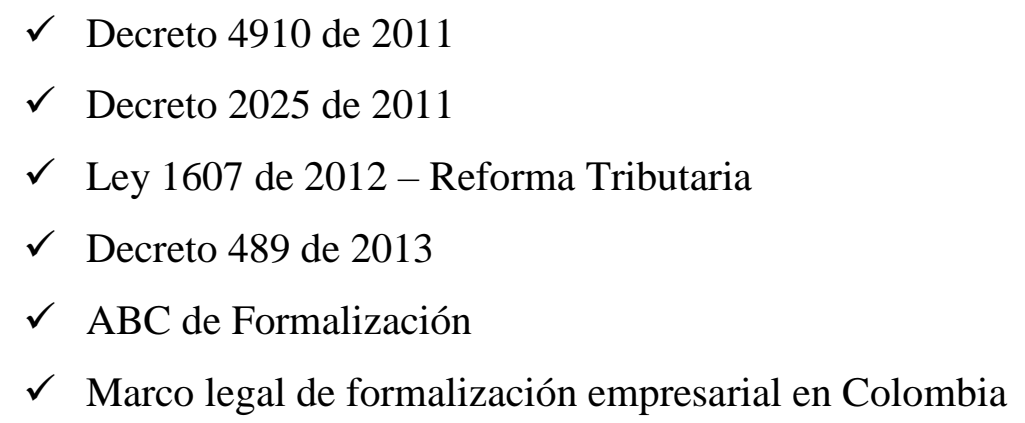

Dentro de los efectos de las leyes citadas anteriormente, el gobierno estipula concretamente los siguientes beneficios para que las Pymes se integren de manera formal al sistema tributario legal.

Al interior de las disposiciones legales para ser beneficiario de las ventajas que da la ley; encontramos las siguientes según el personal que interactúe al interior de la organización:

\subsubsection{Trabajadores}

1. Menores de 28 años.

2. Mujeres mayores de 40 años.

3. Personas en situación de desplazamiento.

4. Personas en proceso de reintegración.

5. Personas en condición de discapacidad.

6. Empleados que devenguen entre 1 y 1,5 SMMLV.

7. Personas cabezas de familia de los niveles 1 y 2 del SISBÉN.

Dentro de los requisitos, también es fundamental tener en cuenta los elementos que debe tener una organización para ser reconocida legalmente; para ello, debe cumplir con los siguientes requisitos:

\subsubsection{Requisitos legales}

$\checkmark$ Matricula mercantil

$\checkmark$ Causar los impuestos de: Renta, ICA, Rete-Fuente, otros.

$\checkmark$ Vincular a sus empleados a riesgos profesionales 
$\checkmark$ Cumplir con la normatividad en cuanto a prestaciones sociales

$\checkmark$ Tener el Registro Único Tributario, y todo lo establecido a los impuestos de carácter distrital, departamental y nacional.

$\checkmark$ Tener una estructura contable sobre el marco amparado por la ley, el cual para este caso sería las Normas Internacionales Financieras- NIF.

$\checkmark$ Cumplir con las normas relacionadas con la apertura y funcionamiento de establecimientos de comercio: SAYCO - ACINPRO, normas ambientales, de seguridad física, del uso de suelo, sanitarias y de salud. (Ministerio de Comercio de Colombia)

Según los docentes e investigadores de la Universidad EAN, Rafael Ignacio Pérez-Uribe, director del grupo de investigación G3Pymes, y María del Pilar Ramírez para el 2014 las Pymes en Colombia aportan cerca del 38\% del PIB total (dinero, 2015)

Para el 2013 se encontró la creación de 75.520 empresas, de las cuales el 99\% fueron microempresas, seguidas de las pequeñas empresas con un uno por ciento (1\%) y las medianas con un participación del $0.13 \%$, gráfica 2 (Distribución de empresa según su tamaño) evidenciará lo indicado anteriormente.

\section{Gráfica 2 Distribución de empresas según su tamaño}

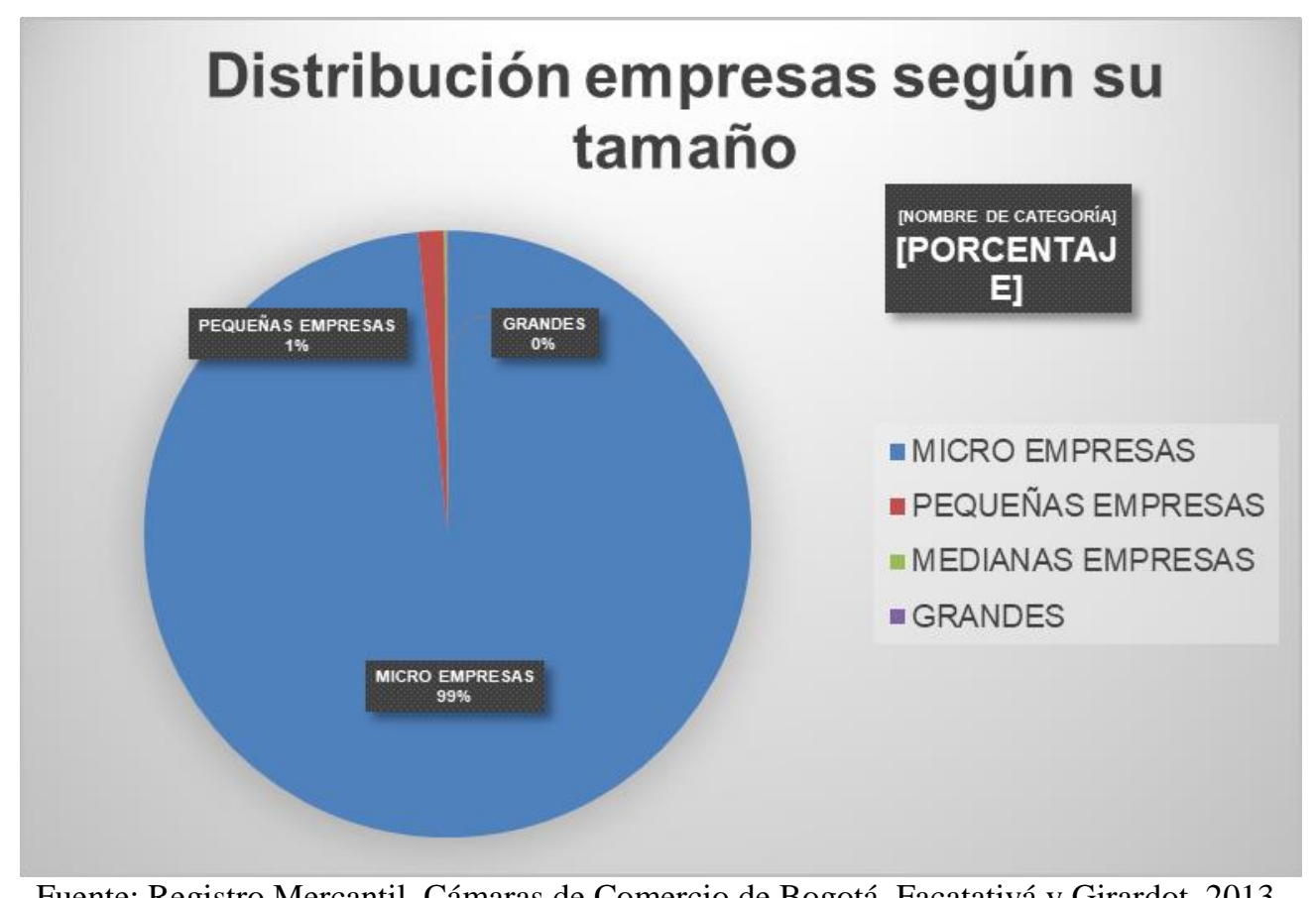

Fuente: Registro Mercantil, Cámaras de Comercio de Bogotá, Facatativá y Girardot, 2013. 
Del mismo modo, es pertinente señalar que entre el 2010 y el 2013 las microempresas presentaron un crecimiento del 17\% (en cuanto a cantidad de empresas afiliadas), y las medianas empresas presentaron una contracción del $38 \%$.

Ahora bien, el 33\% de las microempresas registradas en el año 2013 fueron dirigidas al Comercio al por mayor y al por menor; reparación de vehículos automotores y motocicletas, seguido de las creadas en alojamiento y servicios de comida con un $11 \%$ e industrias manufactureras con $10 \%$.

Para las pequeñas empresas la mayor participación se evidencia en empresas de Transporte y almacenamiento con un $17 \%$ y empresas para Comercio al por mayor y al por menor; reparación de vehículos automotores y motocicletas con un porcentaje igual.

En el caso de las medianas empresas el mayor porcentaje se ve para la creación de empresas para el Comercio al por mayor y al por menor; reparación de vehículos automotores y motocicletas con un 29\%, seguido de empresas para el desarrollo de actividades inmobiliarias con un $16 \%$.

\subsubsection{Sector Textil Colombiano}

Teniendo en cuenta, el Decreto 0731 de 2012, se hace necesario establecer un marco normativo con el procedimiento de aplicación de las salvaguardias textiles pactadas en los acuerdos comerciales internacionales vigentes para Colombia, ya que dicho marco normativo es necesario para garantizar condiciones de acceso estables y predecibles para los textiles y confecciones a Colombia.

Por otra parte, existe la Resolución 1950 de 2009, se encuentra que mediante Resolución 1264 del 26 de junio de 2007 el Ministerio de Comercio,

Industria y Turismo expidió el Reglamento Técnico sobre etiquetado de confecciones, la cual fue publicada en el Diario Oficial No. 46674 del 29 de junio de 2007.

Que se requirió modificar y adicionar textos del Reglamento Técnico sobre etiquetado de confecciones con el fin de clarificar su interpretación, mejorar el procedimiento de evaluación de la conformidad, para facilitar la operatividad comercial de los productos, así como de las actividades realizadas por las entidades de vigilancia y control, por ello, se expidió la Resolución modificatoria 3207 del 26 de diciembre de 2007, publicada en el Diario Oficial 46854 del 27 de diciembre de 2007.

Que se necesita unificar en un documento el contenido de estas dos Resoluciones con el objeto de permitir a las Alcaldías Municipales ejercer su función de vigilancia y control y 
sancionatoria, y de la misma manera, delimitar las competencias de actuación entre las entidades de vigilancia y control del Reglamento Técnico.

Entre tanto como bien se sabe, Colombia ha suscrito acuerdos comerciales que prevén para el sector textil y confecciones mecanismos para adquirir de terceros países materiales o insumos considerados de escaso abasto, que al incorporarse en mercancías objeto del intercambio comercial entre las partes adquieren la condición de "originarias" y, en consecuencia, tienen derecho a disfrutar los beneficios del programa de liberación arancelaria pactado.

Que la Ley 172 de 1994 aprobó el Tratado de Libre Comercio entre los Estados Mexicanos y la República de Colombia; la Ley 1143 de 2007 aprobó el Acuerdo de Promoción Comercial entre la República de Colombia y los Estados Unidos de América; la Ley 1241 de 2008 aprobó el Tratado de Libre Comercio entre Colombia y los países del Triángulo Norte y la Ley 1363 de 2009 aprobó el Acuerdo de Libre Comercio entre la República de Colombia y Canadá.

Que para hacer uso del mecanismo de escaso abasto de los referidos acuerdos comerciales y en los demás acuerdos que posteriormente lo incorporen es considera necesario agotar un trámite interno, previo a la presentación de las solicitudes de escaso abasto ante los Estados con los que se suscribieron dichos acuerdos, para garantizar condiciones de igualdad, transparencia y seguridad jurídica a los usuarios de comercio exterior, en el proceso de establecer el abastecimiento de determinadas materias primas e insumos del sector textil y confecciones dentro del territorio colombiano.

Por otra parte, Desde la implementación de la Ley Anticontrabando (Ley 1762 de 2015), el sector textil y confecciones se ha visto enormemente beneficiado. Además de esto, el Ministerio de Comercio, Industria y Turismo y la DIAN tienen en marcha 10 acciones para beneficiar a los empresarios y mejorar la competitividad: diversificación y valor agregado a través de la Política de Desarrollo Productivo; apoyo efectivo a innovadores y emprendedores; financiamiento presente y futuro a través de Bancóldex; promoción del mercado interno a través de compre colombiano; formalización para juego limpio y cancha equilibrada; sin tregua contra el contrabando; aranceles contra precios ostensiblemente bajos; promoción de comercio exterior; acciones para atraer compradores internacionales; y la Alianza del Pacífico.

Lo anterior se da, gracias a que esta ley tiene por objeto modernizar y adecuar la normativa existente a la necesidad de fortalecer la lucha contra la competencia desleal realizada por personas y organizaciones incursas en operaciones ilegales de contrabando, lavado de activos y defraudación fiscal. La ley moderniza y adecua la normativa necesaria para prevenir, controlar y sancionar el contrabando, la defraudación fiscal y el favorecimiento de esas conductas; para fortalecer la capacidad institucional del Estado; para establecer mecanismos que faciliten que los 
autores y organizaciones dedicadas o relacionadas con este tipo de actividades sean procesadas y sancionadas por las autoridades competentes; y para garantizar la adopción de medidas patrimoniales que disuadan y castiguen el desarrollo de esas conductas.

\subsection{Marco Económico}

En términos económicos, el país presenta desaceleración de crecimiento económico como se ve en la tabla 8 (Crecimiento económico de Colombia).Dentro de los sectores que configuran el sistema productivo del PIB nacional la manufactura tiene gran relevancia, gracias a las políticas gubernamentales por medio de los programas de transformación productiva que han ejercido resultados en cuanto a producción y tecnificación del sector.

\section{Tabla 8 Crecimiento económico de Colombia}

\begin{tabular}{|c|c|c|c|c|c|c|c|}
\hline & \multicolumn{3}{|c|}{2015} & \multicolumn{4}{|c|}{2016} \\
\hline & Ene-Sept & Trim IV & Año & Trim I & Trim II & Trim III & Ene-Sept \\
\hline Agropecuario & 2,9 & 4,7 & 3,3 & 0,8 & 0,0 & $-1,7$ & $-0,3$ \\
\hline Café & 14,4 & 19,2 & 15,6 & 9,8 & 0,8 & $-15,4$ & $-2,5$ \\
\hline Otros agricolas & $-0,1$ & 2,7 & 0,6 & $-2,9$ & $-3,3$ & 1,2 & $-1,6$ \\
\hline Pecuario & 3,2 & 3,1 & 3,2 & 1,8 & 3,3 & $-0,3$ & 1,6 \\
\hline Madera, pesca & 1,6 & $-2,4$ & 0,6 & 2,4 & 2,0 & 1,3 & 1,9 \\
\hline Minería & 1,4 & $-1,5$ & 0,6 & $-4,6$ & $-7,1$ & $-6,1$ & $-5,9$ \\
\hline Carbón & $-2,5$ & $-5,7$ & $-3,3$ & $-7,1$ & 2,9 & 16,9 & 3,9 \\
\hline Petróleo & 2,1 & $-0,9$ & 1,3 & $-6,0$ & $-11,1$ & $-12,7$ & $-9,9$ \\
\hline Industria Manufacturera & 0,4 & 3,7 & 1,2 & 4,2 & 5,6 & 2,0 & 3,9 \\
\hline Electricidad, gas y agua & 2,6 & 3,8 & 2,9 & 2,9 & $-0,9$ & $-1,8$ & 0,0 \\
\hline Construcción & 3,7 & 4,7 & 4,0 & 5,2 & 1,0 & 5,8 & 4,0 \\
\hline Edificaciones & 0,5 & 7,0 & 2,1 & 11,0 & 2,7 & 11,0 & 8,1 \\
\hline Obras Civiles & 6,1 & 3,2 & 5,4 & 0,5 & $-0,4$ & 1,9 & 0,7 \\
\hline Comercio, restaurantes y hoteles & 4,4 & 3,3 & 4,1 & 2,6 & 1,5 & 0,1 & 1,4 \\
\hline Transporte, comunicaciones & 1,7 & 0,7 & 1,4 & 1,9 & 0,1 & $-1,2$ & 0,3 \\
\hline Finanzas, servicios a las empresas & 4,3 & 4,3 & 4,3 & 4,1 & 4,9 & 3,9 & 4,3 \\
\hline Servicios sociales, comunales, personales & 2,7 & 3,5 & 2,9 & 2,0 & 2,4 & 1,8 & 2,1 \\
\hline Gobierno & 1,9 & 3,9 & 2,4 & 1,4 & 2,1 & 1,3 & 1,6 \\
\hline PIB Total & 3,0 & 3,3 & 3,1 & 2,5 & 2,0 & 1,2 & 1,9 \\
\hline
\end{tabular}

Fuente: DANE

El Banco Mundial señalo que la caída del precio de petróleo fue una de las causas de la contracción del PIB Nacional, presentado un crecimiento para el 2016 del orden del $2 \%$, cuando en años anteriores era superior al $4 \%$. Esta circunstancia tiene dos caras, la primera muestra una contracción interna de la producción y por ende, del consumo interno, lo cual no deja muy bien parado el desarrollo de la malla empresarial del país; y por otra, que a pesar de los problemas en la Latinoamérica, Colombia es una economía que tiene elementos valiosos como su política 
monetaria que la han llevado a mantenerse como una economía en crecimiento. (Bancomundial, 2017); Esto lo veremos en la tabla 9 (tasa de crecimiento anual del PIB, por ramas de la actividad económica 2017-IV /2016-IV).

Tabla 9 Tasa de crecimiento anual del PIB, por ramas de la actividad económica 2017-IV /2016-IV

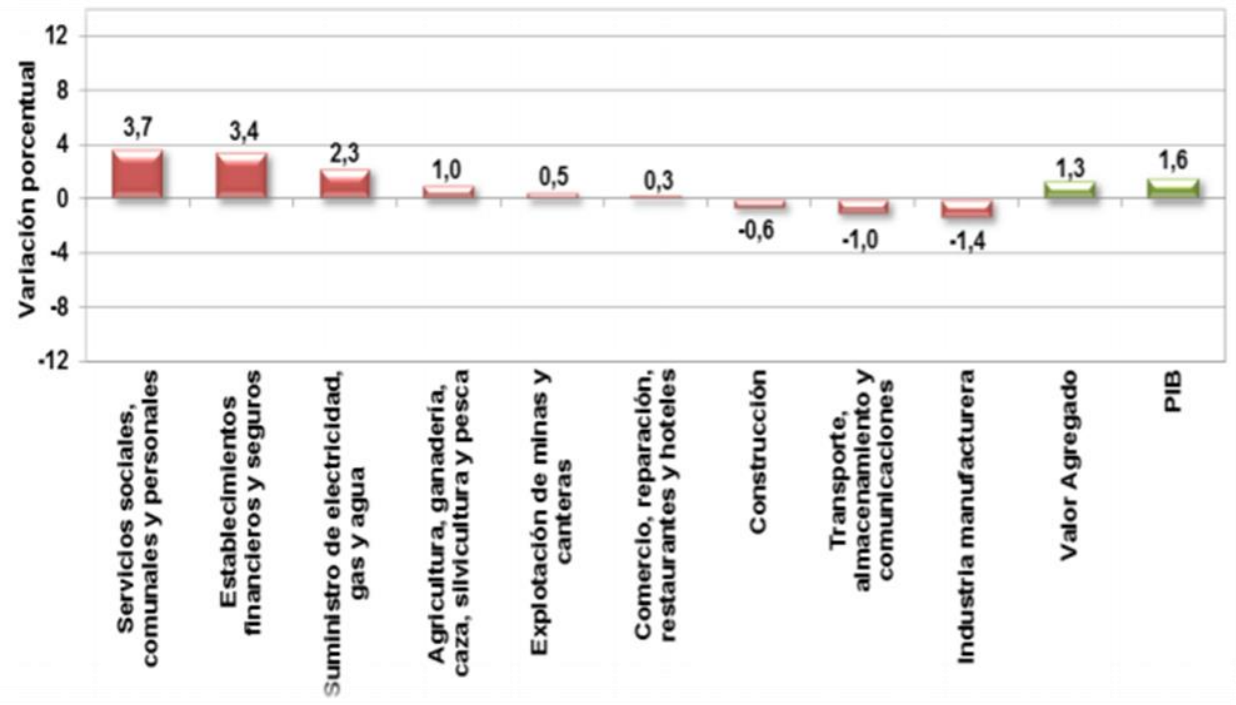

Fuente: (DANE, 2017)

Otros factores macroeconómicos y microeconómicos para tener en cuenta.

$\checkmark$ Depreciación de la moneda local, lo cual afecto la balanza comercial en solo un crecimiento de $1.6 \%$ vía exportaciones. (Bancomundial, 2017)

$\checkmark$ En Colombia, se pasó de comprar 8 prendas a 15. (El Espectador, 2017)

$\checkmark$ No existe construcción de marca a nivel básico de las microempresas del sector textil. (El Espectador, 2017)

\subsection{Datos Económicos Del Sector Textil}

La industria textil y confección en Colombia cuenta con más de 100 años de experiencia y una cadena de producción consolidada y experimentada. El sector representa el 7,5\% del PIB manufacturero y el 3\% del PIB nacional, constituye más del 5\% del total de exportaciones del país. (DANE, 2015)

Por otro lado, en términos locales la ocupación del sector Confecciones se concentra en Bogotá (26,8\%), Antioquia (26,3\%) y Valle del Cauca (10\%), con lo cual se sustenta la tesis de la 
gran evolución de los textiles Bogotanos a nivel nacional. Sin embargo, en el tema en cuestión es importante mirar cual es la evolución de la fabricación de ropa de tejido de punto en el país, puesto que ese segmento es donde Velerito ejecuta su proceso productivo. La incidencia en el empleo por uso del tejido plano para el 2013 estuvo cercana a los 35000 empleos directos (DANE, 2015).

En cuanto a la producción industrial nacional, superar la barrera de las 1300 miles de millones de pesos en el valor de producción en fabrica y lo cual es un indicio de la capacidad creciente de la industria textil colombiana y la necesidad para que el gobierno impulse este sector, el cual tiene un gran potencial, con programas de transformación productiva (EL TIEMPO, 2015). Las confecciones son dentro de los subsectores del PIB industrial, uno de los que más aporta, según cálculos del DANE, esto se observa en la tabla 10 (subsectores que contribuyeron positivamente al PIB Industrial y manufacturero).

\section{Tabla 10 Subsectores que contribuyeron positivamente al PIB Industrial y manufacturero}

\begin{tabular}{|c|c|c|c|c|}
\hline \multirow[b]{2}{*}{ Sector } & \multicolumn{2}{|c|}{ Variación (\%) } & \multirow{2}{*}{$\begin{array}{c}\text { Contribución } \\
2015\end{array}$} & \multirow{2}{*}{$\begin{array}{c}\text { Participación } \\
2015\end{array}$} \\
\hline & 2014 & 2015 & & \\
\hline Tejidos y artículos de punto y ganchillo y prendas de vestir & 1,9 & 4,4 & 0,3 & 7,3 \\
\hline Elaboración de bebidas & 3,5 & 4,5 & 0,3 & 6,8 \\
\hline Sustancias y productos químicos & 1,2 & 1,9 & 0,2 & 13,0 \\
\hline Molinería, alimentos preparados para animales; panadería, macarrones, fideos & $-2,4$ & 4,3 & 0,2 & 5,4 \\
\hline Fabricación de papel, cartón y productos de papel y cartón & 3,3 & 4,5 & 0,2 & 4,2 \\
\hline Productos de caucho y de plástico & 1,0 & 3,3 & 0,1 & 4,3 \\
\hline Productos de café & 11,9 & 12,4 & 0,1 & 1,0 \\
\hline Carne y pescado & 2,1 & 4,0 & 0,1 & 2,4 \\
\hline Transformación de la madera, productos de madera y de corcho, excepto muebles & 2,1 & 7,4 & 0,1 & 1,2 \\
\hline Productos minerales no metálicos & 10,4 & 0,9 & 0,1 & 9,5 \\
\hline Fabricación de muebles & 0,8 & 1,7 & 0,0 & 2,3 \\
\hline Productos lácteos & 1,1 & 1,6 & 0,0 & 1,8 \\
\hline Actividades de edición e impresión y de reproducción de grabaciones & 1,0 & 0,8 & 0,0 & 3,8 \\
\hline Productos metalúrgicos básicos (excepto maquinaria y equipo) & 3,5 & 0,4 & 0,0 & 6,9 \\
\hline Ingenios, refinerías de azúcar y trapiches & 12,8 & 1,4 & 0,0 & 1,5 \\
\hline Aceites, grasas animales y vegetales, cacao, chocolate, productos de confiteria & 4,1 & 0,1 & 0,0 & 4,5 \\
\hline Industrias manufactureras n.c.p. ${ }^{*}$ & 2,5 & 0,1 & 0,0 & 2,3 \\
\hline
\end{tabular}

Fuente: DANE- Cálculos OEE-Mincit

La gráfica 3 (Porcentaje de Valor Agregado de manufactura del PIB Colombiano) muestra el declive de valor agregado que las manufacturas aportan al PIB Colombiano. 
Gráfica 3 Porcentaje de Valor Agregado de manufactura en el PIB Colombiano

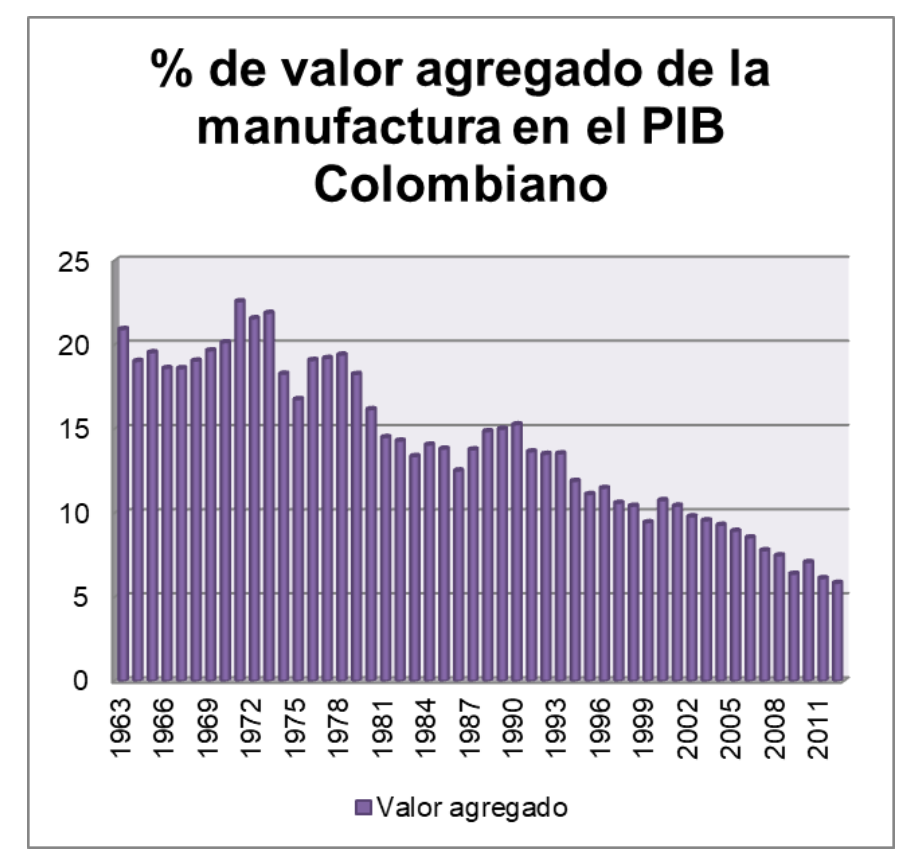

Fuente: DANE 2012

\subsection{Marco social}

El desarrollo de la división de transformación estratégica de Inexmoda es una herramienta diseñada para el fortalecimiento de los nuevos precursores de la industria de las confecciones en el país. Estos nuevos jugadores son quienes a partir de microempresas desarrollan y crean espacio para la distribución de ropa para todo tipo de personas; un escenario de estas características es San Victorino.

$\checkmark$ La herramienta que Inexmoda ha desarrollado busca direccionar a los microempresarios desde diversas aristas del negocio, las cuales pueden ir desde diseño, mercadeo o ventas.

$\checkmark$ Desarrollo de incubadoras que buscan a empresas consolidadas para llevarlas a otro nivel de organización, trabajo que realiza INDEXMODA, Cámara de Comercio de Bogotá, Pro Colombia.

$\checkmark$ Gasto per cápita en vestuarios de los Colombianos esta alrededor de los $\$ 22,750$ mensual (El Espectador, 2017)

Dentro del estudio demográfico es fundamental hacer mención a los grupos de edades de niños y niñas que se encuentran en el territorio nacional, con el fin de determinar el comportamiento del mercado objetivo de Velerito. Se representará a continuación en la gráfica 4 
(cuadro comparativo de crecimiento demográfico entre los niños y niñas entre los cero a los catorce años) para posteriormente dar un vistazo a la tasa de crecimiento de niñas.

Gráfica 4 Cuadro comparativo de crecimiento demográfico entre niños y niñas entre los cero a los 14 años

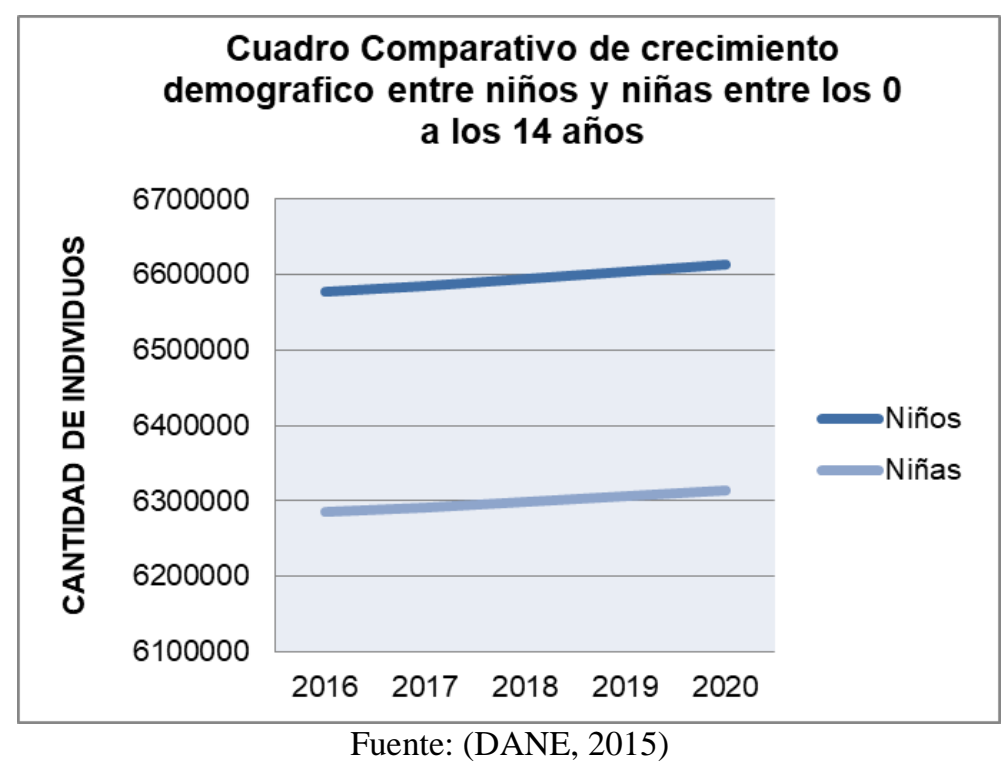

Según la tabla 11 (población de niñas en Colombia) la proyección del segmento y/o universo de estudio de velerito crecerá continuamente hasta el 2020. Siendo esto una oportunidad de mercado para Velerito.

Tabla 11 Población de niñas en Colombia

\begin{tabular}{|c|c|c|c|c|c|}
\hline \multicolumn{6}{|c|}{ GRUPO DE EDADES DE NINAS ENTRE LOS O A LOS 14 AÑOS EN } \\
EL TERRITORIO COLOMBIANO \\
Edades & 2016 & 2017 & 2018 \\
$0-4$ & 2.116 .945 & 2.123 .053 & 2.128 .308 & 2.132 .032 & 2.134 .273 \\
$5-9$ & 2.083 .159 & 2.086 .679 & 2.091 .199 & 2.095 .960 & 2.100 .022 \\
$10-14$ & 2.086 .363 & 2.081 .054 & 2.078 .839 & 2.078 .399 & 2.079 .220 \\
Total & 6.286 .467 & 6.290 .786 & 6.298 .346 & 6.306 .391 & 6.313 .515 \\
\hline \multicolumn{6}{c}{ Fuente: DANE 2016} \\
\hline
\end{tabular}

Puntos económicos a tener en cuenta: 
Según EUROMONITOR INTERNACIONAL la cadena colombiana textilconfección logro una taza compuesta anual de 4,2\%, en los últimos 10 años, colocándolo como el tercer país más importante de textil-confección, comparada con Sur América. (SURA, 2016)

$\checkmark$ Colombia es el séptimo prestatario del Banco Mundial en términos de exposición al Banco Internacional de Reconstrucción y Fomento (BIRF) con US\$9.5 mil millones de deuda pendiente. (Bancomundial, 2017)

$\checkmark$ Desde el 2016, las exportaciones textil- confecciones cayeron en un $15 \%$ respecto a 2015; sin embargo existen alternativas como Costa Rica que tiene un gravamen de cero arancel, siendo un mercado atractivo y alternativo para direccionar las exportaciones.

Ecuador quito las salvaguardias que tenía para la entrada de confecciones para Colombia.

Dentro de las organizaciones que más dan la mano al sector textil en Colombia encontramos que, Indexmoda con ayuda del gobierno ha desarrollado espacios para la interacción entre los agentes textileros más importantes del país y con más de 700 empresarios internacionales de todo el mundo. Estas son plataformas que se han diseñado para el país con miras a aprovechar su tradición textil, la posición geográfica y e incentivar la llegada de IED. Además, como objetivo importante el generar negocios. Por su parte, Proexport reporta negocios por US\$68 millones, de los cuales se concretaron US\$47 millones. (Procolombia, 2015)

Con respeto a cadena textil - confección mundial, según datos de la OMC-(Organización Mundial de Comercio) en el 2014 de las exportaciones mundiales US\$314.146 millones correspondieron a confecciones, dentro de los cuales China con el 45,08\% e Italia 6,01\% lideraron el potencial exportador mundial, seguidos de Alemania, India y Hong Kong.

En términos latinoamericanos, México es el primero en capacidad productiva de la región y está en el puesto 19 con 0,95\% a nivel mundial, seguido de El Salvador en el puesto 26 con 0,42\% a nivel mundial. Esto refleja que la región sur se ha quedado relegada en la creación de manufactura textilera debido a, según la misma $\mathrm{OMC}$, la fuerte competencia internacional y al posible atraso tecnológico en los procesos de producción como por ejemplo fibras textiles.

En la tabla 13 se muestra el incremento productivo a nivel mundial de las confecciones y a su vez, nos pone a reflexionar sobre el poderío Chino en la producción manufacturera mundial, puesto que para el caso Colombiano, las confecciones asiáticas son una competencia directa 
debido a sus niveles de exportación a Colombia, los cuales para el 2014 estuvieron a la orden de $37,1 \%$ del total de importaciones Colombianas.

Por su parte, Colombia según la OMC se encuentra en el puesto 45 en producción de Confecciones con el $0,14 \%$ a nivel mundial, lo cual muestra su desventaja productora referente a los gigantes asiáticos. Es decir, que Colombia y su cadena textil confección aún tienen una gran oportunidad para expandir y fortalecer su producción.

Las importaciones del mundo se han contraído de manera significativa según la OMC, un ejemplo es el caso Chino que para el primer trimestre del 2016 redujo sus importaciones en un $17 \%$, similar a Rusia quien estuvo por el orden del $18 \%$.

\section{Gráfica 5 Tasa de desempleo en América Latina}

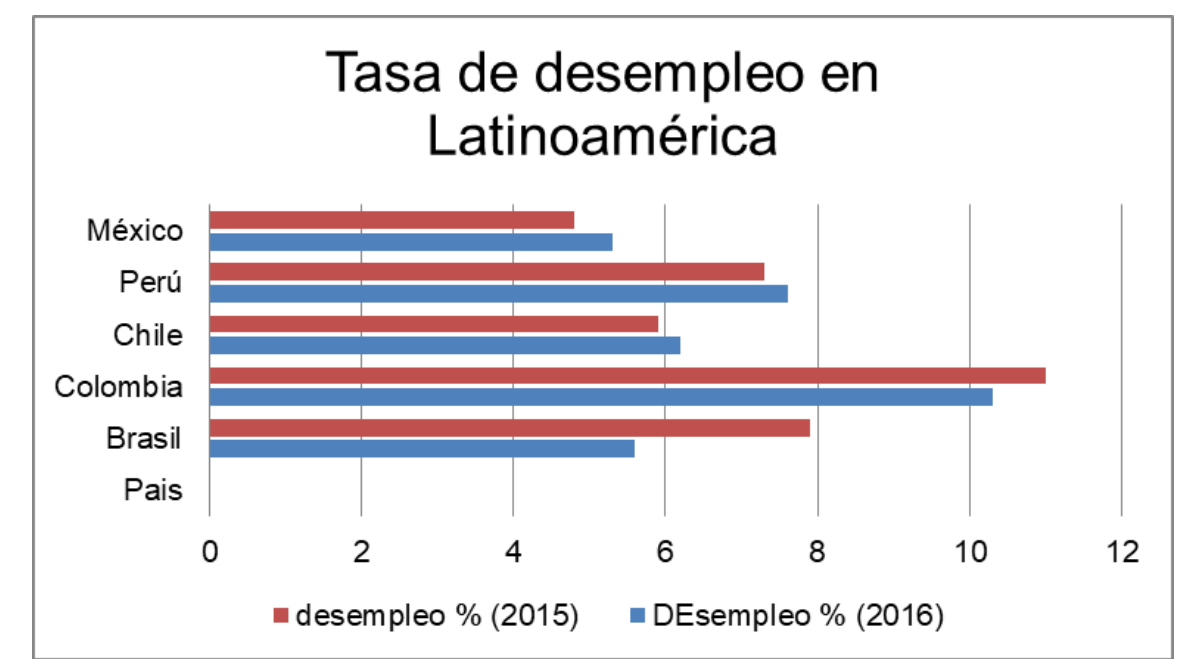

Fuente: Centros estadísticos de cada país- Ministerio de Industria y turismo de Colombia. 2017

Colombia, como se ve en la tabla 12 (tasa de inflación en América Latina) evidencia frente a la región inestabilidad de precios, lo cual perjudica la pérdida de valor del peso colombiano, por ende, genera repercusiones negativas para los importadores debido a la pérdida de competitividad de la moneda en el ámbito internacional. Por otro lado, el aumento al 8\% también es producto de caída de la producción nacional, lo cual catapulta la subida de precios. 
Tabla 12 Tasa de Inflación en América Latina

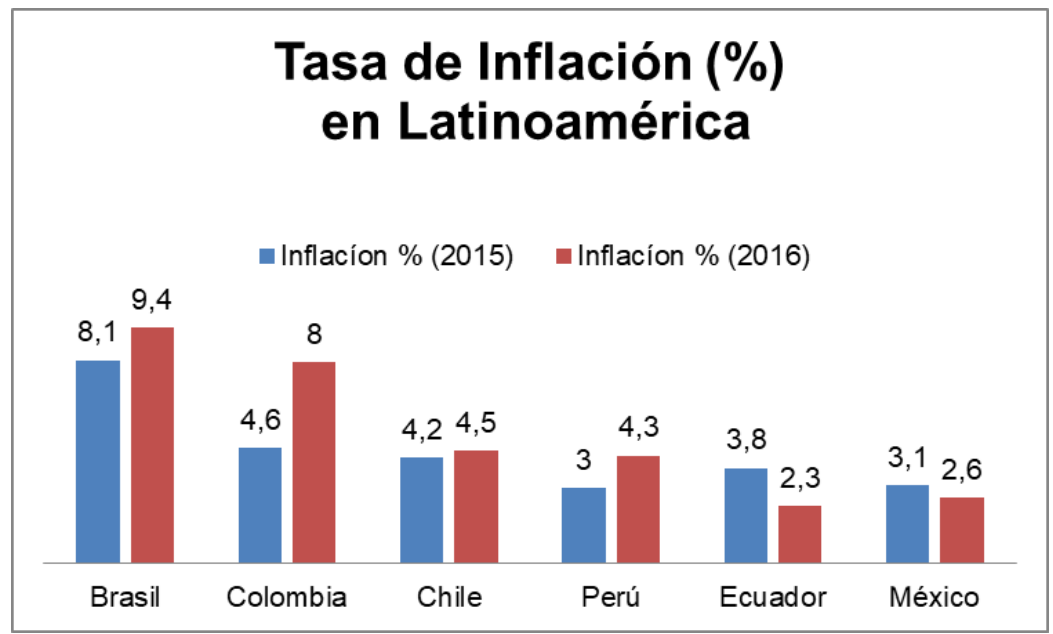

Fuente: Centros estadísticos de cada país- Ministerio de Industria y turismo de Colombia.

Tabla 13 Crecimiento de la industria manufacturera mundial

\begin{tabular}{|c|c|c|}
\hline \multicolumn{3}{|c|}{ CRECIMIENTO INDUSTRIA MANUFACTURERA } \\
\hline País & Año 2015 & $\begin{array}{c}\text { Enero-Octubre } \\
2016\end{array}$ \\
\hline CHINA & 6,1 & 6,0 \\
\hline COLOMBIA (EOIC) & 0,5 & 3,9 \\
\hline ESPAÑA & 4,0 & 2,7 \\
\hline ITALIA & 1,0 & 1,7 \\
\hline UNIÓN EUROPEA & 2,3 & 1,5 \\
\hline TURQUÍA & 3,4 & 1,4 \\
\hline EUROZONA & 2,2 & 1,4 \\
\hline ALEMANIA & 0,4 & 1,2 \\
\hline *MÉXICO & 2,6 & 0,9 \\
\hline FRANCIA & 1,2 & 0,4 \\
\hline ESTADOS UNIDOS & 0,8 & 0,0 \\
\hline REINO UNIDO & $-0,2$ & 0,0 \\
\hline CHILE & $-0,6$ & $-1,0$ \\
\hline PORTUGAL & 1,2 & $-1,4$ \\
\hline *JAPÓN & $-1,2$ & $-1,5$ \\
\hline *PERÚ & $-1,7$ & $-2,8$ \\
\hline BRASIL & $-9,9$ & $-7,0$ \\
\hline \multicolumn{3}{|c|}{ Fuente: Departamentos de Estadistica de los diferentes paises } \\
\hline
\end{tabular}

Fuente: Departamentos de Estadística de diferentes países 2017

La cadena textil confecciones, como lo cataloga el DANE se encuentra agrupada bajo el sector de la industria manufacturera con el CIIU 1400; razón por la cual es pertinente exponer la tabla 13 en la cual la industria manufacturera Colombiana muestra un interesante comportamiento, al ser la única economía que mostro un crecimiento, teniendo en cuenta : que el crecimiento 
económico mundial bajo, el producto interno bruto mundial se contrajo por consecuencia de los problemas de la UE, la caída el precio del petróleo y contracción de la economía China. Esto muestra la potencia de la industria manufacturera nacional.

\subsection{Tecnológico}

En relación al campo tecnológico, el sector textil colombiano denota un retraso por lo menos de 20 años con respecto a los grandes exportadores de textiles en el mundo. (Silva, 2017). Gran parte de sistema de confecciones del país trabaja con tecnología mecánica, las cuales no están a la vanguardia de las que hoy se conocen en el mundo que cuentan con sus propios programas de software, que son automáticas, y que además tienen ahorro de batería mediante servomotores que a su vez mitigan la contaminación auditiva que producen los motores de las máquinas de coser, por ejemplo, lo anterior lo sustenta Enrique Gómez, vicepresidente de la Cámara Colombiana de la Confección.

Como punto adicional Enrique Gómez sustenta que la mayoría de "los equipos tienen un rezago de 20 años, es decir, que la mayoría de las máquinas son modelo 86 al 90 y provienen de Italia, Japón y China”. Entre las marcas destaca: Yamato y Kansai Especial de Japón y Siruba de China, entre otras del gigante asiático" (Silva, 2017)

La relación entre la tecnología y la eficiencia la representan grandes de la industria que poseen:

$\checkmark$ Máquinas robóticas de fabricación italiana que corta 45.000 partes de vestimenta al día, mientras que la que posee el 89\% del sector apenas puede hacer 3.000 al día (Silva, 2017).

$\checkmark$ Máquinas Flaximer, que operada por una sola persona sustituye a tres, ya que filetea (une las piezas), recubre y pule. Pero igual que la cortadora robótica esta máquina no está en más del 5\% del sector (Silva, 2017).

Otro agravante dentro del desarrollo tecnológico es el del recurso humano, pues para muchos industriales la educación necesaria para el aprovechamiento de la capacidad instalada es ineficiente, razón por la cual las empresas sostienen que son ellas quienes se han tenido a la tarea de formar y guiar al personal, siendo este un coste adicional en recursos y tiempo que imposibilita la adquisición de tecnología de punta. (Silva, 2017).

En la tabla 14 (World digital competitiveness ranking- Colombia) se evidencia el rezago que presenta el sector no solo se evidencia en las confecciones, sino que es un problema casi que 
de todas las áreas productivas del país; esto lo demuestra el ranking de competitividad digital en el cual Colombia año a año decae en la lista por la falta de modernización e inversión en términos de tecnología y conocimiento para el de estructuras empresariales eficaces y eficientes.

Tabla 14 World digital competitiveness ranking- Colombia

\begin{tabular}{|lccc|}
\hline Factores & WDC 2016 & WDC 2017 & Cambio \\
\hline En general & 56 & 58 & Baja 2 \\
\hline Conocimiento & 56 & 57 & Baja 1 \\
\hline Tecnología & 59 & 60 & Baja 1 \\
\hline Preparación para el futuro & 44 & 53 & Baja 9 \\
\hline
\end{tabular}

Fuente: (Colombia compite, 2016)

Otro indicador preocupante que podría marcar el futuro de las empresas en Colombia es la transición que está sufriendo el mercado colombiano hacia la transformación digital, en la gráfica 6 (Porcentaje de empresas que están adoptando una estrategia de transformación digital) se evidencia la tenencia de las empresas por ingresar en la transformación acerca de la manera en que el consumidor evalúa, busca y compra lo que necesita así este en otro lado del mundo. No en vano empresas como Amazon o Ali express están liderando las ventas online por medio de una estrategia B to $\mathrm{C}$.

\section{Gráfica 6 Porcentaje de empresas que están adoptando una estrategia de transformación digital}

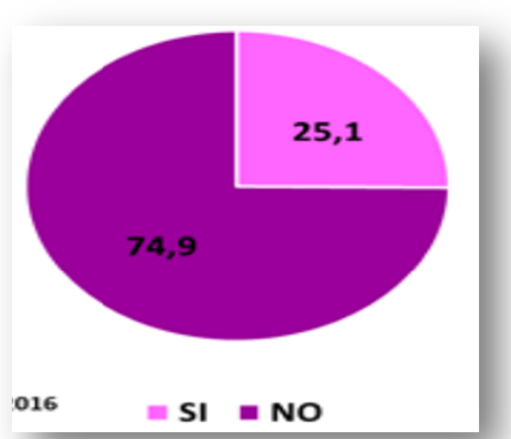

Fuente: Encuesta de opinión popular ANDI 
Es claro el atraso en la tecnificación y automatización de procesos en las empresas del país, lo cual afecta significativamente la generación de valor agregado.

Teniendo cuenta el anterior proceso descriptivo de cada una de las aristas externas de las cuales componen la metodología PESTEL, se procederá a desarrollar una lista de chequeo con los componentes más determinantes encontrados con el fin de tener un criterio del ambiente externo que puede afectar a Velerito como unidad productiva.

\subsection{Lista de Chequeo Matriz PESTEL}

\section{Lista de Chequeo 1 Aspectos Externos con base en metodología PESTEL}

\begin{tabular}{|c|c|c|}
\hline \multirow[t]{2}{*}{ ASPECTOS EXTERNOS IDENTIFICADOS } & \multicolumn{2}{|c|}{ CLASIFICACIÓN } \\
\hline & POSITIVA & NEGATIVA \\
\hline \multicolumn{3}{|l|}{ ASPECTOS EXTERNOS POLITICOS } \\
\hline $\begin{array}{l}\text { - Estabilidad política } \\
\text { - Apertura para el intercambio tecnológico y acceso a nuevos } \\
\text { mercados } \\
\text { - Instituciones que formen y capaciten el sector textil- } \\
\text { confección } \\
\text { - Impuestos e incentivos al empresario } \\
\text { - Estabilidad fiscal } \\
\text { - Inversión en el sector por parte del gobierno } \\
\text { Protección al sector }\end{array}$ & $\begin{array}{l}X \\
X\end{array}$ & $\begin{array}{l}\mathrm{x} \\
\mathrm{x} \\
\mathrm{x} \\
\mathrm{x} \\
\mathrm{x}\end{array}$ \\
\hline \multicolumn{3}{|l|}{ ASPECTOS EXTERNOS ECONOMICOS } \\
\hline $\begin{array}{l}\text { - Estabilidad cambiaria } \\
\text { - Competencia internacional } \\
\text { - Posicionamiento internacional del país } \\
\text { - Crecimiento del consumo interno } \\
\text { - Crecimiento del PIB Nacional } \\
\text { - Inflación }\end{array}$ & & $\begin{array}{l}\mathrm{X} \\
\mathrm{X} \\
\mathrm{X} \\
\mathrm{X} \\
\mathrm{X} \\
\mathrm{X}\end{array}$ \\
\hline \multicolumn{3}{|c|}{ ASPECTOS EXTERNOS SOCIO - CULTURALES } \\
\hline $\begin{array}{l}\text { - Celebraciones o espacios culturales que afecten a la } \\
\text { industria }\end{array}$ & $\begin{array}{l}X \\
X\end{array}$ & \\
\hline $\begin{array}{l}\text { 7.9 Crecimiento demográfico } \\
\text { - Formación académica y profesional }\end{array}$ & & $\mathrm{X}$ \\
\hline \multicolumn{3}{|c|}{ ASPECTOS EXTERNOS TECNOLOGICOS } \\
\hline $\begin{array}{l}\text { - Rezago de la industria manufacturera Colombiana en la } \\
\text { modernización de sus herramientas tecnológicas y digitales. } \\
\text { - Nivel de capacitación para la mano de obra en aras de adoptar } \\
\text { nivel tecnológicos superiores. }\end{array}$ & & $X$ \\
\hline
\end{tabular}


- Oportunidades de intercambio con otros país que han desarrollado tecnologías superiores $\mathrm{X}$

\section{ASPECTOS EXTERNOS ECOLOGICOS}

- Protección y cuidado del medio ambiente

- Normas de calidad que contemplen exigencias para la apertura de mercados

\section{ASPECTOS EXTERNOS LEGALES}

- Requisitos para la formalización y constitución de una empresa

- Declaraciones de impuestos

- Facilidades de tramites

$\mathrm{X}$

- Mecanismos de recaudo tributario

Fuente: Elaboración propia - (Coopers y Lybrand , 1997)

Según la Matriz PESTEL en términos generales el ambiente externo que afecta al sector y a la empresa objeto de estudio tiene un margen de des favorabilidad del $66 \%$, de los cuales el factor económico es el que más incidencia tiene como se muestra en la gráfica 7 (Margen de favorabilidad de factores externos). Además de la estancación del sector textil, dentro de las diversas causas es preciso establecer la competencia de los países asiáticos, y las divergencias entre las políticas tributarias y las disyuntivas de la economía global.

\section{Gráfica 7 Margen de favorabilidad de factores externos}

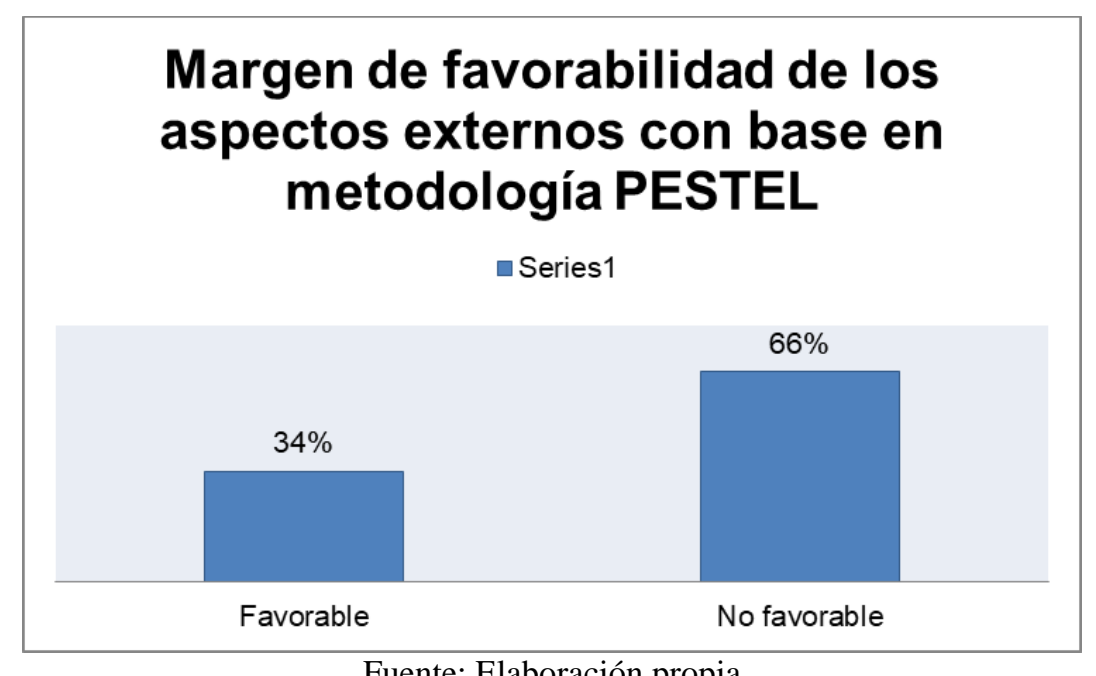

Fuente: Elaboración propia

De acuerdo con el análisis externo, se procedió a establecer el alcance de negociación de Velerito con sus Stackeholders, para lo cual se aplicó la metodología de las fuerzas de Porter, 
mediante las cuales se establecerán si es positiva o negativa la relación comercial y empresarial con sus grupos de interés.

\subsection{Análisis PORTER}

\section{Lista de Chequeo 2 Análisis de las 5 Fuerzas de Porter}

ANÁLISIS DE PORTER

Poder de negociación de los proveedores

Este ítem tendrá por factibilidad de poder negociación dos características cruciales, la primera es el tamaño de las empresas y capacidad de cada parte de la negociación, y la segunda la relación que se tenga entre las partes.

\section{Proveedores}

Materias primas: Fenditex, Portofino (desfavorable). Son empresas constituidas que manejan volúmenes superiores de clientes y de producción en el área textil, además cuentan con más tradición y posición nacional e internacional como el caso de Portofino, la cual es filial de Pat primo, empresa líder en tejido de punto y plano.

Además, la relación que se dispone no llega a hacer de alto nivel, lo cual implica poco nivel de negociación.

Sin embargo, cabe anotar que hay varias posibilidades de proveedores textiles que aún no se han indagado, lo cual abre camino para el esquema de propuesta de este ejercicio académico

Procesos de apoyo tercer izados: unidad contable, transporte. Se precisa que al no ser unidades que confirmen los procesos operativos y por el tamaño de Velerito, existe un alto poder de negociación para la empresa. Además, se indica que de contar con la variedad de empresas que existen dedicadas al tema contable y al transporte urbano, lo cual permite no depender de ninguna de ellas frente a cualquier eventualidad.

Amenazas de nuevos aspirantes

La entrada de nuevos competidores para Velerito es desfavorable en términos de negociación. En primera instancia porque el mercado del

\section{CLASIFICACIÓN}

POSITIVA NEGATIVA 
madrugón en el cual Velerito se encuentra es un espacio de fácil acceso, es decir que constantemente hay entrada y salida de productores que podrían ser potenciales competidores. . Además, el producto estrella que Velerito fábrica es de fácil simulación, puesto que son cortes clásicos t-shirt que constan de cuatro piezas y que requieren de maquinaria básica de confección (Fileteadora y Collarín) para su fabricación.

Por otro lado, el contrabando y la entrada de productos foráneos provenientes de Asia, es un riesgo para la estabilidad empresarial de Velerito en el mercado. Según el diario el País, entraron más de 16086 prendas de vestir vía contrabando en el 2017.

\section{Poder de negociación de los compradores}

Los compradores que Velerito tiene en su base de datos están descritos en el anexo2 (lista de compradores). Dicha lista de compradores comprende 50 clientes frecuentes que están ubicados en diversas partes del territorio nacional. Los clientes, están segmentados según el tipo de clima en el cual se encuentran, puesto que está variable es fundamental para la creación de la oferta por parte de la empresa, además determina gustos en colores he implementación de materiales. También se estipula la variable género, como factor determinante a la hora de establecer estudios psicográficos del mercado.

Las consideraciones que se describirán, son extraídas de la base de datos de clientes que estará en el anexo 2. Estas consideraciones son pautas para el desarrollo de estudios de mercado futuros por parte de la empresa Velerito.

- $\quad$ El 83\% de los clientes son mujeres

- Las ciudades que más concentran clientes son: Bogotá, Bucaramanga, Popayán.

- El rango de frecuencia media de compra por parte de los clientes es de 30 días (un mes).

- El 63\% de los clientes provienen de climas cálidos, mientras el $37 \%$ de climas fríos.

Respecto al poder de negociación, Velerito frente a sus clientes es alta, puesto que:

- Es una cantidad considerable

- Por su ubicación geográfica, están distantes, es decir, no existe 


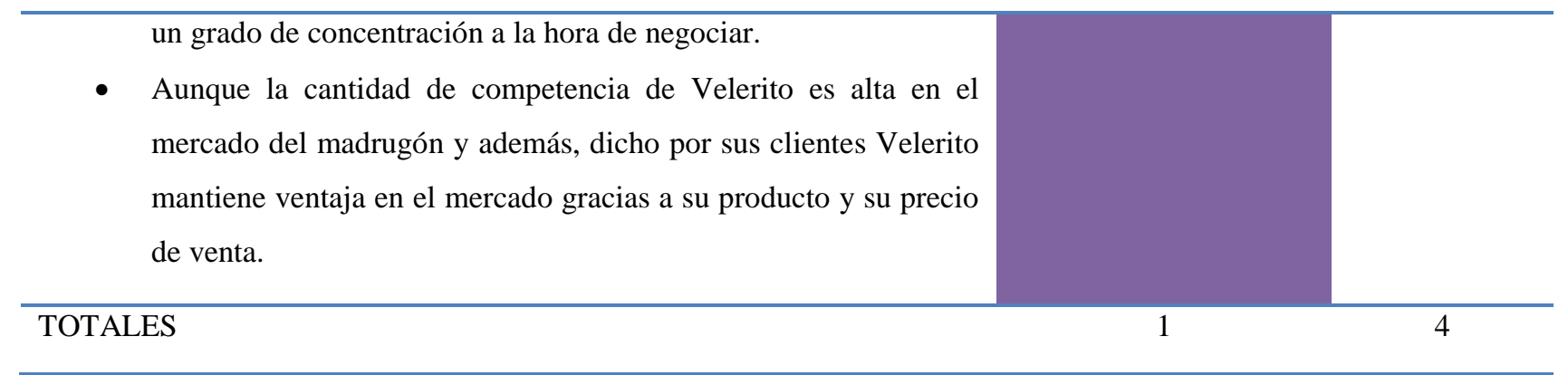

Fuente: Elaboración propia - (Coopers y Lybrand , 1997)

Como conclusión frente al análisis de las fuerzas de Porter, Velerito tiene varias desventajas a la hora de establecer negociaciones dentro de su entorno, sobre todo en relación a sus proveedores. Gran parte de esta situación se expresa a la falta de planeación dentro de la ausencia de una dirección estratégica, lo cual en caso de proveedores impide la creación de relaciones a largo plazo.

\subsection{Unidad de Mercadeo}

\subsubsection{El madrugón}

5000 expositores, más de 15 bodegas y tres (3) centros comerciales realizan el madrugón, un espacio en el que actualmente se encuentran empresas dedicadas a la fabricación y comercialización de prendas de todo tipo, sean jean, pijameria, camisas, sudaderas, ropa informal o formal, en fin. Villalobos Herrera (El Gran San, 2012)

Para FENALCO hay una vinculación de más de 2000 empresas, donde sus ventas superan los 50 millones de pesos al mes, además se estima que cerca de 100 mil personas visitan este espacio comercial y que de este estimado el $60 \%$ participan con el fin de surtir sus propios negocios (Díaz, 2012).

Las bodegas están comprendidas entre las calles 12 y 10 y las carreras 10 y Caracas, allí podemos encontrar cerca de 24 bodegas que abren sus puertas de 2:00 am hasta las 11:00am los días miércoles y sábados, y están destinadas para la llegada en principio de compradores que provienen del Eje cafetero, la costa norte de Colombia, del meta, de Cali, Medellín, Bucaramanga, Popayán, y la mayoría de municipios del sur de Colombia. Este espacio se caracteriza además por enfocarse en la venta al por mayor, es decir haciendo una mezcla entre precios relativamente bajos con distribución de altos volúmenes de prendas de vestir. 
Las 22 bodegas se clasifican de la siguiente forma: Gran San Martín, Pasaje Paisa, Gran San y Medellín con el 52\% de expositores. La Gran Esquina, Baratón - Volga, Coopfe- madrugón, Los Andes, La Carolina, Luz 37, Mago, Nariño y Centrolandia tienen el 37\% de expositores. Las 10 bodegas restantes tengan una participación mínima del 1\%. (Díaz C. A., 2012).

Una característica de este espacio son las temporadas en las cuales el consumo según Fenalco puede llegar a representar el 50\% de las ventas totales del año para los empresarios que allí confluyen. Dentro de este espacio de temporadas se encuentran la temporada escolar, día de la madre, temporada de mitad de año, temporada de las grandes cadenas y por último, la temporada navideña, la cual es la más representativa del año. En la gráfica 8 (comportamiento de consumo del sector) se puede entender la tendencia de consumo en las temporadas anteriormente descritas. $\mathrm{X}$

\section{Gráfica 8 Comportamiento de consumo del sector}

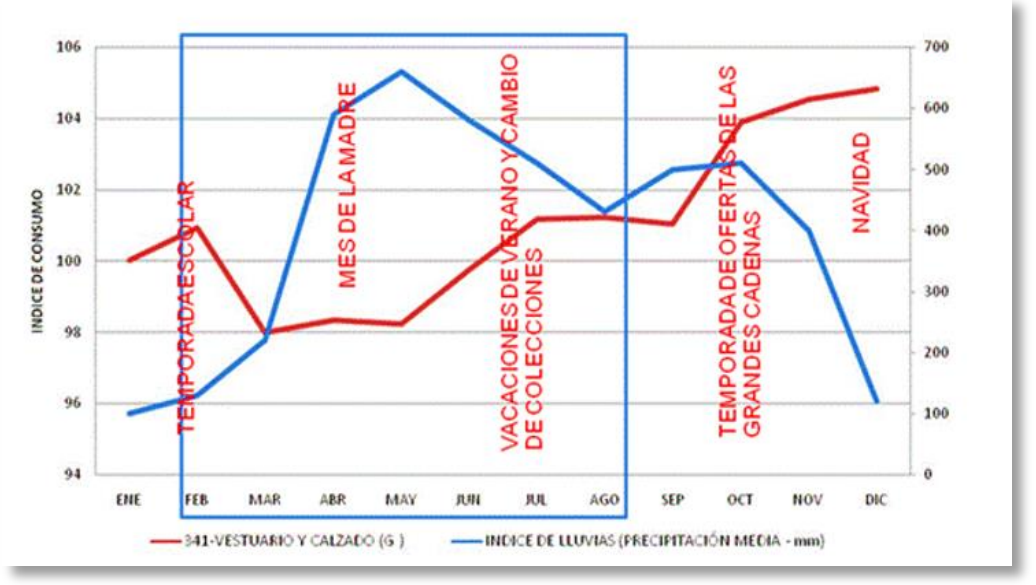

Fuente: revisión sector moda (raddar, 2016)

\subsubsection{Benchmarking}

De acuerdo con los lineamientos metodológicos de este trabajo de fortalecimiento se desarrolló un ejercicio de Benchmarking partiendo de variables homogéneas de las organizaciones que serán objeto de estudio y que confluyen en el sector textil - confección infantil femenina. De acuerdo a lo anterior, los criterios para establecer las organizaciones seleccionadas son, el mercado objetivo y la línea de producción que tienen dentro del sector textil-confección.

Es importante mencionar que el mercado de ropa para niñas está alcanzando su mayoría de edad en Colombia donde el aumento de competidores locales y la llegada de empresas extranjeras 
especializadas en este mercado así lo evidencian. Desde el Observatorio de Moda (Raddar) se señala que el negocio de ropa para niños mueve alrededor de $\$ 1,2$ billones de pesos al año, lo cual lo hace un mercado atractivo sí tenemos en cuenta que en el país existen más de seis millones de niñas como lo muestra la gráfica demográfica de crecimiento poblacional en el apartado de PESTEL (raddar, 2016). Por tal razón existen marcas tanto locales como internacionales que han sentado su oferta textil en el territorio colombiano. Por tal razón en la tabla 15 (Comparativo de empresas de confecciones relevantes en Colombia) se diseñó un ejercicio comparativo que resalta los proyectos más importantes de las compañías seleccionadas para el benchmarking con el fin de establecer los proyectos que demarcaron apertura comercial y crecimiento económico para establecer los factores internos que propiciaron los efectos económicos y posicionales de las marcas en el mercado. Todo esto para establecer un marco de referencia de los puntos estratégicos que las empresas que lideran el mercado de ropa infantil desarrollan como ventajas competitivas y que los hacen ser sostenibles en el tiempo.

Según el informe de PROCOLOMBIA, en su Catálogo oferta exportable de Colombia estas son las mejores empresas colombianas que ofertan productos de exportación en ropa infantil.

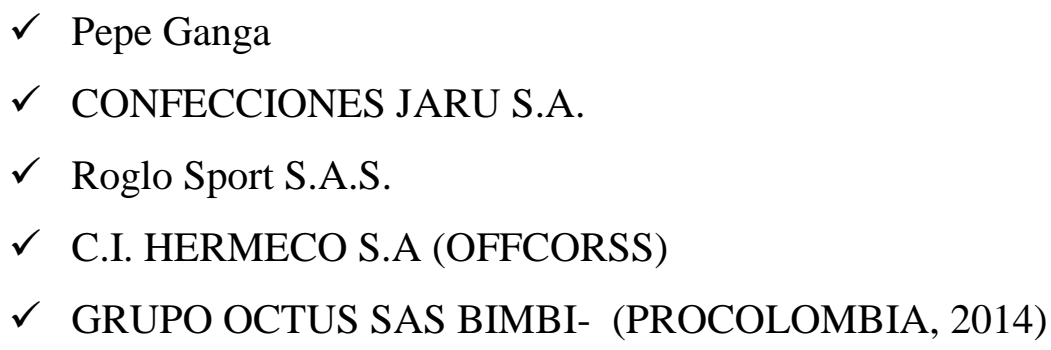

A continuación, y siguiendo con los datos suministrados por pro-Colombia se estructura la tabla 15 comparativa de las empresas que lideran el mercado de ropa infantil en Colombia.

Tabla 15 Comparativo de empresas de confecciones relevantes en Colombia.

\begin{tabular}{|c|c|c|c|c|}
\hline Empresa & Proyecto & $\begin{array}{l}\text { Elementos claves con los que } \\
\text { debe contar la empresa para el } \\
\text { desarrollo de sus proyectos }\end{array}$ & Consecuencia & Origen \\
\hline $\begin{array}{l}\text { Pepe Ganga y } \\
\text { Baby Ganga }\end{array}$ & $\begin{array}{l}\text { Estrategias de alianzas con } \\
\text { marcas extranjeras (marca } \\
\text { inglesa Mamas\&Papas), para } \\
\text { fortalecer variedad de } \\
\text { productos. }\end{array}$ & $\begin{array}{l}\text { Inversiones para establecer } \\
\text { investigaciones de mercado para } \\
\text { encontrar necesidades. Es decir que } \\
\text { cuentan con un esquema solido } \\
\text { administrativo y de gerencia que } \\
\text { traslada sus proyectos a rentabilidad } \\
\text { y expansión para la empresa. }\end{array}$ & $\begin{array}{l}\text { Para desarrollar estrategias } \\
\text { que impacten en la } \\
\text { participación de la empresa } \\
\text { en el mercado y ampliar su } \\
\text { mercado objetivo de niños } \\
\text { entre los } 0 \text { a los } 3 \text { años, para } \\
\text { lograr llegar hasta los } 12 \\
\text { años. }\end{array}$ & Colombiana \\
\hline
\end{tabular}




\begin{tabular}{|c|c|c|c|c|}
\hline $\begin{array}{l}\text { Pepe Ganga y } \\
\text { Baby Ganga }\end{array}$ & $\begin{array}{l}\text { Expansión de nicho de } \\
\text { mercado. }\end{array}$ & $\begin{array}{l}\text { Desarrollo de viabilidad financiera, es } \\
\text { decir se elaboran planeación } \\
\text { financiera para la toma de decisiones } \\
\text { de expansión de mercado. }\end{array}$ & $\begin{array}{l}\text { La proyección de esta firma } \\
\text { que empieza a tener } \\
\text { presencia en Latinoamérica } \\
\text { es alcanzar ventas por } \\
\text { US } \$ 2,5 \text { millones en el primer } \\
\text { año de operación en } \\
\text { Colombia. }\end{array}$ & Colombiana \\
\hline TUCTUC & $\begin{array}{l}\text { Apertura de su primera tienda } \\
\text { en Bogotá. Se trata de una } \\
\text { boutique ubicada en el centro } \\
\text { comercial Santafé, la primera } \\
\text { de la multinacional en la } \\
\text { región. }\end{array}$ & $\begin{array}{l}\text { Desarrollo de canales de distribución. } \\
\text { Inversión en logística, y sistemas de } \\
\text { información de inventarios en tiendas } \\
\text { propias. Estructura administrativa y } \\
\text { gerencial clara y articulada con los } \\
\text { procesos operativos de la empresa. }\end{array}$ & $\begin{array}{l}\text { Cuenta con } 60 \text { tiendas y } \\
4.000 \text { puntos de distribución } \\
\text { en el mundo. Sus ventas en } \\
\text { el mercado externo } \\
\text { representan } 50 \% \text { del total de } \\
\text { sus ingresos totales. }\end{array}$ & Española \\
\hline $\begin{array}{l}\text { EPK (El } \\
\text { principito Kids) }\end{array}$ & $\begin{array}{l}\text { Estrategias de consolidación } \\
\text { de la marca. Ubicación de } \\
\text { puntos de venta en ciudades } \\
\text { intermedias. La ropa para } \\
\text { niños dentro del mercado } \\
\text { formal más económica del } \\
\text { mercado. }\end{array}$ & $\begin{array}{l}\text { Esquemas estratégicos definidos, } \\
\text { estrategias de expansión definidas, } \\
\text { inversión en investigación de } \\
\text { mercados definida. Planeación } \\
\text { financiera definida. }\end{array}$ & $\begin{array}{l}\text { Apertura de } 41 \text { tiendas en } \\
\text { Colombia. Para el } 2014 \\
\text { alcanzó un crecimiento de } \\
25 \% \text { en volumen de ventas. }\end{array}$ & Venezolana \\
\hline OffCorss & $\begin{array}{l}\text { Aumento de } 5 \text { almacenes más } \\
\text { y desarrollo de } 20 \text { estructuras } \\
\text { de franquicias. Apertura } \\
\text { internacional de más puntos } \\
\text { propios de venta en Ecuador } \\
\text { y México. }\end{array}$ & $\begin{array}{l}\text { Claros lineamientos de crecimiento. } \\
\text { Desarrollo de oferta exportable. } \\
\text { Apertura de comercio exterior. } \\
\text { Estructura de producción clara y } \\
\text { alineada con las proyecciones de } \\
\text { expansión. Inversión en investigación } \\
\text { y desarrollo para nuevas líneas de } \\
\text { productos. }\end{array}$ & $\begin{array}{l}70 \text { almacenes propios. Tiene } \\
\text { planes de inversión alcanzan } \\
\text { los US } \$ 20 \text { millones. Para el } \\
2014 \text { la producción alcanzo } \\
6,2 \text { millones de unidades y } \\
\text { que sus ventas los } \$ 192.000 \\
\text { millones. }\end{array}$ & Colombiana \\
\hline
\end{tabular}

Fuente: (raddar, 2016)

\subsubsection{Conclusiones del ejercicio de benchmarking:}

$\checkmark$ Claramente, las empresas que lideran el mercado textil en Colombia tiene lineamientos claros frente a sus políticas de expansión y estrategias de crecimiento.

$\checkmark$ Las empresas analizadas tienen esquemas administrativos y gerenciales definidos que repercuten en la toma de decisiones tanto de mercadeo, como de penetración a nuevos mercados.

Las empresas se encuentran en desarrollo de círculos de calidad continuos, es decir que establecen políticas de adaptabilidad e innovación constante.

$\checkmark$ Todas están organizaciones descritas enfocadas en la creación de valor, lo cual es consecuencia de la creación de ventajas competitivas, sea por precio, o por distribución o por diseño. Claramente es valor que se ha forjado al interior de los procesos productivos de las compañías que se encuentran en esta investigación. 
Para Velerito es fundamental, según el análisis del entorno competitivo desarrollar ventajas que le permitan definir su orientación como empresa, las cuales se definen en la formación de estructura organizacional lógica y coherente que le permita diseñar estrategias y lineamientos que se adapten a las necesidades del mercado. Esto permitirá que Velerito establezca estrategias de expansión, campañas publicitarias, estudios de mercado, y planes de mejoramiento continuo.

Dentro del ejercicio de diagnóstico, el análisis de mercadotecnia es crucial para entender la dinámica de mercado en la que Velerito se desarrolla. Toda la información recolectada y plasmada en el formato de lista de chequeo para el análisis de mercadotecnia, que se ejecutó en conjunto con clientes, y fundadores de la organización. Dentro de los componentes del formato de chequeo se da espacio a:

$\checkmark$ Oferta, incidencia del producto sobre las necesidades y exigencias puntuales del mercado.

$\checkmark$ Demanda, incidencia del comportamiento del mercado objetivo en la toma de sesiones al interior de Velerito

$\checkmark$ Precio, Factor clave de vinculación de la empresa con el mercado

$\checkmark$ Competencia, aplicación de benchmarking dentro de la dinámica de mercado; en este caso el madrugón.

Dentro del contexto de diagnóstico de mercadeo, se mirará el impacto que la empresa genera en el círculo económico al que pertenece, de igual forma, se determina la necesidad de utilizar el comportamiento que presente la demanda para el desarrollo de una oferta de más valor para el mercado. Todo esto bajo la premisa de la maximización de utilidades y la creación de valor para la compañía como para sus clientes. Para determinar lo anterior se tomaron los siguientes elementos de que formulan la lista de chequeo de mercadeo.

Agentes de los procesos de mercadeo: este ítem busca establecer las relaciones que Velerito tiene con los agentes que interfieren directamente en los canales de comercialización de su proceso productivo.

Márgenes: este ítem propone estudiar sí el proceso productivo de la compañía genera un impacto significativo en términos de dinero tanto para los consumidores para la misma organización. Este punto es importante porque daría cavidad al nivel de gestión administrativa y financiera que la organización en su interior está desarrollando. Siendo un punto de partida para el análisis de la propuesta a desarrollar. 
Canales: analiza el vínculo de cómo la empresa llega al consumidor y mayorista de la forma más eficaz y eficiente que contribuya a la creación de un margen que permita la sostenibilidad del vínculo comercial.

Ventas: Es la unidad más importante del sistema empresarial de Velerito, por ende este ítem importante en esta evaluación. Por tal razón se espera definir el verdadero estado de la estructura de ventas y la gestión que vía administrativa necesite esta unidad teniendo en cuenta los antecedentes que preceden la realización de este ejercicio académico.

Publicidad: determinar la situación de cómo la empresa comunica a sus clientes y al mercado en general su oferta productiva al interior del mercado. Este punto determinará la correlación existente entre canales y ventas.

\section{Lista de Chequeo 3 Análisis de mercadotecnia en procesos de desarrollo empresarial}

ASPECTOS DE MERCADOTECNIA

CLASIFICACIÓN

(Con una $\mathrm{x}$ )

$\begin{array}{cc}\text { Positiva } & \text { Negativa } \\ \text { (Fortaleza) } & \text { (Debilidad) }\end{array}$

MERCADO

OFERTA

1. El producto o servicio es reconocido en el mercado

X

2. La cantidad de productos o servicios que ofrece abastece las necesidades del consumidor

3. El producto o servicio tiene un diferenciador frente a los demás.

$\mathrm{x}$

4. Los productos o servicios que ofrece la empresa cuentan con normas de calidad. X

5. Los clientes están satisfechos con los productos $\mathrm{X}$

6. Hay variedad de productos según las necesidades de los consumidores. Total Oferta

4

\section{DEMANDA}

1. Se investigan regularmente las necesidades del mercado objetivo. $\mathrm{X}$

2. Se planifica la producción con base a las demandas del mercado. X

3. Está delimitado el mercado objetivo al que se ofrece el producto o servicio

X

4. Se realizan de forma regular estudios e informes del mercado.

5. Hay segmentación de mercado $\mathrm{X}$

6. Hay estudios de correlación de precios y productos

7. Existen productos sustitutos. $\mathrm{X}$

8. Existen productos complementarios $\mathrm{X}$

9. Se realizan estudios de posibles clientes potenciales

\section{X}


Total demanda

6

\section{PRECIOS}

1. Se revisan los precios de forma periódica

2. Los precios se ajustan al mercado

3. Los precios están al alcance de los consumidores

$\mathrm{X}$

4. Se estudian los precios de la competencia de forma periódica

5. Los precios son estables

X

6. Se evalúan paulatinamente las alzas de precios

$\mathrm{X}$

7. El cliente valora positivamente el precio

Total precios

3

\section{COMPETENCIA}

1. Conoce en profundidad a sus principales competidores

2. Se realizan con regularidad informes y evaluaciones de mercado

3. Se hacen estudios comparativos en relación a la competencia.

4. Los productos tienen diferenciadores frente a la competencia

5. Sus productos son de preferencia en el mercado

$\mathrm{X}$

$\mathrm{X}$

2

\section{MERCADEO}

\section{AGENTES DE LOS PROCESOS DE MERCADEO}

1. Se tienen alianzas con mayoristas.

$\mathrm{X}$

2. Los gastos de almacenamiento y/o transporte son más bajos que los de ventas.

$\mathrm{X}$

3. La comercialización del producto o servicio tiene muchos intermediarios

4. Es adecuado el canal de distribución para llegar al cliente $\mathrm{X}$

5. Hay contacto directo con el fabricante

$\mathrm{X}$

6. Se sabe los requerimientos de los detallistas

Total Agentes de los procesos de mercadeo

$4 \quad 2$

\section{MARGENES}

1. Los márgenes que se manejan dejan utilidad a la compañía.

2. El margen de contribución es alto para el consumidor.

X

3. El margen de contribución es alto para el productor.

$\mathrm{X}$

4. El margen de contribución es el esperado por la empresa

Total márgenes $\mathrm{X}$

2

\section{CANALES}

1. Se realiza idoneidad de los canales de forma sistemática

2. Se estudia la posibilidad de ingresar a nuevos canales

3. Se hace seguimiento a los canales más importantes.

4. Los canales de distribución son los adecuados $\mathrm{X}$

5. Hay correlación entre los diferentes canales. 


\section{VENTAS}

1. La fuerza de ventas es suficiente para cubrir todo el mercado

2. Hay políticas claras en el área de ventas para llevar a cabo las labores

3. La cantidad de ventas se ajusta a los objetivos planteados.

4. El cubrimiento de las ventas es a nivel nacional.

5. Hay un plan estratégico de marketing.

$\mathrm{X}$

6. Las ventas mensuales se ajustan a los objetivos organizacionales

7. Se hacen evaluaciones periódicas de los resultados en ventas

8. Hay planes motivacionales en el área de ventas para realizar de manera óptima las labores

Total ventas

\section{PUBLICIDAD}

1. Hay buenas estrategias de publicidad. $\quad \mathrm{X}$

2. Se utilizan varios medios publicitarios. $\quad \mathrm{X}$

3. La publicidad que se tiene genera recordación para los consumidores. $\mathrm{X}$

4. Se realizan campañas publicitarias de la mano de agentes externos de importancia $\mathrm{X}$ mundial

5. La publicidad está relacionada con todos los agentes en los canales de distribución X Total Publicidad

0

5

Fuente: (Coopers y Lybrand, 1997)

\section{Tabla 16 Análisis de resultados- lista de Chequeo 3}

\begin{tabular}{|l|r|r|}
\hline Factor de análisis & Positivos & \multicolumn{2}{|c|}{ Negativos } \\
\hline Oferta & 4 & 3 \\
\hline Demanda & 6 & 3 \\
\hline Precios & 3 & 3 \\
\hline Competencia & 2 & 3 \\
\hline Agentes de los & 4 & 2 \\
\hline procesos de & & \\
\hline mercadeo & & \\
\hline Márgenes & 2 & 2 \\
\hline Canales & 2 & 3 \\
\hline Ventas & 0 & 6 \\
\hline Publicidad & 0 & 5 \\
\hline Total & $\mathbf{2 3}$ & $\mathbf{3 0}$ \\
\hline
\end{tabular}

Fuente: Lista de Chequeo 3 
Como se observa en la tabla 16 (análisis de resultados) Velerito tiene problemas en su oferta de acuerdo a la relación con la situación real económica del mercado, del sector y los detallistas. Por otro lado, el estudio de demanda que realiza Velerito es muy poco, de hecho, la información que se logró canalizar fue escasa por la carencia de canales de información que permitieran a ciencia cierta determinar cuál era la perspectiva del cliente frente al producto y la empresa. Esto dificulta el diseño de planes de mercadeo, de publicidad y diseño de nuevos productos. En relación al precio se estipula que hay una percepción favorable, Velerito maneja precios que están dentro de los rangos que otros participantes del sector textil infantil del mercado de madrugón manejan y esto se evidencia por la circulación de ventas y por la cantidad de clientes frecuentes que suma la cifra de 80 .

\section{Gráfica 9 Análisis de Mercadotecnia en procesos de desarrollo empresarial}

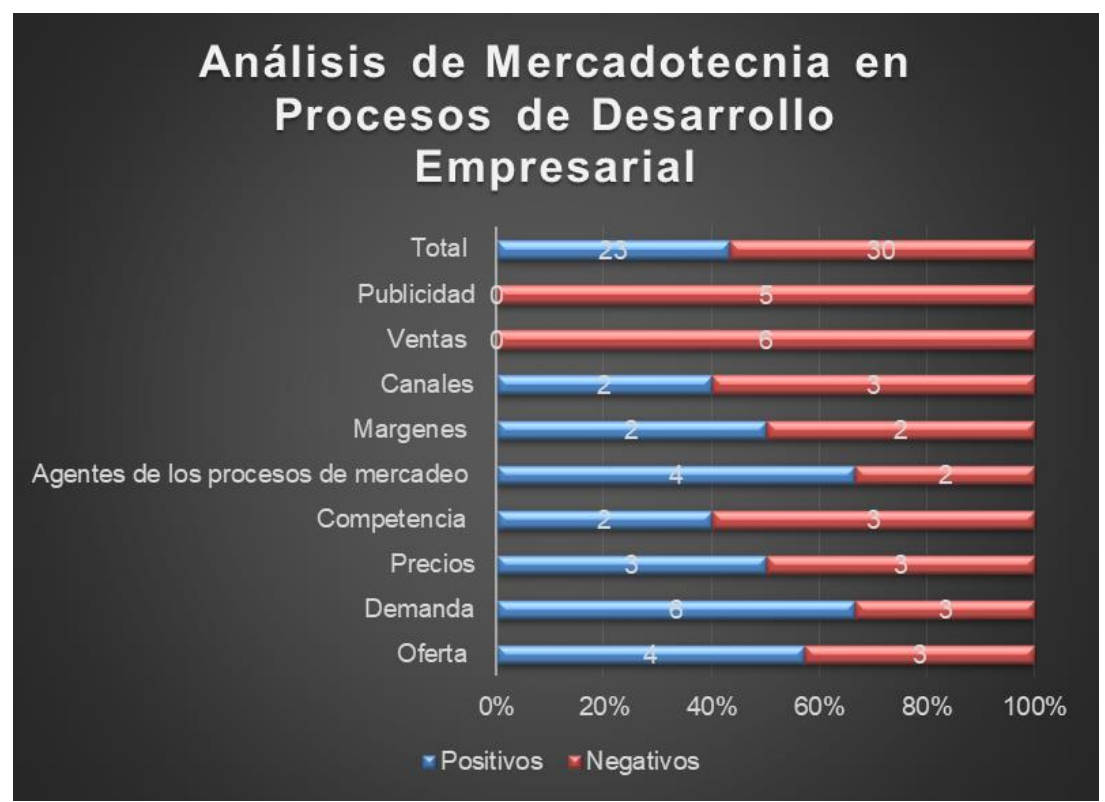

Fuente: Lista de Chequeo 3- Análisis de mercadotecnia en procesos de desarrollo empresarial

Otro punto de análisis del entorno dentro del área del mercadeo es la competencia. Para este ejercicio, Velerito no tiene claridad sobre el manejo que la competencia tiene al desarrollo de nuevos productos, manejo de canales, y no tiene en consideración las amenazas que pueden afectar su posición en el mercado en los próximos años. Carece de una estructura que le permita definir las líneas de ejecución de un benchmarking que le permita definir acciones estratégicas en aras de mejorar su posición de mercado y su margen de utilidad. 
Dentro de la mirada de mercado y de cómo Velerito efectúa procesos de intercambio al interior del mercado en el que se desenvuelve, se encuentra que la empresa cuenta debido a la estructura del madrugón con oportunidades de gestión con los agentes que efectúan un papel de distribuidores de los productos a nivel nacional y que se sujetan a la política de ventas al contado que Velerito implementa. Sin embargo, existen problemas en cuanto a la creación de valor por parte de la empresa (vía, bajo nivel de diferenciación) y su generación de márgenes tanto para empresa y mayoristas, es decir que existen problemas de fondo en la formulación de la propuesta de valor y planeación administrativo.

En cuanto a los canales de ventas y ventas como lo muestra la gráfica 9-(Análisis de Mercadotecnia en procesos de desarrollo empresarial) se evidencia una relación poco fructífera pues son pocos los canales de venta de los cuales dispone Velerito, los cuales solo van de la mano en el efecto que el mercado de madrugón desarrolla, pero que quedan insuficientes frente a la ausencia de plan que promueva la comunicación del producto y la marca al interior del mercado mayorista.

Al interior de la función operacional de mercadotecnia de Velerito, se encontraron elementos susceptibles de análisis, por ejemplo, el nivel de innovación que velerito imprime a sus productos, el cual según los fundadores no es demasiado por las implicaciones de costos que esto conlleva y que según ellos el mercado no está dispuesto a asumir, además de precisar que su producto estrella (t-shirt infantil femenina) no ha presentado modificaciones sustanciales desde hace tres años. Dentro de otra característica desfavorable frente al producto se evidencia la poca importante que la empresa le da al manejo publicitario y desarrollo de la marca, esto se reafirma según las pruebas hechas en los anteriores formatos de chequeo que tocan este punto de mercadeo.

Con respecto a la plaza, hay varios elementos benéficos para la creación de valor por parte de Velerito, entre ellos encontramos que la aglomeración de mayoristas de todo el país, se ubican en un plano único y aun rango de tiempo determinado propiciando un espacio diseñado para comprar y vender de forma rápida y de contado; esto posibilita la reducción de costes de arriendos, de fuerza de ventas y estipula oportunidad para diseñar estrategias de publicidad focalizadas en zonas y tiempos preciosos para lograr vincular a más mayoristas con los productos de Velerito.

En conclusión, se puede inferir que la plaza es una oportunidad para que Velerito ampliara su nivel de ventas, a partir de la ampliación de su oferta a mayorista que confluyen de todos lados del territorio nacional. 


\section{Gráfica 10 Análisis de Factores de Mercadotecnia}

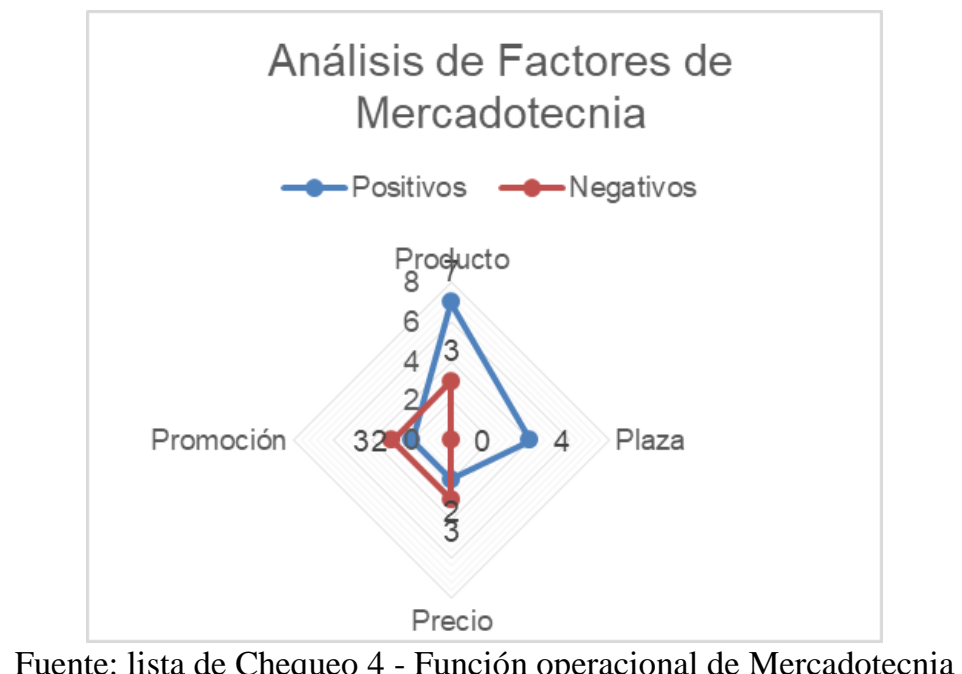

Frente al precio Velerito pone al descubierto varias desventajas, una de ellas es que el mercado impone los rangos de precio en los cuales el producto de velerito debe comercial sus productos debido a la cercanía de sus competidores, que debido esto su rentabilidad se puede ver afectada. Sin embargo, cabe mencionar que un factor clave que seguro se evidenciará en el análisis financiero será su política de venta y compra, la cual se realiza de contado, lo cual le ha posibilitado tener capital de trabajo para sostener la operación de forma continua y creciente.

Por último, frente al tema que evalúa la promoción cabe anotar que Velerito apunta las temporadas comerciales que se presentan durante el año y que fueron descritas en el apartado inicial del tema de mercadotecnia. Por otra parte, en términos de publicidad y atención al cliente no hay mayor planeación, de hecho, no existe manuales para la interacción del vendedor con el cliente y tampoco para el desarrollo de marca en el mercado.

\section{Lista de Chequeo 4 Función operacional de Mercadotecnia}

\begin{tabular}{lcc}
\hline PRODUCTO - SERVICIO & Fortaleza & Debilidad \\
\hline Valor Agregado (Innovación) & $\mathrm{X}$ \\
Calidad & $\mathrm{X}$ & \\
Perecedero & $\mathrm{X}$ & $\mathrm{X}$ \\
Duradero & $\mathrm{X}$ & $\mathrm{X}$ \\
Practicidad & $\mathrm{X}$ & $\mathrm{X}$ \\
Satisface una necesidad & & $\mathrm{X}$ \\
Diseño & & \\
Logo & & \\
Marca & & \\
\hline
\end{tabular}




\begin{tabular}{|c|c|c|}
\hline Empaque & $\mathrm{X}$ & \\
\hline Total de producto & 7 & 3 \\
\hline \multicolumn{3}{|l|}{ PLAZA } \\
\hline Nicho de mercado & $\mathrm{X}$ & \\
\hline Cliente Objetivo & $\mathrm{X}$ & \\
\hline Ubi-cuidad & $X$ & \\
\hline Canal de Distribución & $\mathrm{X}$ & \\
\hline Total de plaza & 4 & 0 \\
\hline \multicolumn{3}{|l|}{ PRECIO } \\
\hline Indicadores Financieros & & $\mathrm{x}$ \\
\hline Costos & & $\mathrm{x}$ \\
\hline Proveedores & & $\mathrm{x}$ \\
\hline Temporada & $\mathrm{x}$ & \\
\hline Formas de Pago & $\mathrm{x}$ & \\
\hline Total de precio & 2 & 3 \\
\hline \multicolumn{3}{|l|}{ PROMOCIÓN } \\
\hline Cantidad & & $\mathrm{x}$ \\
\hline Temporada & $\mathrm{x}$ & \\
\hline Descuentos Especiales & $\mathrm{x}$ & \\
\hline Publicidad & & $\mathrm{x}$ \\
\hline Atención al cliente & & $\mathrm{x}$ \\
\hline Total de promoción & 2 & 3 \\
\hline
\end{tabular}

Fuente: Elaboración propia - (Coopers y Lybrand , 1997)

Dentro de los elementos tomados para los procesos de evaluación de la empresa Velerito fue necesario demarcar otros que correspondía a aspectos tales como: físicos, económicos, sociales y administrativos, jurídico, ambientales. Esto con el fin de ampliar el rango de estudio y tener un panorama más completo de la empresa en su desarrollo interno.

\section{Lista de Chequeo 5 Aspectos Internos de la Empresa a considerar.}

\begin{tabular}{|c|c|c|}
\hline \multirow[t]{2}{*}{ Aspectos internos a identificar } & \multicolumn{2}{|c|}{ Clasificación } \\
\hline & POSITIVA & NEGATIVA \\
\hline Aspectos In & & \\
\hline Oficina propia & $\mathrm{X}$ & \\
\hline Ubicación de la oficina & $\mathrm{X}$ & \\
\hline Material representativo en la empresa & & $\mathrm{X}$ \\
\hline Material y equipo de trabajo & $\mathrm{x}$ & \\
\hline Espacios y bodegas & $\mathrm{X}$ & \\
\hline Vehículos & $\mathrm{X}$ & \\
\hline Otros, maqui aria, & $\mathrm{X}$ & \\
\hline
\end{tabular}

Aspectos Internos Económicos y Financieros

Funciona con recursos propios. 


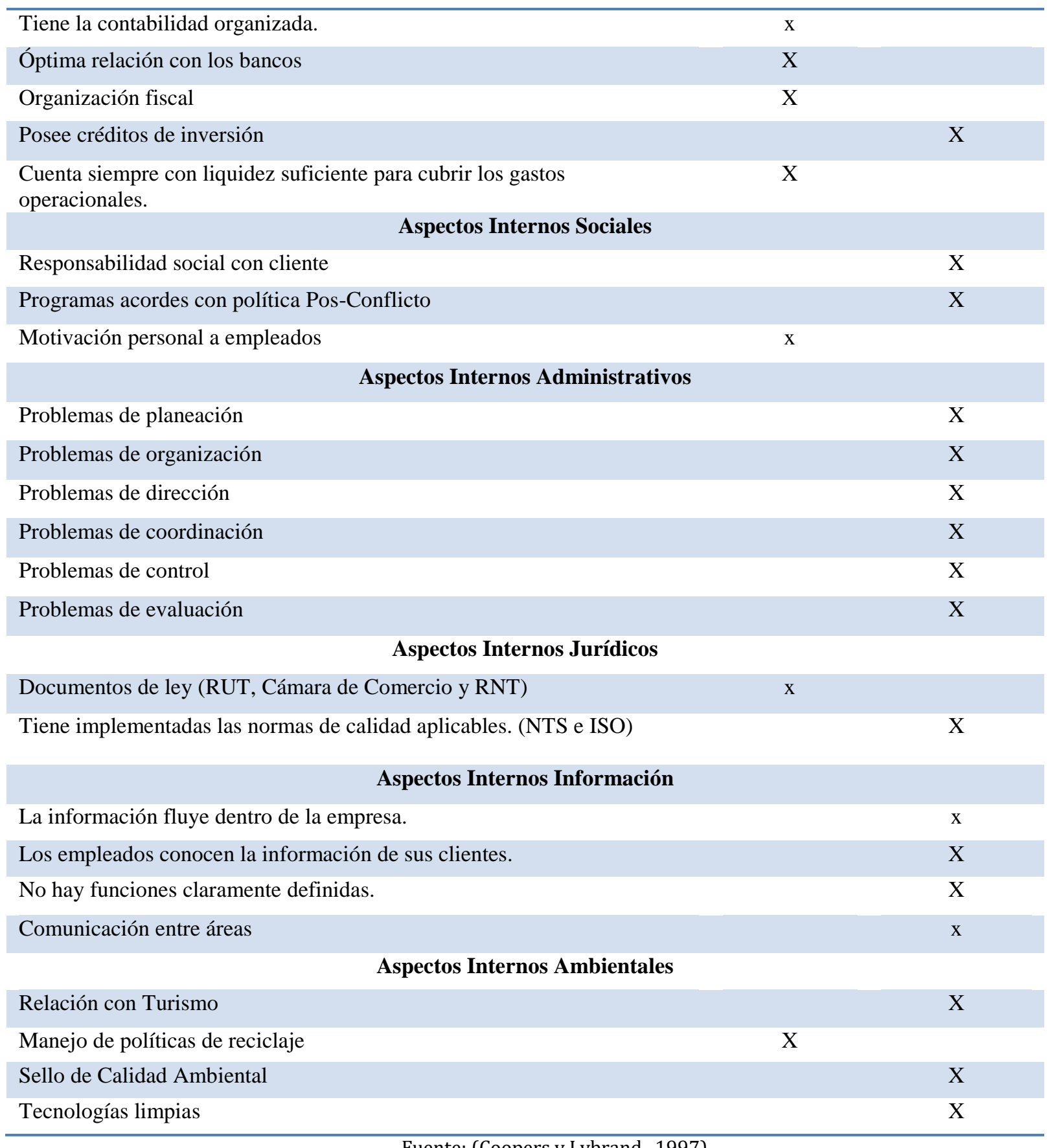

Fuente: (Coopers y Lybrand , 1997)

Dentro de los aspectos físicos se encontraron varias fortalezas como vehículos, espacios para oficina, materias primas y espacios para bodega y trabajo, Desde el aspecto financiero encontramos varios puntos a resaltar, la primera el funcionamiento de la empresa a partir de recursos propios, lo cual implica bajos niveles de endeudamiento, por ende existen excelentes relaciones con bancos y además por su política de ventas, Velerito cuenta con cerca de 3 pesos libre por peso de deuda corriente. 
Frente a los aspectos sociales Velerito no cuenta con planes claros sobre Responsabilidad social o temas relacionados con post conflicto.

Por otro lado, Velerito cuenta con problemas de estructura administrativa, debido a la carencia de sistematización, organización y digitalización de la información lo cual no permite evidenciar procesos de planeación, de coordinación, dirección y control. Esto limita el flujo de información interno, provocando ineficiencia en la coordinación de procesos para hacer uso adecuado de los recursos con los que cuenta la empresa. Sin embargo, cabe anotar que aun cuando existe la ausencia del esqueleto administrativo, el pequeño tamaño de la organización permite que existan posibilidades de cambio más rápidas e inmediatas sí se destina a la creación de procesos y estructurarles de la empresa.

Un punto de hallazgo frente al tema administrativo es la ausencia de un sistema de información que permita entender las dinámicas de los procesos que integran la cadena de valor de la empresa, lo cual dificulta la toma de decisiones.

\subsection{Unidad Financiera}

Dentro del análisis de balances y cuentas de pérdidas y ganancias (P y G) se indican algunos aspectos relevantes para el desarrollo del análisis financiero de la compañía.

Gráfica 11 Variación porcentual de ventas Velerito (2015-2016-2017)

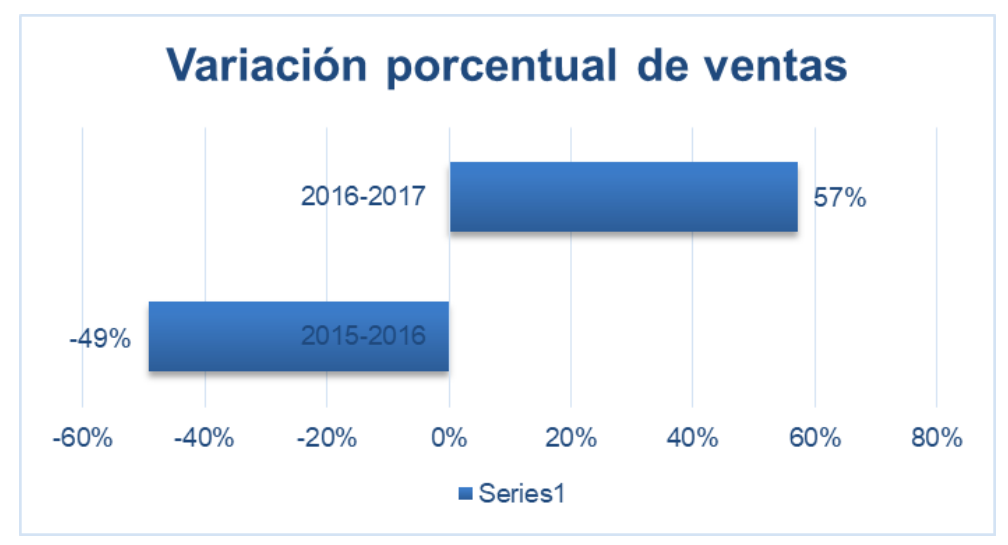

Fuente: P y G de Velerito

De acuerdo a la gráfica 11 (variación porcentual de ventas) se presentó un aumento de ventas para el año 2017; luego de la caída sufrida en 2016. Este comportamiento es favorable puesto que muestra una tendencia de favorabilidad de la empresa frente a la aceptación de la demanda a los productos y demás elementos que conforman el marketing de la empresa. 
Sin embargo, en contraste con las utilidades como se ve en la gráfica 12 (Comportamiento relativo de la utilidad antes de impuestos) se muestra una preocupante tendencia de la empresa en cuanto a perdida de patrimonio y consecuentemente rentabilidad para los accionistas. Esto puede evidenciar alguna destrucción de valor en términos de rentabilidad frente a ventas, las cuales en dicho periodo aumentaron en un 57\%. Y deja al descubierto que existen anomalías en términos administrativos y gerenciales.

\section{Gráfica 12 Comportamiento relativo de la utilidad antes de impuestos}

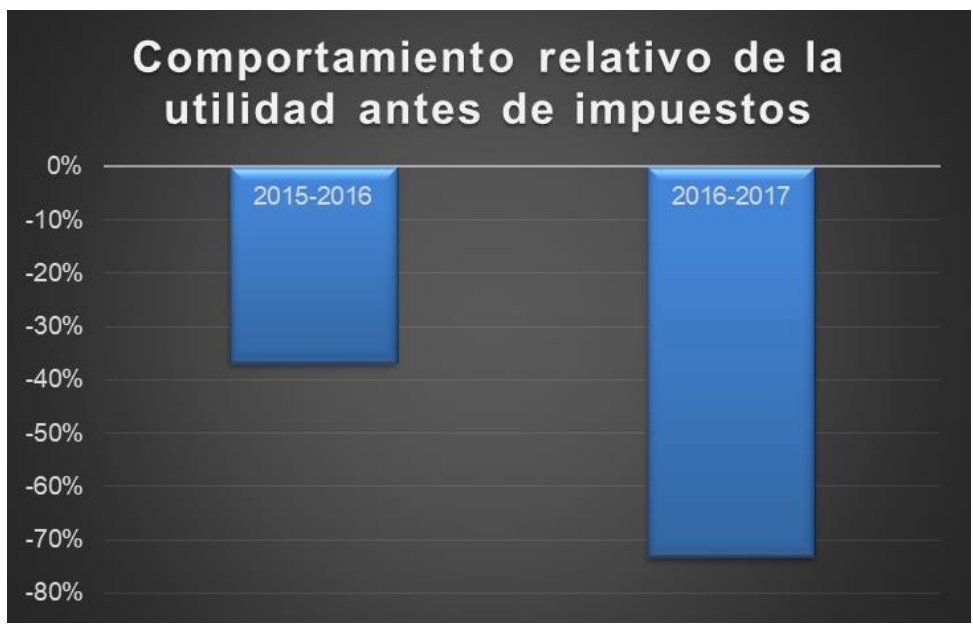

Fuente: Balances de la empresa

Para poder establecer el análisis de los factores financieros que conforman una empresa, se elaboró una lista de chequeo 6 (detalles de análisis económico financiero) en la cual se establecieron las debilidades y fortalezas que la empresa tiene frente a aspectos tales como: estructura, personal, análisis de información y control.

\section{Lista de Chequeo 6 Detalles De Análisis Económicos Y Financieros}

\begin{tabular}{|c|c|c|}
\hline $\begin{array}{l}\text { ANÁLISIS ECONÓMICO Y FINANCIERO } \\
\text { ÍTEM A EVALUAR }\end{array}$ & $\begin{array}{l}\text { FORTALEZA } \\
\text { (Positiva) }\end{array}$ & $\begin{array}{l}\text { DEBILIDAD } \\
\text { (Negativa) }\end{array}$ \\
\hline 1.1 ESTRUCTURA & & \\
\hline 1.1.1 Instalaciones & & $\mathrm{X}$ \\
\hline 1.1.2 Software & & $\mathrm{X}$ \\
\hline 1.1.3 Departamento Financiero & & $\mathrm{X}$ \\
\hline 1.1.4 Equipos de oficina (Hardware) & & $\mathrm{X}$ \\
\hline Total ítem "estructura" & 0 & 4 \\
\hline
\end{tabular}




\begin{tabular}{|c|c|c|}
\hline 1.2.1 Equipo interno & $\mathrm{X}$ & \\
\hline 1.2.2 Capacitaciones equipo interno & & $\mathrm{X}$ \\
\hline 1.2.3 Equipo externo & & X \\
\hline Total ítem "personal" & 1 & 2 \\
\hline \multicolumn{3}{|l|}{1.3 ANÁLISIS DE INFORMACIÓN } \\
\hline 1.3.1 Análisis estático & & $\mathrm{X}$ \\
\hline 1.3.2 Análisis dinámico & & $\mathrm{X}$ \\
\hline 1.3.3 Establecimiento de objetivos & & $\mathrm{X}$ \\
\hline 1.3.3 Suministro de información a todos los interesados & & $\mathrm{X}$ \\
\hline Total aspectos "análisis de información" & 0 & 4 \\
\hline \multicolumn{3}{|l|}{ 1.4 CONTROL } \\
\hline 1.4.1 Documentos físicos (Libros contables, informes...) & $\mathrm{X}$ & \\
\hline 1.4.2 Control de calidad (ISO) & & $\mathrm{X}$ \\
\hline 1.4.3 Legalidad de la información & & $\mathrm{X}$ \\
\hline Total ítem "control" & & \\
\hline Total aspectos ANÁLISIS ECONÓMICO Y FINANCIERO & 2 & 12 \\
\hline
\end{tabular}

Fuente: (Coopers y Lybrand , 1997)

\subsection{Conclusiones de factores financieros}

Según el análisis realizado en la lista de chequeo 6, se aprecia que más del $80 \%$ de los factores estudiados presenta una tendencia desfavorable para la empresa Velerito. Un punto a resaltar es la deficiencia que presenta la empresa frente al análisis de su información financiera como se ve representado en los ítems de análisis de información de la tabla 17- resultados parciales de los estados financieros; esto muestra la carencia de un manejo de información adecuado debido a la falta de una estructura administrativa que pueda llevar un registro de datos de manera ordenada y lógica bajo las directrices del direccionamiento estratégico de la empresa.

\section{Gráfica 13 Resultados de análisis de factores financieros}

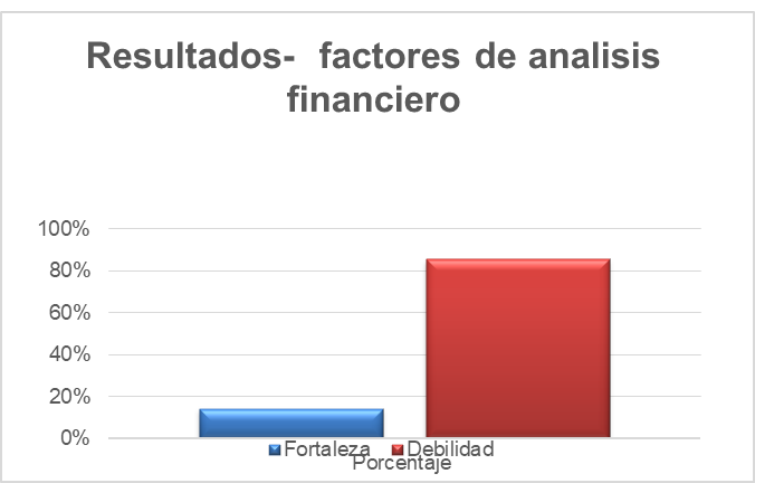

Fuente: Balance de Velerito. 
Tabla 17 Resultados parciales de los factores financieros.

\begin{tabular}{|ccc|}
\hline Factores financieros & fortaleza & Debilidad \\
\hline Estructura & 0 & 4 \\
\hline Personal & 1 & 2 \\
\hline Análisis de información & 0 & 4 \\
\hline Control & 1 & 2 \\
\hline Total & 2 & 12 \\
\hline Porcentaje & $14 \%$ & $86 \%$ \\
\hline
\end{tabular}

Fuente: Elaboración propia

\subsection{Análisis financiero}

\section{Tabla 18 Razones financieras de 2016 de Velerito}

\begin{tabular}{|c|c|c|c|c|}
\hline $\begin{array}{l}\text { Razones } \\
\text { financieras }\end{array}$ & Fórmula & Valor total & Análisis & $\begin{array}{l}\text { Fortaleza } \\
\text { (F) o } \\
\text { Debilidad } \\
\text { (D) }\end{array}$ \\
\hline Razón corriente & $\begin{array}{l}\text { Total de activo } \\
\text { corriente sobre } \\
\text { Total de pasivo } \\
\text { corriente }\end{array}$ & 3,904606949 & $\begin{array}{l}\text { Por cada peso (\$1) adeudado Velerito tiene } \$ 3,9 \\
\text { pesos para pagar, lo que puede reflejar una } \\
\text { comodidad en los pagos de las obligaciones de corto } \\
\text { plazo; sin embargo, una sobre-liquidez que no } \\
\text { genera ninguna clase de rentabilidad, es decir que se } \\
\text { está destruyendo valor para la compañía, a través de } \\
\text { la perdida de costo de oportunidad. } \\
\text { En este sentido, la cuenta que más influencia } \\
\text { presenta en este indicador, es la de otros activos } \\
\text { corrientes". Por lo tanto para efectuar un análisis más } \\
\text { acertado con la realidad, es necesario determinar loe } \\
\text { elementos que integran esta cuenta. }\end{array}$ & $\mathrm{F}$ \\
\hline Prueba acida & $\begin{array}{l}\text { Total activos } \\
\text { circulante menos } \\
\text { los inventario } \\
\text { sobre total } \\
\text { pasivo corriente }\end{array}$ & 3,449729441 & $\begin{array}{l}\text { Por cada peso ( } \$ 1 \text { ) adeudado, la Empresa tiene } \$ 3,44 \\
\text { pesos (por activos de fácil convertibilidad), para } \\
\text { cubrir sus deudas de corto plazo. A pesar de que los } \\
\text { inventarios son el } 18 \% \text { de los activos corrientes de } \\
\text { Velerito, existe un gran flujo circulante de dinero. }\end{array}$ & $\mathrm{f}$ \\
\hline $\begin{array}{l}\text { Capital de trabajo } \\
\text { neto }\end{array}$ & $\begin{array}{l}\text { Total activo } \\
\text { corriente menos } \\
\text { total activo } \\
\text { corriente }\end{array}$ & $\begin{array}{l}\$ \\
267.382 .149,91\end{array}$ & $\begin{array}{c}\text { Si la empresa pagara sus deudas de corto plazo, } \\
\text { tendría una liquidez de } \$ 267.382 .149 \text { para efectuar } \\
\text { de nuevo el ejercicio (en cuanto al desarrollo de su } \\
\text { CORE de negocios). }\end{array}$ & $\mathrm{F}$ \\
\hline $\begin{array}{l}\text { Rotación de } \\
\text { inventario }\end{array}$ & $\begin{array}{l}\text { Ventas sobre } \\
\text { inventario }\end{array}$ & 1,74833 & $\begin{array}{l}\text { Los inventarios rotaron } 1,7 \text { veces en el año, en otras } \\
\text { palabras, aproximadamente cada seis meses se vende } \\
\text { todo el inventario. La mercancía duro casi seis meses } \\
\text { en fábrica. }\end{array}$ & $\mathrm{n}$ \\
\hline $\begin{array}{l}\text { Rotación de } \\
\text { cuentas por cobrar }\end{array}$ & $\begin{array}{l}\text { Cuentas por } \\
\text { cobrar por } 360 \\
\text { días, sobre } \\
\text { ventas }\end{array}$ & 6,443447107 & $\begin{array}{l}\text { Velerito recupera cartera cada } 6 \text { días, lo cual es } \\
\text { coherente con su política de ventas de contado, esto } \\
\text { es interesante y justifica el nivel de liquidez que } \\
\text { posee para hacer frente a las obligaciones a corto } \\
\text { plazo }\end{array}$ & $\mathrm{p}$ \\
\hline $\begin{array}{l}\text { Margen bruto en } \\
\text { ventas }\end{array}$ & $\begin{array}{l}\text { Utilidad } \\
\text { operacional } \\
\text { sobre ventas }\end{array}$ & $31 \%$ & $\begin{array}{l}\text { Cada unidad de venta deja una utilidad antes de } \\
\text { impuestos del } 30 \%\end{array}$ & $\mathrm{~N}$ \\
\hline
\end{tabular}




\begin{tabular}{|l|l|l|l|l|}
\hline $\begin{array}{l}\text { Margen neto en } \\
\text { ventas }\end{array}$ & $\begin{array}{l}\text { Utilidad después } \\
\text { de impuestos } \\
\text { sobre ventas }\end{array}$ & 0,295065496 & $\begin{array}{l}\text { Cada unidad de venta deja una utilidad después de } \\
\text { impuesto del 29\% }\end{array}$ & $\mathrm{n}$ \\
\hline $\begin{array}{l}\text { Pasivo total / } \\
\text { Activo total }\end{array}$ & $13 \%$ & El 13\% de los activos pertenecen a los proveedores. & $\mathrm{p}$ \\
\hline $\begin{array}{l}\text { Endeudamiento } \\
\text { Laverage }\end{array}$ & $\begin{array}{l}\text { Pasivo total/ } \\
\text { patrimonio total }\end{array}$ & $15 \%$ & $\begin{array}{l}\text { El nivel de endeudamiento de Velerito con sus } \\
\text { acreedores es del 15\% }\end{array}$ & $\mathrm{P}$ \\
\hline $\begin{array}{l}\text { Pasivo } \\
\text { corriente/Total } \\
\text { pasivo }\end{array}$ & $100 \%$ & $\begin{array}{l}\text { Las obligaciones de corto plazo conforman todas las } \\
\text { obligaciones que tiene Velerito }\end{array}$ & $\mathrm{P}$ \\
\hline $\begin{array}{l}\text { Pasivo no } \\
\text { corriente/ total } \\
\text { pasivo }\end{array}$ & $0 \%$ & La empresa no presenta obligaciones de largo plazo & $\mathrm{p}$ \\
\hline $\begin{array}{l}\text { Retorno sobre el } \\
\text { capital }\end{array}$ & $\begin{array}{l}\text { Utilidad Neta/ } \\
\text { Activo total }\end{array}$ & $3 \%$ & $\begin{array}{l}\text { De cada } 100 \text { pesos de activos, los accionistas tienen } \\
3 \% \text { de utilidades netas }\end{array}$ & \\
\hline
\end{tabular}

Fuente: (Murcia H. H., 2014)

\subsection{Conclusiones del análisis de las razones financieras.}

Liquidez

Rentabilidad

Endeudamiento

Conclusión general de razones financieras
-A partir de las pruebas realizadas en la tabla 19, se encuentra que ---Velerito cuenta con un nivel de liquidez alto para hacer frente a todas sus obligaciones, incluso sin necesidad de utilizar los recursos que posee en inventario. Esto, es sano para poder hacer inversiones que permitan posicionar el negocio dentro de un marco empresarial organizado y afianzado para el mercado en el cual confluye.

-Velerito tiene problemas en la rotación de su inventario, el cual para 2016 cayó en un $33 \%$., sin embargo, su rotación de cuentas por cobrar determina una política de ventas sana, porque estipula en su mayoría ventas al contado, lo cual fortalece su capacidad de liquidez.

-La rentabilidad importante a mirar con profundidad, no por el valor relativo que presenta las pruebas de este segmento, si no afectación que puede tener este margen frente a la rotación de inventario, la cual no es muy favorable.

-Frente a este Ítem las prueban arrojan una sana política de obligaciones, es decir, que es una empresa que prácticamente no tiene deudas. Esto lo posibilita analizar otras opciones de riesgo con aras de tomar una posición preponderante en el mercado en el que se encuentra.

La empresa Velerito tiene una política de ventas y compras sana que le ha permitido aguantar la no tan favorable situación del sector textil confección. Debe iniciar a aprovechar su capacidad de liquidez para máxima ganancias. Por otro lado se debe analizar. 


\section{Unidad Administrativa}

Dentro del diagnóstico, la unidad administrativa es un aspecto fundamental a analizar puesto que de este se desprende toda la lógica del manejo de recursos y diseño de estrategias que permiten a una empresa crear valor, desarrollar ventajas tanto comparativas, como competitivas y establecer una estructura que permita la gestión sostenible de la empresa en el tiempo. Para Velerito, la situación administrativa es desfavorable como se evidencia en la Gráfica 14 (Análisis de resultados- lista de chequeo administrativa) debido a la carencia de un plan empresarial, razón por la cual no existen planes de corto, mediano y largo plazo; tampoco se encontraron herramientas que apoyen al proceso gerencial en el diseño de estrategias y de planeación vertical. Esto se traduce en una debilidad crucial porque puede significar el inadecuado uso de recursos de la empresa, descoordinación de las unidades que conforman la organización, lo cual traduce en pérdida de valor y posible amenaza en la sostenibilidad de la empresa en el mercado.

Velerito no presenta un manual de funciones tangible y, por ende, no tiene indicadores que permitan evaluar constantemente el cumplimiento y la eficiencia de los procesos productivos que componen la unidad operativa. Lo cual supone problemas frente al tema de dirección puesto que no existe un enfoque que proyecte el cumplimiento de planes y programas, puesto que no hay delimitación de campos de acción por departamentos u áreas.

En términos de proceso de control cabe anotar que no existen registros físicos de gestión de los procesos operativos y gerenciales; además mencionar que el control presupuestal se establece en la "mente "de los dueños de la empresa, es decir que tampoco hay una directriz financiera que decante el tema presupuestario. Sí se tuviera que delimitar la carencia existente del área de control y o mejor, de los procesos administrativos se podría denotar en la ausencia de un control sistemático y digital. Es importante tener en consideración que la permanencia y crecimiento de la organización depende también de las transformaciones graduales innovadoras en la adaptabilidad a la evolución digital, teniendo en cuenta que sí estas innovaciones resultan exitosas la empresa formará parte de la evolución tecnológica avanzando y adaptándose al ritmo acelerado de la digitalización.

Finalizando los procesos administrativos, la evaluación es pieza clave para la retroalimentación y el fortalecimiento de los planes y/o estrategias que implementa la empresa y que son susceptibles de cambios o ejercicios de adaptabilidad por los entornos. Para Velerito este proceso tienen presenta diversas debilidades que denotan ausencia de evaluaciones ex ante, en desarrollo y final de proyectos como se evidencia en la tabla 20 (Análisis de Aspectos 
Administrativos Dentro Del Diagnóstico Estratégico De Velerito), lo cual indica la falta de retroalimentación para diseño de futuros planes o estrategias. Por consecuente, no están plenamente identificados los mecanismos de seguimiento de las actividades y sus fines al interior de la compañía.

En conclusión, Velerito carece de una estructura administrativa que le permita sentar las bases del direccionamiento estratégico del negocio para alinear todos sus procesos empresariales, desarrollar una propuesta de valor acorde con las tendencias actuales y futuras del mercado, y crear ventajas competitivas que refrenden la sostenibilidad de la empresa en el tiempo, y le permitan crear un impacto social y económico en la malla empresarial del país y del sector al que pertenece.

\section{Lista de Chequeo 7 Administrativo}

\begin{tabular}{|c|c|c|}
\hline \multirow{3}{*}{ SITUACION ADMINISTRATIVA A IDENTIFICAR } & \multicolumn{2}{|c|}{$\begin{array}{l}\text { CLASIFICACION } \\
\text { (con una } x \text { ) }\end{array}$} \\
\hline & $\begin{array}{c}\text { Positiva } \\
\text { (Fortaleza) }\end{array}$ & $\begin{array}{c}\text { Negativa } \\
\text { (Debilidad) }\end{array}$ \\
\hline & \multicolumn{2}{|l|}{ PLANEACION } \\
\hline 1. Existencia de Plan Empresarial (Institucional) & & $\mathbf{X}$ \\
\hline $\begin{array}{l}\text { 2. Planes a largo plazo (de tres a diez años, por } \\
\text { ejemplo) }\end{array}$ & & $\mathbf{X}$ \\
\hline 3. Planes a mediano Plazo (uno a tres años) & & $\mathbf{X}$ \\
\hline 4. Planes a corto plazo (menos de un año) & & $\mathbf{X}$ \\
\hline $\begin{array}{l}\text { 5. Proceso participativo de planeación (abajo } \\
\text { hacia arriba, bottom up) }\end{array}$ & $X$ & \\
\hline $\begin{array}{l}\text { 6. Planeación vertical ( de arriba hacia abajo, top } \\
\text { down) }\end{array}$ & \multirow[t]{4}{*}{$\mathrm{X}$} & \\
\hline 7. Asistencia técnica o asesoría para planeación & & $\mathbf{X}$ \\
\hline 8. Capacitación para planeación. & & $\mathbf{X}$ \\
\hline 9. Objetivos y metas definidas & & $\mathbf{X}$ \\
\hline \multirow[t]{2}{*}{ Total planeación } & 2 & 7 \\
\hline & \multicolumn{2}{|l|}{ ORGANIZACIÓN } \\
\hline $\begin{array}{l}\text { 1. Existencia de organigramas (líneas de } \\
\text { jerarquía) }\end{array}$ & \multirow[t]{4}{*}{$\mathrm{X}$} & \\
\hline 2. Manuales de funciones & & $\mathbf{X}$ \\
\hline 3. Distribución de actividades y tareas & & $\mathbf{X}$ \\
\hline $\begin{array}{l}\text { 4. Elaboración de cronogramas, calendarios de } \\
\text { trabajo }\end{array}$ & & $\mathbf{X}$ \\
\hline $\begin{array}{l}\text { 5. Otros procedimientos de programación } \\
\text { (reticular, por ejemplo PERT, CPM, etc.) }\end{array}$ & $\mathrm{X}$ & \\
\hline 6. Reglamentos de trabajo & \multirow{4}{*}{$\mathrm{X}$} & $\mathbf{X}$ \\
\hline 7. Unidad de mando & & \\
\hline $\begin{array}{l}\text { 8. Grupos de mejoramiento continuo o círculos } \\
\text { de calidad }\end{array}$ & & $\mathbf{X}$ \\
\hline 9. Capacitación o asistencia para organización & & $\mathbf{X}$ \\
\hline Total organización & 3 & 6 \\
\hline \multicolumn{3}{|c|}{ DIRECCION } \\
\hline 1. Dirección centralizada & & $\mathbf{X}$ \\
\hline \multicolumn{3}{|l|}{ 2. Dirección participativa } \\
\hline 3. Dirección enfocada hacia las personas & & $\mathbf{x}$ \\
\hline $\begin{array}{l}\text { 4. Dirección enfocada en cumplimiento de } \\
\text { planes y programas }\end{array}$ & & $\mathbf{x}$ \\
\hline 5. Capacitación o asistencia para dirección & & $\mathbf{x}$ \\
\hline 6. Estilo de liderazgo & & $\mathbf{x}$ \\
\hline
\end{tabular}




\section{Conflictos de poder o de mando Total dirección}

1. Definición de competencias o campos de acción de cada división o departamento 2. Integración de competencias o campos de acción

3. Trabajo en equipo

4. Mecanismos para coordinación y

programación de actividades

5. Capacitación o asistencia para

coordinación

Total coordinación

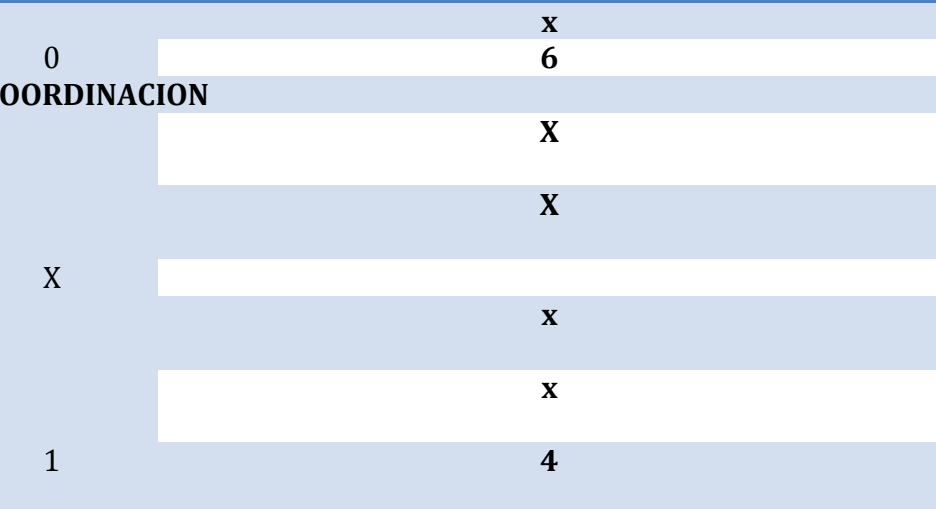

CONTROL

\section{Existencia de registros físicos}

\section{Registros contables}

3. Organización contable en general

4. Control presupuestal

5. Control de calidad (normas ISO)

6. Control sistematizado de la empresa

(hardware, software)

7. Capacitación o asistencia para control

Total control

1. Evaluación ex ante (antes de empezar cualquier proyecto)

2. Evaluación en desarrollo (performance)

3. Evaluación al finalizar (ex post)

4. Mecanismos de seguimiento

5. Ejecución de actividades de acuerdo a lo planeado

6. Realización constante de actividades

"imprevistas"

7. Capacitación o asistencia para evaluación

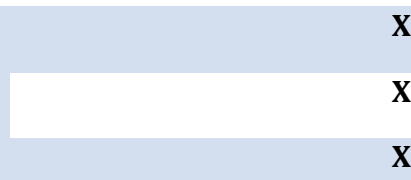

$\mathrm{X}$ $\mathbf{X}$ $\mathbf{X}$

$\mathbf{X}$

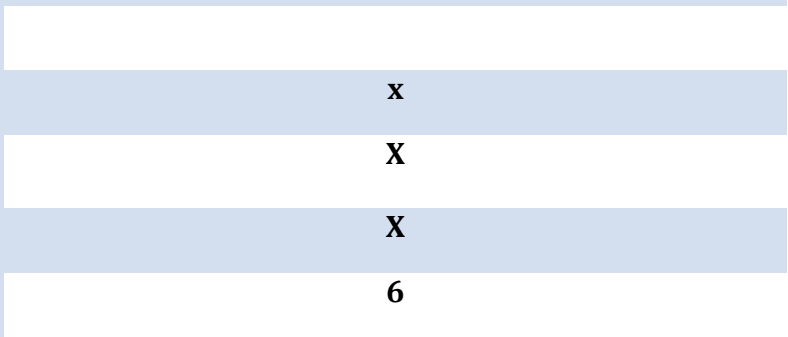

EVALUACION

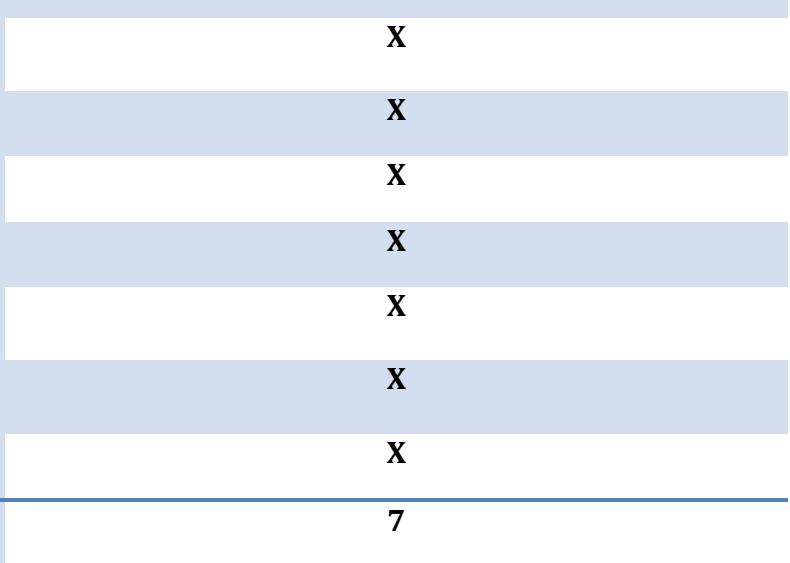

Fuente: Elaboración propia

Según los resultados de la lista de Chequeo 7, se elaboró la tabla 20, con el fin de graficar y demarcar las razones clave que llevaron a concluir la des favorabilidad que Velerito presenta en planeación, organización, dirección, coordinación, control y evaluación, es decir, en cuanto a la temática administrativa. 
Tabla 19 Resultados y conclusiones, unidad administrativa

\begin{tabular}{|l|l|l|l|}
\multicolumn{1}{c}{$\begin{array}{c}\text { Proceso } \\
\text { administrativo }\end{array}$} & Positivos & \multicolumn{1}{c|}{ Negativos } & \multicolumn{1}{c|}{ Conclusiones } \\
\hline Planeación & 2 & 7 & no hay planes visibles de ningún tipo ( corto, mediano o largo plazo) \\
\hline Organización & 3 & 6 No hay organización de funciones, y líneas de mando. \\
\hline Dirección & 0 & $6 \begin{array}{l}\text { No hay un estilo definido de liderazgo, ni planeación frente al tema. } \\
\text { Existe trabajo en grupo, pero no hay lineamientos claros frente a } \\
\text { competencias frente al equipo de trabajo. }\end{array}$ \\
\hline Coordinación & 1 & $\begin{array}{l}\text { No hay sistemas de información, por ende no hay mecanismo tangible } \\
\text { para hacer seguimiento a los procesos. }\end{array}$ \\
\hline Control & 1 & $\begin{array}{l}\text { No hay indicadores, ni manuales de funciones. Por ende, no hay } \\
\text { lineamientos para la retroalimentación y evaluación. }\end{array}$ \\
\hline Evaluación & 0 & $\begin{array}{l}\text { En términos generales, la situación de la empresa frente al tema } \\
\text { administrativos es desfavorable. Existe la ausencia de una estructura } \\
\text { que permita organizar de forma sistemática los procesos que tiene la } \\
\text { empresa, esto se evidencia por el resultado de la aplicación de la lista } \\
\text { de chequeo. }\end{array}$ \\
\hline $\begin{array}{l}\text { Total } \\
\text { Administrativa }\end{array}$ & &
\end{tabular}

Fuente: Lista de chequeo 7 (administrativa)

\section{Gráfica 14 Análisis de resultados- lista de chequeo administrativa}

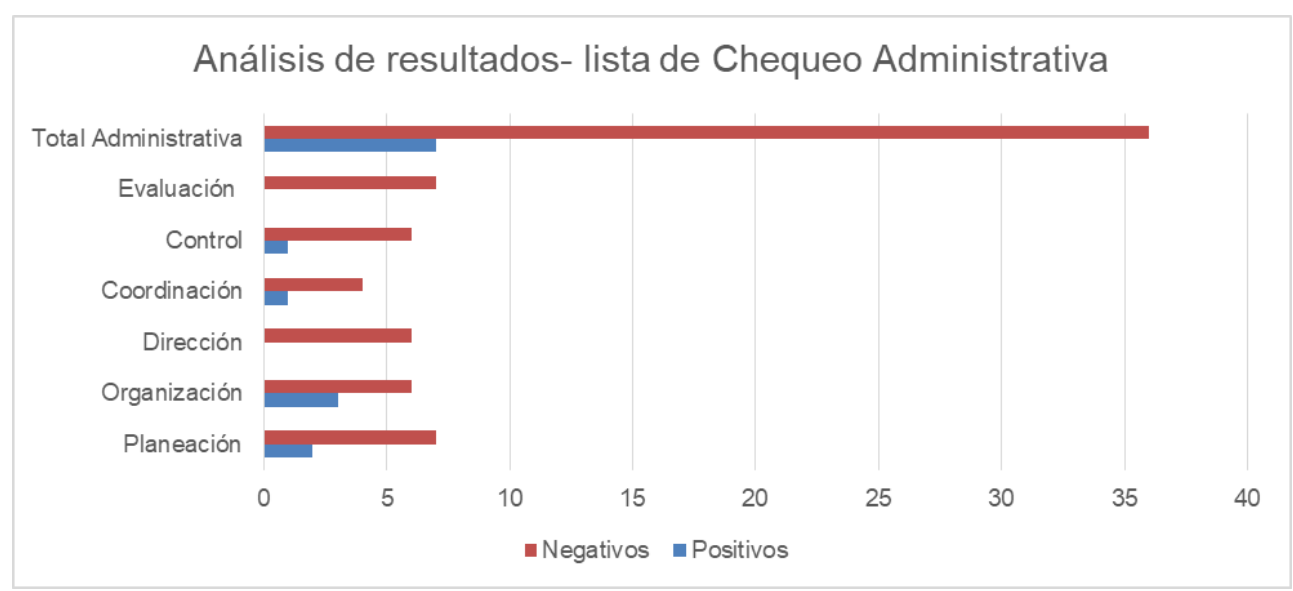

Fuente: Tabla 19 (resultados y conclusiones, unidad administrativa)

En la Tabla 21-Análisis de aspectos administrativos dentro del diagnóstico estratégico de Velerito, se identifican los aspectos encontrados en la lista de chequeo 7 para poder determinar su carácter positivo o negativo en la organización y de paso proponer una acción de cambio que permita fortalecer la unidad administrativa de la empresa. 
Tabla 20 Análisis de aspectos administrativos dentro del diagnóstico estratégico de Velerito.

\begin{tabular}{|c|c|c|c|c|}
\hline $\begin{array}{l}\text { Elemento a } \\
\text { estudiar }\end{array}$ & Situación actual & $\begin{array}{l}\text { Positivo } \\
\text { o } \\
\text { negativo }\end{array}$ & $\begin{array}{l}\text { Quien debe } \\
\text { actuar }\end{array}$ & Acción de solución \\
\hline \multicolumn{5}{|c|}{ ASPECTOS ADMINISTRATIVOS EN EL ÁMBITO DEL PROYECTO } \\
\hline PLANEACIÓN & $\begin{array}{l}\text { No existe una plataforma } \\
\text { estratégica definida, lo } \\
\text { cual implica poca } \\
\text { planeación de los } \\
\text { procesos productivos de } \\
\text { la empresa. } \\
\text { Planeación "en la mente" } \\
\text { del empresario }\end{array}$ & $\mathrm{N}$ & $\begin{array}{l}\text { Empresario } \\
\text { Empresario }\end{array}$ & $\begin{array}{c}\text { Diseñar los objetivos de la organización } \\
\text { para dar inicio a los lineamientos de la } \\
\text { planeación requerida. }\end{array}$ \\
\hline ORGANIZACIÓN & $\begin{array}{l}\text { NO hay un manual de } \\
\text { funciones. } \\
\text { Carencia de reglamentos } \\
\text { al interior de la } \\
\text { organización. } \\
\text { Carencia } \\
\text { organigramas. }\end{array}$ & $\begin{array}{l}\mathrm{N} \\
\mathrm{N} \\
\mathrm{N}\end{array}$ & Empresario & $\begin{array}{l}\text { Definir las funciones y cargos que } \\
\text { componen la cadena de producción }\end{array}$ \\
\hline DIRECCIÓN & $\begin{array}{l}\text { Dirección de tipo } \\
\text { democrático, que facilita } \\
\text { la toma de decisiones de } \\
\text { manera holística. } \\
\text { No hay objetivos claros } \\
\text { en la organización }\end{array}$ & $\mathrm{N}$ & Empresario & $\begin{array}{l}\text { Fortalecer todas las áreas productivas de } \\
\text { la empresa a partir de la relación existente } \\
\text { con el recurso humano }\end{array}$ \\
\hline CONTROL & $\begin{array}{l}\text { Falta de registros físicos } \\
\text { y contables. }\end{array}$ & $\mathrm{N}$ & Empresarios & $\begin{array}{l}\text { Desarrollar herramientas de registro que } \\
\text { permitan llevar control de las actividades } \\
\text { de la empresa. }\end{array}$ \\
\hline EVALUACIÓN & $\begin{array}{l}\text { No existen indicadores } \\
\text { de evaluación de los } \\
\text { procesos } \\
\text { No hay procesos de } \\
\text { peritaje durante las } \\
\text { actividades internas. }\end{array}$ & $\mathrm{N}$ & $\begin{array}{l}\text { Empresario } \\
\text { Empresario }\end{array}$ & $\begin{array}{l}\text { Al interior de los procesos que conforman } \\
\text { la organización desarrollar indicadores } \\
\text { que permitan medir de manera constante } \\
\text { la evolución de los procesos operativos, } \\
\text { así como la gestión administrativa de la } \\
\text { compañía. }\end{array}$ \\
\hline
\end{tabular}

Fuente: tabla 19(resultados y conclusiones)

Para concluir, en términos de diagnóstico administrativo, se indica que la empresa objeto de estudio carece de una alineación de procesos, implicando la digitalización y sistematización de la información; es decir, que no hay una estructura que permita planificar, direccionar, coordinar, evaluar y controlar de manera eficaz la cadena de valor de la compañía, lo cual implica el hallazgo de múltiples anomalías en las listas de chequeo y que ponen en peligro la supervivencia de la empresa en el sector textil -confección en el corto plazo. 
Tabla 21 Análisis de ASPECTOS SOCIALES dentro de un Diagnóstico Estratégico

\begin{tabular}{ccc}
\hline Elemento a estudiar & \multicolumn{1}{c}{ Situación actual } & $\begin{array}{c}\text { Positivo o } \\
\text { negativo }\end{array}$ \\
ASPECTOS SOCIALES A NIVEL MACRO & $\mathrm{N}$ \\
INDICES DE DESARROLLO & $\begin{array}{l}\text { Coeficiente de GINI del 0,539 } \\
\text { Índice de pobreza extrema 20,2\%; Ingreso per } \\
\text { cápita 5, 400 USD; Índice de desarrollo humano } \\
\text { para el 2017 fue de 0,72. } \\
\text { (El tiempo, 2017) }\end{array}$ \\
& $\begin{array}{l}\text { Población bajo la línea de pobreza: 37.2\% } \\
\text { Esperanza de Vida: 74.79 años }\end{array}$ & P \\
EMPLEO U OCUPACIÓN & $\begin{array}{l}\text { La cadena textil- confección genera cerca de 600 } \\
\text { empleos, es decir que es el cuarto sector que más } \\
\text { genera empleos en el país. Datos para el 2017 }\end{array}$ \\
\hline
\end{tabular}

Fuente: Elaboración propia

Tabla 22 Matriz - Si crea empresa

\begin{tabular}{|c|c|c|c|c|}
\hline Elemento a Estudiar & Situación Actual & $\begin{array}{c}\text { Positivo o } \\
\text { Negativo }\end{array}$ & $\begin{array}{l}\text { Quien debe } \\
\text { actuar }\end{array}$ & Acción de Solución \\
\hline $\begin{array}{c}\text { ANTECEDENTES } \\
\text { (Aspectos del ayer que } \\
\text { influyen hoy) }\end{array}$ & $\begin{array}{l}\text { Carencia de formación } \\
\text { administrativa lo cual impacta en } \\
\text { la poca planificación que se tiene } \\
\text { por parte del empresario para } \\
\text { desarrollar un sistema que genera } \\
\text { más valor para el mercado } \\
\text { mayorista en el que compite. } \\
\text { Poca inversión en tecnología, que } \\
\text { va desde maquinaria especializada } \\
\text { para potencializar por ejemplo del } \\
\text { área de estampación, hasta un } \\
\text { sistema que permita llevar control } \\
\text { del inventario y por ende, un } \\
\text { sistema de control que permita } \\
\text { recolectar información pertinente } \\
\text { para la toma de decisiones, sobre } \\
\text { todo las que corresponden a la } \\
\text { compra. }\end{array}$ & $\mathrm{N}$ & & \\
\hline \multicolumn{5}{|c|}{ ASPECTOS EXTERNOS (Fuera del límite del sistema) } \\
\hline \multirow[t]{2}{*}{ Internacionales } & $\begin{array}{l}\text { Tipo de cambio y la entrada de } \\
\text { contrabando y productos textiles } \\
\text { del Asia, son en una gran } \\
\text { perspectiva las variables más } \\
\text { preocupantes para el desarrollo y } \\
\text { crecimiento de toda la cadena }\end{array}$ & $\mathrm{N}$ & Empresario & $\begin{array}{l}\text { Enfatizar en la creación de } \\
\text { valor. }\end{array}$ \\
\hline & $\begin{array}{l}\text { textil-confección en Colombia. } \\
\text { Barreras arancelarias en } \\
\text { concordancias con los programas } \\
\text { de fortalecimiento del gobierno }\end{array}$ & $\mathrm{N}$ & & $\begin{array}{l}\text { Estruturar politicas } \\
\text { comerciales que se ajuste a lá } \\
\text { realidad del escenario } \\
\text { econômico que se dispone, en } \\
\text { este caso el de la cadena têxtil- }\end{array}$ \\
\hline
\end{tabular}




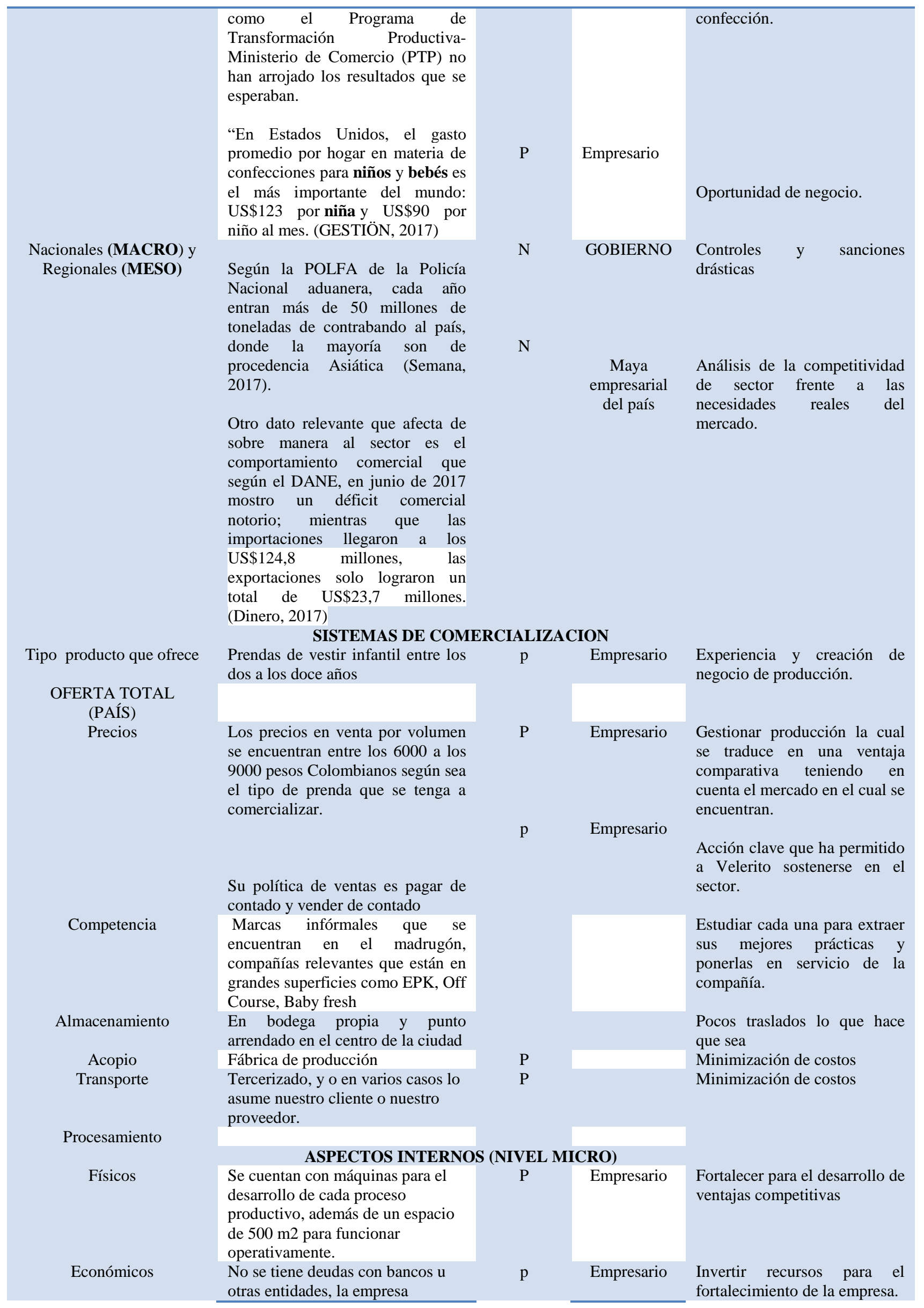


funciona con sus propios recursos.

Humanos Se cuenta con un equipo de trabajo

que solo cumple sus funciones

$\mathrm{P}$

Empresario

Gestionar el conocimiento y

habilidades del recurso operativas

humano con el que se cuenta.

Fuente: Elaboración propia 


\section{Conclusión de diagnóstico}

Dentro de las conclusiones generales del proceso de diagnóstico se establece que son más las debilidades que presenta la empresa frente a las fortalezas encontradas, esto se observa en la gráfica 15 (comparativo general de fortalezas y debilidades de velerito). También se evidencia que la temática administrativa y de mercadeo son las que más dificultades presentan frente a los demás ítems evaluados.

\section{Gráfica 15 Comparativo general de fortalezas y debilidades de Velerito.}

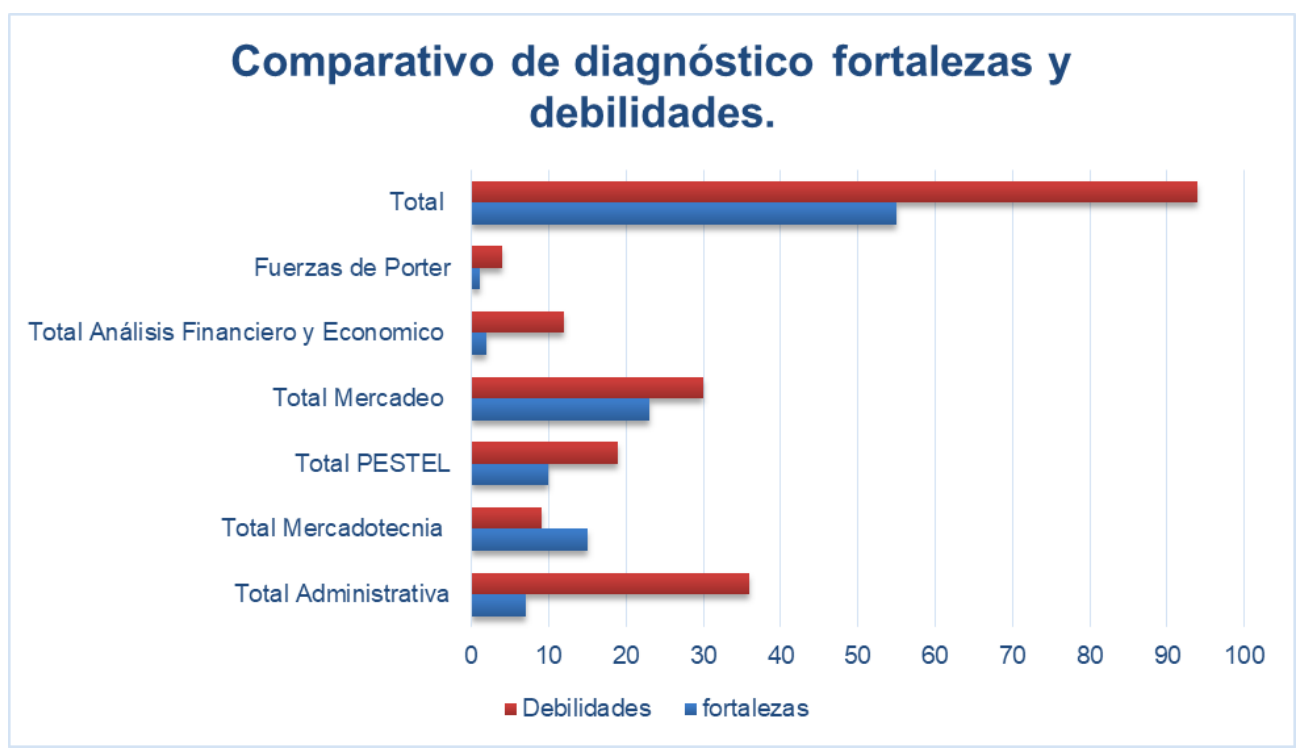

Fuente: Listas de chequeo, y tablas que configuran el capítulo 1 (diagnóstico).

Luego de la aplicación de las herramientas descritas en la parte metodológica para la elaboración del diagnóstico de la empresa objeto de estudio, se extrajeron diferentes conclusiones específicas, las cuales configuran el escenario general establecido en la gráfica 13(comparativo general de fortalezas y debilidades de Velerito). Dichas conclusiones específicas serán utilizadas como insumo principal para el desarrollo de la matriz DOFA.

La tabla 23 -Conclusiones de Diagnóstico, será distribuida en debilidades, fortalezas, amenazas y oportunidades en la matriz DOFA, de forma se pueda seguir la hoja de ruta demarcada en la metodología para el cumplimiento de los objetivos establecidos para este ejercicio académico. El criterio establecido para direccionar las conclusiones obtenidas será definir a qué tipo de entorno pertenece, es decir interno o externo. 
Tabla 23 Conclusiones de diagnóstico.

Listado de conclusiones

\begin{tabular}{|c|c|}
\hline Conclusiones & $\begin{array}{l}\text { Tipo } \\
\text { entorno }\end{array}$ \\
\hline - Experiencia en el mercado, (12 años) & Internas \\
\hline - Conocimiento técnico de fabricación y uso de prendas en tejido de punto. & Internas \\
\hline - Bajos niveles de endeudamiento. & Internas \\
\hline - Infraestructura & Internas \\
\hline - Segmentación media & Internas \\
\hline - Alta liquidez, política de venta y compra sana. & Internas \\
\hline Buenas relaciones con bancos. & Internas \\
\hline Carencia de planes visibles en cuanto a mercado, & Internas \\
\hline Carencia de sistemas de información de los procesos que configuran a Velerito, & Internas \\
\hline Carencia de manuales de funciones & Internas \\
\hline No hay un plataforma estratégica definida & Internas \\
\hline Carencia de estrategias claras y medibles (Ventas, Producción, mercadeo) & Internas \\
\hline Carencia de innovación. & Internas \\
\hline Bajo nivel de rotación de inventarios, en contraste con caída de ventas. & Internas \\
\hline No hay marca o manejo de ella como tal. & Internas \\
\hline Carencia de infraestructura tecnológica de punta & Internas \\
\hline Desconocimiento del sector y de sus competidores por parta de la empresa. & Internas \\
\hline carencia de una plataforma estratégica & Internas \\
\hline $\begin{array}{l}\text { Carencia de elementos que conforman el ejercicio organizacional de una compañía } \\
\text { (departamentos, jerarquías) }\end{array}$ & Internas \\
\hline Carencia de control presupuestal. & Internas \\
\hline Carencia de mecanismos de evaluación e indicadores de gestión. & Internas \\
\hline Carencia de un reglamento interno físico de fácil comunicación al interior de la empresa. & Internas \\
\hline - Precio de los insumos & Externas \\
\hline $\begin{array}{l}\text {-Debido al pequeño tamaño de la organización en cuanto a personal es posible que existe una } \\
\text { adaptación al cambio rápida y eficiente. }\end{array}$ & Externas \\
\hline - Integración con proveedores de alto nivel de innovación. & Externas \\
\hline - Mano de obra barata & Externas \\
\hline - Ferias y eventos para la generación de vínculos comerciales. & Externas \\
\hline $\begin{array}{l}\text { Adhesión del sector textil por parte del gobierno al sector textil al Programa de } \\
\text { Transformación. }\end{array}$ & Externas \\
\hline Incentivos tributarios a pequeñas y nuevas empresas. & Externas \\
\hline La plaza donde Velerito comercializa sus productos. & Externas \\
\hline - Carencia de personas con habilidades técnicas en este sector industrial & Externas \\
\hline
\end{tabular}


- Precios de los insumos
-Problemas en el Erario público, lo cual ocasiona aumento de impuestos que afectan directamente el desarrollo del comercio, en este caso el sector textil.

- Competencia desleal

- Contrabando

La inestabilidad del sector textil evidenciado su poco crecimiento en el PIB de manufacturas en los últimos años
Externas

Externas

Externas

Externas

Externas

Fuente: Resultados del diagnóstico de fortalecimiento empresarial.

El diagnóstico efectuado a la empresa Velerito desde la perspectiva holística y sistémica dentro del entorno interno y externo observando todas las áreas de la empresa, se da por cumplido es decir que se logra alcanzar el primer objetivo específico de este ejercicio de fortalecimiento, por consiguiente, se procede a canalizar la información denotada para definir las debilidades, oportunidades, amenazas y fortalezas que Velerito presenta. Para esto se utilizará la matriz DOFA, la cual permitirá llevar a cabo la definición de los puntos más importantes encontrados en el diagnóstico realizado anteriormente. 


\section{Capítulo 3- Priorización e Identificación de la Problemática a Solucionar.}

De acuerdo con la hoja de ruta establecida en la parte metodológica, se procede a aplicar los pasos establecidos para el cumplimiento del objetivo número dos (priorizar e identificar la problemática a solucionar). La herramienta DOFA la cual es una abreviación de los términos debilidades, oportunidades, fortalezas y amenazas, es una herramienta que ayuda a la consolidación de información identificada en el proceso de diagnóstico, con el fin de ayudar en el desarrollo de estrategias a partir del mapeo global de la empresa. Dentro de esta matriz confluyen elementos de todas las áreas de la empresa (económico, estratégico, administrativo, etc.) (Gómez, Gerencia estrategica, 1994), lo cual es coherente con la metodología holística y sistémica establecida al inicio del documento.

\subsection{Matriz DAFO}

Teniendo en cuenta el estudio realizado, se llevó a cabo la materialización de la matriz DOFA, presentada a continuación... 
Tabla 24 Matriz DAFO- Velerito

\begin{tabular}{|c|c|c|}
\hline & $\begin{array}{l}\text { Fortalezas } \\
\text { - Experiencia en el mercado, (16 años) } \\
\text { - Conocimiento técnico de fabricación y } \\
\text { uso de prendas en tejido de punto. } \\
\text { - Bajos niveles de endeudamiento. } \\
\text { - Infraestructura } \\
\text { - Segmentación media } \\
\text { - Alta liquidez, política de venta y } \\
\text { compra sana. } \\
\text {-Buenas relaciones con bancos. }\end{array}$ & $\begin{array}{l}\text { Debilidades } \\
\text { Carencia de planes visibles en cuanto a mercado. } \\
\text { Carencia de sistemas de información de los procesos que configuran a Velerito. } \\
\text { Carencia de manuales de funciones. } \\
\text { No hay una plataforma estratégica definida. } \\
\text { Carencia de estrategias claras y medibles (Ventas, Producción, mercadeo). } \\
\text { Carencia de innovación. } \\
\text { No hay marca o manejo de ella como tal. } \\
\text { Carencia de infraestructura tecnológica de punta } \\
\text { de rotación de inventarios, en contraste con caída de ventas. } \\
\text { Desconocimiento del sector y de sus competidores por parta de la empresa. } \\
\text { Carencia de una plataforma estratégica } \\
\text { Carencia de elementos que conforman el ejercicio organizacional de una compañía (departamentos, } \\
\text { jerarquías) } \\
\text { Carencia de control presupuestal. } \\
\text { Carencia de mecanismos de evaluación e indicadores de gestión. } \\
\text { Carencia de un reglamento interno físico de fácil comunicación al interior de la empresa. } \\
\text { Desorden de información. } \\
\text { Desconociendo de la competencia. } \\
\text { Carencia de recursos metodológicos en las áreas de gerencia. }\end{array}$ \\
\hline $\begin{array}{l}\text { Oportunidades } \\
\text { - Precio de los insumos } \\
\text {-Debido al pequeño tamaño de la } \\
\text { organización en cuanto a personal es } \\
\text { posible que existe una adaptación al cambio } \\
\text { rápida y eficiente. } \\
\text { - Integración con proveedores de alto nivel } \\
\text { de innovación. } \\
\text { - Mano de obra barata } \\
\text { - Ferias y eventos para la generación de } \\
\text { vínculos comerciales. } \\
\text { - Adhesión del sector textil por parte del } \\
\text { gobierno al sector textil al Programa } \\
\text { de Transformación. } \\
\text { - Incentivos tributarios a pequeñas y } \\
\text { nuevas empresas. } \\
\text { La plaza donde Velerito comercializa } \\
\text { sus productos. }\end{array}$ & $\begin{array}{l}\text { FO } \\
\text { - Potencializar el conocimiento técnico } \\
\text { de la empresa por medio de los aliados } \\
\text { estratégicos } \\
\text { - Renovación tecnología a partir del } \\
\text { esquema productivo de la empresa. } \\
\text { - Dar un mejor uso la infraestructura que } \\
\text { se tiene a partir de la integración con } \\
\text { proveedores estratégicos. }\end{array}$ & $\begin{array}{l}\text { DO } \\
\text { - Aprovechar la integración existente con los proveedores para mejorar y diseñar los procesos de } \\
\text { innovación. } \\
\text { - Enfatizar en las estrategias de compras teniendo en cuenta los precios internacionales de los insumos a } \\
\text { usar. }\end{array}$ \\
\hline
\end{tabular}




\section{Amenazas}

- Carencia de personas con habilidades

técnicas en este sector industrial

- Precios de los insumos

-Problemas en el heraldo público, lo cual

desiona aumento de impuestos que afectan calidad y eficiencia de los procesos

directamente el desarrollo del comercio, en productivos que desarrollamos.

este caso el sector textil.

- Competencia desleal

- Contrabando

- La inestabilidad del sector textil

evidenciado su poco crecimiento en el PIB

- Hacer frente al contrabando por medio

de la calidad y la experiencia del sector.

- Afianzar el conocimiento técnicos que

se tienen para innovar dentro del

de manufacturas en los últimos años

Política de ventas de contado sana, lo

cual le permite tener un nivel de liquidez 


\subsection{Priorización de debilidades}

Posterior a la extracción de la lista de debilidades encontradas en la tabla DOFA, y según con lo establecido en la metodología de fortalecimiento, se procedió al ejercicio de priorización de debilidades a partir del sistema democrático, por medio del cual los fundadores de la empresa votaron y seleccionaron para determinar el orden de las debilidades a fortalecer. Está votación se estableció bajo el criterio de la experiencia de los fundadores frente a su empresa y sector, y al previo conocimiento de los resultados que arrojó el diagnóstico denotado en la capitulo1 de este documento. Además, mencionar que el propósito de este ejercicio es encontrar una acción transversal que nos permita dar un cambio general a toda la compañía. Todo lo anterior se verá en la tabla 25 (Resultados de la aplicación del proceso democrático para el ordenamiento de debilidades para priorización).

Tabla 25 Resultados de la aplicación del proceso democrático para el ordenamiento de debilidades encontradas.

\begin{tabular}{|c|c|c|c|c|}
\hline Columna1 & Debilidades & Votos por debilidad & Porcentaje & Puesto \\
\hline 1 & Carencia de planeación frente al mercado, & 4 & $6 \%$ & 9 \\
\hline 2 & $\begin{array}{l}\text { Carencia de sistemas de información de los } \\
\text { procesos que configuran a Velerito, }\end{array}$ & 8 & $13 \%$ & 2 \\
\hline 3 & Carencia de manuales de funciones & 4 & $6 \%$ & 10 \\
\hline 4 & $\begin{array}{l}\text { Carencia de una estructura administrativa } \\
\text { definida }\end{array}$ & 9 & $14 \%$ & 1 \\
\hline 5 & $\begin{array}{l}\text { Carencia de estrategias claras y medibles } \\
\text { (Ventas, Producción, mercadeo) }\end{array}$ & 7 & $11 \%$ & 3 \\
\hline 6 & Carencia de innovación. & 2 & $3 \%$ & 12 \\
\hline 7 & No hay marca o manejo de ella como tal. & 4 & $6 \%$ & 8 \\
\hline 8 & Carencia de infraestructura tecnológica de punta & 4 & $6 \%$ & 7 \\
\hline 9 & $\begin{array}{l}\text { Desconocimiento del sector y de sus } \\
\text { competidores por parta de la empresa. }\end{array}$ & 3 & $5 \%$ & 11 \\
\hline 10 & $\begin{array}{l}\text { Carencia de elementos que conforman el } \\
\text { ejercicio organizacional de una compañía ( } \\
\text { departamentos, jerarquías) }\end{array}$ & 5 & $8 \%$ & 5 \\
\hline 11 & Carencia de control presupuestal. & 2 & $3 \%$ & 13 \\
\hline 12 & $\begin{array}{l}\text { Carencia de mecanismos de evaluación e } \\
\text { indicadores de gestión. }\end{array}$ & 7 & $11 \%$ & 4 \\
\hline 13 & $\begin{array}{l}\text { Carencia de un reglamento interno físico de } \\
\text { fácil comunicación al interior de la empresa. }\end{array}$ & 4 & $6 \%$ & 6 \\
\hline 14 & $\begin{array}{l}\text { Bajo nivel de rotación de inventarios, en } \\
\text { contraste con caída de ventas. }\end{array}$ & 1 & $2 \%$ & 14 \\
\hline
\end{tabular}

Total 
Luego de los resultados obtenidos en el proceso de votación por parte de los dueños de la empresa y sugerido como método de priorización de debilidades en la metodología de fortalecimiento aplicada, se prosiguió al ordenamiento de la información a partir del principio de Pareto. Según la tabla 26 (Priorización de debilidades) los demarcados de color amarillo son el $80 \%$ de los problemas registrados en el ejercicio de diagnóstico, y en orden de priorización son los que tienen más urgencia de ser atendidos dado su nivel de concentración. Para confirmar los datos determinados en la tabla 26, se elabora un diagrama de Pareto para detectar los problemas que más relevancia tiene la compañía. Está metodología establece en una gráfica la clasificación de datos por orden descendente. Luego de la aplicación del diagrama de Pareto, se podrá llevar a cabo el desarrollo del esquema espina de pescado para focalizar y decantar el problema clave, y poder concluir el proceso de priorización, cumpliendo el segundo objetivo específico de este ejercicio de fortalecimiento empresarial.

\section{Tabla 26 Priorización de debilidades}

\begin{tabular}{|c|c|c|c|}
\hline Debilidades & Porcentaje & Puesto & $\begin{array}{l}\text { Acumula } \\
\text { do }\end{array}$ \\
\hline Carencia de una estructura administrativa definida & $14 \%$ & 1 & $14 \%$ \\
\hline Carencia de sistemas de información de los procesos que configuran a Velerito, & $13 \%$ & 2 & $27 \%$ \\
\hline Carencia de estrategias claras y medibles (Ventas, Producción, mercadeo) & $11 \%$ & 3 & $38 \%$ \\
\hline Carencia de mecanismos de evaluación e indicadores de gestión. & $11 \%$ & 4 & $48 \%$ \\
\hline $\begin{array}{l}\text { Carencia de elementos que conforman el ejercicio organizacional de una compañía ( } \\
\text { departamentos, jerarquías) }\end{array}$ & $8 \%$ & 5 & $56 \%$ \\
\hline Carencia de un reglamento interno físico de fácil comunicación al interior de la empresa. & $6 \%$ & 6 & $63 \%$ \\
\hline Carencia de infraestructura tecnológica de punta & $6 \%$ & 7 & $69 \%$ \\
\hline No hay marca o manejo de ella como tal. & $6 \%$ & 8 & $75 \%$ \\
\hline Carencia de planeación frente al mercado, & $6 \%$ & 9 & $81 \%$ \\
\hline Carencia de manuales de funciones & $6 \%$ & 10 & $88 \%$ \\
\hline Desconocimiento del sector y de sus competidores por parta de la empresa. & $5 \%$ & 11 & $92 \%$ \\
\hline Carencia de innovación. & $3 \%$ & 12 & $95 \%$ \\
\hline Carencia de control presupuestal. & $3 \%$ & 13 & $98 \%$ \\
\hline - Bajo nivel de rotación de inventarios, en contraste con caída de ventas. & $2 \%$ & 14 & $100 \%$ \\
\hline
\end{tabular}

Fuente: Elaboración Propia 


\subsection{Diagrama de Pareto}

Este diagrama tiene por finalidad mostrar de forma gráfica el resultado de la priorización de las debilidades extraídas para determinar cuál es la de mayor importancia y así establecer la condensación de la problemática a resolver (Murcia, 2014).

\section{Gráfica 16 Diagrama de Pareto}

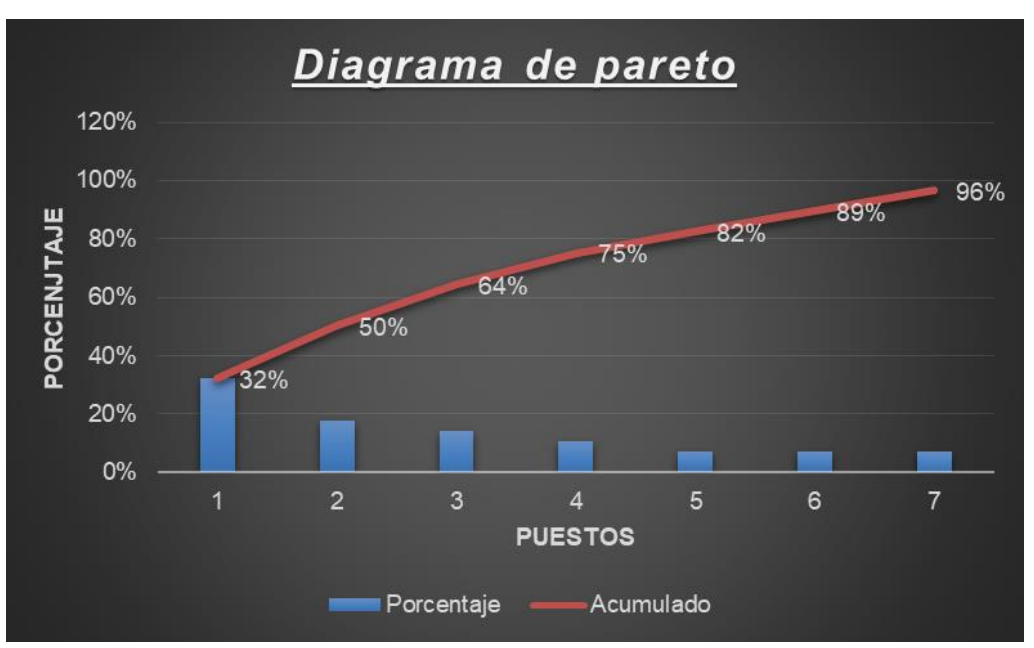

Fuente: Elaboración propia

Como resultante de la priorización de debilidades, se extrajeron los 6 puntos débiles más preponderantes dentro del desarrollo de la matriz DOFA, para usarlos como insumos principales en la definición del problema transversal que es susceptible de mejoramiento por parte de la empresa.

De acuerdo a la metodología establecida se procedió al desarrollo del diagrama de espina de pescado, como herramienta idónea para la configuración final del problema. Esta herramienta, como se indica en la tabla 3 (esquema metodológico) se utiliza para mostrar dinámicas de causa y efecto de manera lógica que permita establecer relaciones racionales. 
10.4 Diagrama Espina de Pescado

Gráfica 17 Diagrama " Espina de Pescado"

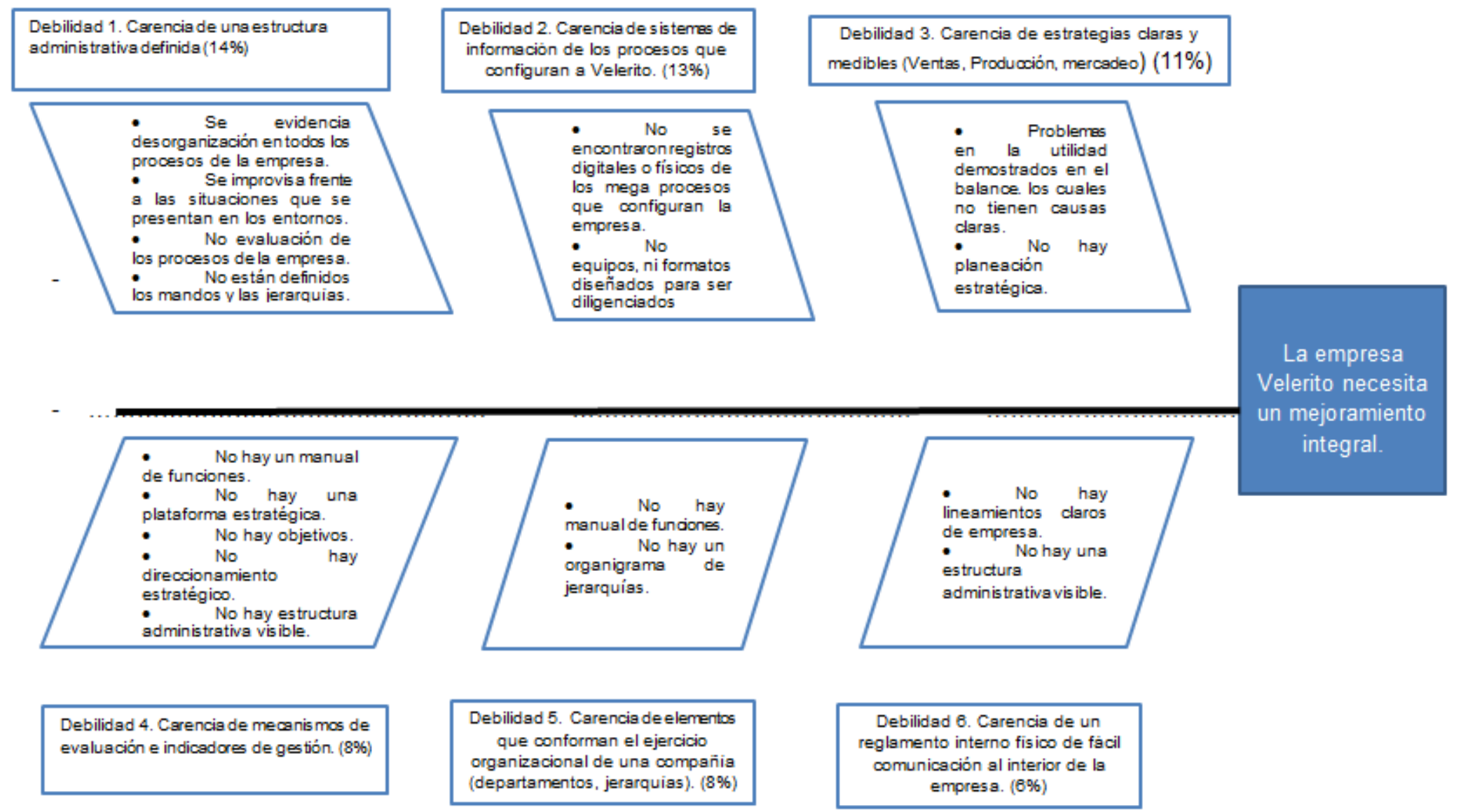

Fuente: Elaboración propia 
Tabla 27 Diagrama como- como de Velerito

\begin{tabular}{|c|c|c|}
\hline & Organizar los procesos de la empresa & $\begin{array}{l}\text { - Contratar a personal capacitado para organizar, y estructurar el ordenamiento de los } \\
\text { procesos de la empresa. } \\
\text { - Establecer el direccionamiento estratégico de la empresa. } \\
\text { - Determinar las actividades que se realizan al interior de la organización. } \\
\text { - Alinear las actividades que la empresa ejecuta con el direccionamiento estratégico } \\
\text { establecido. }\end{array}$ \\
\hline \multirow[t]{3}{*}{$\begin{array}{l}\text { Definir una } \\
\text { estructura } \\
\text { administrativa. }\end{array}$} & $\begin{array}{l}\text { Establecer una planeación que sea } \\
\text { adapte a las situaciones del entorno. }\end{array}$ & $\begin{array}{l}\text { - Definir los objetivos de la empresa en el corto, mediano y largo plazo } \\
\quad \text { Planificar las actividades diarias, semanales y } \\
\text { - Control y verificación del cumplimiento de las actividades. }\end{array}$ \\
\hline & Evaluar los procesos de la empresa & $\begin{array}{l}\text { - Diseño de indicadores para cada uno de los procesos de la empresa. } \\
\text { - Diseño de formatos para registro de información relevante en cada una de las } \\
\text { unidades de la empresa. } \\
\text { - Procesamiento de la información extraída. ( informe) }\end{array}$ \\
\hline & $\begin{array}{l}\text { Establecer el organigrama de la } \\
\text { empresa. }\end{array}$ & $\begin{array}{l}\text { - Establecer las actividades que se realizan al interior de la organización. } \\
\text { - Agruparlos según el tipo de proceso que representan para la empresa. } \\
\text { - Delimitar las líneas de mando. } \\
\text { - Establecer cargos y funciones (manual de funciones). }\end{array}$ \\
\hline
\end{tabular}

Fuente: (Murcia H. H., 2014) 
Este diagrama fue elaborado a partir de la debilidad, que en el proceso de calificación tuvo la valuación más alta, con el fin de establecer los mecanismos de acción convenientes para hacer del cambio una realidad en la empresa. Es importante mencionar que las actividades que se desprendieron de este diagrama, son la base para el desarrollo del cronograma mediante el cual se darán tiempos, responsables y recursos necesarios para establecer los cambios que la propuesta de este ejercicio establezca.

\subsection{Formulación del problema}

Dentro del análisis causa- efecto como se observó en la gráfica 17 (Diagrama " Espina de Pescado") se indica ahí la necesidad de una estructura administrativa capaz de organizar, sistematizar y digitalizar la información que la empresa contiene para fortalecer la toma de decisiones y, por ende, su gestión productiva.

Como se puede observar, se ratifica que la unidad administrativa presenta la mayor cantidad de debilidades referente a las otras listas de chequeo aplicadas al resto de la empresa. De esta forma se da por cumplido el segundo objetivo específico, establecido para este fortalecimiento empresarial. 


\section{Capítulo 4- Diseño De Propuesta}

Dando al cumplimiento al tercer objetivo específico de este ejercicio se da inicio a la propuesta. De esta forma se seguirá la hoja de ruta descrita en el apartado metodológico de este documento.

\subsection{Problemática a solucionar}

Necesidad de una estructura administrativa que permita direccionar estratégicamente la empresa Velerito.

\subsubsection{Cambio esperado}

Delinear la estructura administrativa que requiere Velerito para gestionar mejor sus recursos y fortalecer la toma de decisiones.

Dentro de la configuración de la propuesta, es fundamental detallar cómo se logrará alcanzar el cambio esperado que la empresa necesita. Para esto se aplicarán las técnicas y los procesos descritos en el apartado de la metodología. Razón a esto se iniciará por determinar la ubicación del cambio esperado a partir del mapa de procesos diseñado en la descripción y presentación de la compañía (Gutiérrez, 2001).

\section{Gráfica 18 Mapa de procesos (propuesta)}

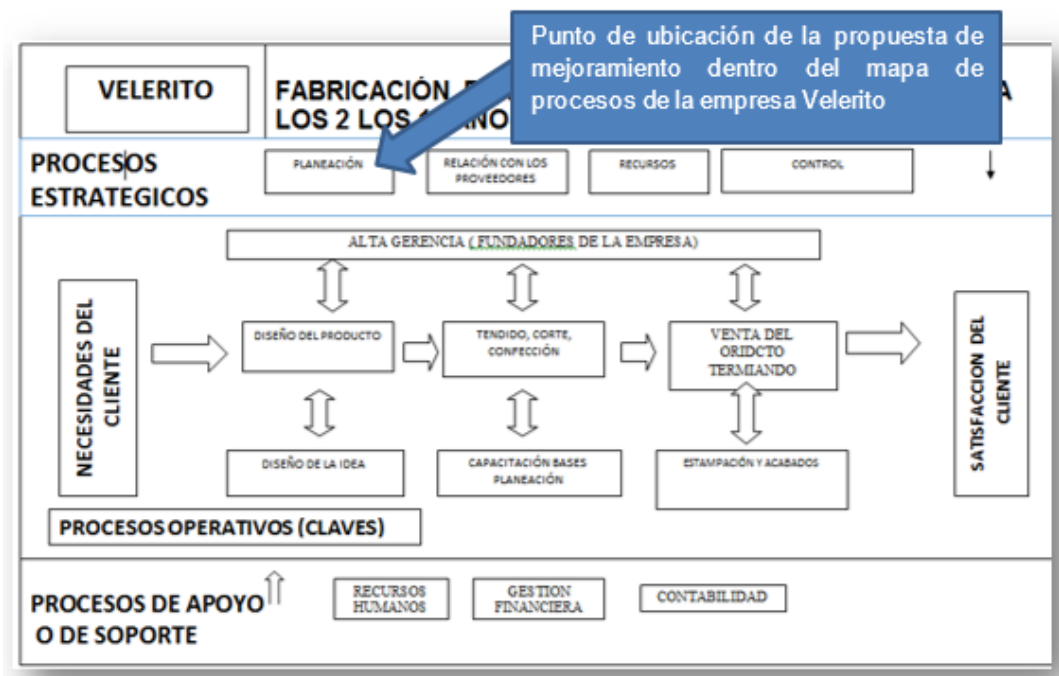

Fuente: (Garzón, 2017) 
Esta ubicación permite comprender que el cambio esperado radica principalmente en la formalización de un intangible que genera y propicia la creación de valor al interior de la empresa. Puesto que la planeación es la cabeza de los procesos administrativos que proporciona a las empresas ventajas competitivas, y que hacen única a una empresa en el sector donde se encuentre.

La planeación, como la capacidad que tienen las empresas de anticipar el futuro, por ende, de estimular la toma de decisiones a partir del estudio de contextos, de entornos, de posibilidades reales que permiten al estratega utilizar los recursos que dispone de manera lógica y sincronizada con las tendencias que pueden afectar el alcance de los objetivos empresariales de la organización. Es por esto que está herramienta es vital para la construcción de la sostenibilidad de cualquier organización que aspire a posicionarse en el mercado. (Shapiro, 1993).

Por último, evidenciar que establecida la ubicación del cambio dentro de los mega procesos de la compañía, se dar por sentado el cumplimiento del objetivo general de este trabajo, puesto que a partir del desarrollo del estudio metodológico que para este caso fue de fortalecimiento empresarial, se logró determinar áreas de mejoramiento al interior de la empresa Velerito.

Dentro del análisis que se realizó en el capítulo 2, más específicamente en el diagrama de cómo- cómo, se desprendieron actividades que tiene por fin, el darle solución a la problemática que se evidencio en el diagrama de Pareto. De acuerdo con el ejercicio descrito anteriormente, se quiso fortalecer la técnica de cómo- cómo a partir de la extracción de las debilidades encontradas en la lista de chequeo administrativa, y su depuración desde el cambio que supone la mejora que se debe hacer. A continuación en la tabla 28 se procesará de forma ordenada los cambios de los problemas que la lista de chequeo evidencio, y que se transformarán en un producto que pueda fortalecer la creación del área administrativa que la empresa necesita para su sostenibilidad.

Tabla 28 Tabla comparativa (debilidades administrativas frente a cambios y productos)

Debilidades de la unidad Cambio $\quad$ Producto Alcance
administrativa
$\begin{aligned} & \text { Se estipula que son debilidades, } \\ & \text { debido a que o no existen en la } \\ & \text { compañía de forma visible y } \\ & \text { sistemática. }\end{aligned}$
PLANEACIÓN




\begin{tabular}{|c|c|c|c|}
\hline $\begin{array}{l}\text { 2. Planes a largo plazo (de tres a diez } \\
\text { años, por ejemplo) }\end{array}$ & $\begin{array}{l}\text { Desarrollar direccionamiento de } \\
\text { la empresa }\end{array}$ & $\begin{array}{l}\text { Creación de visión, misión, } \\
\text { objetivos de la compañía, } \\
\text { valores, etc. }\end{array}$ & $\begin{array}{l}\text { Todos los megos procesos de la } \\
\text { empresa. }\end{array}$ \\
\hline $\begin{array}{l}\text { 3. Planes a mediano Plazo (uno a tres } \\
\text { años) }\end{array}$ & $\begin{array}{l}\text { Desarrollar direccionamiento de } \\
\text { la empresa }\end{array}$ & $\begin{array}{l}\text { Creación de visión, misión, } \\
\text { objetivos de la compañía, } \\
\text { valores, etc. }\end{array}$ & $\begin{array}{l}\text { Todos los megos procesos de la } \\
\text { empresa. }\end{array}$ \\
\hline $\begin{array}{l}\text { 4. Planes a corto plazo (menos de un } \\
\text { año) }\end{array}$ & $\begin{array}{l}\text { Planificar actividades a ejecutar } \\
\text { para el fortalecimiento } \\
\text { empresarial de Velerito }\end{array}$ & $\begin{array}{l}\text { cronograma de actividades para } \\
\text { el fortalecimiento de empresa }\end{array}$ & $\begin{array}{l}\text { Todos los megos procesos de la } \\
\text { empresa. }\end{array}$ \\
\hline $\begin{array}{l}\text { 7. Asistencia técnica o asesoría para } \\
\text { planeación }\end{array}$ & $\begin{array}{l}\text { Incorporar personal } \\
\text { especializado en el área } \\
\text { administrativa y de planeación. }\end{array}$ & $\begin{array}{l}\text { Contratación de } \\
\text { especializado }\end{array}$ personal & Proceso gerenciales \\
\hline 9. Objetivos y metas definidas & $\begin{array}{l}\text { Desarrollar el direccionamiento } \\
\text { de la empresa }\end{array}$ & $\begin{array}{l}\text { Creación de visión, misión, } \\
\text { objetivos de la compañía, } \\
\text { valores, etc. }\end{array}$ & $\begin{array}{l}\text { Todos los megos procesos de la } \\
\text { empresa. }\end{array}$ \\
\hline ORGANIZACIÓN & & & \\
\hline
\end{tabular}

\begin{tabular}{|c|c|c|c|}
\hline 2. Manuales de funciones & Realizar manual de funciones & Manual de funciones & $\begin{array}{l}\text { Alinear todos los mega procesos } \\
\text { funcionales de la empresa descritos } \\
\text { en la tabla } 4 \text { (mega procesos) }\end{array}$ \\
\hline 3. Distribución de actividades y tareas & Realizar manual de funciones & Manual de funciones & $\begin{array}{l}\text { Alinear todos los mega procesos } \\
\text { funcionales de la empresa descritos } \\
\text { en la tabla } 4 \text { (mega procesos) }\end{array}$ \\
\hline $\begin{array}{l}\text { 4. Elaboración de cronogramas, } \\
\text { calendarios de trabajo }\end{array}$ & $\begin{array}{l}\text { Aplicación del cronograma de } \\
\text { actividades recomendado la } \\
\text { metodología de fortalecimiento } \\
\text { empresarial }\end{array}$ & Formato de cronograma & $\begin{array}{l}\text { Todos los mega procesos de la } \\
\text { empresa. }\end{array}$ \\
\hline 6. Reglamentos de trabajo & $\begin{array}{l}\text { Diseño y adaptación de } \\
\text { reglamento de trabajo }\end{array}$ & Reglamento de trabajo & $\begin{array}{l}\text { Todos los mega procesos de la } \\
\text { empresa. }\end{array}$ \\
\hline $\begin{array}{l}\text { 9. Capacitación o asistencia para } \\
\text { organización }\end{array}$ & $\begin{array}{l}\text { Capacitar para el equipo de } \\
\text { trabajo de alta gerencia. }\end{array}$ & $\begin{array}{l}\text { Vinculación con entidades que } \\
\text { apoyen este ejercicio. ( Cámara } \\
\text { de Comercio de Bogotá, } \\
\text { Ministerio de Comercio } \\
\text { "Procesos de transformación } \\
\text { productiva") }\end{array}$ & Procesos gerenciales. \\
\hline
\end{tabular}




\begin{tabular}{|c|c|c|c|}
\hline 1. Dirección centralizada & $\begin{array}{l}\text { Definir estilo de liderazgo a } \\
\text { partir de la plataforma } \\
\text { estratégica establecida. }\end{array}$ & Estilo de liderazgo & $\begin{array}{l}\text { Todos los mega procesos de la } \\
\text { empresa. }\end{array}$ \\
\hline 2. Dirección participativa & $\begin{array}{l}\text { Definir estilo de liderazgo a } \\
\text { partir de la plataforma } \\
\text { estratégica establecida. }\end{array}$ & Estilo de liderazgo & $\begin{array}{l}\text { Todos los mega procesos de la } \\
\text { empresa. }\end{array}$ \\
\hline $\begin{array}{l}\text { 3. Dirección enfocada hacia las } \\
\text { personas }\end{array}$ & $\begin{array}{l}\text { Definir estilo de liderazgo a } \\
\text { partir de la plataforma } \\
\text { estratégica establecida. }\end{array}$ & Estilo de liderazgo & $\begin{array}{l}\text { Todos los mega procesos de la } \\
\text { empresa. }\end{array}$ \\
\hline $\begin{array}{l}\text { 4. Dirección enfocada en } \\
\text { cumplimiento de planes y programas }\end{array}$ & $\begin{array}{l}\text { Definir estilo de liderazgo a } \\
\text { partir de la plataforma } \\
\text { estratégica establecida. }\end{array}$ & Estilo de liderazgo & $\begin{array}{l}\text { Todos los mega procesos de la } \\
\text { empresa. }\end{array}$ \\
\hline $\begin{array}{l}\text { 5. Capacitación o asistencia para } \\
\text { dirección }\end{array}$ & $\begin{array}{l}\text { Definir estilo de liderazgo a } \\
\text { partir de la plataforma } \\
\text { estratégica establecida. }\end{array}$ & Estilo de liderazgo & $\begin{array}{l}\text { Todos los mega procesos de la } \\
\text { empresa. }\end{array}$ \\
\hline 6. Estilo de liderazgo & $\begin{array}{l}\text { Definir estilo de liderazgo a } \\
\text { partir de la plataforma } \\
\text { estratégica establecida. }\end{array}$ & Estilo de liderazgo & $\begin{array}{l}\text { Todos los mega procesos de la } \\
\text { empresa. }\end{array}$ \\
\hline 7. Conflictos de poder o de mando & $\begin{array}{l}\text { Implementación de reglamento } \\
\text { interno }\end{array}$ & Reglamento de trabajo & $\begin{array}{l}\text { Todos los mega procesos de la } \\
\text { empresa. }\end{array}$ \\
\hline COORDINACION & & & \\
\hline $\begin{array}{l}\text { 1. Definición de competencias o } \\
\text { campos de acción de cada división o } \\
\text { departamento }\end{array}$ & $\begin{array}{lcc}\begin{array}{l}\text { Diseñar } \\
\text { jerarquía }\end{array} & \begin{array}{c}\text { organigrama } \\
\text { empresarial }\end{array} & \text { de } \\
\text { velerito. } & & \end{array}$ & Organigrama & Procesos gerenciales. \\
\hline $\begin{array}{l}\text { 2. Integración de competencias o } \\
\text { campos de acción }\end{array}$ & $\begin{array}{l}\text { Implementación de la estructura } \\
\text { empresarial desarrollada por la } \\
\text { parte gerencial y administrativa } \\
\text { de la empresa. }\end{array}$ & Control & $\begin{array}{l}\text { Procesos gerenciales } \\
\text { administrativos }\end{array}$ \\
\hline $\begin{array}{l}\text { 4. Mecanismos para coordinación y } \\
\text { programación de actividades }\end{array}$ & $\begin{array}{l}\text { Implementación de la estructura } \\
\text { empresarial desarrollada por la } \\
\text { parte gerencial y administrativa } \\
\text { de la empresa. }\end{array}$ & Control & $\begin{array}{l}\text { Procesos gerenciales } \\
\text { administrativos }\end{array}$ \\
\hline
\end{tabular}




\begin{tabular}{|c|c|c|c|}
\hline 1. Existencia de registros físicos & $\begin{array}{l}\text { Diseñar de plantillas para el } \\
\text { registro físico de información de } \\
\text { los procesos que configuran la } \\
\text { organización. }\end{array}$ & Plantilla de registro & $\begin{array}{l}\text { Todos los mega procesos de la } \\
\text { empresa. }\end{array}$ \\
\hline $\begin{array}{l}\text { 6. Control sistematizado de la } \\
\text { empresa (hardware, software) }\end{array}$ & $\begin{array}{l}\text { Configurar un sistema de para el } \\
\text { control las planillas de registro } \\
\text { que se llevarán a cabo. }\end{array}$ & Esquema básico en Excel & Unidad administrativa \\
\hline EVALUACION & & & \\
\hline $\begin{array}{l}\text { 1. Evaluación ex ante (antes de } \\
\text { empezar cualquier proyecto) }\end{array}$ & $\begin{array}{l}\text { Diseñar esquema básico para el } \\
\text { análisis de la información que } \\
\text { requiere el nuevo proyecto. }\end{array}$ & $\begin{array}{l}\text { Esquema básico de análisis de } \\
\text { información. }\end{array}$ & Unidad administrativa \\
\hline $\begin{array}{l}\text { 2. Evaluación en desarrollo } \\
\text { (performance) }\end{array}$ & $\begin{array}{l}\text { Diseñar indicadores de gestión } \\
\text { para las unidades que } \\
\text { configuran la empresa y realizar } \\
\text { supervisión personal }\end{array}$ & $\begin{array}{l}\text { Indicadores de } \\
\text { Implementación del cargo de } \\
\text { supervisión. }\end{array}$ & $\begin{array}{l}\text { Todos los mega procesos de la } \\
\text { empresa. }\end{array}$ \\
\hline 3. Evaluación al finalizar (ex post) & $\begin{array}{l}\text { Diseñar indicadores de gestión } \\
\text { para las unidades que } \\
\text { configuran la empresa y realizar } \\
\text { supervisión personal }\end{array}$ & $\begin{array}{l}\text { Indicadores de } \\
\text { Implementación del cargo de } \\
\text { supervisión. }\end{array}$ & $\begin{array}{l}\text { Todos los mega procesos de la } \\
\text { empresa. }\end{array}$ \\
\hline 4. Mecanismos de seguimiento & $\begin{array}{l}\text { Diseñar indicadores de gestión } \\
\text { para las unidades que } \\
\text { configuran la empresa y realizar } \\
\text { supervisión personal }\end{array}$ & $\begin{array}{l}\text { Indicadores de } \\
\text { Implementación del cargo de } \\
\text { supervisión. }\end{array}$ & $\begin{array}{l}\text { Todos los mega procesos de la } \\
\text { empresa. }\end{array}$ \\
\hline $\begin{array}{l}\text { 7. Capacitación o asistencia para } \\
\text { evaluación }\end{array}$ & $\begin{array}{l}\text { Capacitar el equipo de trabajo } \\
\text { de alta gerencia. }\end{array}$ & $\begin{array}{l}\text { Vinculación con entidades que } \\
\text { apoyen este ejercicio. ( Cámara } \\
\text { de Comercio de Bogotá, } \\
\text { Ministerio de Comercio } \\
\text { "Procesos de transformación } \\
\text { productiva") }\end{array}$ & Procesos gerenciales. \\
\hline
\end{tabular}

Fuente: Lista de Chequeo 7 Administrativo

Como resultantes del ejercicio anterior de la tabla 28, se encuentran la siguiente lista de productos que se necesitan desarrollar para dar cavidad a una estructura administrativa sólida y coherente con el diagnóstico y la priorización anteriormente descritas.

Lista de productos necesarios para la instauración de la estructura administrativa:

$\checkmark$ Plantilla de registro de información. 
$\checkmark$ Manuales de funciones.

$\checkmark$ Creación de la plataforma estratégica de la organización.

$\checkmark$ Vinculación con entidades que propicien la capacitación a las empresas (Cámara de comercio, Ministerio de Comercio, etc.)

$\checkmark$ Diseño de indicadores de gestión.

$\checkmark$ Reglamento de trabajo Definición de estilo de liderazgo.

$\checkmark$ Cronograma de actividades.

$\checkmark$ Organigrama de la empresa.

$\checkmark$ Contratación de personal capacitado en temas administrativos.

El listado de productos anteriormente descrito va en la misma dirección que las actividades resultantes del diagrama de cómo-cómo, el cual se desarrolló en el capítulo 2 (priorización de problemas). Esto es relevante para el desarrollado de la propuesta, en cuanto al alcance que los productos y las actividades puedan presentar en aras de la sostenibilidad de la empresa.

\subsection{Recursos para el desarrollo de la estructura administrativa}

De acuerdo con el listado de los productos resultantes tanto de la tabla 28 (debilidades administrativas frente a cambios y productos) y al diagrama de cómo- cómo, se procederá a establecer el diseño de cada uno de ellas a partir de la información consolidada en los anteriores capítulos.

\section{Tabla 29 Plataforma estratégica}

\begin{tabular}{|c|c|}
\hline Visión & $\begin{array}{l}\text { Velerito buscará tener una cuota de mercado del } 10 \% \text { a nivel nacional en } 3 \text { años, con el propósito de } \\
\text { liderar en la fabricación de prendas infantiles femeninas. Además, buscará liderar procesos } \\
\text { innovadores en el área de las confecciones para el sector textil colombiano, por ende, ser parte del top } \\
\text { de América Latina en no menos de } 10 \text { años. Todo lo anterior con un enfoque social y de inclusión al } \\
\text { sector laboral de la economía. }\end{array}$ \\
\hline Misión & $\begin{array}{l}\text { Velerito es una empresa de confecciones orientada a la elaboración de prendas infantiles femeninas de } \\
\text { vestir que va desde los } 2 \text { años hasta los } 11 \text { años. }\end{array}$ \\
\hline \multicolumn{2}{|l|}{ Objetivos } \\
\hline $\begin{array}{c}\text { Principios de la } \\
\text { organización }\end{array}$ & $\begin{array}{l}\text { - Eficacia: Cuando los procesos logran los objetivos de la empresa. } \\
\text { - Eficiencia: Desarrollo el proceso productivo en función del aprovechamiento máximo de los } \\
\text { recursos. (Chiavenato, Teoría General de la Administración) }\end{array}$ \\
\hline
\end{tabular}




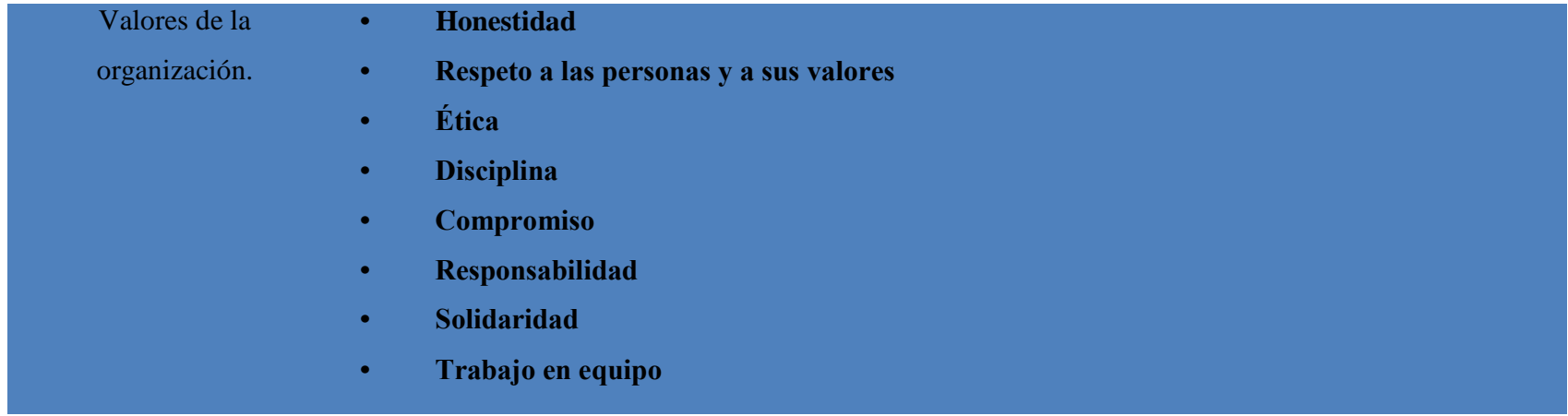

Fuente: Elaboración propia

\subsection{Organigrama}

Este instrumento tiene por fin la consolidación de la estructura jerárquica y administrativa de la organización. En este, se configuran los procesos en los cuales los cargos contribuyen a la creación de valor al interior de la empresa, además estipulan la línea estratégica que se debe aplicar para la formulación de proyectos nuevos o mejoras que tienen efecto sobre todo el sistema de la organización. (Gómez, Gerencia estrategica, 1994).

\section{Tabla 30 Organigrama de velerito.}

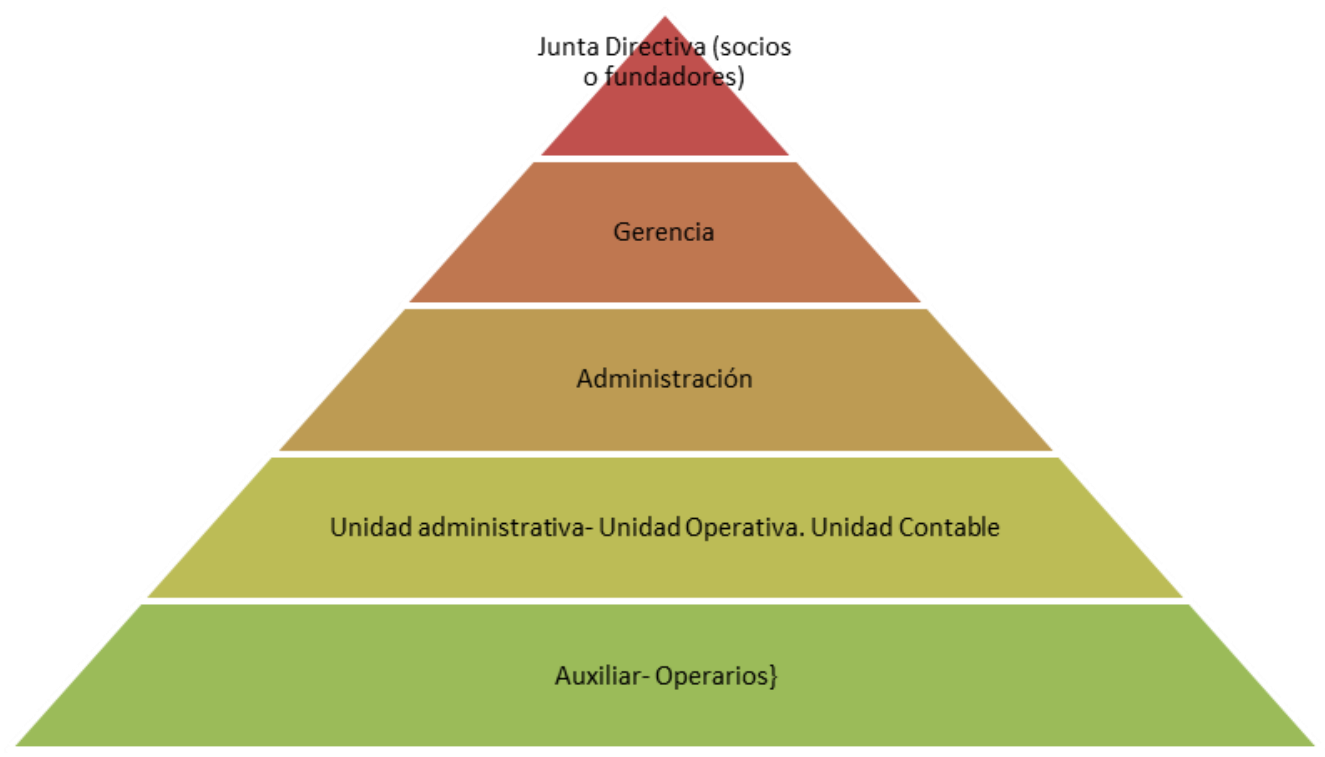

Fuente: (Gómez, Gerencia Estratégica, 2003)

Como se observa en la tabla 30, otro lineamiento fundamental para la creación del organigrama y las líneas de autoridad al interior de la organización es la definición del tipo de liderazgo, puesto que esto delineará los procesos de control y evaluación de los procesos 
operativos y de apoyo que conforman la cadena de valor de la compañía. Es importante recalcar que la elección que se propone, es establecida a partir de diagnóstico que se desarrolló en los temas de carácter organizacional de la empresa (Fincowsky, 2009).

\section{Tabla 31 Definición de estructura de mando.}

\begin{tabular}{|l|l|}
\hline $\begin{array}{l}\text { Definición de } \\
\text { estructura }\end{array}$ & $\begin{array}{l}\text { De acuerdo al tamaño de la empresa (número de empleados), se estipula que el estilo de mando } \\
\text { corresponde a estructura simple, donde la coordinación, supervisión directa y control es ejercida por la } \\
\text { parte alta de los procesos gerenciales de Velerito. Esto indica que es una estructura organizativa } \\
\text { formal puesto que divide el trabajo en áreas simples o elementales debido al proceso de producción que } \\
\text { efectúa la empresa. }\end{array}$ \\
\hline $\begin{array}{l}\text { Tipo de } \\
\text { liderazgo }\end{array}$ & $\begin{array}{l}\text { Se recomienda establecer un tipo de liderazgo demócrata y afiliativo, debido a la estructura de mando } \\
\text { simple que la empresa precede actualmente Fuente especificada no válida.. }\end{array}$ \\
\hline
\end{tabular}

Fuente: (P.Norton, 2004)

La tabla 32, estipula el nivel jerárquico al interior de la organización; con el fin de establecer un orden en el manual de funciones y sea de paso, establecer líneas de rendición de cuentas.

Tabla 32 Índice Jerárquico.

\begin{tabular}{|lr|}
\hline \multicolumn{2}{|c|}{ Índice por nivel jerárquico } \\
\hline Cargo & Código \\
\hline Gerente & 1001 \\
\hline Administrador & 1002 \\
Auxiliar & 1003 \\
Operarios & 1004 \\
\hline Vendedores & 1005 \\
\hline
\end{tabular}

Fuente: Organigrama de la empresa

Dentro del desarrollo del organigrama, es fundamental la instauración de funciones para cada unidad que compone esta dicha figura, por eso, se desarrolló un esquema que está configurado por departamento o unidad, funciones y el mega proceso al cual corresponde. Este esquema es de vital importancia para el desarrollo del manual de funciones de la compañía. Todo lo anterior se puede denotar en la tabla 30 (definiciones de funciones). 
Tabla 33 Definición de funciones.

\begin{tabular}{|c|c|c|}
\hline $\begin{array}{l}\text { Departamento o } \\
\text { Unidad. }\end{array}$ & Funciones & $\begin{array}{c}\text { Mega proceso al } \\
\text { que pertenece }\end{array}$ \\
\hline $\begin{array}{l}\text { Junta Directiva ( socios o } \\
\text { fundadores) }\end{array}$ & $\begin{array}{l}\text { - Planificar los objetivos de la empresa } \\
\text { - Organizar la estructura } \\
\text { - Toma de decisiones de la empresa (compra, estrategias) } \\
\text { - Supervisar la ejecución de la planeación en gestión. } \\
\text { - Contratar el personal para la empresa. } \\
\text { - Analizar los problemas de cada uno de los procesos que la empresa } \\
\text { presente. } \\
\text { - Realizar cálculos matemáticos, algebraicos y financieros. }\end{array}$ & Gerencial \\
\hline Administración & $\begin{array}{l}\text { - Definir metas. } \\
\text { - Apoyar en la formulación de estrategias. } \\
\text { - Desarrollar planes para coordinar actividades. } \\
\text { - Establecer las actividades que deben realizarse } \\
\text { - Apoyar en la toma de decisiones. } \\
\text { - Establecer mecanismos para motivar a empleados } \\
\text { - Apoyar en la resolución de conflictos. } \\
\text { - Apoyar en el proceso de control. } \\
\text { - Definir metas. } \\
\text { - Apoyar en la formulación de estrategias. } \\
\text { - Desarrollar planes para coordinar actividades. } \\
\text { - Establecer las actividades que deben realizarse } \\
\text { - Apoyar en la toma de decisiones. } \\
\text { - Establecer mecanismos para motivar a empleados } \\
\text { - Apoyar en la resolución de conflictos. } \\
\text { - Apoyar en el proceso de control. }\end{array}$ & Gerencial \\
\hline Unidad contable & $\begin{array}{l}\text { - Desarrollar todo el manejo de impuestos que conlleve la actividad } \\
\text { productiva que la empresa realiza. } \\
\text { - Preparar documentos e informes financieros de acuerdo a los criterios } \\
\text { fiscales que el gobierno exija. } \\
\text { - Apoyar en cuento a temas jurídicos en los que la empresa necesite } \\
\text { asesoría. }\end{array}$ & Apoyo \\
\hline Unidad operacional & Actividades descritas en la tabla 4 ( mega procesos de la empresa) & Operacional \\
\hline Unidad administrativa & $\begin{array}{l}\text { - Manejo y consolidación de la información que se obtenga por medio de } \\
\text { los registros establecidos para las áreas de la empresa. } \\
\text { - Presentación de informes que muestren sí los departamentos de la } \\
\text { empresa se acerca a los objetivos establecidos en el direccionamiento } \\
\text { estratégico. } \\
\text { - Desarrollo de técnicas de control y vigilancia sobre costes de } \\
\text { producción. } \\
\text { - Analizar temas de flujo de caja de la empresa, y situación patrimonial de } \\
\text { la misma. }\end{array}$ & Gerencial \\
\hline
\end{tabular}

Fuente: (Chiavenato, 2005)

\subsection{Manual de funciones}

Estas son herramientas de organización, que permiten articular las actividades que se realizan en los departamentos de una empresa, con el personal requerido para dar cumplimiento a las actividades de dichos departamentos. Esta vinculación delimita aptitudes y funciones que deben confluir con la plataforma estratégica de la empresa. Además, está herramienta es insumo para la creación de indicadores de gestión en las diferentes áreas de la empresa. A continuación, se 
estipulan formatos base para la organización de los manuales de funciones, los cuales están descritos a partir de la tabla 32-Indice Jerárquico.

\section{Tabla 34 Gerencia}

\begin{tabular}{|c|c|}
\hline \multicolumn{2}{|l|}{ Datos personales } \\
\hline \multicolumn{2}{|l|}{ Nombres: } \\
\hline \multicolumn{2}{|l|}{ Apellidos } \\
\hline \multicolumn{2}{|l|}{ Número de Cedula } \\
\hline \multicolumn{2}{|l|}{ Número Celular } \\
\hline Cargo & Gerente \\
\hline Código & 1001 \\
\hline Supervisor inmediato & Junta directiva \\
\hline Requisitos, estudios y experiencia & $\begin{array}{l}\text { Experiencia de más de } 4 \text { años en el sector textil. Técnico o profesional en carreras } \\
\text { de las ciencias económicas. }\end{array}$ \\
\hline Unidad a la que pertenece & Gerencial \\
\hline Funciones del cargo & $\begin{array}{l}\text { - Planificar los objetivos de la empresa } \\
\text { - Organizar la estructura de la empresas. } \\
\text { - Supervisar la ejecución de la planeación en gestión. } \\
\text { - Contratar el personal para la empresa. } \\
\text { - Analizar los problemas de cada uno de los megos procesos que la empresa } \\
\text { presente. . } \\
\text { - Realizar cálculos matemáticos, algebraicos y financieros. }\end{array}$ \\
\hline \multicolumn{2}{|l|}{ Fecha de ingreso } \\
\hline Ubicación del cargo & Fabrica ( carrera 41bis\#29c-50 ) \\
\hline Nivel organizacional al que pertenece & Gerencia \\
\hline
\end{tabular}

Fuente: Elaboración propia

\section{Tabla 35 Administrador}

\begin{tabular}{|c|c|}
\hline \multicolumn{2}{|l|}{ Datos personales } \\
\hline \multicolumn{2}{|l|}{ Nombres: } \\
\hline \multicolumn{2}{|l|}{ Apellidos } \\
\hline \multicolumn{2}{|l|}{ Número de Cedula } \\
\hline \multicolumn{2}{|l|}{ Número Celular } \\
\hline Cargo & Administrador \\
\hline Código & 1002 \\
\hline Supervisor inmediato & Gerente \\
\hline \multicolumn{2}{|l|}{ Requisitos, estudios y experiencia } \\
\hline Unidad a la que pertenece & Administrativa \\
\hline Funciones del cargo & $\begin{array}{l}\text { - Definir metas. } \\
\text { - Apoyar en la formulación de estrategias. } \\
\text { - Desarrollar planes para coordinar actividades. } \\
\text { - Establecer las actividades que deben realizarse } \\
\text { - Apoyar en la toma de decisiones. } \\
\text { - Establecer mecanismos para motivar a empleados } \\
\text { - Apoyar en la resolución de conflictos. } \\
\text { - Apoyar en el proceso de control. }\end{array}$ \\
\hline \multicolumn{2}{|l|}{ Fecha de ingreso } \\
\hline Ubicación del cargo & Fabrica ( carrera 41bis\#29c-50 ) \\
\hline Nivel organizacional al que pertenece & Gerencial \\
\hline
\end{tabular}

Fuente: Elaboración propia 
Tabla 36 Auxiliar administrativo.

\begin{tabular}{|c|c|}
\hline \multicolumn{2}{|l|}{ Número de Cedula } \\
\hline \multicolumn{2}{|l|}{ Número Celular } \\
\hline Cargo & Auxiliar \\
\hline Código & 1003 \\
\hline Supervisor inmediato & Administrador y gerente \\
\hline Requisitos, estudios y experiencia & Técnico en administración, con conocimientos en temas financieros y de costos. \\
\hline Unidad a la que pertenece & Administración \\
\hline Funciones del cargo & $\begin{array}{l}\text { - Manejo y consolidación de la información que se obtenga por medio de los registros } \\
\text { establecidos para las áreas de la empresa. } \\
\text { - Presentación de informes que muestren sí los departamentos de la empresa se acerca a los } \\
\text { objetivos establecidos en el direccionamiento estratégico. } \\
\text { - Desarrollo de técnicas de control y vigilancia sobre costes de producción. } \\
\text { - Analizar temas de flujo de caja de la empresa, y situación patrimonial de la misma. }\end{array}$ \\
\hline \multicolumn{2}{|l|}{ Fecha de ingreso } \\
\hline Ubicación del cargo & Fabrica ( carrera 41bis\#29c-50 ) \\
\hline Nivel organizacional al que pertenece & Operacional \\
\hline
\end{tabular}

Fuente: Elaboración propia

\section{Tabla 37 Operario o vendedor}

\begin{tabular}{|c|c|}
\hline \multicolumn{2}{|l|}{ Datos personales } \\
\hline \multirow{2}{*}{\multicolumn{2}{|c|}{ Nombres: }} \\
\hline & \\
\hline \multicolumn{2}{|l|}{ Número de Cedula } \\
\hline \multicolumn{2}{|l|}{ Número Celular } \\
\hline Cargo & Operarios \\
\hline Código & 1004 \\
\hline Supervisor inmediato & administrador y gerente \\
\hline Requisitos, estudios y experiencia & $\begin{array}{c}\text { Técnico con experiencia e temas afines a la actividad de confección. ( unidad } \\
\text { de producción que necesite de este personal) }\end{array}$ \\
\hline \multicolumn{2}{|l|}{ Unidad a la que pertenece } \\
\hline Funciones del cargo & Actividades descritas en la tabla 4 ( mega procesos de la empresa) \\
\hline \multicolumn{2}{|l|}{ Fecha de ingreso } \\
\hline Ubicación del cargo & Fabrica ( carrera 41bis\#29c-50) \\
\hline Nivel organizacional al que pertenece & Operacional \\
\hline
\end{tabular}

Fuente: Elaboración propia

Tabla 38 Esquema básico de planilla de registro de información.

\begin{tabular}{|l|l|l|l|}
\hline \multicolumn{2}{|c|}{ PLANILLA PARA REGISTRO FISICO DE INFORMACIÓN } \\
\hline Nombre & & & \\
\hline Fecha & & \\
\hline Departamento & & \\
\hline Proceso de la unidad & & \\
\hline & & & \\
\hline & & & \\
\hline
\end{tabular}

Fuente: Elaboración propia 


\subsection{Cronograma}

De acuerdo con la lista de productos básicos para la conformación de la estructura administrativa, se desarrolló el cronograma para la consecución del fortalecimiento empresarial. Este producto está configurado por tiempos, actividades a cumplir, responsables y recursos requeridos para el cumplimiento de las actividades descritas.

\begin{tabular}{|c|c|c|c|c|c|c|}
\hline $\begin{array}{l}\text { Grupo al } \\
\text { que } \\
\text { pertenec } \\
\text { en }\end{array}$ & ACTIVIDAD / TIEMPO (mes- semana) & Junio & Julio & Agosto & Responsables & $\begin{array}{l}\text { RECURSOS } \\
\text { REQUERID } \\
\text { OS }\end{array}$ \\
\hline & $\begin{array}{l}\text { Contratar a personal capacitado para organizar, y } \\
\text { estructurar el ordenamiento de los procesos de la } \\
\text { empresa. } \\
\text { Establecer el direccionamiento estratégico de la } \\
\text { empresa. }\end{array}$ & & & & $\begin{array}{l}\text { Fundadores } \\
\\
\text { Fundadores } \\
\text { administra } \\
\text { dor } \\
\text { Fundadores } \\
\text { administra } \\
\text { dor }\end{array}$ & $\begin{array}{l}\text { - Recursos } \\
\text { Humanos: } \\
\text { Administrador } \\
\text { y auxiliar. } \\
\text { - Materiales: } \\
\text { Elementos de } \\
\text { oficina } \\
\text { descritos en la } \\
\text { tabla de costos } \\
\text { de estructura } \\
\text { administrativa. } \\
\text { - Recursos } \\
\text { Económicos: } \\
\text { \$7.814.000 } \\
\text { COP } \\
\text { materiales de } \\
\text { oficina) } \$ \\
\text { 5.445.900 } \\
\text { COP( equipos } \\
\text { de cómputo) } \\
\text { - Recursos } \\
\text { Humanos: } \\
\text { Fundadores, } \\
\text { administrador. } \\
\text { - Materiales: } \\
\text { Material } \\
\text { administrativo } \\
\text { (libros de } \\
\text { formulación } \\
\text { de plataforma } \\
\text { estratégica), } \\
\text { capacitación, } \\
\text { equipo de } \\
\text { cómputo, } \\
\text { software de } \\
\text { trabajo } \\
\text { (Word). } \\
\text { - Recursos } \\
\text { Económicos: } \\
\text { Descrito en las } \\
\text { tablas } 29 \text { y } 30 . \\
\text { - Recursos } \\
\text { Humanos: } \\
\text { Fundadores, } \\
\text { administrador, } \\
\text { auxiliar. } \\
\text { - Materiales: } \\
\text { Equipo de } \\
\text { cómputo, } \\
\text { hojas, } \\
\text { software de } \\
\text { trabajo (Word) } \\
\text { - Recursos } \\
\text { Económicos: } \\
\text { Descrito en las } \\
\text { tablas } 29 \text { y 30. }\end{array}$ \\
\hline
\end{tabular}


Alinear las actividades que la empresa ejecuta con el direccionamiento estratégico establecido.

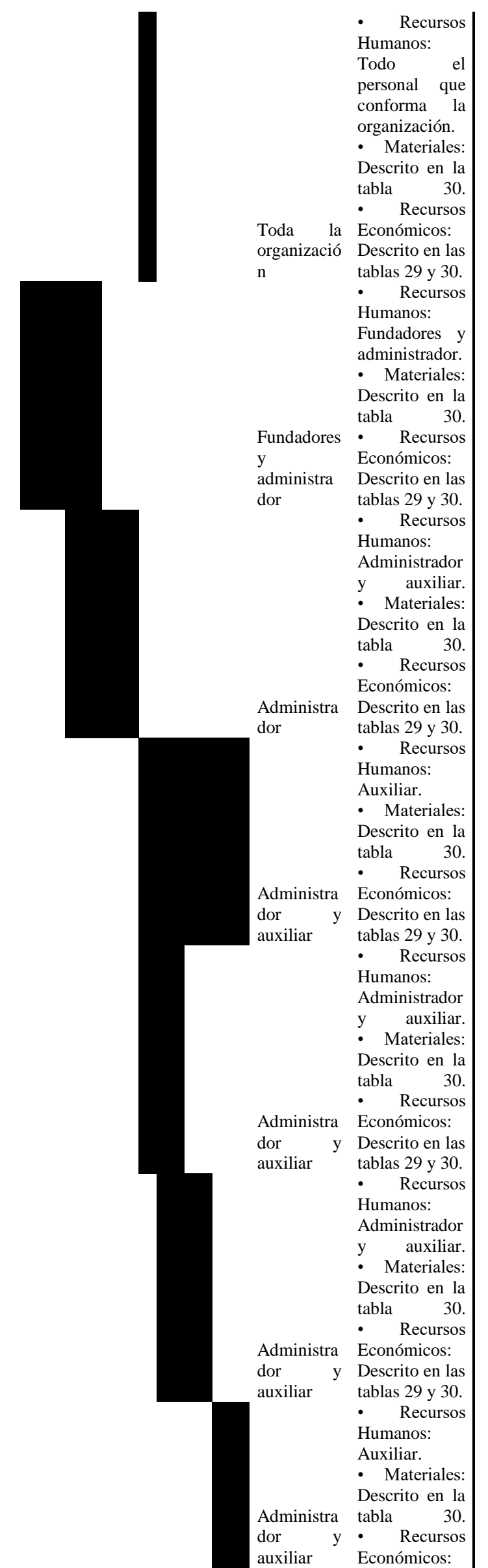

Definir los objetivos de la empresa en el corto, mediano y largo plazo

Planificar las actividades diarias, semanales y mensuales.

Control y verificación del cumplimiento de las actividades.

Diseño de indicadores para cada uno de los procesos de la empresa.

Diseño de formatos para registro de información relevante en cada una de las unidades de la empresa.

Procesamiento de la información extraída. (informe)
- Recursos

Todo

personal que

ponforma la

Descrito en la

tabla 30.

Descrito en las

tablas 29 y 30

- Recursos

ores

crito en la

30.

y Económicos:

dministra Descrito en las

tablas 29 y 30.

Administrador

auxiliar.

Materiales:

tabla 30

- Recursos

escrito en las

Humanos:

.

Materiales:

en 1

ursos

dor y Descrito en las

Humanos:

Administrador

y auxiliar.

Descrito en la

tabla 30.

Administra Económicos.

auxiliar tablas 29 y 30.

- Recurso

manos:

Administrador

- Materiales:

Descrito en la

Desla

Administra Económicos:

tablas 29 y 30.

Auxiliar.

- Materiales:

tabla

do

auxiliar

Económicos: 

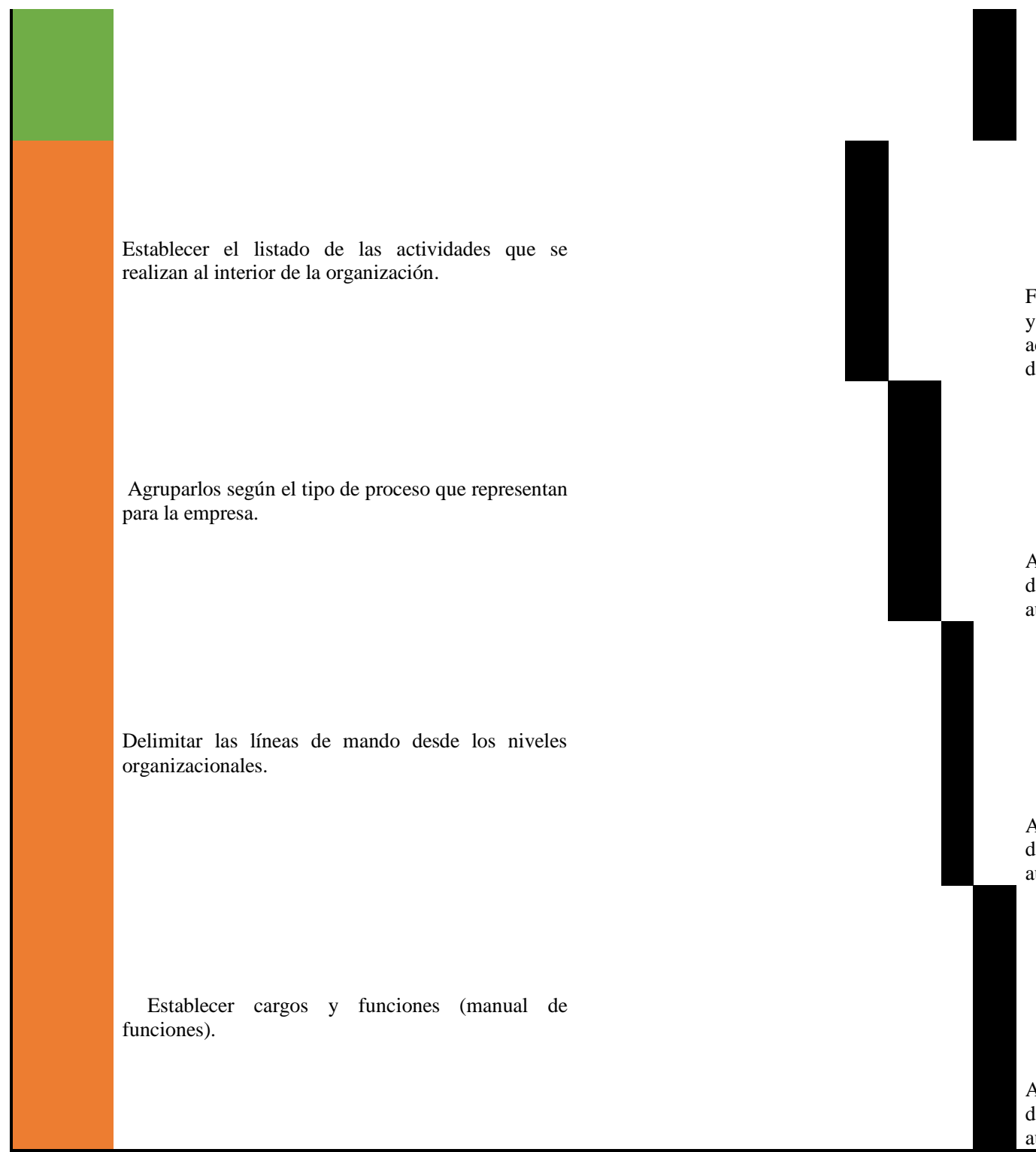

Establecer el listado de las actividades que se realizan al interior de la organización.

Humanos:

Auxiliar.

- Materiales:

Descrito en la

Fundadores tabla 30.

y Económicos:

administra Descrito en las

dor tablas 29 y 30.

- Recursos

Humanos:

Auxiliar.

- Materiales:

Descrito en la

tabla 30.

- Recursos

Administra Económicos:

dor y Descrito en las

auxiliar tablas 29 y 30.

- Recursos

Humanos:

Administrador

- Materiales: Descrito en la

tabla 30.

- Recursos

Administra Económicos:

dor y Descrito en las auxiliar tablas 29 y 30 .

- Recursos Humanos:

Administrador

y auxiliar.

- Materiales: Descrito en la tabla 30. - Recursos

Administra Económicos:

dor y Descrito en las auxiliar tablas 29 y 30.

Fuente: (Murcia H. H., 2014)

\subsection{Recursos Para la Estructura Administrativa}

\subsubsection{Físicos}

De acuerdo con el cambio establecido en la propuesta de este ejercicio de fortalecimiento empresarial, se ha estipulado una serie de recursos físicos necesarios para el desarrollo de la estructura administrativa que requiere Velerito. Por tal razón se efectuará un listado de elementos con el respectivo valor en pesos al 2017. Estos se han clasificado en las tablas 39 y 40, en recursos tecnológicos y materiales (varios). 
Tabla 39 Recursos tecnológicos.

\begin{tabular}{|c|c|c|c|c|c|}
\hline Oficina elementos & Cantidad & \multicolumn{2}{|c|}{ Valor unitario } & \multicolumn{2}{|c|}{ Total } \\
\hline Impresora multifuncional & 1 & $\$$ & 799.000 & $\$$ & 799.000 \\
\hline Portátil HP & 2 & $\$$ & 1.599 .000 & $\$$ & 3.198 .000 \\
\hline Todo en uno HP & 1 & $\$$ & 1.399 .000 & $\$$ & 1.399 .000 \\
\hline Teléfonos fijo Panasonic & 1 & $\$$ & 49.900 & $\$$ & 49.900 \\
\hline Total & & $\$$ & 3.846 .900 & $\$$ & 5.445 .900 \\
\hline
\end{tabular}

Fuente: Elaboración propia

\section{Tabla 40 Materiales varios (estructura administrativa)}

\begin{tabular}{|c|c|c|c|c|c|}
\hline Descripción & Cantidad & Valor & & & Proveedor \\
\hline Papel Carta & 5 & $\$ 8.950$ & $\$$ & 44.750 & Panamericana \\
\hline Folder legajador Oficio & 1 & $\$ 8.700$ & $\$$ & 8.700 & Panamericana \\
\hline Legajador Carta & 1 & $\$ 6.200$ & $\$$ & 6.200 & Panamericana \\
\hline Cosedora 30hjs & 1 & $\$ 23.500$ & $\$$ & 23.500 & Panamericana \\
\hline Grapadora & 1 & $\$ 3.700$ & $\$$ & 3.700 & Panamericana \\
\hline Tajalápiz eléctrico & 1 & $\$ 89.900$ & $\$$ & 89.900 & Panamericana \\
\hline caja lápiz 12 lleva 13 & 1 & $\$ 12.600$ & $\$$ & 12.600 & Panamericana \\
\hline tablero acrílico $80 * 120$ & 1 & $\$ 121.900$ & $\$$ & 121.900 & Panamericana \\
\hline marcadores borrables $\mathrm{x} 4$ & 1 & $\$ 12.000$ & $\$$ & 12.000 & Panamericana \\
\hline borrador tablero acrílico & 1 & $\$ 5.000$ & $\$$ & 5.000 & Panamericana \\
\hline separadora $\mathrm{x} 6$ cartulina & 1 & $\$ 2.200$ & $\$$ & 2.200 & Panamericana \\
\hline Bolígrafo Vic azul & 1 & $\$ 9.600$ & $\$$ & 9.600 & Panamericana \\
\hline Resaltador delgado $\mathrm{x} 2$ & 1 & $\$ 5.800$ & $\$$ & 5.800 & Panamericana \\
\hline Perforadora $\mathrm{x} 40$ hojas & 1 & $\$ 32.800$ & $\$$ & 32.800 & Panamericana \\
\hline Perforadora $\mathrm{x} 70 \mathrm{hojas}$ & 1 & $\$ 69.900$ & $\$$ & 69.900 & Panamericana \\
\hline notas adhesivas & 1 & $\$ 12.900$ & $\$$ & 12.900 & Panamericana \\
\hline borrador miga & 1 & $\$ 2.600$ & $\$$ & 2.600 & Panamericana \\
\hline Botella de tinta negro & 1 & $\$ 33.500$ & $\$$ & 33.500 & Panamericana \\
\hline Botella de tinta magenta & 1 & $\$ 33.500$ & $\$$ & 33.500 & Panamericana \\
\hline Botella de tinta amarillo & 1 & $\$ 33.500$ & $\$$ & 33.500 & Panamericana \\
\hline Botella de tinta Azul & 1 & $\$ 33.500$ & $\$$ & 33.500 & Panamericana \\
\hline Tóner Samsung negro & 1 & $\$ 217.000$ & $\$$ & 217.000 & Panamericana \\
\hline Antivirus McAfee & 1 & $\$ 139.900$ & $\$$ & 139.900 & Panamericana \\
\hline $\begin{array}{l}\text { Licencia eset Small Office } 15 \text { Usuarios+ } 1 \\
\text { servidor }\end{array}$ & 1 & $\$ 420.000$ & $\$$ & 420.000 & K-tronic \\
\hline $\begin{array}{l}\text { licencia office hogar empresa } 2016 \\
\text { vitalicio }\end{array}$ & 3 & $\$ 760.000$ & $\$$ & 2.280 .000 & K-tronic \\
\hline $\begin{array}{l}\text { licencia Windows } 10 \text { profesional equipo } \\
\text { nuevo }\end{array}$ & 3 & $\$ 590.000$ & $\$$ & 1.770 .000 & $\mathrm{~K}$-tronic \\
\hline Escritorio $73.3 \times 170 \times 150 \mathrm{~cm}$ & 3 & $\$ 529.900$ & $\$$ & 1.589 .700 & Centry \\
\hline Silla de Escritorio Style Azul asentí & 4 & $\$ 199.900$ & $\$$ & 799.600 & Centry \\
\hline Total & & 3.418 .950 & & 7.814 .250 & \\
\hline
\end{tabular}

Fuente: Elaboración propia 
Para esta propuesta el valor total de los recursos necesarios para el desarrollo de la estructura administrativa está en los \$13.260.150 COP.

11.7 Recursos humanos para la creación de la estructura empresarial

\begin{tabular}{|c|c|c|c|c|}
\hline \multirow{5}{*}{$\begin{array}{l}\text { Costeo del personal necesario para el desarrollo de la estructura } \\
\text { administrativa }\end{array}$} & Perfil & \multicolumn{2}{|c|}{ Administrativo } & auxiliar \\
\hline & SMLV & \multicolumn{2}{|l|}{3} & 1,5 \\
\hline & salario básico & $\$$ & 2.213 .151 & $\$$ \\
\hline & $\begin{array}{l}\text { Auxilio de } \\
\text { transporte }\end{array}$ & $\$$ & & $\$$ \\
\hline & Total salario & $\$$ & 2.213 .151 & $\begin{array}{l}\$ \\
1.189 .716\end{array}$ \\
\hline \multirow{4}{*}{ Provisiones } & Prima & $\$$ & 184.355 & $\begin{array}{l}\$ \\
99.103\end{array}$ \\
\hline & Cesantías & $\$$ & 184.355 & $\begin{array}{l}\$ \\
99.103\end{array}$ \\
\hline & Vacaciones & $\$$ & 92.067 & $\begin{array}{l}\$ \\
46.034\end{array}$ \\
\hline & $\begin{array}{l}\text { Intereses } \\
\text { Cesantías }\end{array}$ & $\$$ & 22.132 & $\begin{array}{l}\$ \\
11.897\end{array}$ \\
\hline \multirow{3}{*}{ Seguridad social } & Pensión & $\$$ & 265.578 & $\begin{array}{l}\$ \\
132.789\end{array}$ \\
\hline & Caja & $\$$ & 88.526 & $\begin{array}{l}\$ \\
44.263\end{array}$ \\
\hline & ARL & $\$$ & 11.553 & $\begin{array}{l}\$ \\
5.776\end{array}$ \\
\hline \multirow{2}{*}{ Costo total por cargo } & mes & $\$$ & 3.061 .717 & $\begin{array}{l}\$ \\
1.628 .681\end{array}$ \\
\hline & año & $\$$ & 36.740 .608 & $\begin{array}{l}\$ \\
19.544 .174\end{array}$ \\
\hline Cantidad & cantidad & & 1 & 1 \\
\hline Costo total & & $\$$ & 36.740 .608 & $\begin{array}{l}\$ \\
19.544 .174\end{array}$ \\
\hline
\end{tabular}

Fuente: Elaboración propia

Porcentajes que se tuvieron en cuenta para el desarrollo del esquema de pagos de aportes sociales y de ley.

\begin{tabular}{|l|r|r|r|}
\hline Concepto & Prima & Cesantías & Vacaciones \\
\hline Valor & $8,33 \%$ & $8,33 \%$ & $4,16 \%$ \\
\hline
\end{tabular}




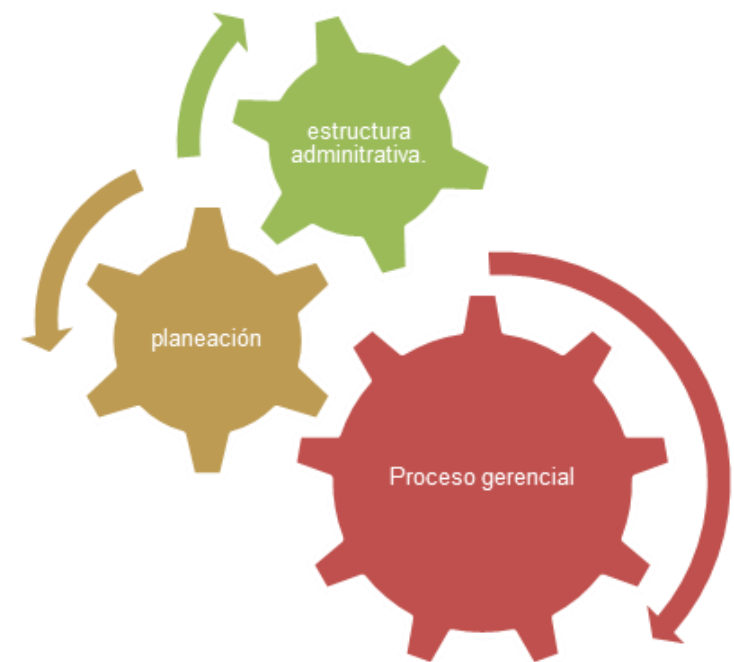

Fuente: Elaboración propia

\subsection{Marco Lógico de la empresa}

\section{Tabla 41 Matriz de Marco Lógico}

\begin{tabular}{|c|c|c|c|c|}
\hline ELEMENTOS & $\begin{array}{c}\text { RESUMEN } \\
\text { NARRATIVO }\end{array}$ & INDICADORES & $\begin{array}{c}\text { MEDIOS DE } \\
\text { VERIFICACION }\end{array}$ & SUPUESTOS \\
\hline $\begin{array}{l}\text { DIRECTRIZ } \\
\text { U OBJETIVO } \\
\text { GENERAL }\end{array}$ & $\begin{array}{l}\text { La empresa Velerito } \\
\text { necesita un mejoramiento } \\
\text { integral }\end{array}$ & $\begin{array}{l}\text { Situación a (FECHA) frente a otro } \\
\text { momento tomado como referencia. } \\
\text { Nuevos productos ofrecidos } \\
\text { Dineros obtenidos } \\
\text { Plan de Desarrollo y } \\
\text { procedimientos administrativos }\end{array}$ & $\begin{array}{l}\text { Plantilla de registro de } \\
\text { información. } \\
\text { Manuales de funciones. }\end{array}$ & $\begin{array}{l}\text { Que los directivos de la } \\
\text { Velerito apliquen las acciones } \\
\text { sugeridas respecto al objetivo } \\
\text { específico establecido. } \\
\text { Que haya apoyo de todo el } \\
\text { personal de la empresa. } \\
\text { Que se consiga apoyo } \\
\text { institucional. }\end{array}$ \\
\hline $\begin{array}{l}\text { OBJETIVO } \\
\text { ESPECIFICO }\end{array}$ & $\begin{array}{l}\text { Crear } \\
\text { administrativa. }\end{array}$ & $\begin{array}{l}\text { Sistematización de la información } \\
\text { resultante diligenciamiento de } \\
\text { registros. } \\
\text { Objetivos de la empresa en el } \\
\text { corto, mediano y largo plazo. } \\
\text { Planificación de las actividades } \\
\text { diarias, semanales y mensuales. } \\
\text { Control y verificación del } \\
\text { cumplimiento de las actividades. }\end{array}$ & $\begin{array}{l}\text { Planillas de registro de } \\
\text { actividades. } \\
\text { Sistema de información } \\
\text { consolidado. }\end{array}$ & $\begin{array}{l}\text { Que se estructure y se alinea a } \\
\text { la empresa con la dirección } \\
\text { estrategia creada para la } \\
\text { empresa. }\end{array}$ \\
\hline PRODUCTOS & $\begin{array}{l}\text { Creación de la plataforma } \\
\text { estratégica de la } \\
\text { organización. } \\
\text { Diseño de indicadores de } \\
\text { gestión. } \\
\text { Reglamento de trabajo. } \\
\text { Definición de estilo de } \\
\text { liderazgo. } \\
\text { Cronograma de } \\
\text { actividades. } \\
\text { Organigrama de la } \\
\text { empresa. }\end{array}$ & $\begin{array}{l}\text { Estos productos hacen parte de los } \\
\text { activos intangibles que la empresa } \\
\text { debe tener para propender por la } \\
\text { sostenibilidad del negocio en el } \\
\text { tiempo. }\end{array}$ & $\begin{array}{l}\text { Registros digitales y } \\
\text { físicos. } \\
\text { Proceso de supervisión } \\
\text { por parte de la } \\
\text { administración y gerente. }\end{array}$ & $\begin{array}{l}\text { Similares anotaciones al punto } \\
\text { anterior }\end{array}$ \\
\hline
\end{tabular}




$\begin{array}{cl}\begin{array}{c}\text { INSUMOS } \\ \text { (Procedentes } \\ \text { de última } \\ \text { columna de } \\ \text { cronograma) }\end{array} & \begin{array}{l}\text { Recursos humanos: } \\ \text { Contratación de dos } \\ \text { personas capacitadas en } \\ \text { temas administrativos. }\end{array} \\ \begin{array}{l}\text { Recursos técnicos: } \\ \text { Vinculación con } \\ \text { entidades que propicien la } \\ \text { capacitación a las } \\ \text { empresas (Cámara de } \\ \text { comercio, Ministerio de } \\ \text { Comercio, etc.) }\end{array} \\ & \begin{array}{l}\text { Recursos físicos: } \\ \text { Estructura física existente. }\end{array} \\ & \begin{array}{l}\text { Recursos económicos: } \\ \text { \$7.814.000 COP } \\ \text { (materiales de oficina), } \$ \\ 5.445 .900 \text { COP (equipos } \\ \text { de cómputo) } \\ \text { Totales: } \$ 13.259 .900 \\ \text { COP }\end{array} \\ & \end{array}$
Presupuestos programados frente a
los ejecutados (contra entrega)

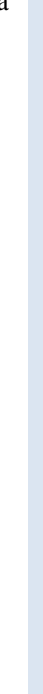

Flujo de caja. Registro de verificación de los productos esperados de la gestión administrativa, los cuales están descritos en el capítulo 3 (propuesta de este documento.

Se establezca el presupuesto requerido $y$ se contrate al personal requerido.

Que se pueda hacer contactos con instituciones que apoyen.

Que se obtengan y se administren los recursos obtenidos de manera organizada

Fuente: Elaboración propia 


\subsection{Análisis de la parte financiera de la propuesta de fortalecimiento empresarial.}

Dentro del esquema de la propuesta, debe existir un componente económico y financiero que dictamine la viabilidad de la ejecución del cambio para la empresa. Desde de los componentes que se deberían incluir en dicho esquema se encuentra el valor o la tasa esperado que la propuesta forjo ejerciendo una dinámica financiera benéfica para la compañía.

Este efecto puede ser vía aumento de ventas, aumento de ingresos o reducción de costes y gastos. Por ende, dicho movimiento económico debería tener un impacto directo sobre la rentabilidad del negocio, sí se tiene en consideración la estructura del estado de pérdidas y ganancias de cualquier compañía.

De esta forma es necesario elaborar un esquema que permita en primera medida dimensionar sobre cual dinámica financiera se efectuará el cambio, para posteriormente definir una tasa interna de retorno, un costo de capital, una proyección de balances y estados de resultados para lograr determinar un valor presente neto que indique sí este proyecto genera o no riqueza, y de paso sí destruye o construye valor, por ende, aceptar o no la ejecución de la propuesta. (Díaz J. A., 2011)

Para efectos de fortalecimiento, se intentó definir de forma precisa el impacto financiero que tendría la creación de la estructura administrativa al interior de la empresa para luego establecer la dinámica financiera de todos los movimientos en costos y en rentabilidad que el cambio de fortalecimiento generaría; sin embargo, al no encontrar información financiera clara como se evidencio en la unidad de diagnóstico financiero, resultaron insuficientes los recursos para hacer un acercamiento al impacto, de hecho solo se logró hacer una análisis básico de razones financieras partir de los balances que la unidad de apoyo contable de la compañía suministro para el desarrollo del ejercicio de diagnóstico. Dificultando así el diseño de la estructura financiera para la propuesta.

Por otro lado, de acuerdo a la naturaleza del cambio que se estipulo en el apartado inicial de la propuesta, que es de tipo administrativo; se determinó que esté es susceptible de no ser representado económicamente de forma inmediata, es decir, que su impacto en términos financieros no necesariamente debe reflejar la creación de riqueza de forma directa, pero sí en términos intangibles desde la creación de valor como se evidencia en los diagramas que se definen en la parte de priorización de problemas.

Es decir que la figura administrativa, es una unidad clave para propiciar la sostenibilidad de cualquier organización en el tiempo, por ende, la medición de su impacto está direccionada en principio a la creación de valor y ventajas competitivas. Es decir que está propuesta es susceptible 
de ser evaluada posterior a su aplicación, si en términos financieros se pretende hacer. Por tal razón es importante determinar por qué esta propuesta es de naturaleza intangible, y lo que esto implica para este ejercicio de fortalecimiento.

Según la Contaduría General de la Nación define a los activos intangibles como "activos no monetarios sin apariencia física susceptibles de valoración económica" (Contaduria General de la Nación, 2014). Es decir que a pesar de no tener un soporte físico o material son capaces de generar valor para la empresa.

A continuación, se enmarcarán los elementos que explicarían la naturaleza de propuesta de este fortalecimiento empresarial, enfocado en la creación de ventajas competitivas, es decir en la creación de valor para la compañía.

Requisitos para determinar un activo intangible:

Ser un activo "Representan los bienes y derechos tangibles e intangibles de propiedad del ente económico, que en la medida de su utilización, son fuente potencial de beneficios presentes o futuros" (PUC, 2018)

$\checkmark$ Que sean controlados por la empresa, es decir, que luego del momento de la incorporación este factor siga controlado por los procesos gerenciales.

$\checkmark$ Que sean separables de la empresa, es decir que se puedan compartir y trasmitir, es implica que puedan ser identificables. (Abad, 2016)

$\checkmark$ Que sean factores o puentes para ayudar a mejorar la gestión de la empresa, sea vía nuevas líneas de negocio, aumento en ventas, reducción de costes. (Abad, 2016)

Los anteriores criterios reafirman lo que se ha descrito sobre la naturaleza del cambio propuesto, lo cual nos permite identificar el carácter intangible que tiene la creación de la estructura administrativa, la cual debe ser calificada como viable o no, desde la creación de valor para la compañía y no necesariamente desde una óptica netamente financiera.

\subsection{Línea de impacto de la estructura administrativa}

Razón a lo anterior, la línea de valor que se establece a partir de los productos forjados en la propuesta como la formulación del organigrama, los manuales de mando, las directrices del direccionamiento estratégico de la compañía, harán que: 
1. Se desarrollen esquemas que permitan a la empresa entender aún más su contexto externo e interno. Dichos esquemas deben apuntar a la creación de sistemas de información bajo la estructura de indicadores de gestión.

2. Se efectúen tomas de decisiones estructuradas y específicas para cada unidad que conforma la empresa, mediante la planeación, organización, dirección y control como funciones administrativas claves que se configuran desde los objetivos de la organización.

3. Las decisiones tomadas serán denotadas como estrategias que la empresa adoptará mediante actividades y programas para cada departamento.

4. Con esto se espera que se efectúen impactos ya sea en la creación de riqueza o en la reducción de costes, para que se vea reflejado en la utilidad que percibirá el accionista al final del ejercicio. 


\section{Capítulo 5- Conclusiones}

Según lo establecido en la metodología, y luego de dar por cumplidos los objetivos para este ejercicio, se establecerán las conclusiones finales, las cuales se desarrollarán para cada objetivo específico dentro de una narrativa concreta, para luego, desembocar en una conclusión general en razón al objetivo principal del fortalecimiento empresarial diseñado para Velerito.

Cabe agregar que este apartado hará un recorrido por los puntos claves de este trabajo, algunos de los cuales son relevantes para el desarrollo de las recomendaciones.

El diagnóstico fue un proceso crucial para lograr entender la realidad de Velerito y extraer los recursos necesarios para la consecución de los demás objetivos específicos de la hoja de ruta metodológica.

Dentro de los recursos extraídos se encontró la necesidad de desarrollar sistemas de información para fortalecer la creación de valor al interior de Velerito, optimizando el área administrativa, puesto que la información de la organización que se encontró no fue de fácil manejo, debido a las falencias en el manejo de la información, lo cual dificulto el desarrollo de las listas de chequeo. Sin embargo, las herramientas metodológicas establecidas lograron demarcar la realidad de la compañía de forma ordenada, sistemática, especifica.

Gracias a esto, se establece que debido a la falta de sistematización de procesos de manera ordenada y lógica bajo el direccionamiento estratégico, se presentan inadecuados procesos en la toma de decisiones. Esto es consecuencia de la ausencia de una base organizacional, que permita alinear todos los procesos administrativos, y por ende, dar claridad sobre el desarrollo de una propuesta para la ejecución de este fortalecimiento empresarial para Velerito.

Lo anterior, también presenta repercusiones negativas frente al manejo de la información del área financiera, de hecho se ratifica en los ítems de análisis de información de la tabla 17(resultados parciales); que demuestran la carencia de un manejo de información financiero adecuado que posibilite la toma de decisiones desde una connotación económica más precisa de la empresa.

Según la Mercadotecnia aplicada, frente al estudio del mercado, se indica que existen vacíos al respecto, que involucran factores importantes y homogéneos activamente influyentes en este proceso, comprendidos desde el conocimiento del cliente, hasta las dinámicas que preceden el sector textil colombiano y mundial. Esto es perjudicial a la hora de planear, desarrollar y ejecutar acciones referentes al diseño de nuevos productos, a la toma de decisiones de expansión o de penetración de nuevos mercados; es decir, hay limitantes de información que afectan directamente 
a la creación de estrategias y planes de acción. Sin embargo, se encontró que la empresa posee oportunidad de negocio en razón al mercado en el que interactúa, el cual establece ciertas características favorables para Velerito.

Estas características describen la interacción de mayoristas de todo el país, los cuales en su conjunto compran al contado posibilitando una alta circulación de dinero en efectivo con moneda local (COP), que beneficia a las empresas formales y trabajadores informales, que allí confluyen para tener capital de trabajo disponible, y de esta manera sostener su operación y su utilidad, además de ser un espacio demarcado que de forma natural, el cual ha establecido lineamientos de tiempo y plaza, que fortalecen la interacción de compra y venta entre mayoristas y productores que en su mayoría ofrecen producción nacional, generando sostenibilidad económica para toda la cadena que está detrás del producto final.

De acuerdo con los análisis financieros establecidos es importante destacar que la empresa Velerito tiene altos indicadores de liquidez, lo cual se traduce en capital de trabajo disponible, beneficiando su proceso productivo; teniendo en cuenta que sus obligaciones de corto y largo plazo son casi nulas estableciendo un sano manejo financiero por parte de la empresa, que sí bien no está demarcado de forma documental precisamente por la desorganización en la que busca trabajar este fortalecimiento empresarial, sí se sustenta en la productividad y crecimiento empresarial funcional, siendo sostenible en el tiempo desde hace más de 12 años.

Por otro lado, los indicadores financieros que establecen niveles de rentabilidad y rotación de inventario no son del todo favorables, de hecho presentan problemas en primera medida en cuanto a la gestión de recursos al interior de la empresa que se ve reflejado en utilidades decrecientes frente a los bajos niveles de rotación de inventarios.

Dentro del análisis de la competencia se puede decir que la propuesta de este ejercicio de fortalecimiento es una consecuencia fundamental de los factores de crecimiento y éxito que se encontraron en Baby Ganga, Off Corss, entre otras, compañías objeto del análisis; las cuales indicaban la relación entre organización administrativa y sostenibilidad, reflejando la importancia que tiene la creación de la estructura administrativa y organizacional para la sostenibilidad en el futuro mediano y a largo plazo de Velerito.

Referente a temas sociales y ecológicos no se encontró relación directa de la empresa frente a estos aspectos; lo cual sí debería ser tenido en cuenta para la creación de marca y reconocimiento en el mercado textil de Velerito; dado que, socialmente, Velerito genera trabajo directo a más de 10 personas, contribuyendo a todo el sistema de seguridad y aportes sociales, y trabajo indirecto a todos los proveedores de insumos y materiales para la elaboración de producto final. 
De acuerdo con el paso de priorización es importante recalcar que los pasos que allí se establecieron, permitieron depurar toda la información concluyente del diagnóstico elaborado; de forma tal, que se decantó el factor clave a solucionar, la estructura organizacional.

Se determina que, para qué Velerito continúe en crecimiento y sea una empresa que dé valor agregado a sus productos y de paso sea perceptible al cliente final, es necesaria la construcción de una base sólida organizacional, puesto que dicha condición marca diferencia entre una empresa como Offcorss y una PYME en crecimiento como Velerito. Por tal razón según el fortalecimiento empresarial ejecutado, el área organizacional daría guía y claridad sobre posibles problemas que estén sucedió en el presente de la empresa, evitando o solucionando oportunamente los mismos.

Desde la Matriz DOFA, en debilidades y fortalezas se estableció que aún hay material susceptible de ser analizado en posteriores estudios que se desarrollen desde la base de la estructura administrativa diseñada en la propuesta. Además que es posible utilizar las estrategias nacientes de la mezcla de factores que se produjeron al interior del DOFA como puntos de partida para delinear las estrategias que conlleven a una consolidación estructural y organizacional de la empresa.

Este paso metodológico fue la piedra angular para identificar el problema clave que fue objeto de cambio en la propuesta, además de establecer un canal vinculatorio para la interacción de los fundadores y propietarios de Velerito, y el estudio que se estaba realizando. Esto facilita la aplicabilidad de la propuesta a la empresa debido al proceso de sensibilización que se presentó con los fundadores, sobre todo en el paso de votación y elección de las debilidades más importantes.

Dentro de los puntos que se desarrollaron en la propuesta, se destacan algunas lecciones aprendidas, las cuales respondieron al cambio que se diseñó. De estás se establece que:

$\checkmark$ La estructura administrativa es un activo intangible que proporciona valor y ventajas competitivas a la empresa.

$\checkmark$ La alineación de procesos se logra a partir de la organización estructural de la compañía.

$\checkmark$ La organización administrativa es el factor clave para la sostenibilidad de la de la empresa, y a su vez es la base para el desarrollo de estrategias que direccionen el "que hacer" de los procesos que configuran la organización, debido a que se establecen parámetros que permiten saber a ciencia cierta qué hace la empresa, cómo lo hace, para qué lo hace, por qué lo hace, y para quien lo hace. 
$\checkmark$ El direccionamiento estratégico es la clave para que la Velerito pueda definir sus hojas de ruta sobre los escenarios cambiantes y fluctuantes de la realidad económica del país y del mundo.

$\checkmark$ El cambio, establecido en la propuesta abre una nueva mirada para la empresa sobre la creación de valor desde el interior de la organización hacia la creación de riqueza para la misma.

$\checkmark$ A partir del cambio que se denoto al interior de este ejercicio académico, se pueden establecer líneas de fortalecimiento para otras áreas que presentaron diversas debilidades. Por ejemplo: la unidad de mercadeo.

Con todo lo anterior es posible decir que se logró cumplir el objetivo general de este trabajo, puesto que se lograron identificar áreas de mejoramiento a partir de un estudio metodológico, el cual consistió en un fortalecimiento empresarial. Además mencionar que se logró reafirmar la formulación de los objetivos específicos puesto que respondieron al propósito del objetivo global del ejercicio académico.

Por otro lado, la metodología aplicada fue la adecuada, puesto que, definió una hoja de ruta concreta, que cumplió con lo establecido en los pasos que configuraron la metodología. De esta forma se reconoce que el estudio realizado sobre, auditoria administrativa y metodología CARIBE, por parte del tutor de este ejercicio de fortalecimiento fue acertado, para la aplicación a un caso real del sector empresarial Colombiano. 


\section{Capítulo 6- Recomendaciones}

A partir de la adaptación de la estructura administrativa a la empresa Velerito se recomienda iniciar la alineación de todos los procesos que configuran la empresa para el desarrollo de nuevas estrategias de fortalecimiento en los puntos que alcanzaron a entrar en el rango de priorización de debilidades tales como: la unidad de mercadeo, que según la Gráfica 15 (comparativo general de fortalezas y debilidades de Velerito) denotada en las conclusiones del diagnóstico, puesto que demostró ser una unidad con diversas anomalías susceptibles de ser estudiadas y corregidas, claro está, desde la estructura administrativa establecida.

Se recomienda establecer un análisis de fondo acerca de los indicadores de rentabilidad de la compañía, y de rotación de inventario dentro de los procesos productivos.

Desde las estrategias establecidas al interior del mix de la matriz DOFA, se recomienda consolidar más propuestas de mejoramiento a partir de la estructura administrativa definida y de la metodología desarrollada en el apartado de priorización de este documento.

Se recomienda establecer un análisis a profundidad sobre la construcción de balances y estados de resultados al interior de la compañía. 


\section{Bibliografía}

Abad, G. G. (2016). Sage Advice. Obtenido de www.sage.com/es-es/blog/activos-intangiblesayudar-empresa/

Bancomundial. (5 de abril de 2017). Colombia Panorama general . Obtenido de http://www.bancomundial.org/es/country/colombia/overview

Chiavenato, I. (2002). Inciación a la Organización y Tecnica Comercial. Rio de Janerio .

Chiavenato, I. (2005). Teoría General de la Administración. Mc Graw Hill. Obtenido de https://es.wikipedia.org/wiki/Henri_Fayol\#Las_funciones_de_Fayol.

Colombia compite. (2016). Colombia compite. Recuperado el 2017 de 06 de 12, de https://compite.com.co/colombia-retrocede-en-el-imd-world-competitiveness-yearbook$2017 /$

Contaduria General de la Nación. (31 de 12 de 2014). Régimen de Contabilidad Pública. Obtenido de http://www.contaduria.gov.co/wps/wcm/connect/ae1d2fa5-01c8-4abe-82f3a288d6875262/PGCP+V++2007.5+a+31-12-

2014.pdf?MOD=AJPERES\&CACHEID=ae1d2fa5-01c8-4abe-82f3-a288d6875262

Coopers y Lybrand . (1997). Control Interno- Estructura Conceptual Integrada. New York : ECOE.

DANE. (2017). Indicadores Coyunturales. Recuperado el 01 de 02 de 2018, de http://www.dane.gov.co/files/ses/ses_2018/Indicadores_Coyunturales_28_02_18.pdf

Díaz, C. A. (2012). CENTRO COMERCIAL GRAN SAN VICTORINO. CENTRO COMERCIAL GRAN SAN VICTORINO . Bogotá, Bogota.

Diaz, J. (04 de 04 de 2013). Emprendices. Recuperado el 2 de 2 de 2017, de https://www.emprendices.co/que-es-un-diagnostico-empresarial/

Díaz, J. A. (2011). Evaluación Financiera de Proyectos. Bogotá: Ediciones de la U.

Dinero. (2017). Sector textil-confección en jaque, ¿cuál es el futuro? Dinero, 1.

dinero, R. (9 de 2 de 2015). DINERO. Obtenido de ¿Por qué fracasan las pymes en Colombia?: http://www.dinero.com/economia/articulo/pymes-colombia/212958

El Espectador. (26 de 1 de 2017). EL ESPECTADOR. Obtenido de http://www.elespectador.com/noticias/economia/el-iva-temor-del-sector-textil-2017articulo-676375

El tiempo. (16 de 02 de 2016). El tiempo . Obtenido de http://www.eltiempo.com/archivo/documento/CMS-16511594 
El tiempo. (21 de Marzo de 2017). EL TIEMPO. Obtenido de www.eltiempo.com/economia/sectores/indice-de-desigualdad-en-colombia-aunmentosegun-programa-de-las-naciones-unidas-para-el-desarrollo-70022

Fincowsky, E. B.-F. (2009). Organización de las empresas- Tercera Edición. México : Mc Graew Hill.

Garzón, M. L. (03 de 02 de 2017). Composición de Velerito. (J. P. Sánchez, Entrevistador)

GESTIÖN. (2017). 50 ideas de negocio rentables. Recuperado el 31 de 02 de 2018, de https://gestion.pe/especial/50-ideas-de-negocios/noticias/prendas-infantiles-y-comerciocrecimiento-noticia-1992832

Gómez, H. S. (1994). Gerencia estrategica. Bogotá: 3R editores.

Gómez, H. S. (2003). Gerencia Estratégica. Bogotá : 3R editores.

Gonzales, L. M. (2017). Check-list para el diagnóstico empresarial: Una herramiente clave para el control de gestión. Profit Editorial.

Gutiérrez, H. C. (2001). Cómo elaborar proyectos. Bogotá: Magisterio .

Murcia, H. H. (2000- 2018). Unidades básicas de la empresa. Bogotá.

Murcia, H. H. (2014). Auditoria Administrativa con base en la innovación organizacional. Bogotá: ediciones de la $\mathrm{U}$.

Murcia, H. H. (2017 de 06 de 2016). sicreaempresa.blogspot. Recuperado el 09 de 02 de 2018, de sicreaempresa.blogspot.com.co

Murcia, H. H. (2017 de 06 de 2016). sicreaempresa.blogspot. Recuperado el 09 de 02 de 2018, de sicreaempresa.blogspot.com.co

Murcia, H. y. (1976). Hacia una agricultura empresarial en America Latina . Costa Rica.

OIT. (02 de 2011). Administración y consultoria. Recuperado el 2016

P.Norton, R. S.-D. (2004). Mapas Estratégicos- Convirtiendo los activos intagibles en resultados tangibles. . Barcelona : Gestión 2000.

Porter, M. (2009). Ser Competitivo. Barcelona: Deusto.

Procolombia. (2015). COLOMBIA crecimiento, confianza y oportunidades para invertirSISTEMA DE MODA. Bogotá: Pro-Colombia.

Procolombia. (2015). COLOMBIA crecimiento, confianza y oportunidades para invertirSISTEMA DE MODA. Bogotá: Pro-Colombia.

PTP. (26 de 1 de 2016). Banco de Comercio Exterior de Colombia. Recuperado el 20 de 5 de 2017, de https://www.ptp.com.co/contenido/contenido.aspx?catID=1\&conID=1373

PUC. (2018). PUC. Obtenido de https://puc.com.co/1 
raddar. (2016). raddar net. Recuperado el 30 de 01 de 2018, de www.raddar.net/revisionsectormoda.html

Real Academia de la Lengua Española. (s.f.). RAE. Recuperado el 14 de 02 de 2018, de http://dle.rae.es/?id=UOMnHDI

Redacción EL TIEMPO. (29 de 1 de 2017). El TIEMPO. Recuperado el 20 de 06 de 2017, de m.tiempo.com/economia/fianzas-personales/tendencias-de-consumo-en-2017-36324

Revista Dinero. (27 de 7 de 2016). aranceles. Obtenido de http://www.dinero.com/empresas/articulo/el-gobierno-anuncia-ayudas-para-el-sectortexti1/226185

Semana. (2017). Contrabando chino en Bogotá: un dragón con el que es imposible competir. Semana, 1 .

Sexton, W. P. (1977). Teoria de la Organización. México: Trillas.

Sexton, W. P. (1977). Teoria de la Organización . México : Trillas.

Silva, I. E. (23 de 01 de 2017). Tecnología textil en Colombia: una modernización a medio camino. Obtenido de ELMUNDO.COM: http://www.elmundo.com/noticia/Tecnologiacute-a-textil-en-Colombiauna-modernizaci-oacute-n-a-medio-camino/45370

SURA. (09 de 2016). METODOLOGIA DESCRIPTIVA DESCRIPCION REGIONAL ENFOCADA A BOGOTA DESCRIPCION COLOMBIA - MUNDO-COLOMBIA. Bogotá .

Thompson, A. A. (1998). Dirección y Administración Estratégicas. México : Mc Graw Hill .

Universidad Nacional de Colombia . (17 de abril de 2007). bdigital. Obtenido de http://revistas.unal.edu.co/index.php/gestion/article/view/1382 
Anexos

Anexo 1 Presentación de empleados de la empresa Velerito 


\begin{tabular}{|cllllll|}
\hline Columna1 & Nombre & Apellidos & EPS & ARL & Pensión & Función \\
\hline 1 & José Alejandro & Cuevas Arévalo & Compensar & Positiva & PROTECCIÓN & Estampador \\
\hline 2 & Juan Pablo & Sánchez Santana & Compensar & Positiva & COLPENSIONES & ventas \\
\hline 3 & Adenia & Marín & Protección & Positiva & PROTECCIÓN & Confección \\
\hline 4 & Hugo & Méndez & Compensar & Positiva & COLPENSIONES & Ventas \\
\hline 5 & Diana Marcela & Rojas Rivera & Famisanar & Positiva & PORVENIR & Confección \\
\hline 6 & Martha Liliana & Zamudio Rojas & Salud Total & Positiva & PORVENIR & Confección \\
\hline 7 & Diana & Beltrán Escobar & Famisanar & Positiva & COLPENSIONES & Confección \\
\hline 8 & Sandra Marcela & Peña Contreras & Salud Total & Positiva & PROTECCIÓN & Confección \\
\hline 9 & Leonardo & Sierra & Cafam & Positiva & COLPENSIONES & Confección \\
\hline 10 & Juan Pablo & Sánchez Duarte & Compensar & Positiva & COLPENSIONES & Fundador \\
\hline 11 & Martha Lucia & Santana Garzón & Sanitas & Positiva & COLPENSIONES & Fundador \\
\hline 12 & Julián & Flores & Sanitas & Positiva & PORVENIR & Estampador \\
\hline
\end{tabular}


Anexo 2 Fotografías de parte física.

Estas fotografías hacen referencia a los maquinarias, muebles y lugar físico de la empresa que se describió en el apartado 2 descripción de la empresa”.

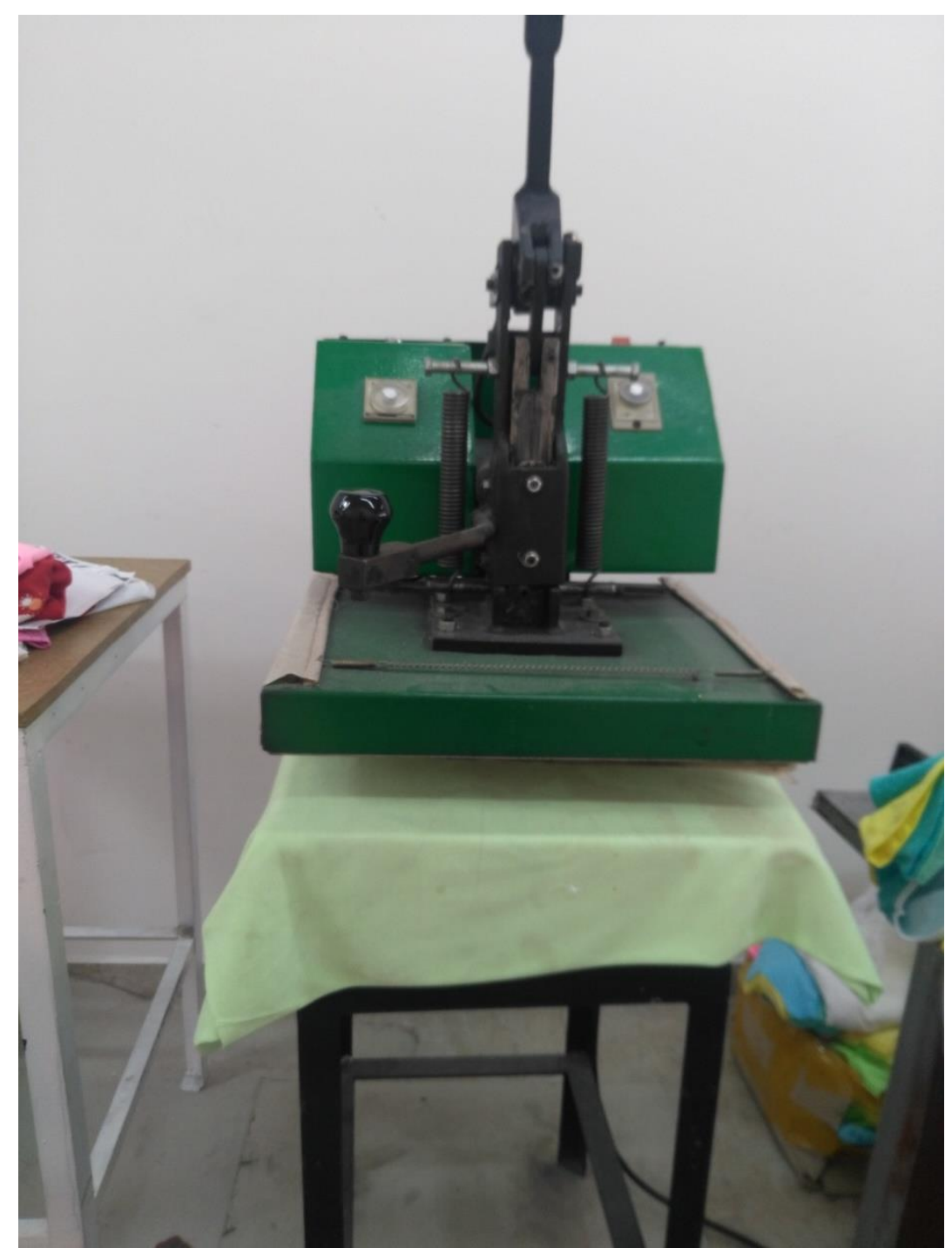



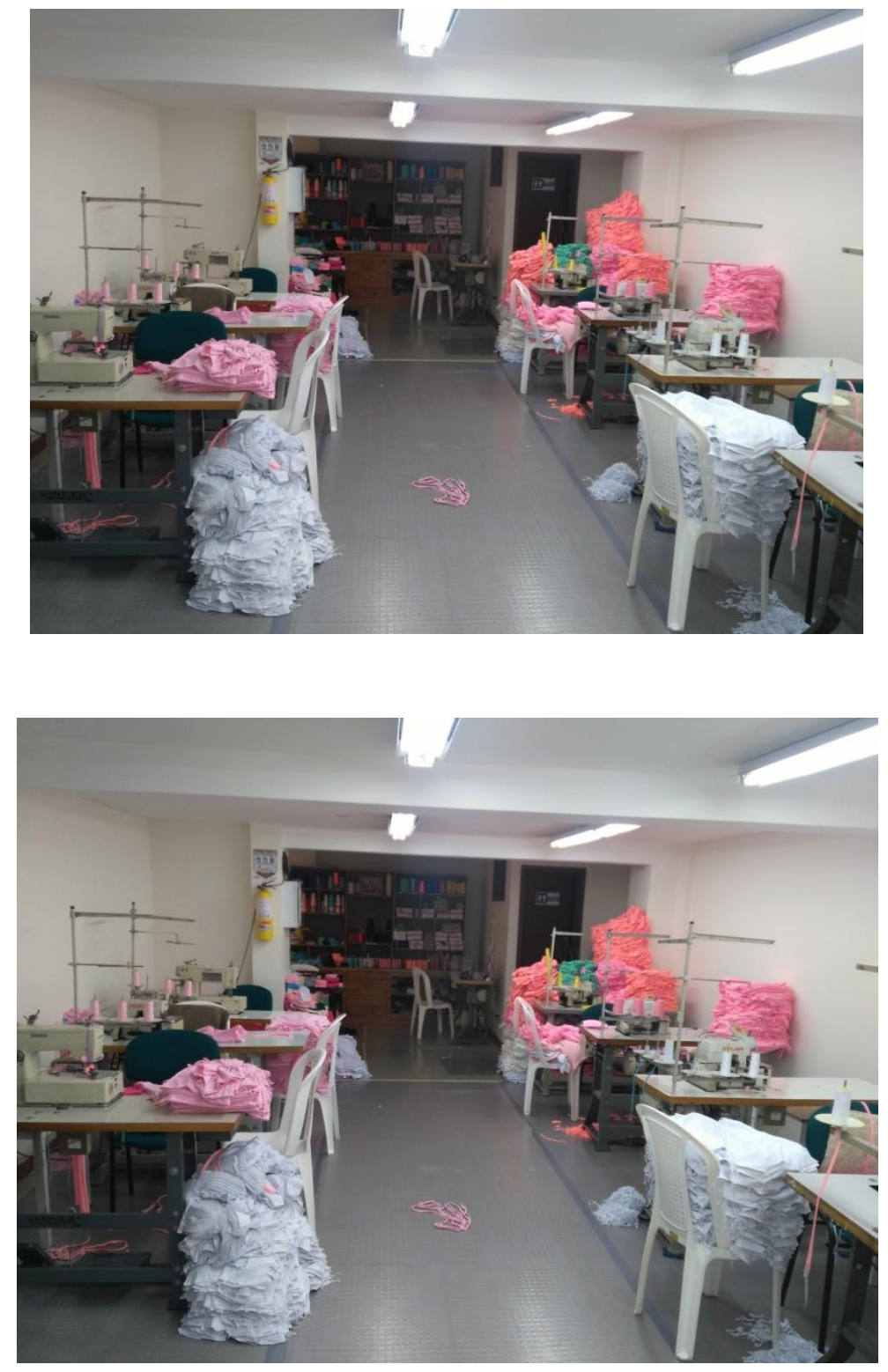

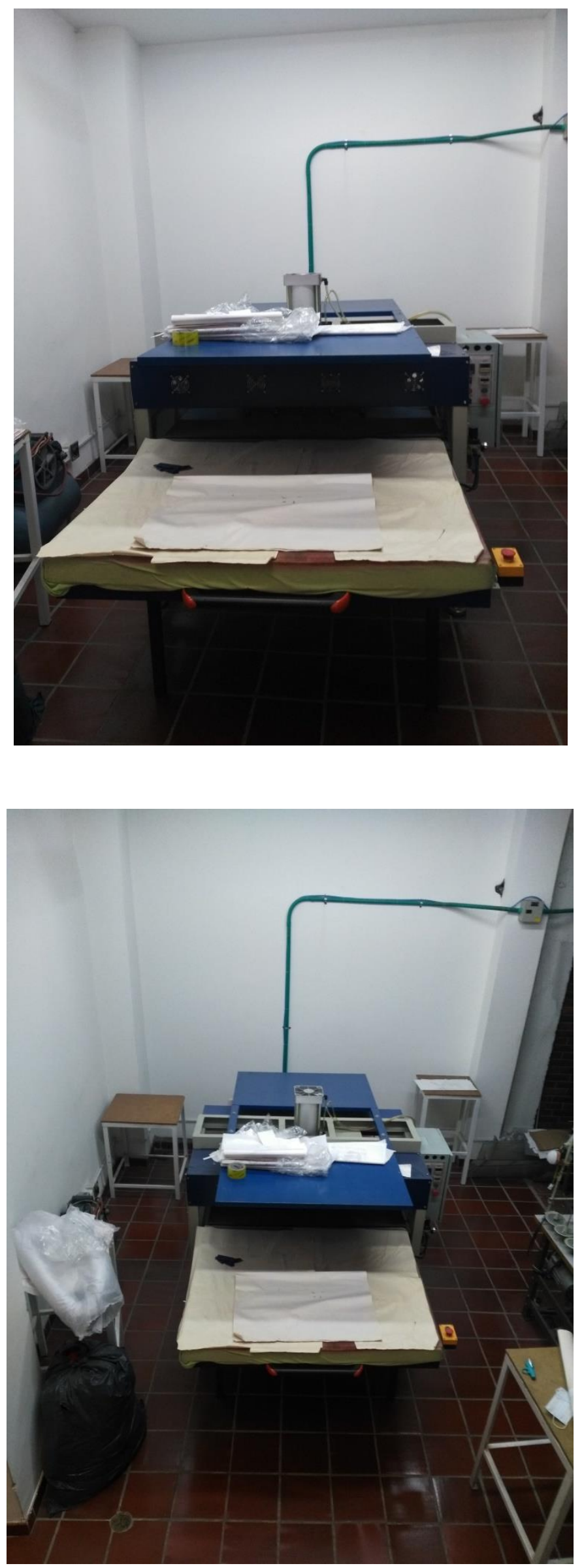

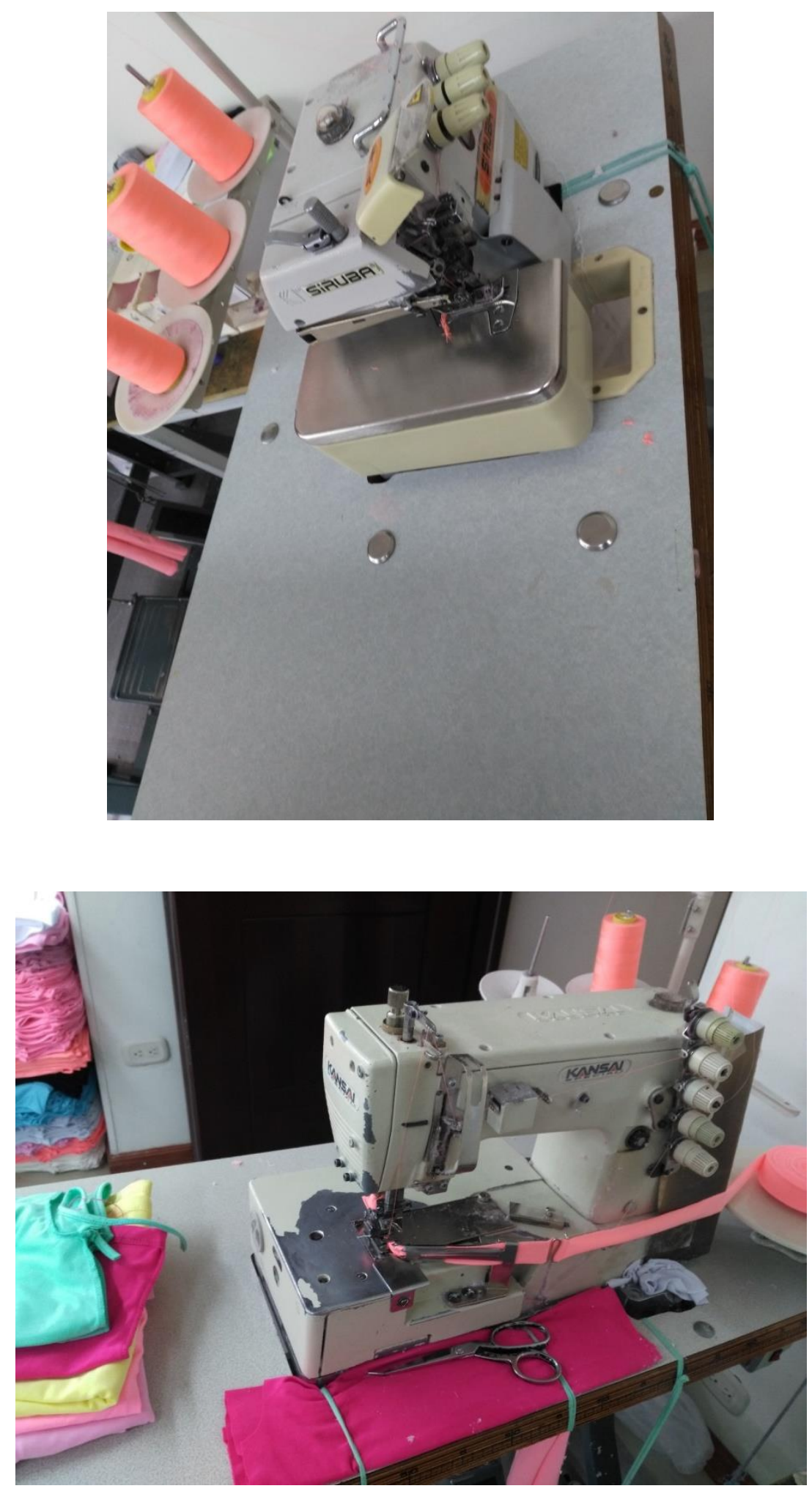

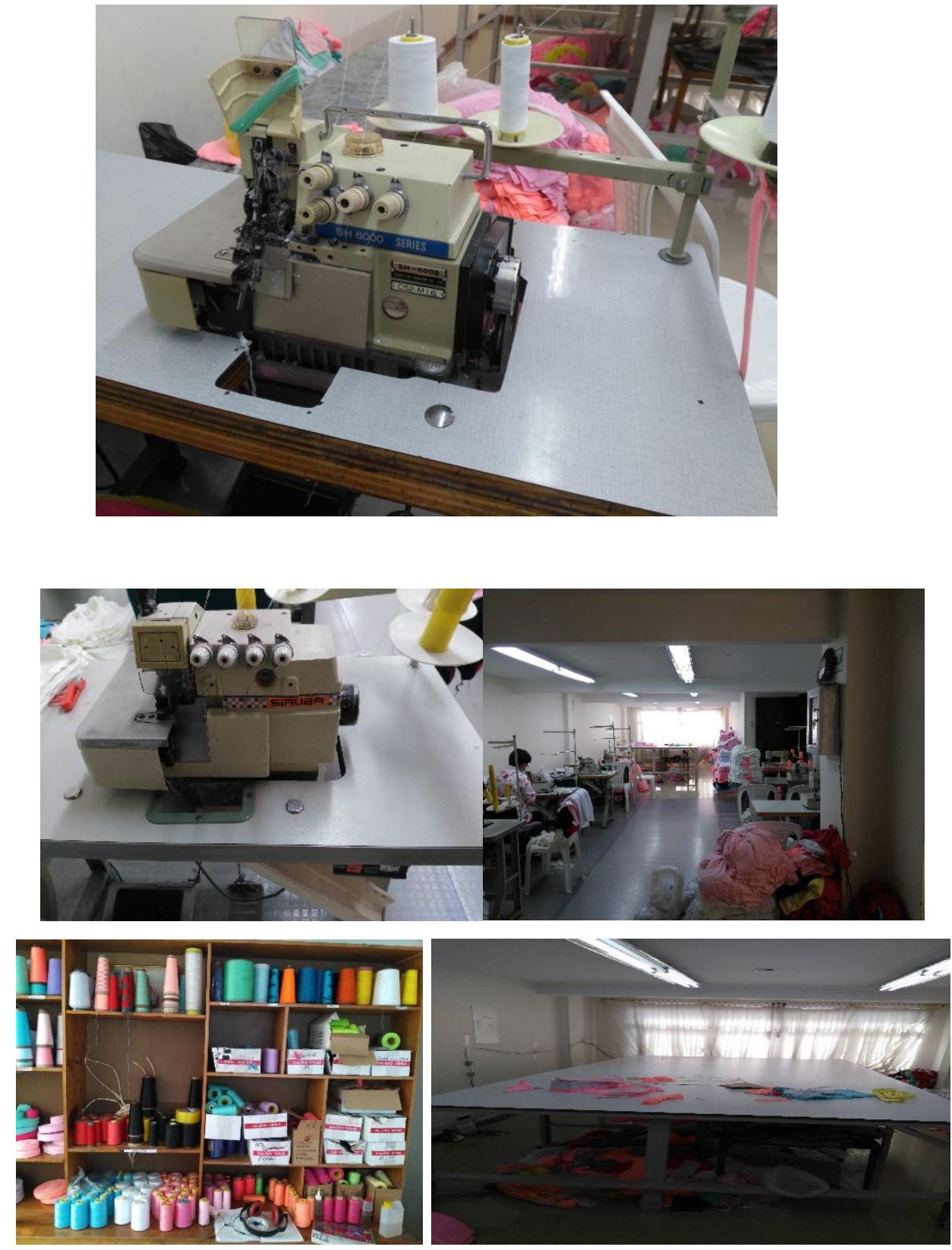

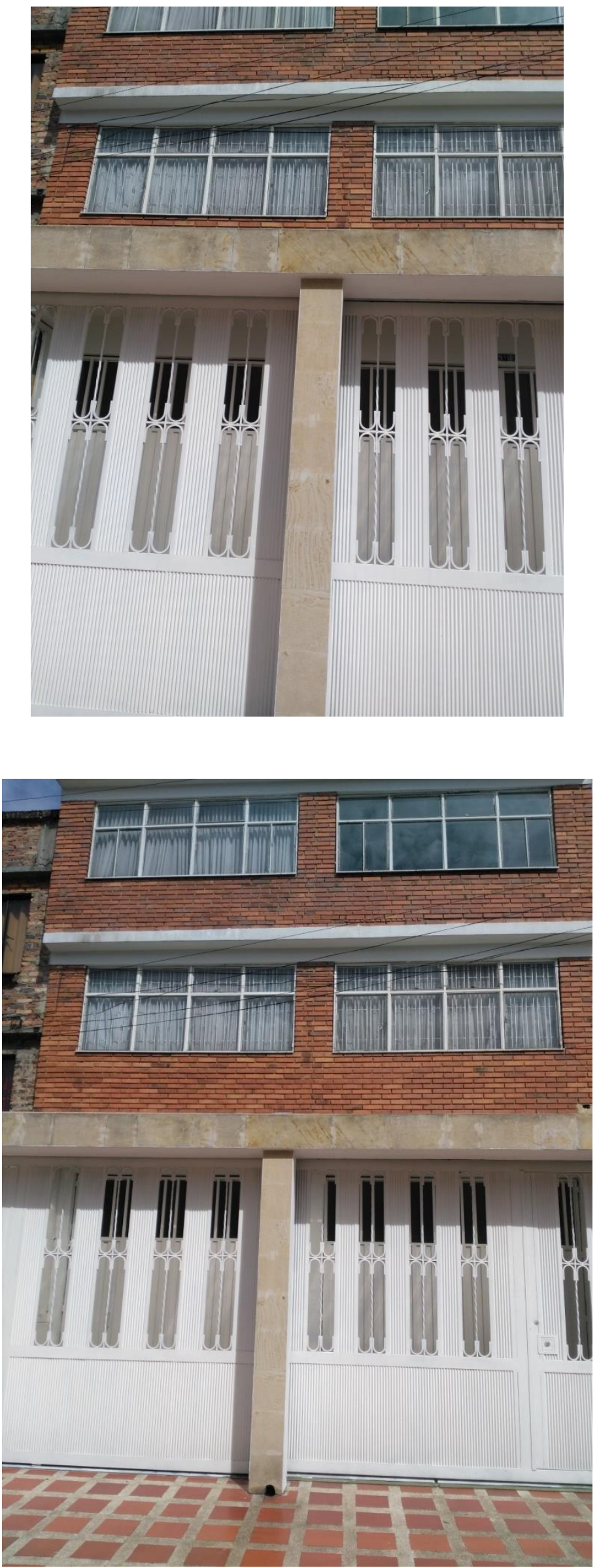


\section{Anexo 3 Listado de clientes de Velerito}

Este listado es la compilación de datos de clientes de Velerito, y fue establecida a partir la información encontrada en los dispositivos móviles de los vendedores de la empresa. Está lista es insumo para el desarrollo de estudios de mercado por parte de la empresa Velerito.

\begin{tabular}{|c|c|c|c|c|c|c|}
\hline Nombre & $\begin{array}{l}\text { Gene } \\
\text { ro }\end{array}$ & Cuidad & $\begin{array}{l}\text { Frecuencia de } \\
\text { compra }\end{array}$ & Celular & $\begin{array}{l}\text { Clim } \\
\mathbf{a}\end{array}$ & $\begin{array}{l}\text { Tipo de ropa que vende en su } \\
\text { negocio }\end{array}$ \\
\hline Adriana Montoya & mujer & Bogotá & cada mes & 3134647595 & frio & Niños \\
\hline Alba Lucia & mujer & $\begin{array}{l}\text { Puente } \\
\text { Nacional }\end{array}$ & Cada 15 días & 3013780809 & $\begin{array}{l}\text { calien } \\
\text { te }\end{array}$ & \\
\hline Alcira & mujer & Bogotá & Cada 8 días & 3133876051 & frio & Niños \\
\hline Alex & $\begin{array}{l}\text { homb } \\
\text { re }\end{array}$ & Bogotá & Cada mes & 3112336099 & frio & Niños \\
\hline Alex Vega & $\begin{array}{l}\text { homb } \\
\text { re }\end{array}$ & & Cada dos meses & 3108173351 & $\begin{array}{l}\text { calien } \\
\text { te }\end{array}$ & Niños \\
\hline Alexandra & mujer & Cañamar & cada mes & 3206405700 & frio & Niños \\
\hline Alexandra & mujer & Tuluá & Cada mes & 3164993716 & $\begin{array}{l}\text { calien } \\
\text { te }\end{array}$ & Niños \\
\hline Ali & $\begin{array}{l}\text { homb } \\
\text { re }\end{array}$ & Agua Chica & Cada mes & 3228784513 & $\begin{array}{l}\text { calien } \\
\text { te }\end{array}$ & Niños \\
\hline Ana Novoa & mujer & Yopal & Cada dos meses & 3209324649 & $\begin{array}{l}\text { calien } \\
\text { te }\end{array}$ & Niños \\
\hline Ángela Castillo & mujer & Bogotá- tercera & Cada 15 días & 3114713945 & frio & Niños \\
\hline $\begin{array}{l}\text { Arístides Muñoz " el } \\
\text { negro" }\end{array}$ & $\begin{array}{l}\text { homb } \\
\text { re }\end{array}$ & Villa & Cada mes & 3108422074 & $\begin{array}{l}\text { calien } \\
\text { te }\end{array}$ & \\
\hline Astrid Lucia & mujer & Popayán & Cada mes & 3103913629 & $\begin{array}{l}\text { calien } \\
\text { te }\end{array}$ & \\
\hline Blanca & mujer & Villao & cada mes & 3143768451 & $\begin{array}{l}\text { calien } \\
\text { te }\end{array}$ & Niños \\
\hline Camilo Gutiérrez & $\begin{array}{l}\text { homb } \\
\text { re }\end{array}$ & Bogotá & Cada 15 días & 3138490957 & frio & \\
\hline Carolina & mujer & Manizales & cada mes & 3104532067 & frio & Niños \\
\hline Claudia & mujer & Bucaramanga & Cada mes & 3114800446 & $\begin{array}{l}\text { calien } \\
\text { te }\end{array}$ & Niños \\
\hline Deisy Echeverría & mujer & & & 3007398267 & $\begin{array}{l}\text { calien } \\
\text { te }\end{array}$ & Niños \\
\hline Diana & mujer & Girardot & Cada 15 días & 3123367751 & $\begin{array}{l}\text { calien } \\
\text { te }\end{array}$ & Niños \\
\hline Franklin & $\begin{array}{l}\text { homb } \\
\text { re }\end{array}$ & San gil & Cada mes & 3102923984 & $\begin{array}{l}\text { calien } \\
\text { te }\end{array}$ & Niños \\
\hline Gladys Salguero & mujer & Bogotá & Cada mes & 3133791626 & $\begin{array}{l}\text { calien } \\
\text { te }\end{array}$ & Niños \\
\hline Gloria & mujer & Bogotá- Bosa & Cada mes & 3212142154 & frio & Niños \\
\hline Herminia Rodríguez & mujer & San Gil & Cada mes & 3123585025 & $\begin{array}{l}\text { calien } \\
\text { te }\end{array}$ & Niños \\
\hline Jazbleidy Arango & mujer & Granada Meta & cada mes & 3133445069 & $\begin{array}{l}\text { calien } \\
\text { te }\end{array}$ & \\
\hline Jose Aponte & $\begin{array}{l}\text { homb } \\
\text { re }\end{array}$ & Tunja & Cada mes & 3123856141 & frio & Niños \\
\hline Laura Socorro & mujer & Santander & Cada mes & 3166029417 & $\begin{array}{l}\text { calien } \\
\text { te }\end{array}$ & \\
\hline Lina Zapata & mujer & Bogotá & Cada mes & 3173169828 & frio & Niños \\
\hline Luz & mujer & Armenia & Cada mes & 3106532368 & $\begin{array}{l}\text { calien } \\
\text { te }\end{array}$ & Niños \\
\hline Marcela cadena & mujer & Bogotá & Cada mes & 3015674881 & frio & Niños \\
\hline
\end{tabular}




\begin{tabular}{|c|c|c|c|c|c|c|}
\hline Mari & mujer & Armenia & Cada mes & 3233642939 & $\begin{array}{l}\text { calien } \\
\text { te }\end{array}$ & Niños \\
\hline Miriam & mujer & & Cada mes & 3203455566 & $\begin{array}{l}\text { calien } \\
\text { te }\end{array}$ & Niños \\
\hline Natalia & mujer & $\begin{array}{l}\text { Bogotá- } \\
\text { Alquería }\end{array}$ & Cada mes & 3213396355 & frio & Niños \\
\hline Sonia & mujer & Ibagué & Cada mes & 3212471437 & $\begin{array}{l}\text { calien } \\
\text { te }\end{array}$ & Niños \\
\hline Sonia Cuadros & mujer & Bucaramanga & Cada 15 días & 3156402002 & $\begin{array}{l}\text { calien } \\
\text { te }\end{array}$ & Niños \\
\hline Soraida Aristizabal & mujer & Girardot & Cada mes & 3204249375 & $\begin{array}{l}\text { calien } \\
\text { te }\end{array}$ & Niños \\
\hline Tatiana & mujer & Bogotá & Cada 10 días & 3123831688 & frio & Niños \\
\hline Verenice Torres & mujer & Bogotá & Cada mes & 3214498797 & frio & Niños \\
\hline Yudi & mujer & Bogotá & Cada 20 días & 3107842614 & frio & Niños \\
\hline Gustavo & $\begin{array}{l}\text { homb } \\
\text { re }\end{array}$ & $\begin{array}{l}\text { Bogotá- } \\
\text { Keneddy }\end{array}$ & Cada mes & 3142658388 & frio & Niños \\
\hline Sandra Valentina & mujer & Yopal & Cada mes y medio & 3228520979 & $\begin{array}{l}\text { calien } \\
\text { te }\end{array}$ & Niños \\
\hline Gladys Barrera & mujer & $\begin{array}{l}\text { Marinilla- } \\
\text { Antioquia }\end{array}$ & Cada mes & 3218043454 & $\begin{array}{l}\text { calien } \\
\text { te }\end{array}$ & Niños \\
\hline Paola Gallo & mujer & Bucaramanga & cada mes y medio & 3186913173 & $\begin{array}{l}\text { calien } \\
\text { te }\end{array}$ & Niños \\
\hline Luz Angela Abello & mujer & Guayabal & Cada mes & 3133079320 & $\begin{array}{l}\text { calien } \\
\text { te }\end{array}$ & Niños \\
\hline Diana Torres & mujer & Moniquira & cada mes & 3124780545 & frio & Niños \\
\hline Raquel Díaz & mujer & Pitalito & Cada mes & 3102673774 & $\begin{array}{l}\text { calien } \\
\text { te }\end{array}$ & Niños \\
\hline Wanda Parra & mujer & Fusa & Cada 15 días & 3204325560 & $\begin{array}{l}\text { calien } \\
\text { te }\end{array}$ & Niños \\
\hline Natalia & mujer & $\begin{array}{l}\text { Marinilla- } \\
\text { Antioquia }\end{array}$ & Cada mes & 3206807653 & $\begin{array}{l}\text { calien } \\
\text { te }\end{array}$ & Niños \\
\hline
\end{tabular}

Datos para tener en cuenta de la lista de clientes de Velerito:

$\checkmark \quad$ El 83\% de los clientes son mujeres

Las ciudades que más concentran clientes son: Bogotá, Bucaramanga, Popayán.

$\checkmark$ El rango de frecuencia media de compra por parte de los clientes es de 30 días (un mes).

$\checkmark$ El 63\% de los clientes provienen de climas cálidos, mientras el 37\% de climas fríos. 
Anexo 4 Balance y Estado de Resultados para los años 2015, 2016, 2017

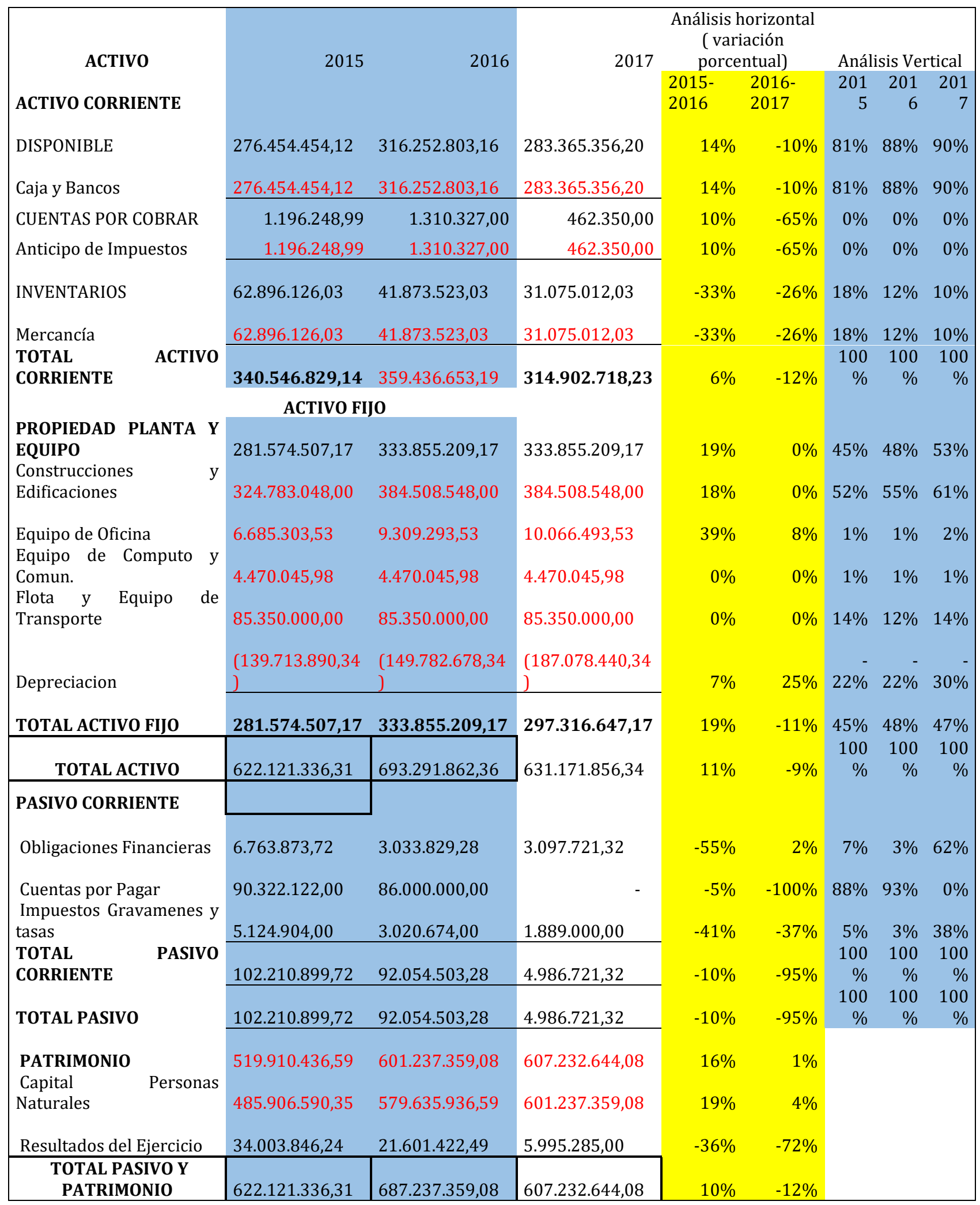


Estado de Pérdidas y Ganancias.

\begin{tabular}{|c|c|c|c|}
\hline & 2015 & 2016 & 2017 \\
\hline INGRESOS OPERACIONALES & $143.932 .811,00$ & $73.208 .907,00$ & $114.997 .887,00$ \\
\hline Venta de Textiles & $143.932 .811,00$ & $73.208 .907,00$ & 114.997.887,00 \\
\hline INGRESOS NO OPERACIONALES & $132.952,76$ & $204.919,70$ & 744,00 \\
\hline Financieros & $132.945,76$ & $204.914,69$ & 744,00 \\
\hline Diversos & 7,00 & 5,01 & \\
\hline $\begin{array}{l}\text { TOTAL INGRESOS DEL } \\
\text { EJERCICIO }\end{array}$ & $144.065 .763,76$ & 73.413.826,70 & 114.998.631,00 \\
\hline $\begin{array}{l}\text { GASTOS OPERACIONALES DE } \\
\text { ADMINISTRACION }\end{array}$ & $36.758 .717,00$ & $13.657 .694,00$ & $40.733 .022,00$ \\
\hline Impuestos & $596.000,00$ & $303.000,00$ & $430.000,00$ \\
\hline Servicios & $1.950 .629,00$ & $1.960 .600,00$ & $1.557 .860,00$ \\
\hline Mantenimiento y Reparaciones & $605.947,00$ & $995.306,00$ & $398.500,00$ \\
\hline Depreciacion & $5.321 .731,00$ & $10.068 .788,00$ & $37.295 .762,00$ \\
\hline Diversos & $28.284 .410,00$ & $330.000,00$ & $1.050 .900,00$ \\
\hline GASTOS NO OPERACIONALES & $2.259 .200,52$ & $294.710,21$ & - \\
\hline Financieros & $2.259 .200,52$ & $294.710,21$ & - \\
\hline COSTOS & $69.768 .000,00$ & $37.127 .000,00$ & $68.270 .324,00$ \\
\hline costo de Ventas & $69.768 .000,00$ & $37.127 .000,00$ & $68.270 .324,00$ \\
\hline $\begin{array}{l}\text { UTILIDAD } \\
\text { IMPUESTOS }\end{array}$ & $35.279 .846,24$ & 22.334.422,49 & $5.995 .285,00$ \\
\hline IMPUESTO DE RENTA & $1.276 .000,00$ & $733.000,00$ & $190.000,00$ \\
\hline UTILIDAD DEL EJERCICIO & 34.003.846,24 & $21.601 .422,49$ & $5.805 .285,00$ \\
\hline
\end{tabular}


Anexo 5 Ficha de producto

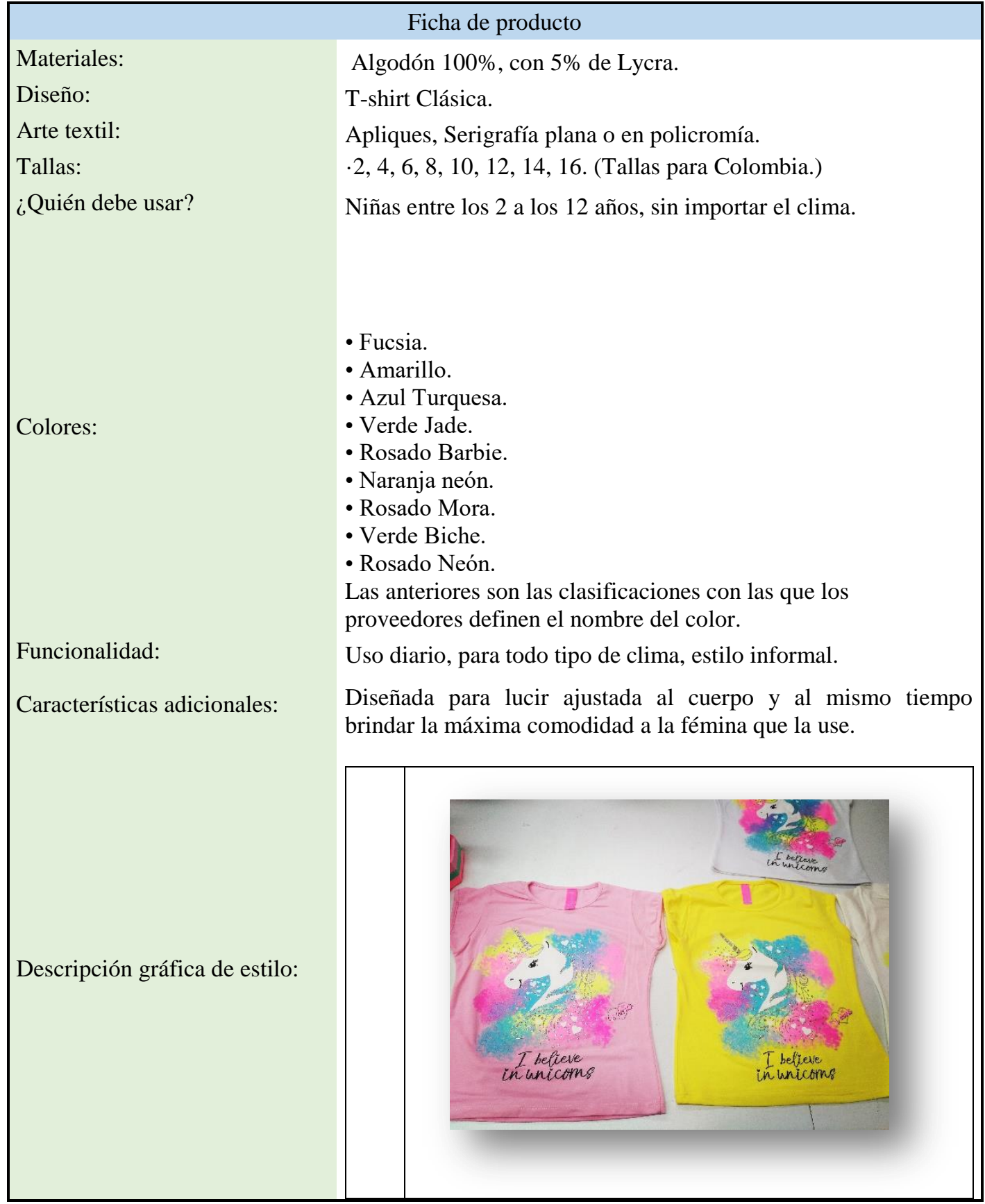




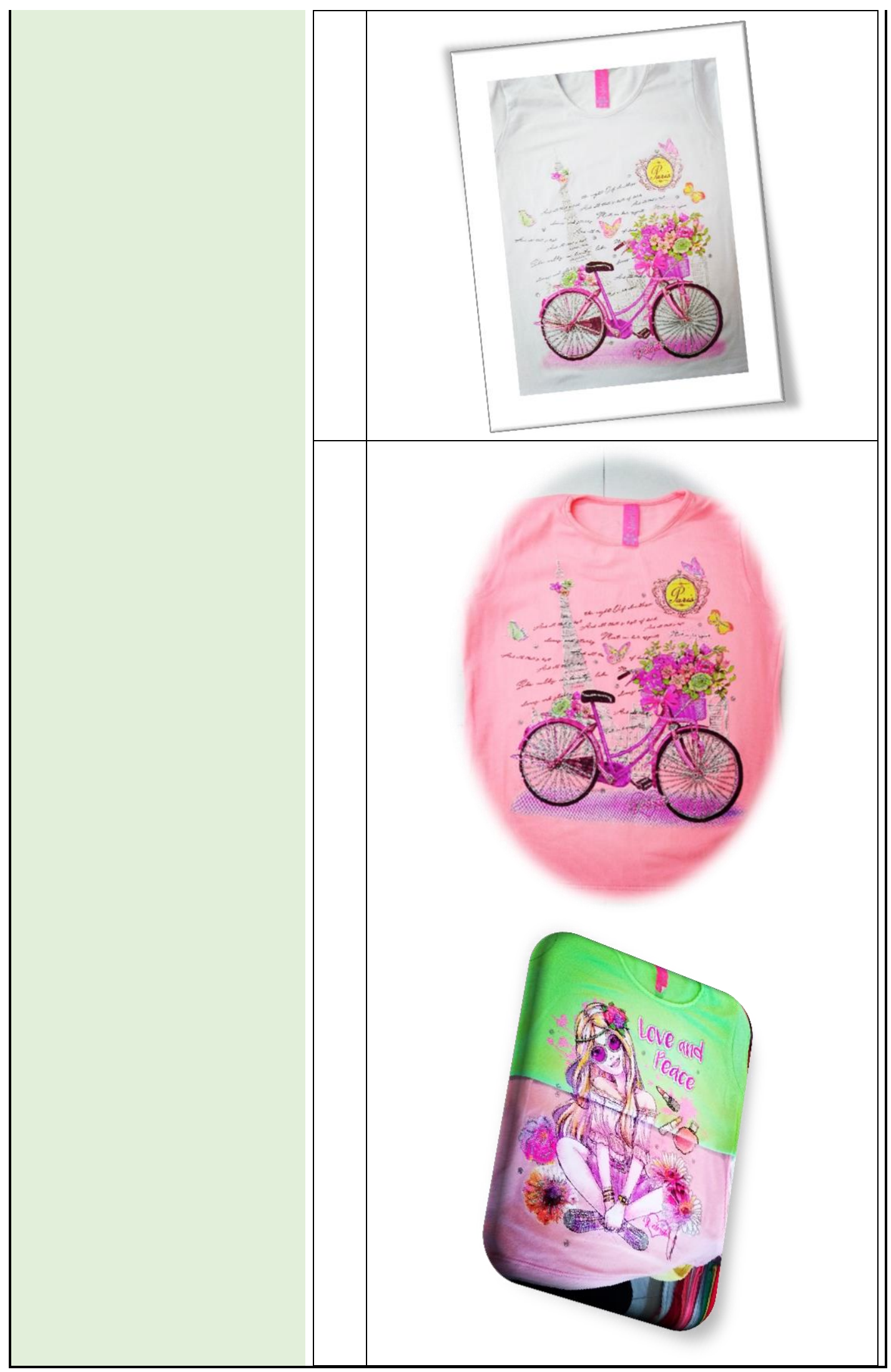




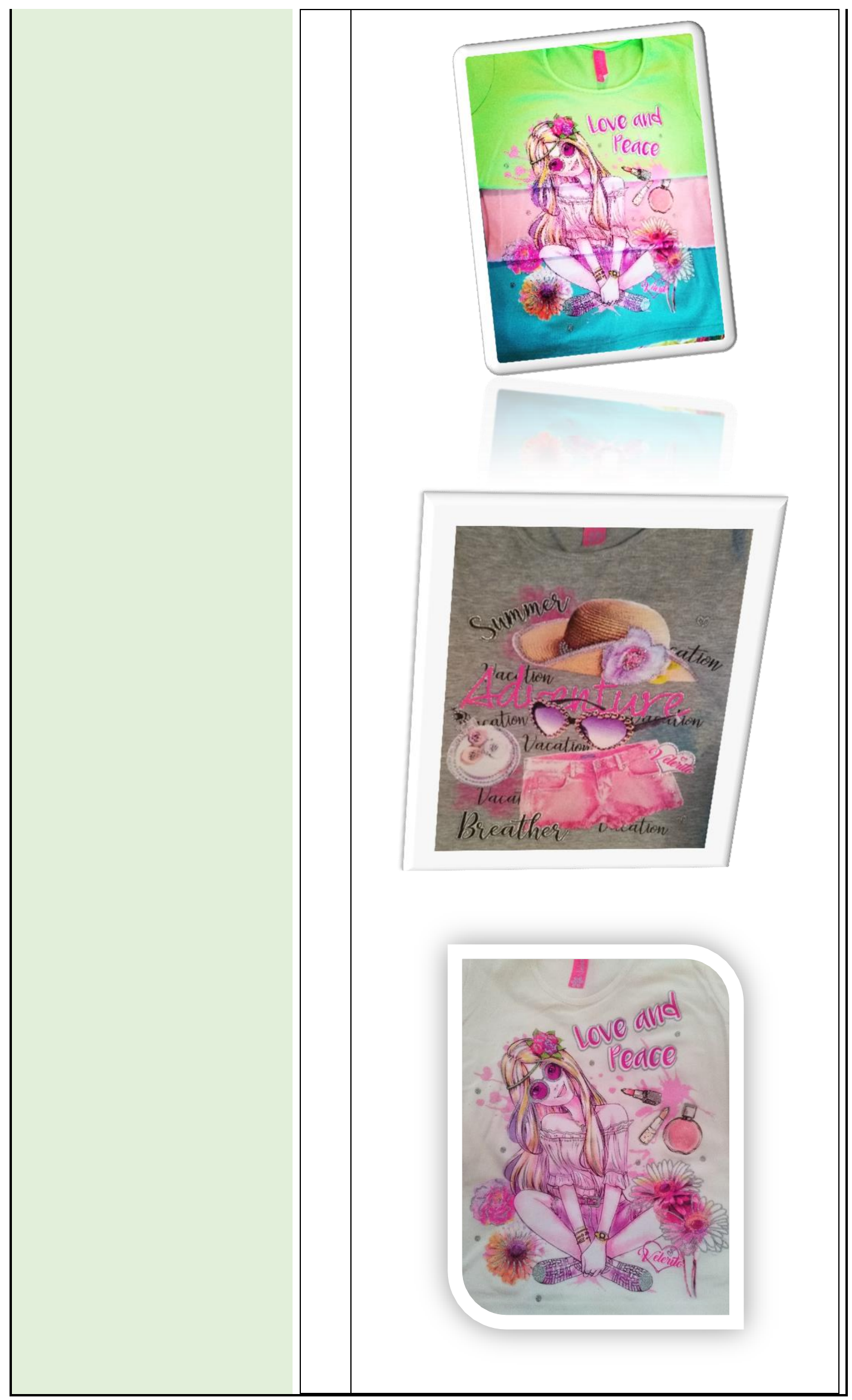

